SANDIA REPORT

SAND97-1287 • UC-721

Unlimited Release

Printed December 1997
RECEIVED

\author{
JAN 121998 \\ OSTI
}

\title{
WIPP Shaft Seal System Parameters Recommended to Support Compliance Calculations
}

L. D. Hurtado, M. K. Knowles, V. A. Kelley, T. L. Jones, J. B. Ogintz, T. W. Pfeifle

Prepared by

Sandia National Laboratories

Albuquerque, New Mexico 87185 and Livermore, California 94550

Sandia is a multiprogram laboratory operated by Sandia Corporation, a Lockheed Martin Company, for the United States Department of Energy under Contract DE-AC04-94AL85000.

Approved for public release; further dissemination unlimited.

\section{Sandia National Laboratories}


Issued by Sandia National Laboratories, operated for the United States Department of Energy by Sandia Corporation.

NOTICE: This report was prepared as an account of work sponsored by an agency of the Lnited States Government. Neither the United States Government nor any agency thereof, nor any of their employees, nor any of their contractors, subcontractors, or their employees, makes any warranty, express or implied, or assumes any legal liability or responsibility for the accuracy, completeness, or usefulness of any information, apparatus, product, or process disclosed, or represents that its use would not infringe privately owned rights. Reference herein to any specific commercial product, process, or serrice by trade name, trademark, manufacturer, or otherwise, does not necessarily constitute or imply its endorsement, recommendation, or favoring by the United States Government, any agency thereof, or any of their contractors or subcontractors. The views and opinions expressed herein do not necessarily state or reflect those of the United States Government, any agency thereof, or any of their contractors.

Printed in the United States of America. This report has been reproduced directly from the best available copy.

Available to DOE and DOE contractors from

Office of Scientific and Technical Information

P.O. Box 62

Oak Ridge, "]N 37831

Prices available from (615) 576-8401, FTS 626-8401

Available to the public from

National Technical Information Service

U.S. Department of Commerce

5285 Port Royal Rd

Springfield, VA 22161

NTIS price codes

Printed copy: A07

Microfiche copy: A01 


\section{DISCLAMIER}

Portions of this docament moy be illegible in electronic imoge prodnets. Insgges are produced from the best available origional docomerter. 


\title{
WIPP Shaft Seal System Parameters Recommended to Support Compliance Calculations
}

\author{
L. D. Hurtado and M. K. Knowles \\ Sandia National Laboratories \\ Albuquerque, NM 87185 \\ V. A. Kelley, T. L. Jones, and J. B. Ogintz \\ INTERA Inc. \\ Austin, TX 78731 \\ T. W. Pfeifle \\ RE/SPEC, Inc. \\ Rapid City, SD 57709
}

\begin{abstract}
The U.S. Department of Energy plans to dispose of transuranic waste at the Waste Isolation Pilot Plant (WIPP), which is sited in southeastern New Mexico. The WIPP disposal facility is located approximately 2150 feet $(650 \mathrm{~m})$ below surface in the bedded halite of the Salado Formation. Prior to initiation of disposal activities, the Department of Energy must demonstrate that the WIPP will comply with all regulatory requirements. Applicable regulations require that contaminant releases from the WIPP remain below specified levels for a period of 10,000 years. To demonstrate that the WIPP will comply with these regulations, the Department of Energy has requested that Sandia National Laboratories develop and implement a comprehensive performance assessment of the WIPP repository for the regulatory period.

This document presents the conceptual model of the shaft sealing system to be implemented in performance assessment calculations conducted in support of the Compliance Certification Application for the WIPP. The model was developed for use in repository-scale calculations and includes the seal system geometry and materials to be used in grid development as well as all parameters needed to describe the seal materials. These calculations predict the hydrologic behavior of the system. Hence conceptual model development is limited to those processes that could impact the fluid flow through the seal system.
\end{abstract}




\section{ACKNOWLEDGMENTS}

This work was supported by the U.S. Department of Energy under contract

DE-AC04AL85000. Sandiat is a multiprogram laboratory operated by Sandia Corporation, a Lockheed Martin company, for the U.S. Department of Energy. 


\section{CONTENTS}

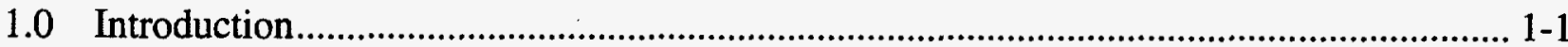

1.1 WIPP Shaft Sealing System................................................................................. 1-1

1.1.1 Site Setting............................................................................................... 1-1

1.1.2 WIPP Shaft Sealing System.................................................................. 1-2

1.1.2.1 Shaft Station Monolith................................................................ 1-2

1.1.2.2 Clay Columns ......................................................................... 1-2

1.1.2.3 Concrete-Asphalt Waterstop Components ..................................... 1-4

1.1.2.4 Compacted Crushed Salt Column..................................................... 1-4

1.1.2.5 Asphalt Column ........................................................................ 1-4

1.1.2.6 Concrete Plugs ......................................................................... 1-4

1.1.2.7 Earthen Fill ............................................................................ 1-4

1.2 Conceptual Model of WIPP Shaft Sealing System................................................... 1-4

1.2.1 Summary of Previous Conceptual Models ...................................................... 1-5

1.2.2 Detailed Conceptual Models......................................................................... 1-5

1.2.3 Compliance Application Model of the Shaft Sealing System ........................ 1-6

1.3 Conceptual Model Parameters ....................................................................................... 1-6

1.3.1 Saturated Flow Parameters .................................................................. 1-8

1.3.2 Disturbed Rock Zone ........................................................................... 1-8

1.3.3 Two-Phase Flow Parameters ................................................................... 1-9

1.3.4 Time-Dependent Properties ............................................................................ 1-9

2.0 Saturated Flow Properties and Initial Conditions ......................................................... 2-1

2.1 Compacted Crushed Salt........................................................................................... 2-1

2.1.1 Material Specifications ………................................................................ 2-1

2.1.2 Intrinsic Permeability ............................................................................ 2-2

2.1.2.1 Parameter Sources...................................................................... 2-2

2.1.2.2 Rationale and Parameter Value..................................................... 2-5

2.1 .3 Porosity ........................................................................................... 2-17

2.1.3.1 Parameter Sources................................................................... 2-18

2.1.3.2 Rationale and Parameter Value................................................ 2-18

2.1.4 Pore-Volume Compressibility .................................................................... 2-18

2.1.5 Initial Wetting Phase Saturation ................................................................ 2-21

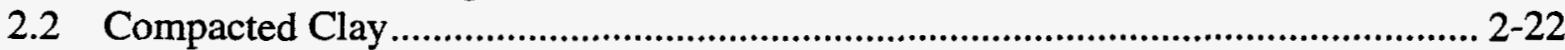

2.2.1 Material Specifications …....................................................................... 2-22

2.2.2 Intrinsic Permeability .............................................................................. 2-22

2.2.2.1 Parameter Sources................................................................... 2-22

2.2.2.2 Rationale and Parameter Value................................................ 2-31

2.2 .3 Porosity ............................................................................................... 2-33

2.2.3.1 Parameter Sources....................................................................... 2-33

2.2.3.2 Rationale and Parameter Value .................................................. 2-33

2.2.4 Pore-Volume Compressibility .............................................................. 2-33

2.2.5 Initial Wetting Phase Saturation ................................................................. 2-34 


\section{CONTENTS (Continued)}

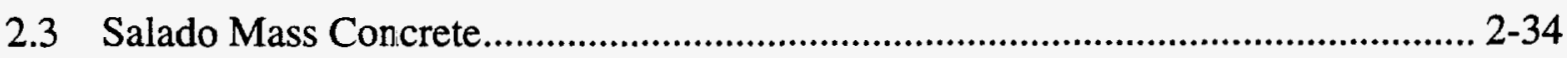

2.3.1 Material Specifications ……….............................................................. 2-34

2.3.2 Intrinsic Permeability ............................................................................... 2-34

2.3.2.1 Parameter Sources...................................................................... 2-35

2.3.2.2 Rationale and Parameter Value..................................................... 2-36

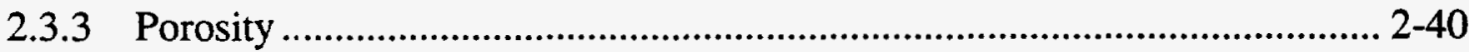

2.3.3.1 Parameter Sources.................................................................. 2-40

2.3.3.2 Rationale and Parameter Value.................................................. 2-42

2.3.4 Pore-Volume Compressibility ……....................................................... 2-42

2.3.4.1 Parameter Sources................................................................. 2-42

2.3.4.2 Rationale and Parameter Value .................................................. 2-43

2.3.5 Initial Wetting Phase Saturation .......................................................... 2-43

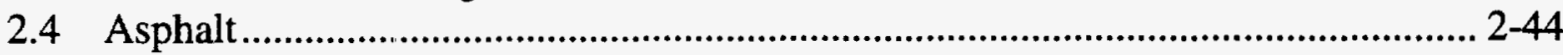

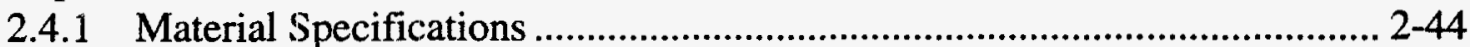

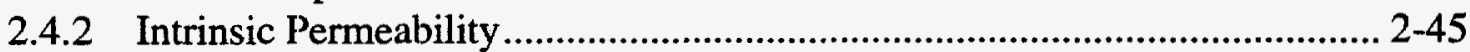

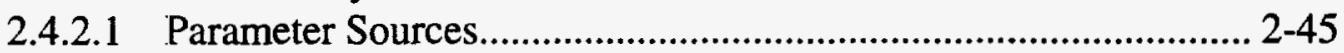

2.4.2.2 Rationale and Parameter Value................................................. 2-47

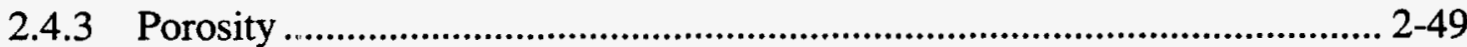

2.4.4 Pore-Volume Compressibility .............................................................. 2-49

2.4.5 Initial Wetting Phase Saturation ................................................................ 2-49

2.5 Compacted Earthen Fill .................................................................................. 2-50

2.5.1 Material Specifications ........................................................................ 2-50

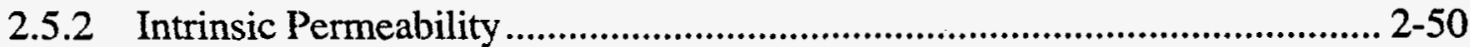

2.5.2.1 Parameter Sources.................................................................... 2-50

2.5.2.2 Rationale and Parameter Value................................................... 2-51

2.5.3 Porosity ................................................................................................ 2-53

2.5.4 Pore-Volume Compressibility .............................................................. 2-53

2.5.5 Initial Wetting Phase Saturation ............................................................... 2-53

3.0 Two-Phase Flow Properties ....................................................................................... 3-1

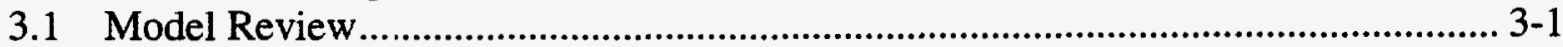

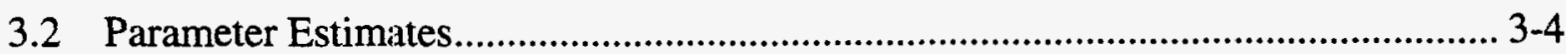

3.2.1 Threshold Pressure ............................................................................... 3-4

3.2.1.1 Parameter Sources.......................................................................... 3-4

3.2.1.2 Parameter Value..................................................................... 3-6

3.2.2 Residual Saturation .......................................................................... 3-6

3.2.2.1 Parameter Sources............................................................... 3-6

3.2.2.2 Parameter Value ...................................................................... 3-6

3.2.3 Pore-Size Distribution Index ................................................................. 3-9

3.2.3.1 Parameter Sources..................................................................... 3-9

3.2.3.2 Parameter Value........................................................................... 3-15

3.3 Comparison of Recommended Two-Phase Flow Parameters to Previously

Used Values. 


\section{CONTENTS (Continued)}

4.0 Disturbed Rock Zone ......................................................................................... 4-1

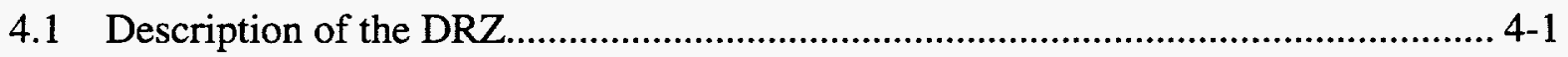

4.2 DRZ Permeability and Extent ....................................................................... 4-2

4.2.1 Parameter Sources............................................................................... 4-2

4.2.1.1 Field Data....................................................................... 4-2

4.2.1.2 Laboratory Data ...................................................................... 4-3

4.2.2 Rationale and Parameter Value.............................................................. 4-3

4.3 Implementation of DRZ Parameters into the Conceptual Model ........................... 4-6

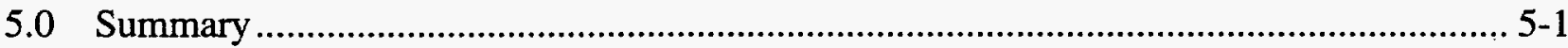

5.1 Saturated Flow Parameters and Initial Conditions ........................................... 5-1

5.2 Two-Phase Flow Parameters .................................................................................. 5-1

5.3 Disturbed Rock Zone .................................................................................... 5-4

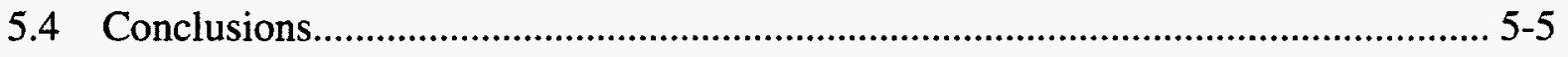

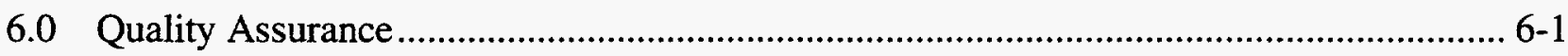

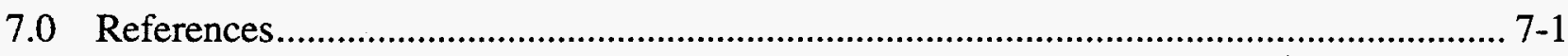

APPENDIX A - Memoranda Regarding Reference Data ...................................................... 


\section{FIGURES}

1-1 Proposed seal design for the WIPP Air Intake Shaft ..................................................... 1-3

1-2 Stratigraphy and conceptual framework for the Air Intake Shaft seal system................. 1-7

2-1 Permeability versus dry fractional density for WIPP crushed salt................................... 2-5

2-2 Measured and predicted permeability versus dry fractional density for the compacted crushed salt column ......................................................................................... 2-9

2-3 Fractional density as a function of time for the compacted crushed salt column at 430,515 , and $600 \mathrm{~m}$ depth below ground surface

2-4 Permeability CDF for compacted crushed salt column at a depth of $515 \mathrm{~m}$ bgs and a time after seal emplacement of 0 yrs

2-5 Permeability CDF for compacted crushed salt column at a depth of $515 \mathrm{~m}$ bgs and a time after seal emplacement of $50 \mathrm{yrs}$......................................................................... 2-15

2-6 Permeability CDF for compacted crushed salt column at a depth of $515 \mathrm{~m}$ bgs and a time after seal emplacement of 100 yrs...

2-7 Permeability CDF for compacted crushed salt column at a depth of $515 \mathrm{~m}$ bgs and a time after seal emplacement of 200 and 400 yrs.............................................................. 2-16

2-8 Porosity versus time for the compacted crushed salt column at a depth of $515 \mathrm{~m}$ bgs.

2-9 Compacted bentonite permeabilities for samples with $\geq 50 \%$ bentonite content.......... 2-30

2-10 Relationship between compacted sodium bentonite intrinsic permeability and clay sample density.

2-11 Sodium bentonite permeability versus density .......................................................... 2-31

2-12 Cumulative frequency distribution function for compacted bentonite ......................... 2-32

2-13 Permeability versus pressure difference determined from laboratory testing of SMC and SSSPT concretes

2-14 Experimental frequency histogram and log triangular PDF for permeability of SMC concrete - laboratory data only.

2-15 Experimental frequency histogram and log triangular PDF for permeability of SMC concrete, upper bound relaxed to account for uncertainty in concrete-salt interface..... 2-39

2-16 Experimental cumulative frequency and $\log$ triangular CDF for permeability of SMC concrete

2-17 Asphalt column permeability cumulative frequency distribution function ................... 2-49

2-18 Representative range of intrinsic permeability for silty and clayey sands .................... 2-52

2-19 Cumulative frequency distribution function for earthen fill ..................................... 2-52

3-1 Threshold displacement pressure curve (after Pihlajavaara, 1991) .................................. 3-5

3-2 Residual liquid saturation distribution by geologic material ...................................... 3-8

3-3 Frequency histogram and cumulative frequency histogram of $\lambda$ values found in the

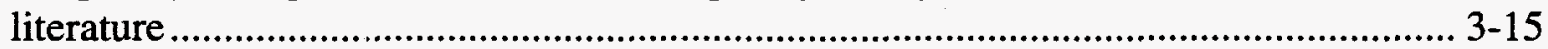

3-4 Cumulative distribution function for $\lambda$ values found in the literature .......................... 3-16

3-5 Lambda distribution by geologic material .............................................................. 3-16

3-6 Log cumulative $\lambda$ data standardized compared to the Lilliefors bounds and the cumulative standard normal distribution 


\section{FIGURES (Continued)}

4-1 Permeability versus dilatant volumetric strain for WIPP salt ........................................ 4-4

4-2 PDF for DRZ skin permeability $\left(k_{i}\right)$ immediately following seal emplacement.............. 4-5

4-3 CDF for DRZ skin permeability $\left(k_{i}\right)$ immediately following seal emplacement .............. 4-5

4-4 Normalized DRZ radius versus depth and time for salt adjacent to compacted clay seals

4-5 Normalized DRZ radius versus depth and time for salt adjacent to compacted crushed salt

4-6 Normalized DRZ radius versus depth and time for salt adjacent to asphalt.................... 4-8

4-7 Log-linear model for the calculation of an effective permeability of the DRZ ............. 4-11

4-8 Composite seal/DRZ permeability calculation methodology ......................................... 4-12 


\section{TABLES}

2-1 Summary of Permeability Measurements for WIPP Crushed Salt ................................ 2-4

2-2 Fractional Density of Crushed Salt for Different Values of Both $\mathrm{A}_{2}$ and Time after Seal Emplacement

2-3 Reference Engineering and Lower and Upper Bound Permeabilities for Compacted

Crushed Salt at 0 and 50 Yrs after Seal Emplacement ................................................ 2-13

2-4 Reference Engineering and Lower and Upper Bound Permeabilities for Compacted Crushed Salt at 100, 200, and 400 Yrs after Seal Emplacement

2-5 Parameters of the Log Triangular Distribution Functions for Permeability of Compacted Crushed Salt for Times of 0, 50, 100, 200, and 400 Yrs after Seal Emplacement $2-17$

2-6 Best Estimators for F'orosity of Compacted Crushed Salt ........................................... 2-19

2-7 Reported Literature Values of Hydraulic Conductivity and Permeability for Compacted Bentonite. $2-23$

2-8 Calculated Permeability Values for Compacted Bentonite .......................................... 2-27

2-9 Summary of Gas Permeability Measurements for SMC and SSSPT Concretes............ 2-36

2-10 Log Triangular Distribution Function Parameters for SMC Permeability ..................... 2-40

2-11 Summary of Air Entrainment for "Green" SMC ............................................................. 2-41

2-12 Summary of Air Entrainment for Cast SMC Monoliths.................................................. 2-41

2-13 Summary of Elastic Properties for Salado Mass Concrete Determined from

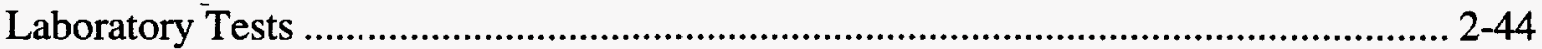

2-14 Literature Hydraulic Conductivity Values for Asphalt ................................................ 2-48

2-15 Reference Properties for Compacted SM and SC Soils.................................................. 2-50

2-16 Reported Hydraulic Conductivity for Silty and Clayey Sands........................................ 2-51

3-1 Literature Values of Residual Liquid Saturations for Geologic Material and Concrete

3-2 Literature Values of $\lambda$ for Geologic Materials......................................................... 3-10

3-3 Comparison of Pararneter Values …....................................................................... 3-18

4-1 Summary of Field Test DRZ Data ............................................................................... 4-3

4-2 Log Triangular Distribution Function Parameters for DRZ Skin Permeability $\left(k_{i}\right)$........ 4-4

4-3 Normalized DRZ Radius as a Function of Depth and Time for Upper and Lower Compacted Clay Seals ........................................................................................................... 4-8

4-4 Normalized DRZ Radius as a Function of Depth and Time for Compacted Crushed Salt Seal ............................................................................................................... 4-9

4-5 Normalized DRZ Radius as a Function of Depth and Time for the Asphalt Seal ........... 4-9

4-6 Extent of the DRZ in. Terms of Normalized Radius at Mid-Height of Component ...... 4-10

5-1 Seal Materials, Uncertainty Sources, and Redundant Components.................................. 5-2

5-2 Reconsolidated Salt Parameters (Component 10) ......................................................... 5-2

5-3 Bentonite Compacted Clay Parameters (Components 4, 8, and 12).............................. 5-3

5-4 Salado Mass Concrete Parameters (Components 2, 5, 7, 9, and 11) ............................. 5-3

5-5 Asphalt Parameters (Component 6) ......................................................................... 5-4

5-6 Earthen Fill Parameters (Components 1 and 3) ............................................................ 5-4 


\section{TABLES (Continued)}

5-7 Capillary Pressure and Relative Permeability Model BRAGFLO Parameters for Compacted Clay, Concrete, Reconsolidated Salt, Asphalt, and Earthen Fill . $5-5$

5-8 Salt DRZ BRAGFLO Parameters (Zones 1 through 4) ………......................................... 5-5

6-1 Contractors for Conceptual Model Development ......................................................... 6-1 


\section{ACRONYMS}

$\begin{array}{ll}\text { AIS } & \text { air intake shaft } \\ \text { AMM } & \text { asphalt-mastic mix } \\ \text { bgs } & \text { below ground surface } \\ \text { CCA } & \text { Compliance Certification Application } \\ \text { CDF } & \text { cumulative distribution function } \\ \text { DOE } & \text { U.S. Department of Energy } \\ \text { DRZ } & \text { disturbed rock zone } \\ \text { ESC } & \text { expansive salt-saturated concrete } \\ \text { FAA } & \text { fluid-applied asphalt } \\ \text { HMAC } & \text { hot-mix asphalt concrete } \\ \text { LHS } & \text { Latin hypercube sample } \\ \text { MDCF } & \text { Multi-Deformation Coupled Fracture } \\ \text { PA } & \text { performance assessment } \\ \text { PDF } & \text { probability distribution function } \\ \text { PNL } & \text { Pacific Northwest National Laboratories } \\ \text { QA } & \text { quality assurance } \\ \text { QED } & \text { Qualification of Existing Data } \\ \text { RCRA } & \text { Resource Conservation and Recovery Act } \\ \text { SMC } & \text { Salado mass concrete } \\ \text { SNL } & \text { Sandia National Laboratories } \\ \text { SPM } & \text { Systems Prioritization Method } \\ \text { SSSPT } & \text { Small Scale Seal Performance Tests } \\ \text { USDA } & \text { United States Department of Agriculture } \\ \text { WES } & \text { Waterways Experiment Station } \\ \text { WIPP } & \text { Waste Isolation Pilot Plant } \\ \end{array}$




\subsection{INTRODUCTION}

The U.S. Department of Energy (DOE) plans to dispose of transuranic waste at the Waste Isolation Pilot Plant (WIPP), which is sited in southeastern New Mexico. The WIPP disposal facility is located approximately $650 \mathrm{~m}$ ( $2150 \mathrm{feet}$ ) below the surface in the bedded halite of the Salado Formation. Prior to initiation of disposal activities, the DOE must demonstrate that the WIPP will comply with all regulatory requirements. The applicable regulations require that contaminant releases from the WIPP remain below specified levels for a period of 10,000 years. To demonstrate that the WIPP will comply with these regulations, the DOE has requested that Sandia National Laboratories (SNL) develop and implement a comprehensive performance assessment (PA) of the WIPP repository for the regulatory period.

The PA process begins with the development of conceptual models that describe the repository behavior. Mathematical relationships are derived to model the waste and waste behavior, mass transport, and mechanical and hydrologic responses of the disposal regions. Engineered barriers, such as panel closures and shaft seals, are modeled as part of the disposal system. Implementation of a conceptual model as a numerical model is the next step in the PA process. The relevant equations are discretized, and a grid is developed from the system geometry. Finally, parameters are defined that apply to the material properties of the modeled region and to numerical values specific to computer codes selected to simulate system behavior. A detailed description of previous PA models and results can be found in the 1992 Preliminary Performance Assessment (WIPP PA, 1992-1993).

This document presents the conceptual model of the shaft sealing system to be implemented in PA calculations conducted in support of the Compliance Certification Application (CCA) for the WIPP (U.S. DOE, 1996). The model was developed for use in a repository-scale, multi-phase flow calculation and includes the seal system geometry and materials to be used in grid development, as well as all parameters needed to describe the seal materials.

\subsection{WIPP Shaft Sealing System}

\subsubsection{Site Setting}

The WIPP underground repository is situated in the Salado Formation, which consists of an approximate $600-\mathrm{m}$ sequence of bedded evaporites. The principal stratigraphic units overlying the Salado Formation are the Dewey Lake Redbeds and the Rustler Formation. The Dewey Lake Redbeds begin 15 to $30 \mathrm{~m}$ below the surface and consist of alternating layers of sandstone and siltstone. The Rustler Formation lies below the Dewey Lake Redbeds and is comprised primarily of anhydrite and dolomite layers. The Culebra and Magenta dolomite members of the Rustler Formation are the only known sources of groundwater in the WIPP repository vicinity. Neither member comprises a significant groundwater source. 
The Salado Formation consists of a Permian-age evaporite sequence and lies below the Rustler Formation. It is largely composed of halite, with intermittent occurrences of polyhalite, clay, glauberite, and anhydrite. These lithologic layers are nearly horizontal at the WIPP repository horizon. The Salado Formation exhibits very low permeability to brine $\left(<10^{-21} \mathrm{~m}^{2}\right.$ for the intact rock) and is essentially impermeable to gas. Several of the thicker layers of Salado anhydrites have been designated as "marker beds." These layers are more transmissive than the halitic sequences but still exhibit very low permeabilities $\left(<10^{-17} \mathrm{~m}^{2}\right)$.

Excavation of underground openings creates a stress difference that is maximal at the free surface. The WIPP repository lithologies exhibit rock deformation behavior that ranges from brittle to ductile. Because of salt's ductile nature, the stress differences induce creep behavior in salt. Over time, the creep process of the salt is expected to result in encapsulation and permanent isolation of waste disposed in an excavation. During the interim period, however, the stress difference leads to microfracturing, which alters the mechanical and hydrologic properties of the rock. The change that can significantly impact seal system performance relates to the increasing permeability associated with microfracturing. The zone of rock that experiences microfracture is known as the disturbed rock zone (DRZ), and it represents a potential fluid migration pathway.

The WIPP shaft sealing system was designed to take advantage of the creep behavior of the Salado salt beds and also to mitigate the impact of the DRZ. Issues specific to these behaviors are discussed in the next section.

\subsubsection{WIPP Shaft Sealing System}

The shaft sealing system, shown schematically in Figure 1-1, consists of 13 elements that completely fill the shaft with low permeability materials. The Salado Formation components provide the primary barrier to fluid transport along the shaft. The Rustler Formation components limit fluid communication of the water-bearing Culebra and Magenta members of the formation. Components from the Rustler Formation to the surface fill the shaft with high density soils, consistent with good engineering practice. The various types of components are briefly described below.

\subsubsection{SHAFT STATION MONOLITH}

At the bottom of each shaft, a concrete monolith supports the local roof and overlying components. This monolith is to be constructed using a salt-saturated concrete, Salado Mass Concrete (SMC), developed for use at the WIPP. The function of the monolith is to provide support for components constructed above it.

\subsubsection{CLAY COLUMNS}

Three columns of densely compacted clay are included in the seal design: the lower Salado column, the upper Salado column, and the Rustler column. The clay is designed to have a minimum density of $1800 \mathrm{~kg} / \mathrm{m}^{3}$ and will have an initial moisture content of approximately 10 to 


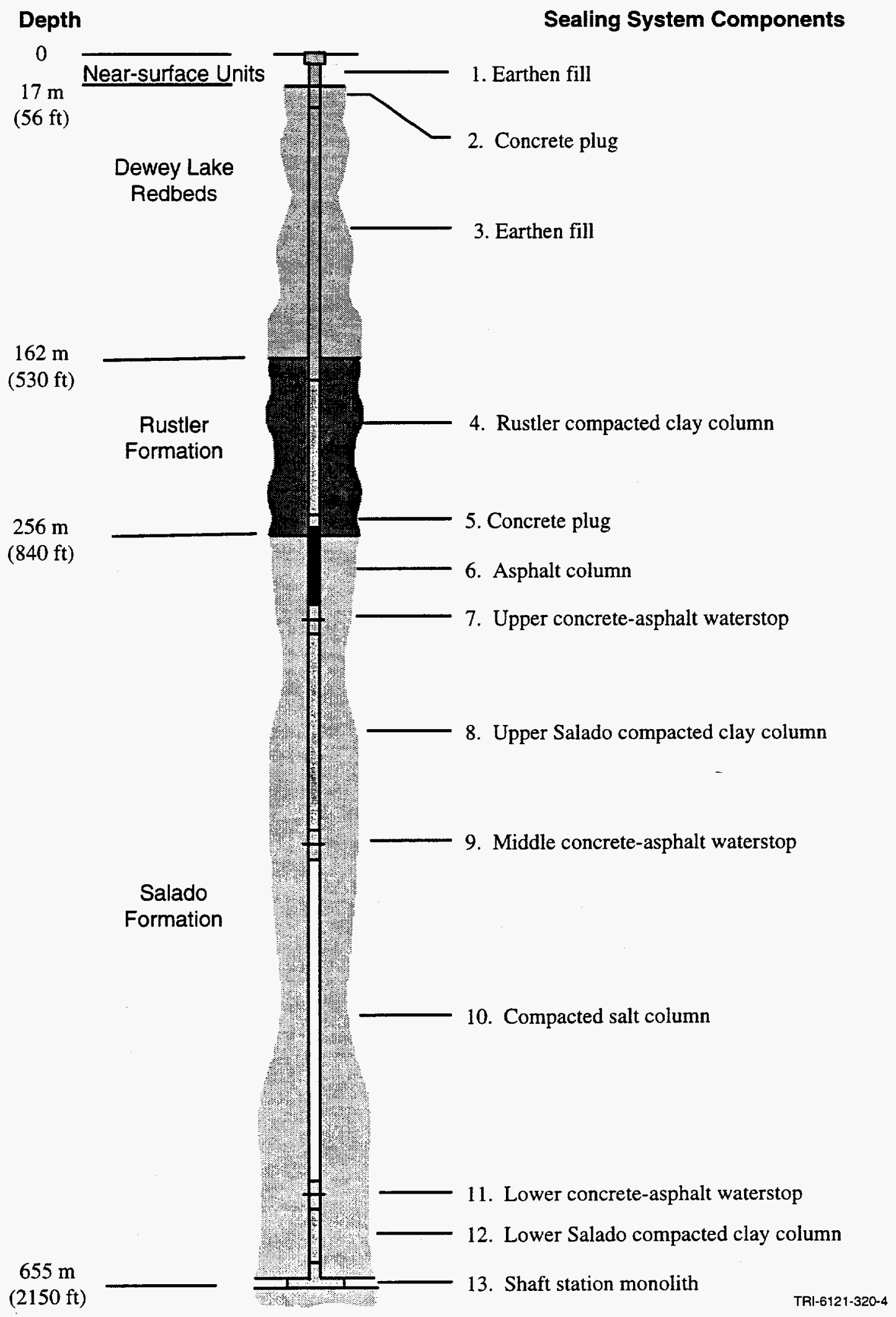

Figure 1-1. Proposed seal design for the WIPP Air Intake Shaft. 
12\%. The clay columns are designed to provide an immediate, permanent barrier to both gas and liquid transport.

\subsubsection{CONCRETE-ASPHALT WATERSTOP COMPONENTS}

Concrete-asphalt waterstop components include three elements: an upper SMC plug, a central asphalt waterstop, and a lower SMC plug. The asphalt used in the waterstop is AR-4000, a graded asphalt of intermediate viscosity. Three such components are located in the Salado Formation. These components provide independent shaft cross section and DRZ seals that are designed to provide immediate barriers to both gas and liquid transport.

\subsubsection{COMPACTED CRUSHED SALT COLUMN}

The shaft seal systern includes a 170-m long column of dynamically compacted crushed Salado salt. The compacted salt will have an initial porosity of approximately $10 \%$ and is designed to reconsolidate because of creep closure of the surrounding Salado salt. The salt column is located near the bottom of the shaft to achieve the most rapid consolidation of the compacted salt. As the consolidation process continues, the permeability of the salt component is designed to reach sufficiently low values to comprise a permanent and essentially impermeable barrier to fluid and contaminant transport through the shafts.

\subsubsection{ASPHALT COLUMN}

An asphalt-mastic mix (AMM) is specified for the asphalt column, which bridges the Rustler/Salado contact. The AMM is a mixture of asphalt, sand, and hydrated lime. The asphalt component is designed as a permanent redundant barrier to fluid flow.

\subsubsection{CONCRETE PLUGS}

A concrete plug is located just above the asphalt column, and another is located near the surface. These plugs are designed to provide additional support during the seal construction process.

\subsubsection{EARTHEN FILL}

The shaft above the Rustler formation is filled with locally available compacted earthen fill. The fill will be dynamically compacted to a bulk density approximating that of the surrounding media (1800 tc $\left.2200 \mathrm{~kg} / \mathrm{m}^{3}\right)$.

\subsection{Coniceptual Model of WIPP Shaft Sealing System}

The conceptual model of the shaft sealing system used by PA analysts reflects the general characteristics and behavior of the detailed seal system design. PA calculations are intended to 
predict the behavior of the complete repository system over a period of 10,000 years. Consistent with this intent, the PA conceptual model of the shaft sealing system does not attempt to identify the detailed processes that occur within individual seal components. Detailed conceptual models of the shaft sealing system designs have been developed to assist in the design and hydrologic assessment of individual seal components (RISD, 1996). This section summarizes conceptual models previously used by PA, describes those used to perform detailed hydrologic design evaluations of shaft sealing systems, and presents the conceptual model used in the WIPP CCA calculations.

\subsubsection{Summary of Previous Conceptual Models}

The Initial Reference Seal System Design (Nowak et al., 1990) proposed a sealing strategy that utilized short-term cementitious components and long-term compacted crushed salt components. This strategy was incorporated into PA models as one or two regions of the simulated sealing system, which were given uniform but time-dependent properties (WIPP PA, 1991-1992; 1992-1993). The four WIPP shafts were modeled as a single shaft, maintaining the area and volume of the four shafts. Seal design changes and refinements were implemented through variation of the lumped seal geometry and properties. A baseline conceptual model of the shaft sealing system was presented as part of the Systems Prioritization Method (SPM) (Prindle et al., 1996). This model divided the seal system into upper and lower sealing units separated by a "shaft" component. Calculations conducted in support of the SPM confirmed that low permeability materials were required in the shafts to limit contaminant transport through the sealed shaft. Uncertainty in the performance of the short-term and long-term sealing concepts proposed in the Initial Reference Seal System Design was addressed through the development of a robust seal design, the performance of which does not rely on short-term and long-term barriers. This design is termed the WIPP Shaft Sealing System Design and is documented in U.S. DOE (1995) and RISD (1996).

\subsubsection{Detailed Conceptual Models}

The lumped systems modeled by PA were considered adequate for simulation of the general behavior of the sealing system, but did not resolve the detailed behavior of the individual components. This resolution was necessary to demonstrate the performance capabilities of the new seal system design. For example, evaluation of long-term salt components is coupled to the performance of other seal components. The reconsolidation process will slow significantly if the pore space in the salt components prematurely resaturates with brine. Models developed for PA could not adequately evaluate the processes likely to affect salt consolidation. In addition, the processes governing flow through the seal components and the DRZ were not well understood. Consequently, detailed models for the design evaluations of the individual seal components and the complete system design were developed concurrently with the new seal system design (RISD, 1996). Information derived from these modeling studies led to the recognition that coupling of the mechanical and hydrological processes governing fluid flow through the sealed WIPP shafts will affect system performance. Detailed studies have addressed these coupled behaviors, and have provided assurance that the seal system design will perform as it is intended (RISD, 1996). 
The level of detail inherent in these studies facilitated the development of the conceptual model needed to assess repository-scale performance issues.

\subsubsection{Compliance Application Model of the Shaft Sealing System}

Evaluation of the shaft seal system on a repository scale required development of a conceptual model which was internnediate in detail relative to the lumped models used previously and those used to assess individual component performance. The four shafts were still modeled as a single shaft. The conceptual framework for the model is shown in Figure 1-2. Some adjustments to stratigraphy and depth were made to accommodate the final stratigraphic layers selected for the WIPP model. Consistent with the sealing strategy, the shaft station monoliths were assigned properties of "fill material." Components overlying the monolith correlate with the actual seal design, with seal component columns retaining the lengths presented for the Air Intake Shaft system (U.S. DOE, 1995). Slight differences will exist for the other three shafts because of variations in stratigraphy, but these differences are assumed to be minor. The effects of the DRZ were incorporated into the model, but it did not include details of seal material/DRZ interactions. These issues are addressed by detailed modeling studies discussed in Section 1.2.2.

The conceptual model of the shaft sealing systems provided for the WIPP CCA (U.S. DOE, 1996) takes advantage of a design strategy that uses multiple components and materials for each sealing function. This strategy provides assurance that the system will fulfill all sealing functions. Previous seal system designs did not provide this assurance. It was therefore necessary to include the probability of system failure into the seal material properties utilized in the lumped models. The redundancy of function provided by the compliance application shaft sealing system design eliminates the need to consider system failure and thus reduces the uncertainty associated with the performance of any given material.

\subsection{Conceptual Model Parameters}

Parameters specific to the seal conceptual model included intrinsic material properties, the initial state of the seal components, and parameters that quantify fluid flow when both gas and liquid phases are present. The time-dependent creep behavior of the salt and limited service period of cementitious seal material resulted in transient parameter specification for some of the seal parameters. Uncertainty exists in the intrinsic properties, two-phase flow parameters, and time-dependent response of the system and is characterized by the range in the parameters. Sources of uncertainty include limitations on availability of relevant data, unresolved issues related to physical processes (such as salt creep and chemical effects), and uncertainties regarding construction methods. The parameter development process for the seal conceptual model utilized the most current information on material properties and processes and sought consistency with the material specifications imposed by the seal system design document (RISD, 1996). This 


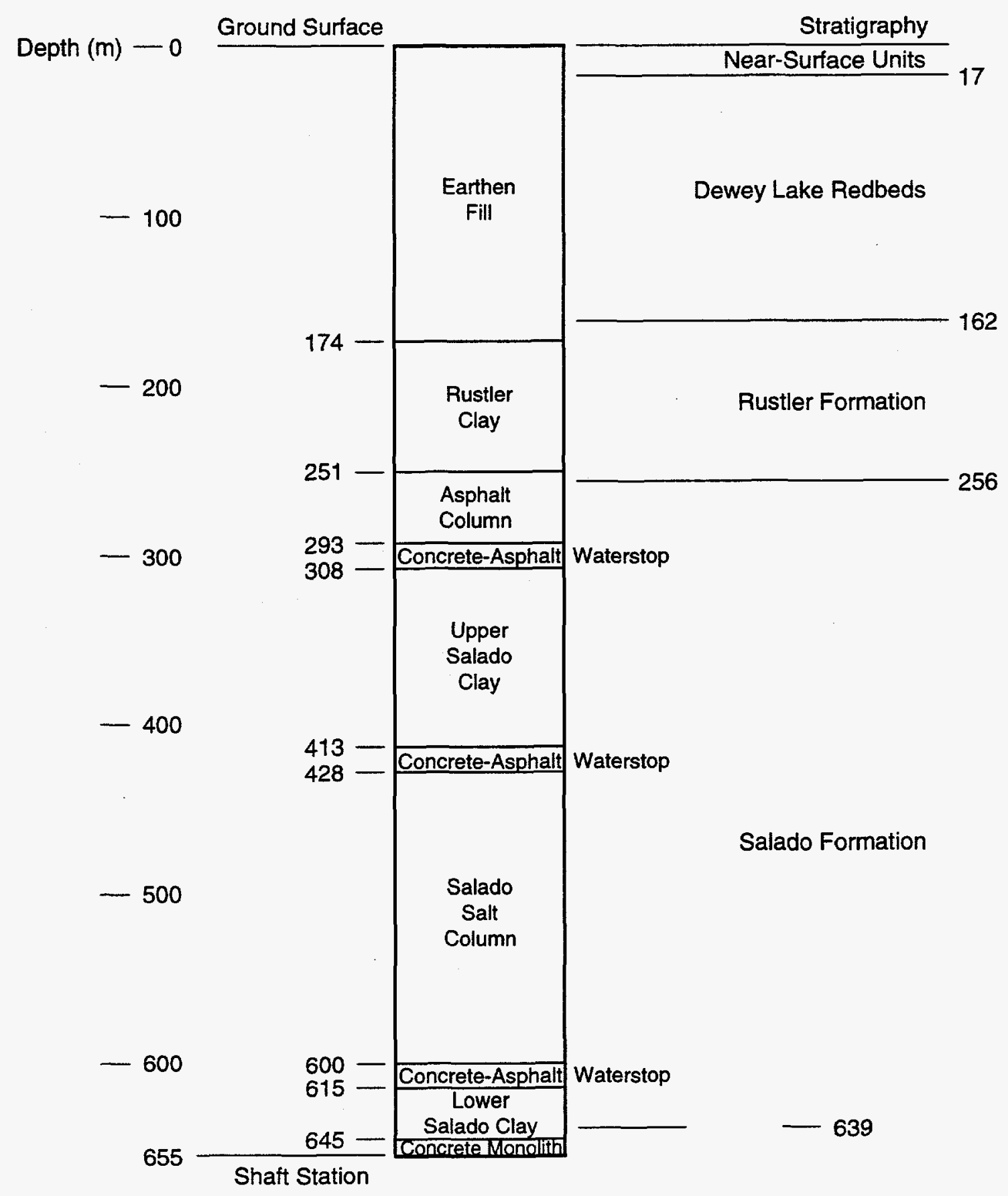

TRI-6121-381-0

Figure 1-2. Stratigraphy and conceptual framework for the Air Intake Shaft seal system. 
approach is consistent with good engineering practice and served to reduce the parameter uncertainty.

The PA process utilized a Latin Hypercube Sample (LHS) method to sample parameter values and to ensure that uncertainty in critical parameters was incorporated into the analysis. The LHS method involves selection over the uncertainty range of those parameters deemed significant. The selection of significant parameters was based on prior sensitivity studies and assumptions made by the PA analysts. The development of the parameters for the seal conceptual model considered existing PA sensitivity studies, engineering judgment by the seal system design team, and results of detailed modeling studies. Where available, standard values and reliable data for material parameters were applied. In other instances, engineering values were developed using professional judgment.

\subsubsection{Saturated Flow Parameters}

Results of PA calculations (WIPP PA, 1992-1993) demonstrated that contaminant transport is sensitive to the intrinsic permeability of the seal materials. Uncertainty in seal material permeabilities is quantified through the development of probability distribution functions (PDFs) for these parameters. Although the seal design completely fills the shaft with low permeability materials, no credit is taken for the sealing ability of the shaft station monolith at the base of the shafts and the earthen fill at the top. The intrinsic permeabilities of the asphalt column, SMC, compacted clay, and compacted crushed salt are considered sufficiently significant and influential such that PDFs are developed for these parameters.

PA sensitivity calculations have shown that fluid flow from the repository is not impacted by the porosity, compressibility, and initial conditions of the seal materials. Although some uncertainty exists in these parameters, it was assumed that the purposes of PA are adequately met through provision of engineering values for these parameters.

\subsubsection{Disturbed Rock Zone}

The creep processes resulting in the formation of a DRZ around open excavations in salt also act to reverse the damage when the opening is sealed. The damage process is governed by stress differences in the formation, which vary with time and depth. Consequently, the damage extent, in terms of both formation permeability and radial penetration into the formation, depends on a number of factors. This variation in DRZ damage and healing has been captured by coupling field data, numerical modeling, and professional judgment. Uncertainty in the approach must be incorporated into the PA conceptual model; this has been implemented through development of relevant PDFs and deterministic calculations of the effect of the DRZ.

For salt intervals containing both seal materials and an adjacent DRZ, composite permeabilities were developed specifically for use in PA calculations. These composite values were calculated from the seal material permeabilities given in Section 2.0. The DRZ permeabilities are developed in Section 4.0. The process used to calculate these composite values is described in detail in Section 4.3. 


\subsubsection{Two-Phase Flow Parameters}

The initially unsaturated state of the seal components and the probability of waste gas generation by the disposed waste necessitate quantification of two-phase flow behavior. Current two-phase-flow conceptual models require experimental derivation of specified parameters. Derivation of these parameters over the range of conditions expected to exist within the seal materials is a formidable task. However, PA sensitivity studies (WIPP PA, 1992-1993) have shown that repository performance is not significantly affected by uncertainty in these parameters. Engineering approximations for the two-phase flow parameters of the seal materials are assumed acceptable for this application.

\subsubsection{Time-Dependent Properties}

Permeability of the crushed salt column and the DRZ will exhibit time-dependent behaviors. Incorporation of the uncertainty in intrinsic material properties, host rock response, and transient behavior of the individual seal components would require sampling over a large number of parameters. The mechanisms that govern temporal values of the seal materials and associated DRZ are relatively well understood by the seal system design team. This knowledge has been incorporated into the PDF development process through the use of engineering judgment. Details of this approach are presented within the relevant sections of this report. 


\subsection{SATURATED FLOW PARAMETERS AND INITIAL CONDITIONS}

This section documents the rationale and specifies values for the saturated flow parameters and the initial hydrologic conditions recommended for use in PA compliance calculations for the shaft seal materials. The saturated flow parameters are the intrinsic permeability, the porosity, and the pore-volume compressibility. The initial conditions are the pore pressure and the wetting-phase (brine) saturation in the seal system at closure. The initial pressures for all of the seal components at closure were assumed to be atmospheric. The saturated flow parameters and initial conditions for the seal materials were developed independently of any DRZ parameters adjacent to the seal materials. The specifications given for each material are those designated for the shaft sealing system design (RISD, 1996).

\subsection{Compacted Crushed Salt}

The use of crushed salt as a sealing material within salt formations has been advocated for nearly forty years. As the intact rock creeps closed around a crushed salt seal, it is assumed that the crushed salt will reconsolidate so that it becomes indistinguishable from the host rock. In spite of its long history of acceptance, limited experimental and theoretical verification of crushed salt consolidation exists within the published literature (e.g., Brodsky, 1994; Holcomb and Hannum, 1982; Holcomb and Shields, 1987; Zeuch et al., 1991). Because crushed salt is proposed as a sealing material for the WIPP, recent efforts have focused on filling the gap between assumptions and verification (RISD, 1996). These efforts included: (1) development of a constitutive model for crushed salt consolidation, (2) implementation of the model in a structural numerical code, and (3) correlation of consolidation to hydrological parameters. These efforts were integrated into the development of parameters for the crushed salt seal component. The following sections provide details of the process.

\subsubsection{Material Specifications}

Reuse of salt excavated during the construction of the repository by returning the natural material to its original setting ensures physical, chemical, and mechanical compatibility with the host formation. The salt component consists of crushed Salado salt with the addition of small amounts of water. Natural Salado salt (WIPP salt) is typical of most salts in the Permian basin; it has an overall composition approaching 90 to $95 \%$ halite with minor amounts of clay, carbonate, anhydrite, and other evaporite minerals. Field and laboratory tests have verified that natural salt can be compacted to a fractional density (material bulk density divided by material matrix density) of equal to or greater than 0.9 with the addition of modest amounts of water. In situ WIPP salt contains approximately $0.5 \mathrm{wt} \%$ water. After it is mined, transported, and stored, some of the connate water is lost to evaporation and dehydration. The water content of the bulk material that will be used for compaction in the shaft is normally about $0.25 \mathrm{wt} \%$. A fine mist of water will be sprayed onto the crushed salt as it is compacted to increase the total water content to between 1.5 and $2 \%$ by weight. Measurements of the water content of the salt will be 
necessary during construction to calculate the appropriate amount of water to be added (RISD, 1996).

\subsubsection{Intrinsic Permeability}

Intrinsic permeability is a measure of the ease with which fluid can flow through a porous medium. The relationship between permeability and Darcy's Law is provided below.

Darcy's Law states:

$$
v=-\mathrm{K} \frac{d h}{d l}
$$

where:

$$
\begin{aligned}
\nu & =\text { specific discharge or Darcy velocity }(\mathrm{m} / \mathrm{s}), \\
d h / d l & =\text { hydraulic gradient }(\mathrm{m} / \mathrm{m}), \text { and } \\
\mathrm{K} & =\text { constant of proportionality }(\mathrm{m} / \mathrm{s})
\end{aligned}
$$

The constant $\mathrm{K}$, referred to as the hydraulic conductivity, relates the rate of fluid flow through a porous medium to the fluid pressure gradient induced across the medium. The hydraulic conductivity is a property of both the porous medium and the fluid flowing through the medium (Hubbert, 1956). Intrinsic permeability $\left(\mathrm{m}^{2}\right), k$, and hydraulic conductivity are related (Hubbert, 1956) by:

$$
\mathrm{K}=\frac{k \rho g}{\mu}
$$

where:

$$
\begin{aligned}
& \rho=\text { fluid density }\left(\mathrm{kg} / \mathrm{m}^{3}\right) \\
& g=\text { acceleration of gravity }\left(\mathrm{m} / \mathrm{s}^{2}\right), \text { and } \\
& \mu=\text { fluid viscosity }(\mathrm{kg} / \mathrm{ms})
\end{aligned}
$$

The intrinsic permeability is independent of the fluid flowing through a medium and is a property of the medium only.

\subsubsection{PARAMETER SOURCES}

Three principal sources contributed to the development of the compacted crushed salt permeability PDF: (1) gas permeability measurements on dynamically compacted salt specimens, (2) brine permeability rneasurements on mine-run salt consolidated in the laboratory, and (3) numerical calculations of crushed salt consolidation. 
Brodsky (1994) measured brine permeability as part of a comprehensive study to characterize both the consolidation characteristics and permeability of WIPP crushed salt. Sixteen steady-state brine permeability tests were performed in the study, including 15 tests performed on crushed salt specimens consolidated by Brodsky and one test performed on crushed salt consolidated by SNL (Zeuch et al., 1991). All samples consisted of loose mine-run salt consolidated under conditions of hydrostatic and shear consolidation stresses and were saturated in brine before the permeability tests were conducted. Tests were performed using brine as the permeant and a salt sample having nominal dimensions of $100 \mathrm{~mm}$ in diameter by $200 \mathrm{~mm}$ in length. The brine was manufactured by saturating distilled water with WIPP crushed salt ground to a fine powder. The brine was assumed to be saturated when salt precipitated out of the solution. The permeability tests were performed using a brine-filled accumulator located on the upstream side of the sample to induce a brine pressure difference that ranged from 0.05 to 2.01 $\mathrm{MPa}$ and a buret located on the downstream side of the specimen to measure flow. Confining pressures in the tests ranged from 0.86 to $4.02 \mathrm{MPa}$. In all tests, the flow-versus-time curves were nonlinear with higher flow rates measured early in the test and lower rates measured later in the test. The reported permeabilities are listed in Table 2-1 and represent values calculated from the high flow rates measured during the early portion of each test. These data are plotted as a function of fractional density in Figure 2-1 and show that permeability decreases as the fractional density increases.

Ahrens and Hansen (1995) reported gas permeability measurements for WIPP crushed salt from tests performed as part of a large-scale dynamic compaction demonstration. In this test, about $40 \mathrm{~m}^{3}$ of WIPP crushed salt was placed in a steel cylindrical chamber and compacted in three lifts by dropping a $9000-\mathrm{kg}$ weight in a systematic pattern to achieve an input energy of three times Modified Proctor Energy. The chamber had a diameter of $3.65 \mathrm{~m}$ and a height of $3.65 \mathrm{~m}$. Each lift was $1.2 \mathrm{~m}$ in original thickness, and sufficient water was added to the lifts to bring the moisture content of the crushed salt up to about $1.0 \mathrm{wt} \%$. After the mass was compacted, seven vertical test holes were drilled into the compacted crushed salt to recover cores for density determinations and also to provide access for in situ gas permeability equipment. The fractional density of the compacted mass was determined to be approximately 0.88 . A total of 14 nitrogen gas permeability measurements were taken in the test holes with a reported average permeability of $9.0 \times 10^{-14} \mathrm{~m}^{2}$. This value is included in Table 2-1 and is plotted in Figure 2-1.

Gas permeability tests were recently performed by Brodsky et al. (1996) on samples prepared from cores recovered from the large-scale dynamic compaction test and from two smallscale dynamic compaction tests (Hansen et al., 1995). The samples tested were nominally 100 $\mathrm{mm}$ in diameter with lengths that varied from 100 to $200 \mathrm{~mm}$. The tests were performed with nitrogen gas using a steady-state flow technique. Gas pressure differences of $0.345 \mathrm{MPa}$ or smaller were used in each test, and rotameter flowmeters were used to measure gas flow rates. The samples were confined with a pressure of $1 \mathrm{MPa}$ during the permeability measurements. Thirteen tests were performed, including seven tests on samples recovered from the large-scale dynamic compaction test, two tests on samples from the first small-scale dynamic compaction test, and four tests on samples from the second small-scale dynamic compaction test. The density of each specimen was determined before the permeability tests were conducted using fluid displacement and direct measurement techniques. The data from these tests are included in Table 2-1 and Figure 2-1. 
Table 2-1. Summary of Permeability Measurements for WIPP Crushed Salt

\begin{tabular}{|c|c|c|c|}
\hline $\begin{array}{c}\text { Specimen } \\
\text { Identification No. }\end{array}$ & Fractional Density $^{(a)}$ & Permeability $\left(\mathrm{m}^{2}\right)$ & Reference \\
\hline $\begin{array}{c}\text { HC1A } \\
\text { HC2A } \\
\text { HC3A } \\
\text { HC4A } \\
\text { HC5A } \\
\text { HC6A } \\
\text { SC1B } \\
\text { SC2A } \\
\text { SC3A } \\
\text { SC4A } \\
\text { SC5A } \\
\text { SC6A } \\
\text { SC7A } \\
\text { SC8A } \\
\text { SC9B } \\
\text { 19JUN90 }\end{array}$ & $\begin{array}{l}0.8953 \\
0.9377 \\
0.9333 \\
0.9272 \\
0.9907 \\
0.9907 \\
0.9546 \\
0.9788 \\
0.9607 \\
0.9428 \\
1.0051 \\
0.9678 \\
0.9691 \\
0.9629 \\
0.9804 \\
0.9709\end{array}$ & $\begin{array}{l}6.34 \times 10^{-18} \\
4.88 \times 10^{-18} \\
2.14 \times 10^{-19} \\
1.37 \times 10^{-19} \\
3.42 \times 10^{-22} \\
1.00 \times 10^{-20} \\
3.54 \times 10^{-19} \\
1.23 \times 10^{-18} \\
3.22 \times 10^{-19} \\
5.18 \times 10^{-19} \\
6.90 \times 10^{-19} \\
2.56 \times 10^{-20} \\
9.24 \times 10^{-20} \\
1.29 \times 10^{-19} \\
3.31 \times 10^{-20} \\
5.77 \times 10^{-20}\end{array}$ & Brodsky, 1994 \\
\hline In Situ & 0.8800 & $9.00 \times 10^{-14(b)}$ & $\begin{array}{c}\text { Hansen and Ahrens, } \\
1996\end{array}$ \\
\hline $\begin{array}{c}\mathrm{CS} / \mathrm{DC} 1-4-1 / 3 / 1 \\
\mathrm{CS} / \mathrm{DC} 1-8-3 \\
\mathrm{CS} / \mathrm{DC} 2 / \mathrm{MM}-1 / 1 \\
\mathrm{CS} / \mathrm{DC} 2 / \mathrm{MM}-2 / 1 \\
\mathrm{CS} / \mathrm{DC} 2 / \mathrm{T} 2 S-1 / 1 \\
\mathrm{CS} / \mathrm{DC} 2 / \mathrm{T} 2 S-3 / 2 \\
\mathrm{DCCS} 3 / 3 / 3-1 \\
\mathrm{DCCS} 3 / 2 / 1-1 \\
\mathrm{DCCS} 3 / 1 / 1-4 \\
\mathrm{DCCS} 3 / 3 / 1-4 \\
\mathrm{DCCS} 3 / 3 / 1-4 \\
\mathrm{DCCS} 3 / 3 / 1-4 \\
\mathrm{DCCS} 3 / 3 / 1-4\end{array}$ & $\begin{array}{l}0.9026 \\
0.8644 \\
0.8782 \\
0.8220 \\
0.8626 \\
0.8349 \\
0.8892 \\
0.9012 \\
0.8886 \\
0.9007 \\
0.9160 \\
0.9289 \\
0.9339\end{array}$ & $\begin{array}{l}2.50 \times 10^{-15} \\
2.43 \times 10^{-13} \\
1.71 \times 10^{-13} \\
4.11 \times 10^{-13} \\
5.71 \times 10^{-13} \\
1.10 \times 10^{-12} \\
7.88 \times 10^{-14} \\
4.99 \times 10^{-14} \\
5.51 \times 10^{-14} \\
4.99 \times 10^{-14} \\
2.63 \times 10^{-14} \\
4.58 \times 10^{-15} \\
4.95 \times 10^{-15}\end{array}$ & Brodsky et al., 1996 \\
\hline
\end{tabular}

(a) Fractional density is based on an intact salt density of $2160 \mathrm{~kg} / \mathrm{m}^{3}$.

(b) Average of fourteen gas flow tests. 


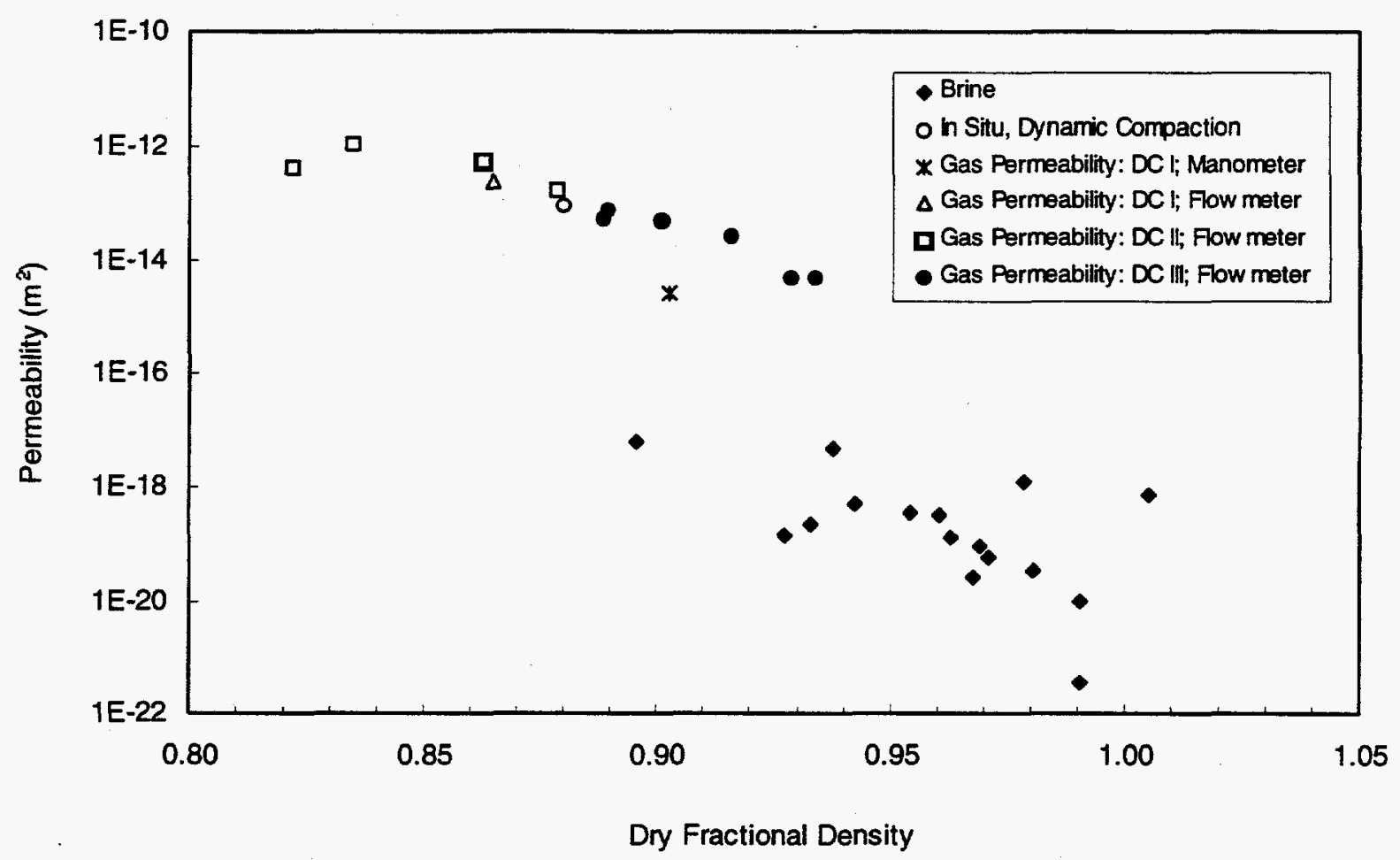

Figure 2-1. Permeability versus dry fractional density for WIPP crushed salt.

A Klinkenberg correction was not applied to these data. This correction would have reduced gas permeabilities by approximately $20 \%$. Relative permeability effects were also not considered during data reduction. Due to the low brine saturation of the samples, relative permeability effects were considered small.

\subsubsection{RATIONALE AND PARAMETER VALUE}

As discussed earlier, the natural process of shaft closure resulting from creep deformations of the intact salt rock surrounding the shaft is assumed to reconsolidate the dynamically-compacted crushed salt comprising the crushed salt seal. This process is expected to increase the fractional density of the crushed salt from 0.90 to 1.0 so that the crushed salt becomes indistinguishable from the intact salt. As shown in Figure 2-1, the intrinsic permeability of crushed salt decreases as density increases. Furthermore, since the density increase is a time-dependent or transient process, the permeability is also a transient process which requires that the PDF for the permeability of the crushed salt seal be treated as a transient function.

The development of a transient PDF for crushed-salt permeability requires both (1) the development of a relationship between permeability and density (or fractional density) and (2) the accurate prediction of density (or fractional density) with time. The experimental data presented in Table 2-1 and Figure 2-1 were used to relate permeability to density. However, neither experimental data nor natural analogs for the time-dependent process for crushed salt reconsolidation are available for long times (up to 10,000 years), so the prediction of density with 
time was made using structural analyses coupled with material models developed specifically for WIPP crushed salt and WIPP intact salt. The sources of data and rationale for development of the models will be discussed. first for the permeability versus fractional density relationship and then for the transient PDF.

\section{Permeability Versus Fractional Density Relationship}

As discussed in Section 2.1.2.1, three sources of data were available for the development of a relationship between permeability and fractional density. The data acquired by Brodsky (1994) were from brine perneability measurements performed on loose mine-run WIPP salt consolidated to relatively high densities under conditions of hydrostatic and shear consolidation stresses, while the data acquired by Hansen and Ahrens (1996) and Brodsky et al. (1996) were from gas permeability measurements performed on dynamically compacted crushed salt. Although the crushed salt seal is expected to comprise dynamically-compacted crushed salt, the use of all data (both from loose mine-run and dynamically-compacted crushed salt) for the development of the permeability versus fractional density was considered appropriate because (1) the hydrologic properties of the dynamically compacted crushed salt specimens are expected to closely approximate those present in the WIPP compacted salt column immediately following seal system construction (i.e., relatively low density and high permeability) and (2) the hydrologic properties of the loose mine-run crushed salt specimens are considered to represent the WIPP compacted salt column at long times (i.e., relatively high density and low permeability). Additional justification for the use of all data is provided below as well as a description of the method used to develop a relationship between permeability and fractional density.

The development of a permeability versus fractional density relationship required a careful examination of the experimental data acquired from the three studies. The data naturally fall into two groups: (1) gas permeability measurements performed on dynamically compacted crushed salt and (2) brine permeability measurements performed on loose mine-run salt. The gas permeability measurements can be subdivided into measurements performed on dynamically compacted crushed salt frorn the two small-scale dynamic compaction tests (Hansen et al., 1995) represented in Figure 2-1 by the open symbols and measurements performed on dynamicallycompacted crushed salt frorn the large-scale dynamic compaction test (Hansen and Ahrens, 1996) represented in Figure 2-1 by the one in situ measurement and the filled circles. From a historical perspective, the brine permeability tests (Brodsky, 1994) on the relatively high-density specimens represent the earliest test results and were followed, respectively, by gas permeability tests on dynamically compacted crushed salt from the two small-scale dynamic compaction tests and the one large-scale dynamic compaction test. This historical perspective is important because the impetus for performing the gas permeability tests on the dynamically compacted crushed salt from the large-scale test was to acquire permeability data in the transition region between relatively low-density specimens (i.e., specimens from the two small-scale tests) and high-density specimens (i.e., specimens from the brine tests) so that the general trend of the permeability versus fractional density relationship could be established. Although the specimens prepared from the crushed salt recovered from the large-scale test had an initial fractional density of approximately 0.9 , their densities were increased to cover the transition region densities (fractional densities of 0.9 to 0.95 ). The increase in density was obtained by subjecting the 
specimens to a hydrostatic consolidation stage in which the induced stresses were as high as 15 $\mathrm{MPa}$. Measurements were performed during this consolidation stage to acquire permeability data at different levels of fractional density. These data are represented by solid circles in Figure 2-1.

The data acquired from the brine testing of mine-run crushed salt and gas testing of crushed salt from the two small-scale compaction tests suggests that a linear relationship is a good approximation for the permeability (transformed using logarithms) versus fractional density plot shown in Figure 2-1. However when the data from the crushed salt recovered from the large-scale test (filled circles in Figure 2-1) are compared to this linear relationship, there appears to be an anomaly. That is, the permeability of the crushed salt recovered from the large-scale test is higher than the permeability predicted by the linear trend through the transition region based on the test data from the brine tests on mine-run salt and the gas tests on dynamically-compacted crushed salt from the two small-scale tests. An explanation for this apparent anomalous behavior is that the deformation process that occurred during the consolidation stage described above for the crushed salt from the large-scale test may have affected the permeability measurement. For example, it is well known that two deformation mechanisms contribute to the consolidation process for crushed salt and that one mechanism dominates the other depending on moisture content. Under dry conditions, the effective consolidation process (i.e., void space reduction) for crushed salt is crystal plasticity; whereas under wet conditions, the effective consolidation process for crushed salt is pressure solution/redeposition, a mechanism of mass movement facilitated by the presence of moisture on the grain boundaries. Void reduction by crystal plasticity is not effective in filling minute void spaces along grain boundaries. Therefore, at equivalent densities, dry consolidation salt would remain more permeable than wet deformed salt.

In the large-scale dynamic compaction test, water was added to the crushed salt to increase its moisture content to greater than $1.0 \mathrm{wt} \%$. This moisture content is considered high enough to activate the pressure solution/redeposition mechanism during consolidation. Unfortunately, the specimens recovered from the large-scale test and subsequently tested in the laboratory (Brodsky et al., 1996) for permeability were quite dry $(<0.4 \mathrm{wt} \%)$. Moisture was unavoidably lost during the large-scale test because the field test chamber for the dynamic compaction demonstration was heated, and the test required over three months to complete. Additionally, samples extracted from the test chamber may have lost moisture during handling, transport, and specimen preparation activities. Although the specimens of crushed salt from the large-scale test were known to be quite dry, it was not known whether the remaining moisture in the salt was sufficient to activate the pressure solution/redeposition mechanism during consolidation. Therefore, optical and scanning microscopy of deformed and undeformed samples of crushed salt obtained from the test specimens were performed to document the deformational processes that produced consolidation and to provide an explanation for the apparent anomalous data acquired for the specimens of crushed salt from the large-scale test. As observed through microscopy, consolidation of these specimens was dominated not by pressure solution/ redeposition as assumed but rather by crystal plasticity. As a result, the permeability measurements made on these specimens may not be consistent with the permeability expected in the placed shaft seal. Also, the densification process should be slower for dry specimens (Holcomb and Shields, 1987). The consolidation data acquired for the dynamically compacted specimens support the microscopy data in that the crushed salt consolidated more slowly or 
required higher hydrostatic stresses to achieve the higher densities associated with wet salt consolidation. In placing crushed salt in the shaft, the initial moisture content of the crushed salt will be increased to $1.5 \mathrm{wt} \%$ by adding water during the dynamic compaction process (RISD, 1996). The placed shaft seal salt is not expected to dry in a manner similar to the large-scale compaction test and is expected to retain moisture so the consolidation process in the shaft is fluid-aided pressure solution. Therefore, the permeability results obtained from tests of dry crushed salt from the large-scale compaction test may not represent the low permeability that will occur in the wet crushed salt seal.

More recent experiments conducted on dry specimens (Stuhrenberg and Zhang, 1995) further substantiate that moisture content and particle size significantly impact the initial permeability and consolidation process of crushed salt. At moisture contents similar to those of the dynamically compacted specimens (i.e., $<1 \%$ ), permeabilities comparable to the dynamically compacted specimens were measured. It was also shown that permeability decreased as the maximum particle size decreased. It can be argued that the extreme particle size distribution present in the WIPP dynamically compacted seals will produce a favorable result in the consolidation process. The presence of fine particles mixed throughout the compacted mass is likely to result in rapid consolidation because of the higher surface area attributable to these particles. As this process continues, the connected porosity and, hence, permeability of the composite mass is expected to reduce at rates greater than those predicted by WIPP experiments on dynamically compacted salt. This hypothesis is further substantiated by Stuhrenberg and Zhang's result that compaction of specimens having smaller grains produces lower permeabilities than specimens composed of large particles. Therefore, based on the above arguments, the permeability measurements made on dynamically compacted crushed salt specimens having densities in the range of 0.90 to 0.95 do not represent expected in situ conditions.

Based on the discussion and justification presented above, it was assumed that a loglinear model relating permeability (transformed into logarithmic space) and fractional density was the most reasonable approximation to the laboratory data presented in Figure 2-1. A linear least squares fit was performed using the following model:

$$
k_{\log 10}=m \bar{\rho}+b
$$

where:

$$
\begin{aligned}
k_{\log 10} & =\text { logarithmically transformed permeability (base } 10), \\
\bar{\rho} & =\text { fractional density based on an intact salt density of } 2160 \mathrm{~kg} / \mathrm{m}^{3}, \text { and } \\
m, b & =\text { fitting pararneters. }
\end{aligned}
$$

Based on the least squares fitting technique, the model relating permeability and density is:

$$
k_{\log 10}=54.885 \bar{\rho}+34.613
$$

This relationship corresponds to the "best fit" line in Figure 2-2. The permeability data given in Figures 2-1 and 2-2 show considerable variation, with differences of more than four orders of magnitude at an equivalent fractional density. To address this variation in permeability for a 


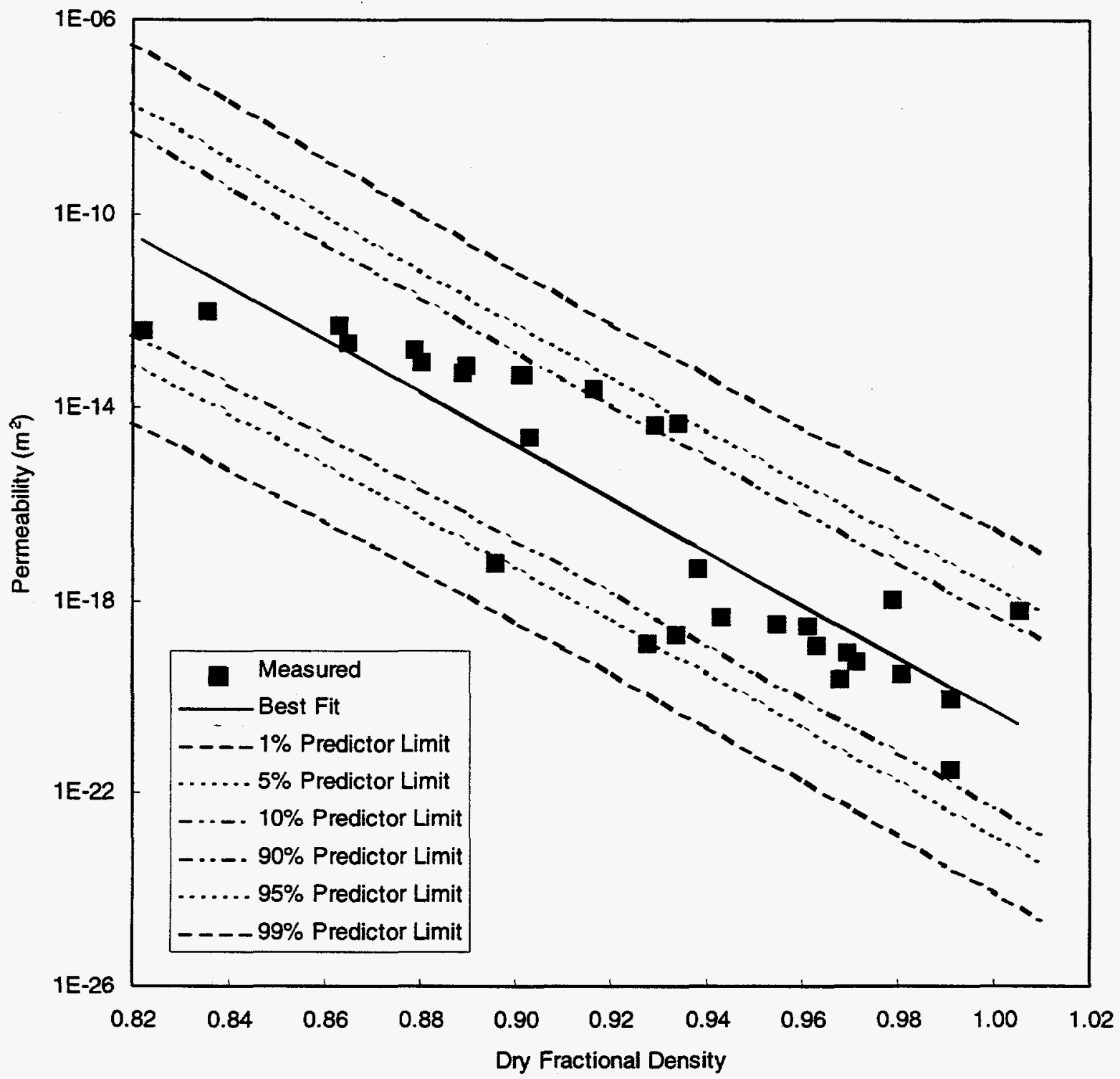

Figure 2-2. Measured and predicted permeability versus dry fractional density for the compacted crushed salt column.

given value of density, a probability interval was established around the predicted value. The probability interval that incorporates both the error from the fitted model and the error associated with future observations is termed a prediction interval (Montgomery and Peck, 1982). Three prediction intervals were determined for the empirical model, including the $80 \%$ prediction interval bounded by the 10 and $90 \%$ predictor limits, the $90 \%$ prediction interval bounded by the 5 and $95 \%$ predictor limits, and the $98 \%$ prediction interval bounded by the 1 and $99 \%$ predictor limits. Each of these intervals is superposed on the data given in Figure 2-2. As shown, the $90 \%$ prediction interval (bounded by the 5 and $95 \%$ prediction limits) contains all of the laboratory 
and in situ measurements of permeability. This predictor interval is used in the development of the transient PDF for crushed salt permeability as described below.

Development of Transient PDF

Although Equation 2-4 provides a relationship between permeability and density, it does not provide any information regarding density of the crushed salt with time, and no field analogs exist from which density can be inferred for long times. Structural analyses were performed to predict the density of the crushed salt as a function of time. The analyses made use of a "pineapple slice" structural model taken through the midheight of the crushed salt column (a depth of $515 \mathrm{~m}$ ), and assumed the initial emplaced fractional density of the crushed salt was 0.90 $\left(1944 \mathrm{~kg} / \mathrm{m}^{3}\right)$.

Figure 2-3 plots the density of the crushed salt as a function of time for three depths and indicates that the crushed salt column at a depth of $515 \mathrm{~m}$ (column midheight) is fully reconsolidated after approximately 140 years. The data presented in this figure were determined using the "pineapple slice" structural model combined with reference engineering values for the parameters in all of the constitutive models (e.g., the Multi-Deformation Coupled Fracture [MDCF] model for intact salt and the Sjaardema-Krieg [S-K] model for crushed salt). Some uncertainty exists in these constitutive models because of the uncertainty associated with the model parameters. In the development of the PDF for crushed salt permeability, it was assumed that all the model uncertainty could be attributed to one parameter in the MDCF model for intact salt. This parameter, $A_{2}$, is the leading coefficient of what is known as the undefined steady-state deformation mechanism and has been treated in previous analyses as a random variable having a lognormal distribution (Fossum et al., 1994). The effect of changes in the value of $A_{2}$ on density was analyzed by predicting density at five specific times $(0,50,100,200$, and 400 years) using the decile levels of $A_{2}$ calculated from its lognormal distribution. The results showed that fractional density was significantly affected by changes in the value of $A_{2}$ as shown in Table 2-2. For example, at 100 years after emplacement, the fractional density at a depth of $515 \mathrm{~m}$ could vary from 0.9577 to 1.0 .

The development of the PDF for crushed salt permeability required the incorporation of both (1) the uncertainty in the constitutive models used to predict fractional density and (2) the uncertainty in the permeability versus fractional density relationship described above. In addition, because the density and, therefore, the permeability change with time, the PDF was required to be a transient function. To characterize the transient nature of the PDF, distribution functions were developed for five specified times including $0,50,100,200$, and 400 years after seal emplacement. The process used to develop the transient PDFs and to combine the two sources of uncertainty is surnmarized as follows:

1) At each specified time after seal emplacement (i.e., 0, 50, 100, 200, and 400 years), permeability was estimated using Equation 2-4 for each of the ten values of fractional density given in Table 2-2. These permeability estimates are given in Tables 2-3 and 2-4 under the column of "Reference Engineering." 


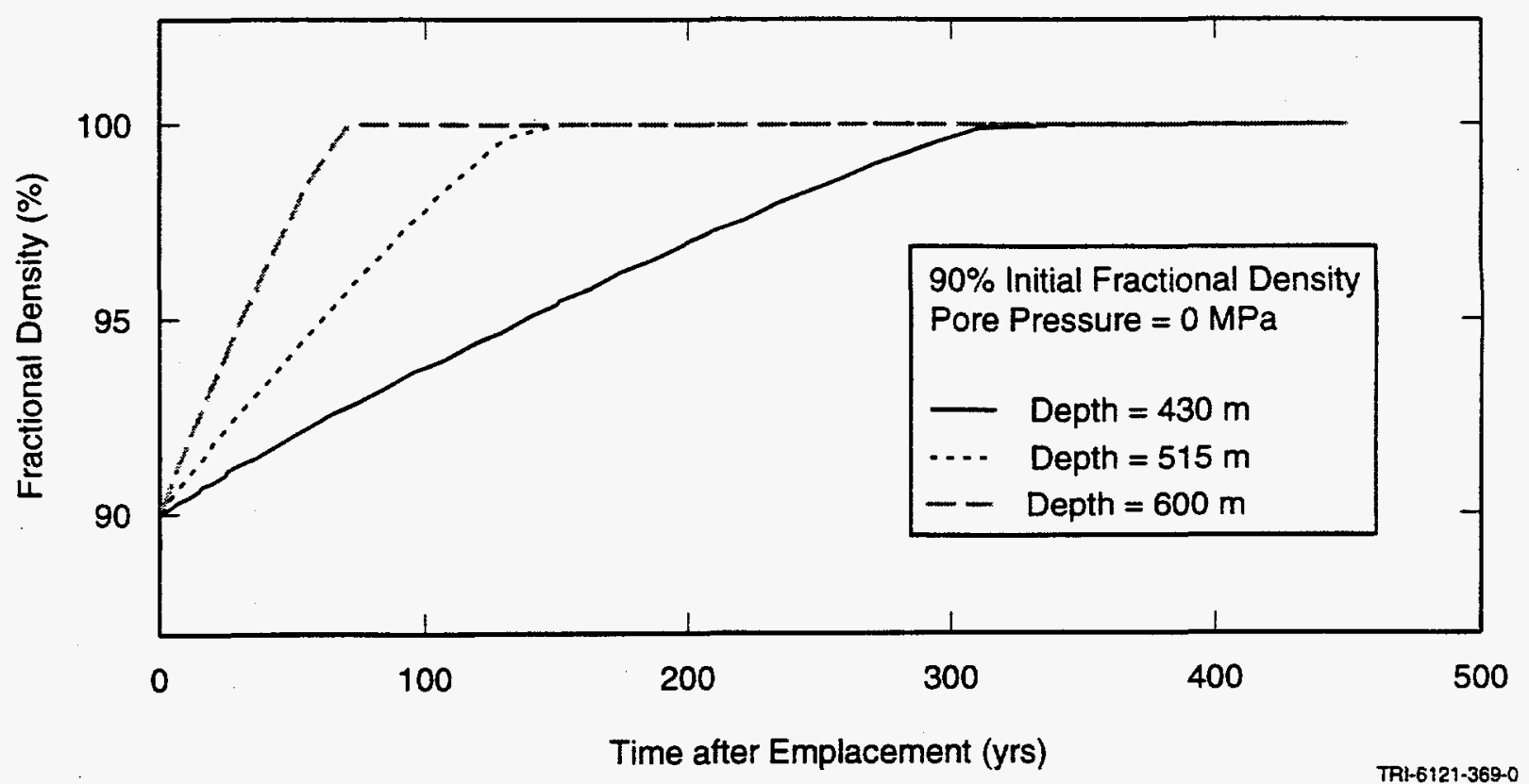

Figure 2-3. Fractional density as a function of time for the compacted crushed salt column at 430 , 515 , and $600 \mathrm{~m}$ depth below ground surface.

Table 2-2. Fractional Density of Crushed Salt for Different Values of Both $A_{2}$ and Time after Seal Emplacement

\begin{tabular}{cccccc}
\hline MDCF Parameter $A_{2}$ & \multicolumn{5}{c}{ Fractional Density ${ }^{(2)}$} \\
\cline { 2 - 6 } $10^{+20} /$ year & 0 years & 50 years & 100 years & 200 years & 400 years \\
\hline 2.550 & 0.9000 & 0.9305 & 0.9577 & 1.0000 & 1.0000 \\
3.600 & 0.9000 & 0.9392 & 0.9742 & 1.0000 & 1.0000 \\
4.130 & 0.9000 & 0.9434 & 0.9819 & 1.0000 & 1.0000 \\
4.600 & 0.9000 & 0.9471 & 0.9883 & 1.0000 & 1.0000 \\
5.710 & 0.9000 & 0.9553 & 0.9999 & 1.0000 & 1.0000 \\
6.940 & 0.9000 & 0.9639 & 1.0000 & 1.0000 & 1.0000 \\
8.450 & 0.9000 & 0.9737 & 1.0000 & 1.0000 & 1.0000 \\
10.41 & 0.9000 & 0.9853 & 1.0000 & 1.0000 & 1.0000 \\
13.31 & 0.9000 & 0.9991 & 1.0000 & 1.0000 & 1.0000 \\
18.73 & 0.9000 & 1.0000 & 1.0000 & 1.0000 & 1.0000 \\
\hline
\end{tabular}

(a) At a depth of $515 \mathrm{~m}$ (based on an intact salt density of $2160 \mathrm{~kg} / \mathrm{m}^{3}$ ). 
2) The ten values of permeability estimated using Equation 2-4 were plotted as a Cumulative Distribution Function (CDF) for each time after seal emplacement assuming the decile levels of the value of $A_{2}$ corresponded to the decile levels of permeability (Figures 2-4 through 2-7). This CDF incorporated uncertainty in the constitutive models, but did not address uncertainty in the permeability versus density relationship.

3) Upper and lower bounds on the determined permeabilities were also developed based on the predictor intervals shown in Figure 2-2. The predictor limits used were for $90 \%$ coverage (i.e., the 5 and $95 \%$ predictor limits defined previously). The permeabilities corresponding to the upper and lower predictor limits are also given in Tables 2-3 and 2-4.

4) The upper and lower bound permeabilities were drawn around the CDFs at the 5 and $95 \%$ bounds (see Figures 2-4 through 2-7). These bounds represent the uncertainty in the CDF inherent in the permeability versus density relationship.

5) A log triangular distribution function was then developed by assuming (1) the lower limit or bound of the distribution (parameter $a$ defined below) was equivalent to the first decile of the lower predictor interval (i.e., $5 \%$ bound), (2) the upper limit or bound of the distribution (parameter $b$ also defined below) was equivalent to the ninth decile of the upper predictor interval (i.e., 95\% bound), and (3) the most probable estimator of permeability (parameter $u$ also defined below) was equivalent to the permeability calculated using the reference engineering value of $A_{2}$. These log triangular CDFs are shown in Figures 2-4 through 2-7 denoted by "Proposed CDF." Table 2-5 summarizes the log triangular distribution parameters for compacted crushed salt permeability at times after emplacement of $0,50,100$, $200 \mathrm{k}$, and 400 years.

As discussed above, the permeability of the compacted crushed salt column was treated as a transient random variable defined by a log triangular distribution. The PDF for a triangular distribution was expressed as (Ang and Tang, 1975):

For $a \leq x \leq u$ :

$$
f_{x}(x)=\frac{2}{(b-a)}\left(\frac{x-a}{u-a}\right)
$$

For $u \leq x \leq b:$

$$
f_{x}(x)=\frac{2}{(b-a)}\left(\frac{b-x}{b-u}\right)
$$

where:

$x=$ transformed value of permeability,

$a, b=$ lower and upper endpoints of the distribution in transformed space, respectively,

and

$$
u=\text { transformed best estimator of the distribution. }
$$


Table 2-3. Reference Engineering and Lower and Upper Bound Permeabilities for Compacted Crushed Salt at 0 and 50 Years after Seal Emplacement

\begin{tabular}{|c|c|c|c|}
\hline \multirow{2}{*}{$\begin{array}{c}\text { Dry Fractional } \\
\text { Density }\end{array}$} & \multicolumn{3}{|c|}{ Permeability $\left(\mathrm{m}^{2}\right)$} \\
\hline & $\begin{array}{c}\text { Reference } \\
\text { Engineering }\end{array}$ & $\begin{array}{l}\text { Lower Bound } \\
\text { (5\% Predictor) }\end{array}$ & $\begin{array}{l}\text { Upper Bound } \\
\text { (95\% Predictor) }\end{array}$ \\
\hline \multicolumn{4}{|c|}{0 Years after Seal Emplacement } \\
\hline 0.9000 & $1.65 \times 10^{-15}$ & $5.00 \times 10^{-18}$ & $5.43 \times 10^{-13}$ \\
\hline 0.9000 & $1.65 \times 10^{-15}$ & $5.00 \times 10^{-18}$ & $5.43 \times 10^{-13}$ \\
\hline 0.9000 & $1.65 \times 10^{-15}$ & $5.00 \times 10^{-18}$ & $5.43 \times 10^{-13}$ \\
\hline 0.9000 & $1.65 \times 10^{-15}$ & $5.00 \times 10^{-18}$ & $5.43 \times 10^{-13}$ \\
\hline 0.9000 & $1.65 \times 10^{-15}$ & $5.00 \times 10^{-18}$ & $5.43 \times 10^{-13}$ \\
\hline 0.9000 & $1.65 \times 10^{-15}$ & $5.00 \times 10^{-18}$ & $5.43 \times 10^{-13}$ \\
\hline 0.9000 & $1.65 \times 10^{-15}$ & $5.00 \times 10^{-18}$ & $5.43 \times 10^{-13}$ \\
\hline 0.9000 & $1.65 \times 10^{-15}$ & $5.00 \times 10^{-18}$ & $5.43 \times 10^{-13}$ \\
\hline 0.9000 & $1.65 \times 10^{-15}$ & $5.00 \times 10^{-18}$ & $5.43 \times 10^{-13}$ \\
\hline 0.9000 & $1.65 \times 10^{-15}$ & $5.00 \times 10^{-18}$ & $5.43 \times 10^{-13}$ \\
\hline \multicolumn{4}{|c|}{50 Years after Seal Emplacement } \\
\hline 0.9305 & $3.49 \times 10^{-17}$ & $1.09 \times 10^{-19}$ & $1.12 \times 10^{-14}$ \\
\hline 0.9392 & $1.16 \times 10^{-17}$ & $3.60 \times 10^{-20}$ & $3.75 \times 10^{-15}$ \\
\hline 0.9434 & $6.83 \times 10^{-18}$ & $2.10 \times 10^{-20}$ & $2.22 \times 10^{-15}$ \\
\hline 0.9471 & $4.28 \times 10^{-18}$ & $1.31 \times 10^{-20}$ & $1.40 \times 10^{-15}$ \\
\hline 0.9553 & $1.52 \times 10^{-18}$ & $4.57 \times 10^{-21}$ & $5.05 \times 10^{-16}$ \\
\hline 0.9639 & $5.12 \times 10^{-19}$ & $1.50 \times 10^{-21}$ & $1.75 \times 10^{-16}$ \\
\hline 0.9737 & $1.48 \times 10^{-19}$ & $4.21 \times 10^{-22}$ & $5.24 \times 10^{-17}$ \\
\hline 0.9853 & $3.43 \times 10^{-20}$ & $9.23 \times 10^{-23}$ & $1.27 \times 10^{-17}$ \\
\hline 0.9991 & $5.99 \times 10^{-21}$ & $1.50 \times 10^{-23}$ & $2.40 \times 10^{-18}$ \\
\hline 1.0000 & $5.35 \times 10^{-21}$ & $1.33 \times 10^{-23}$ & $2.15 \times 10^{-18}$ \\
\hline
\end{tabular}


Table 2-4. Reference Engineering and Lower and Upper Bound Permeabilities for Compacted Crushed Salt at 100, 200, and 400 Years after Seal Emplacement

\begin{tabular}{cccc}
\hline $\begin{array}{c}\text { Dry Fractional } \\
\text { Density }\end{array}$ & $\begin{array}{c}\text { Reference } \\
\text { Engineering }\end{array}$ & $\begin{array}{c}\text { Lower Bound } \\
(5 \% \text { Predictor })\end{array}$ & $\begin{array}{c}\text { Upper Bound } \\
(95 \% \text { Predictor })\end{array}$ \\
\cline { 2 - 4 } & 100 Years after Seal Emplacement \\
\hline 0.9577 & $1.12 \times 10^{-18}$ & $3.35 \times 10^{-21}$ & $3.75 \times 10^{-16}$ \\
0.9742 & $1.39 \times 10^{-19}$ & $3.94 \times 10^{-22}$ & $4.93 \times 10^{-17}$ \\
0.9819 & $5.27 \times 10^{-20}$ & $1.44 \times 10^{-22}$ & $1.92 \times 10^{-17}$ \\
0.9883 & $2.35 \times 10^{-20}$ & $6.23 \times 10^{-23}$ & $8.84 \times 10^{-18}$ \\
0.9999 & $5.42 \times 10^{-21}$ & $1.35 \times 10^{-23}$ & $2.18 \times 10^{-18}$ \\
1.0000 & $5.35 \times 10^{-21}$ & $1.33 \times 10^{-23}$ & $2.15 \times 10^{-18}$ \\
1.0000 & $5.35 \times 10^{-21}$ & $1.33 \times 10^{-23}$ & $2.15 \times 10^{-18}$ \\
1.0000 & $5.35 \times 10^{-21}$ & $1.33 \times 10^{-23}$ & $2.15 \times 10^{-18}$ \\
1.0000 & $5.35 \times 10^{-21}$ & $1.33 \times 10^{-23}$ & $2.15 \times 10^{-18}$ \\
1.0000 & $5.35 \times 10^{-21}$ & $1.33 \times 10^{-23}$ & $2.15 \times 10^{-18}$ \\
\hline
\end{tabular}

200 and 400 Years after Seal Emplacement

\begin{tabular}{llll}
\hline 1.0000 & $5.35 \times 10^{-21}$ & $1.33 \times 10^{-23}$ & $2.15 \times 10^{-18}$ \\
1.0000 & $5.35 \times 10^{-21}$ & $1.33 \times 10^{-23}$ & $2.15 \times 10^{-18}$ \\
1.0000 & $5.35 \times 10^{-21}$ & $1.33 \times 10^{-23}$ & $2.15 \times 10^{-18}$ \\
1.0000 & $5.35 \times 10^{-21}$ & $1.33 \times 10^{-23}$ & $2.15 \times 10^{-18}$ \\
1.0000 & $5.35 \times 10^{-21}$ & $1.33 \times 10^{-23}$ & $2.15 \times 10^{-18}$ \\
1.0000 & $5.35 \times 10^{-21}$ & $1.33 \times 10^{-23}$ & $2.15 \times 10^{-18}$ \\
1.0000 & $5.35 \times 10^{-21}$ & $1.33 \times 10^{-23}$ & $2.15 \times 10^{-18}$ \\
1.0000 & $5.35 \times 10^{-21}$ & $1.33 \times 10^{-23}$ & $2.15 \times 10^{-18}$ \\
1.0000 & $5.35 \times 10^{-21}$ & $1.33 \times 10^{-23}$ & $2.15 \times 10^{-18}$ \\
1.0000 & $5.35 \times 10^{-21}$ & $1.33 \times 10^{-23}$ & $2.15 \times 10^{-18}$ \\
\hline
\end{tabular}




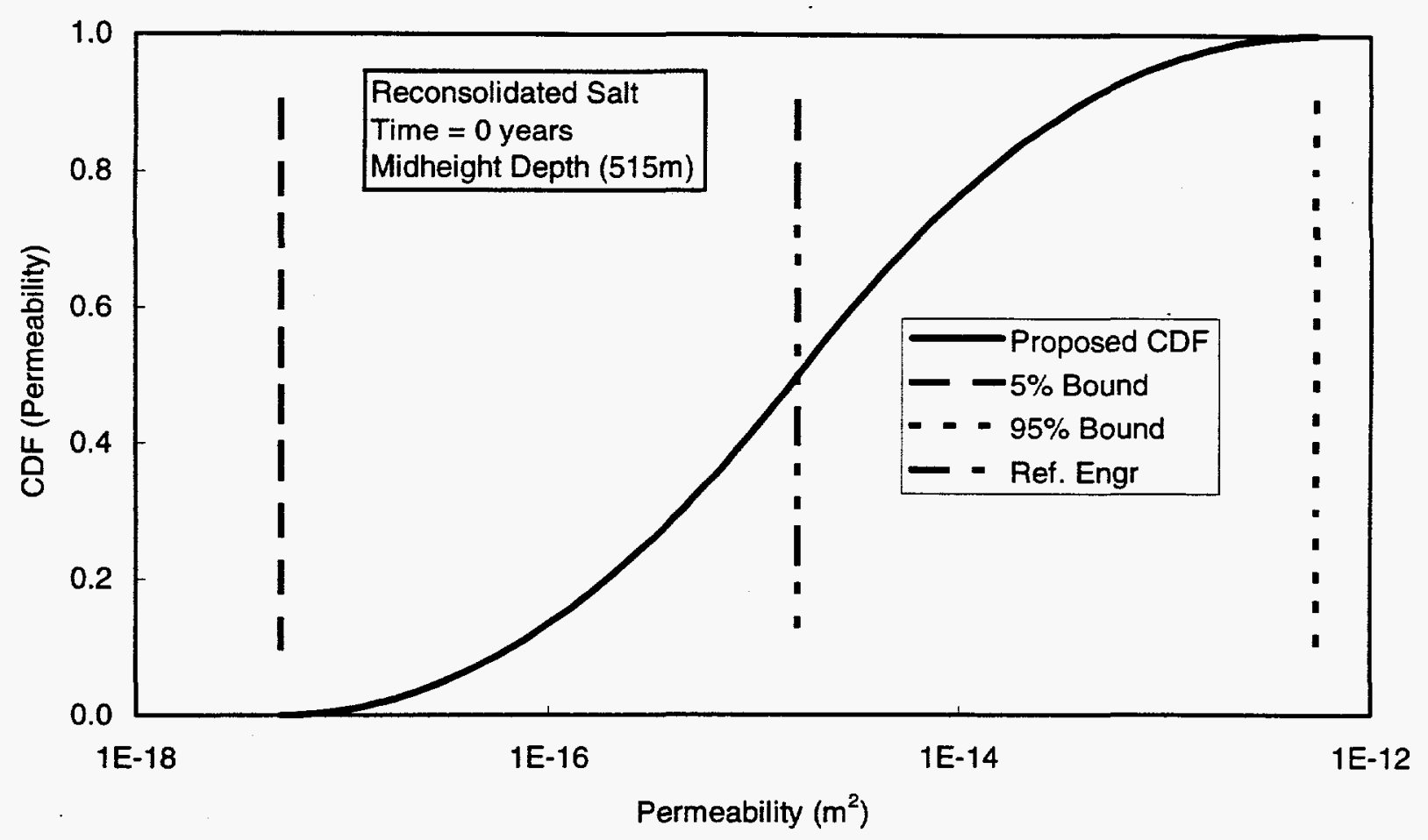

Figure 2-4. Permeability CDF for compacted crushed salt column at a depth of $515 \mathrm{~m}$ bgs and a time after seal emplacement of 0 years.

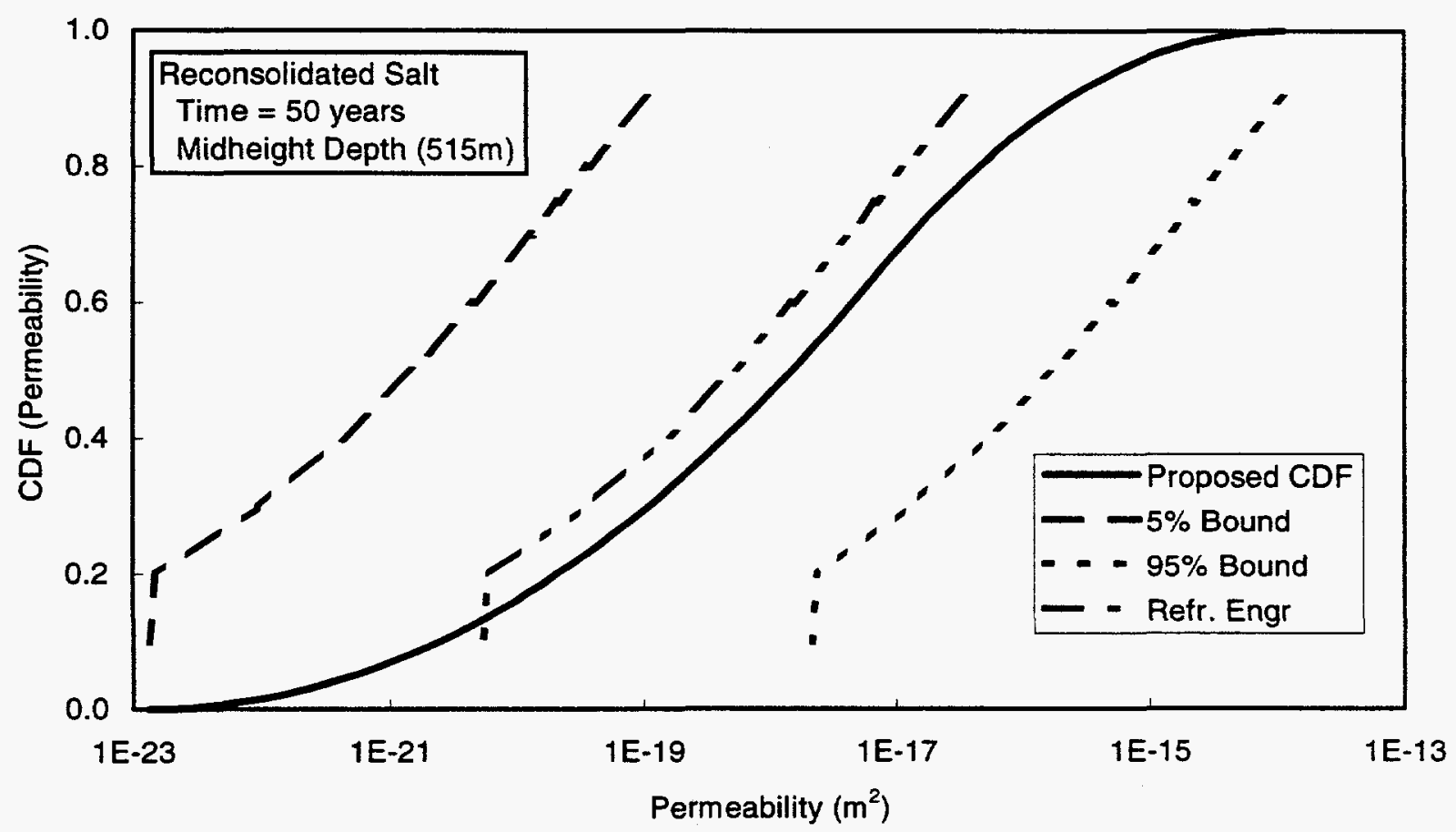

Figure 2-5. Permeability CDF for compacted crushed salt column at a depth of $515 \mathrm{~m}$ bgs and a time after seal emplacement of 50 years. 


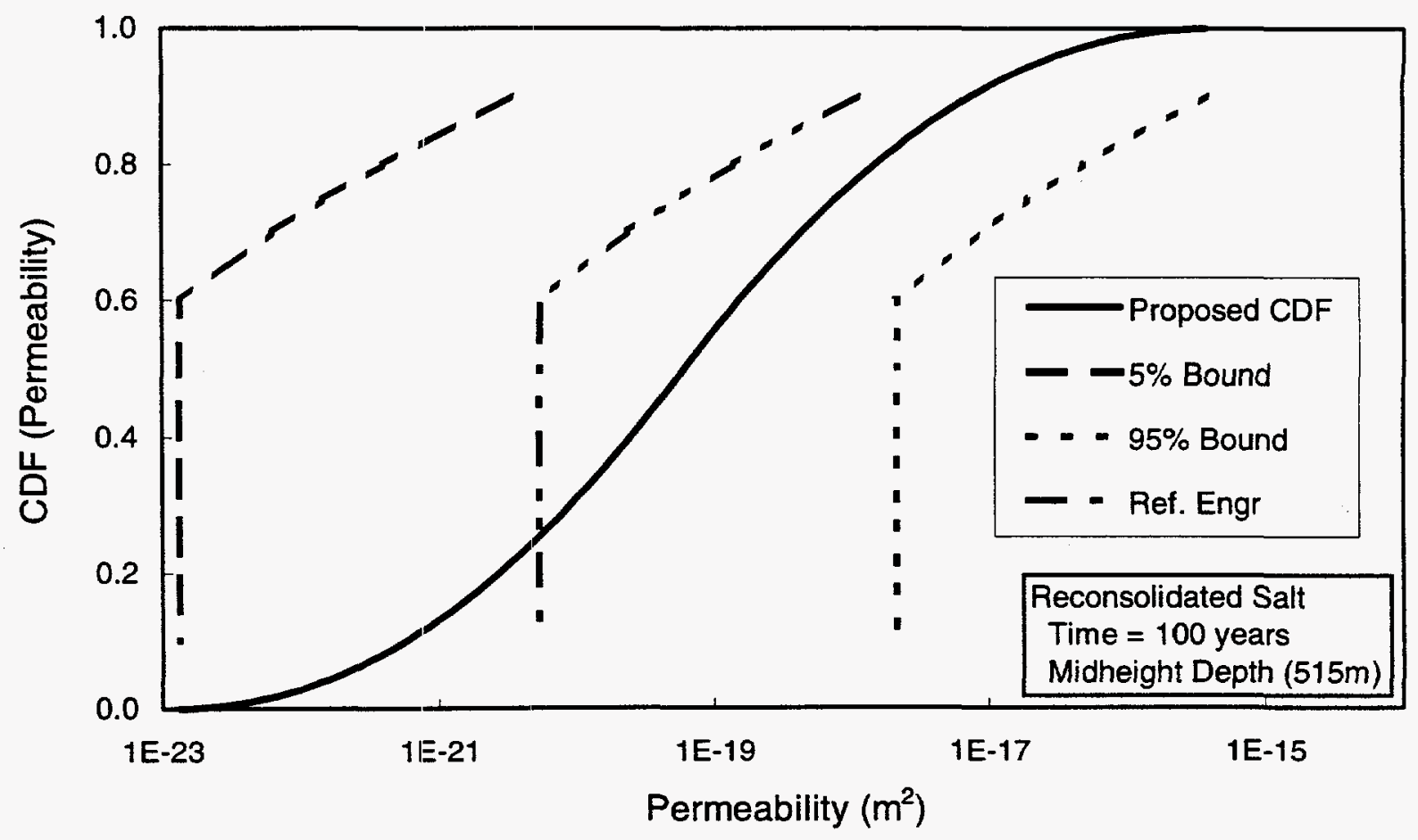

Figure 2-6. Permeability C.DF for compacted crushed salt column at a depth of $515 \mathrm{~m}$ bgs and a time after seal emplacement of 100 years.

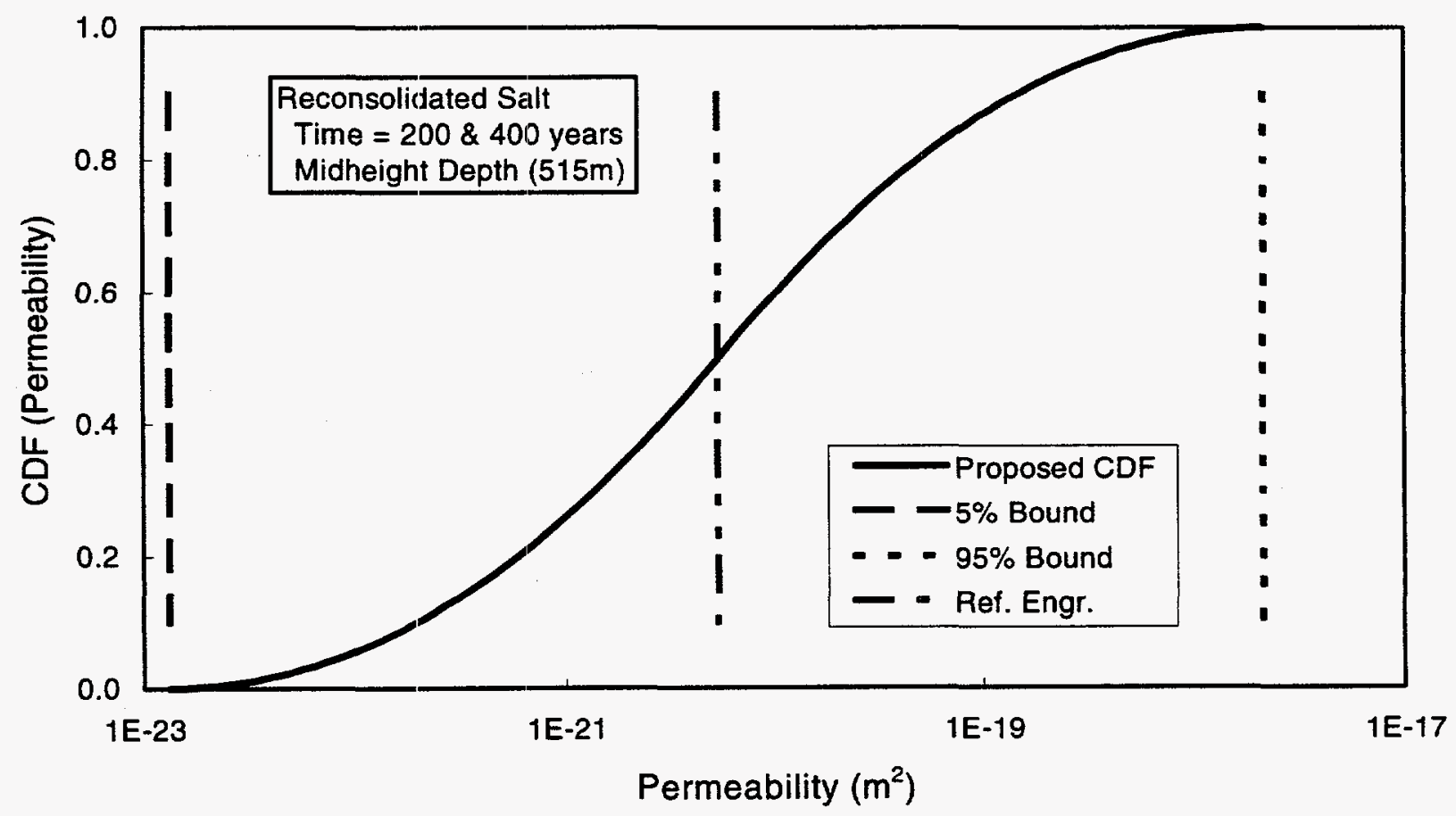

Figure 2-7. Permeability CDF for compacted crushed salt column at a depth of $515 \mathrm{~m}$ bgs and a time after seal emplacement of 200 and 400 years. 
Table 2-5. Parameters of the Log Triangular Distribution Functions for Permeability of Compacted Crushed Salt for Times of 0, 50, 100, 200, and 400 Years after Seal Emplacement

\begin{tabular}{cccc}
\hline $\begin{array}{c}\text { Time after Seal } \\
\text { Emplacement (years) }\end{array}$ & \multicolumn{3}{c}{ Permeability $\left(\mathrm{m}^{2}\right)$} \\
\cline { 2 - 4 } & Lower Bound & Best Estimator & Upper Bound \\
\hline 0 & $5.00 \times 10^{-18}$ & $1.65 \times 10^{-15}$ & $5.43 \times 10^{-13}$ \\
50 & $1.33 \times 10^{-23}$ & $6.83 \times 10^{-18}$ & $1.12 \times 10^{-14}$ \\
100 & $1.33 \times 10^{-23}$ & $5.27 \times 10^{-20}$ & $3.75 \times 10^{-16}$ \\
200 & $1.33 \times 10^{-23}$ & $5.35 \times 10^{-21}$ & $2.15 \times 10^{-18}$ \\
400 & $1.33 \times 10^{-23}$ & $5.35 \times 10^{-21}$ & $2.15 \times 10^{-18}$ \\
\hline
\end{tabular}

The CDF was obtained from the PDF through integration of Equations 2-5 and 2-6 over the limits from $a$ to $u$ and $u$ to $b$, respectively. The best estimator, $u$, was calculated from the transformed permeability data using:

$$
u=3 \bar{k}_{\log }-a-b
$$

where $\bar{k}_{\log }$ is the mean of the transformed permeability values. The distribution parameters are summarized in Table 2-5.

The DRZ permeability adjacent to the Salado crushed salt column was explicitly calculated and then combined with the crushed salt seal permeability in the conceptual model (see Section 4.0).

\subsubsection{Porosity}

Porosity $\left(\mathrm{m}^{3} / \mathrm{m}^{3}\right), \phi$, is defined (Freeze and Cherry, 1979) as the ratio of the volume of voids $\left(\mathrm{m}^{3}\right), V_{v}$, in a material to the total volume of the material $\left(\mathrm{m}^{3}\right), V_{t}$. Thus,

$$
\phi=\frac{V_{v}}{V_{t}}
$$

porosity is usually reported as a decimal fraction or a percent and has units $\mathrm{m}^{3} / \mathrm{m}^{3}$. The porosity of a material may be either interconnected or isolated. Interconnected porosity permits fluid transport through the material, while isolated porosity does not. Material porosity may also be expressed in terms of the bulk density $\left(\mathrm{kg} / \mathrm{m}^{3}\right), \rho$, and the material grain density $\left(\mathrm{kg} / \mathrm{m}^{3}\right), \rho_{g}$, through the relationship: 


$$
\phi=1-\frac{\rho}{\rho_{g}}
$$

The quotient term in Equation 2-9 can be expressed in terms of the salt fractional density $\bar{\rho}$. The grain density of salt, $\rho_{g}$, as determined by Brodsky et al. (1996) is $2160 \mathrm{~kg} / \mathrm{m}^{3}$. However, the intact salt specimens used to determine density had an assumed porosity of $1.0 \%$. To account for this condition, the porosity of the crushed salt can be calculated as follows:

$$
\phi=0.90(1-\bar{\rho})+0.01
$$

Equation $2-10$ is valid for $\bar{\rho} \geq 0.90$ and satisfies the conditions that the porosity is $10 \%(\phi=0.10)$ at an emplaced fractional density of 0.90 . At a fractional density of 1.0 (i.e., intact salt) the porosity is $1 \%(\phi=0.01)$.

\subsubsection{PARAMETER SOURCES}

Data used to develop transient, best estimators for porosity were based on predictions of crushed salt density with time and subsequent calculation of porosity using Equation 2-10. Porosity was determined as a function of time by substituting the density determined from the structural analysis described previously in Section 2.1.2.2 into Equation 2-10. Porosity values were determined for times corresponding to $0,50,100,200$, and 400 years after seal emplacement. These values are summarized in Table 2-6 and plotted in Figure 2-8.

\subsubsection{RATIONALE AND PAFAMETER VALUE}

Although the porosity of the crushed salt column is transient (time-dependent), compliance calculations did not include the time-dependent seal material porosities. Use of a constant was assumed adequate. A constant value of 5\% (0.05) was recommended for the porosity of the crushed salt. Table 2-6 shows that this porosity is representative of early times. However, because the porosity estimates in Table 2-6 do not consider the pore fluid effects on the reconsolidation (and subsequent reduction in pore volume), a simulation value 0.05 was considered appropriate.

\subsubsection{Pore-Volume Compressibility}

Pore-volume compressibility makes up part of the hydraulic diffusivity term for a porous medium. Rock compressibility ( $1 / \mathrm{Pa}), C_{r}$, is equal to the fractional change in volume of a solid rock matrix with a unit charge in pressure and can be expressed as (Jaeger and Cook, 1976):

$$
C_{r}=\frac{1}{K}
$$


Table 2-6. Best Estimators for Porosity of Compacted Crushed Salt

\begin{tabular}{ccc}
\hline $\begin{array}{c}\text { Time after Seal Emplacement } \\
\text { (years) }\end{array}$ & $\begin{array}{c}\text { Density } \\
\left(\mathrm{kg} / \mathrm{m}^{3}\right)\end{array}$ & $\begin{array}{c}\text { Porosity } \\
(\%)\end{array}$ \\
\hline 0 & 1944 & $10.0^{(\mathrm{a})}$ \\
50 & 2038 & $6.1^{(\mathrm{a})}$ \\
100 & 2121 & $2.6^{(\mathrm{a})}$ \\
200 & 2160 & $1.0^{(\mathrm{b})}$ \\
400 & 2160 & $1.0^{(\mathrm{b})}$ \\
\hline
\end{tabular}

(a) Calculated from Equation 2-10.

(b) Equal to the porosity of Salado salt.

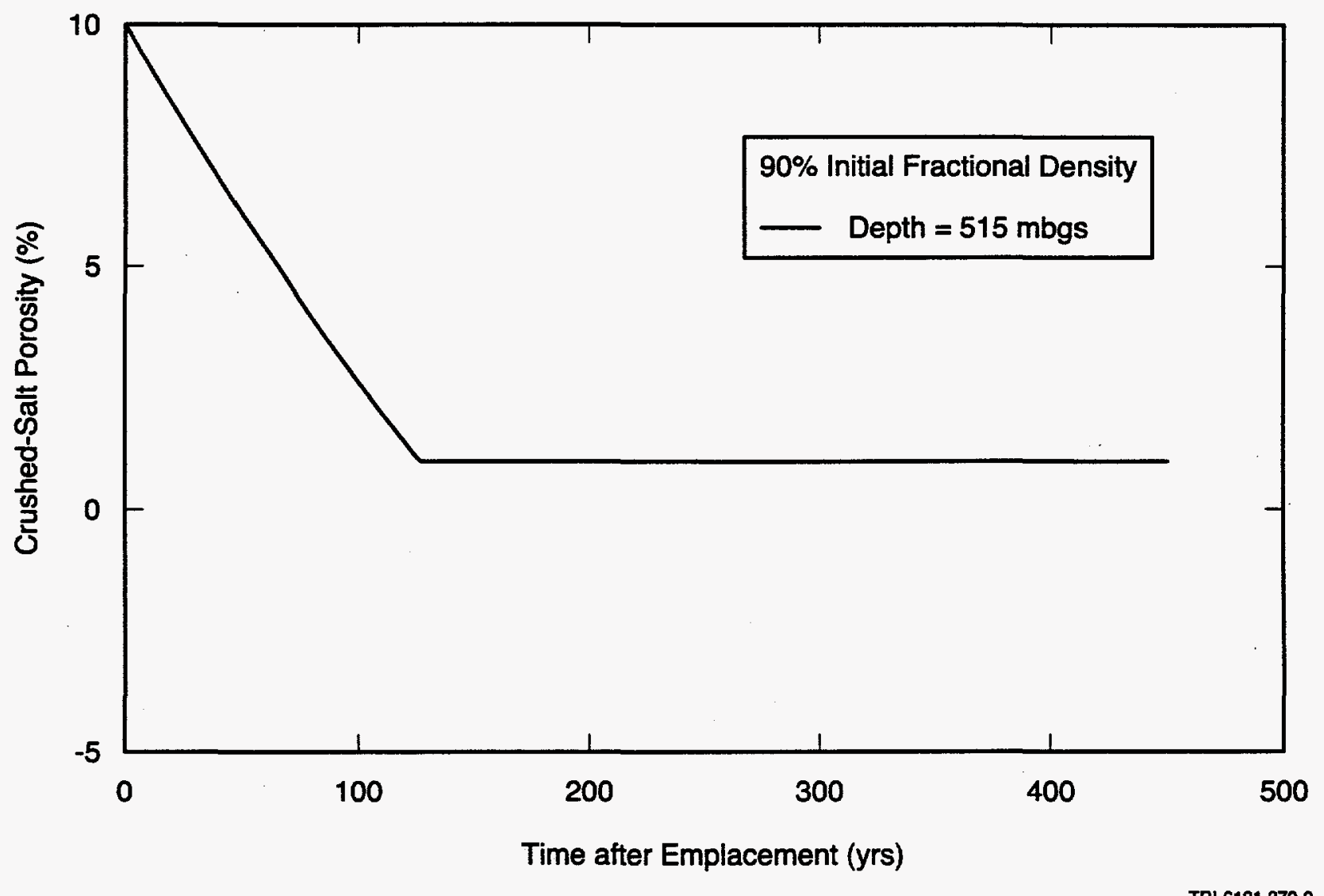

Figure 2-8. Porosity versus time for the compacted crushed salt column at a depth of $515 \mathrm{~m}$ bgs. 
where $K$ is the rock bulk modulus $(\mathrm{Pa})$. Pore-volume compressibility (1/Pa) is defined as the fractional change in pore volume with a unit change in pressure and can be expressed as (Bear, 1972):

$$
C=\frac{d \phi}{d P} \frac{1}{\phi}
$$

where:

$$
P=\text { pressure }(\mathrm{Pa})
$$

To calculate the pore-volume compressibility using Equation 2-12, the rock compressibility must be divided by porosity. The pore-volume compressibility expressed in terms of the bulk modulus of a given material is then equal to:

$$
C=\frac{1}{K} \frac{1}{\phi}
$$

Bulk modulus is an elastic property that relates volume changes of a material to changes in mean stress or pressure applied to the material (Fung, 1977). By definition, bulk modulus, $K$, is expressed as:

$$
K=\frac{P}{\varepsilon_{v}}=\frac{\sigma_{m}}{\varepsilon_{v}}
$$

where:

$$
\begin{aligned}
& \varepsilon_{v}=\text { volumetric strain }(\mathrm{m} / \mathrm{m}), \text { and } \\
& \sigma_{m}=\text { mean stress }(\mathrm{Pa}) .
\end{aligned}
$$

Bulk modulus can be measured directly from a hydrostatic compression test in which the mean stress is increased and the volume deformations are measured, or it can be calculated from other elastic properties such as Young's modulus ( $\mathrm{Pa}), E$, and Poisson's ratio, v, (Fung, 1977) using:

$$
K=\frac{E}{3(1-2 v)}
$$

Young's modulus and Poisson's ratio can also be determined from laboratory tests (e.g., unconfined or confined compression, uniaxial tension, etc.).

The bulk modulus of crushed salt has been determined experimentally by Holcomb and Hannum (1982). In this study, hydrostatic compaction tests were conducted with unload/reload cycles performed at prescribed levels of density. The unload/reload data were used to calculate bulk modulus (using Equation 2-14) at the prescribed levels of density. The data were later used by Sjaardema and Krieg (1987) to estimate the parameters in an empirical model relating bulk modulus to density. The form of this nonlinear model is as follows: 


$$
K=A \exp (B \bar{\rho})
$$

where $A$ (units of $\mathrm{MPa}$ ) and $B$ are fitting parameters and $\bar{\rho}$ is fractional density. Sjaardema and Krieg recommended the values of 0.0176 and 14.10 for $A$ and $B$, respectively, subject to the constraint that $K$ cannot exceed a value of $20,667 \mathrm{MPa}$ (i.e. the bulk modulus of intact salt).

For a porosity of 0.05 (Section 2.1.3), the pore volume compressibility of the crushed salt was determined by using Equations 2-10, 2-16, and 2-13 to successively calculate fractional density, bulk modulus, and compressibility. The fractional density corresponding to a porosity of 0.05 was 0.956 (using Equation 2-10), while the bulk density corresponding to this fractional density was determined to be $12,600 \mathrm{MPa}$ (using Equation 2-16). The pore volume compressibility calculated from Equation 2-13 and recommended for PA calculations was $1.6 \times 10^{-9} \mathrm{~m}^{2} 1 / \mathrm{Pa}$.

\subsubsection{Initial Wetting Phase Saturation}

In a two-phase system, the void space may be partially saturated with respect to one of the phases. Two variables can be used to specify the relative liquid content (water or brine) of a porous medium (Bear, 1979):

$$
\begin{aligned}
& \theta_{l}=\frac{\text { volume of liquid }}{\text { bulk volume }} \\
& s_{l}=\frac{\text { volume of liquid }}{\text { volume of voids }}
\end{aligned}
$$

where $\theta_{l}=\phi s_{l}$. The crushed salt components will have an initial water content of 0.05 to $2 \%$ by weight (RISD, 1996), where

$$
w=\frac{m_{l}}{m_{B}}=\frac{\rho_{l} V_{l}}{\rho_{B} V_{T}(1-\phi)}
$$

and

$$
\begin{aligned}
w & =\text { water content by weight } \\
m_{l} & \equiv \text { liquid mass }(\mathrm{kg}) \\
m_{B} & \equiv \text { bulk mass }(\mathrm{kg}) \\
V_{T} & \equiv \text { total volume }\left(\mathrm{m}^{3}\right) \\
V_{l} & \equiv \text { liquid volume }\left(\mathrm{m}^{3}\right) \\
\rho_{l} & \equiv \text { liquid density } \\
\rho_{B} & \equiv \text { bulk density }
\end{aligned}
$$

Assuming that:

$$
\rho_{B} \approx \rho_{s}
$$


where $\rho_{s}$ is the solid density, and letting the specific gravity, $G=\rho_{s} / \rho_{l}$, the liquid saturation can now be calculated from:

$$
s_{l}=\frac{w G(1-\phi)}{\phi}
$$

Assuming a moisture content of $2 \%$ by weight, solid density of $2160 \mathrm{~kg} / \mathrm{m}^{3}$ for salt, fluid density of $1200 \mathrm{~kg} / \mathrm{m}^{3}$ for brine, and an initial porosity of 0.10 , the resulting initial brine saturation was calculated to be 0.32 for the crushed salt component, and this value was recommended for compliance calculations.

\subsection{Compacted Clay}

Compacted clays are commonly proposed as primary sealing materials for nuclear waste repositories and have been extensively investigated (e.g., Gray, 1993). Compacted clay as a shaft sealing component provides a barrier to brine and possibly to gas flow into or out of the repository and supports the shaft with a high density material to minimize subsidence. In the event that brine does contact the compacted clay column, bentonitic clay can generate a beneficial swelling pressure. Swelling would increase internal supporting pressure on the shaft wall and accelerate healing of any DRZ. Wetted, swelling clay will seal fractures as it expands into available space and will ensure tightness between the clay seal component and the shaft walls.

\subsubsection{Material Specifications}

The Rustler and Salado compacted clay columns are specified to be composed of a commercial, well-sealing grade sodium bentonite. The composition of a typical sodium bentonite, such as Volclay or MX-80, contains between 80 and $90 \%$ montmorillonite, while the remaining fraction is dominated by quartz and feldspars (Gray, 1993). The bentonite seal will be emplaced at a dry density of no less than $1800 \mathrm{~kg} / \mathrm{m}^{3}$ and no greater than $2000 \mathrm{~kg} / \mathrm{m}^{3}$. The higher density of $2000 \mathrm{~kg} / \mathrm{m}^{3}$ may be desirable to carry the weight of the shaft seal effectively and to limit subsidence. The initial water content of the clay will be from 10 to $12 \%$. It is assumed that pure water with low dissolved solids will be used in the clay component construction.

\subsubsection{Intrinsic Permeability}

\subsubsection{PARAMETER SOURCES}

A significant body of literature regarding compacted bentonite permeability was reviewed as shown in Table 2-7. Most literature sources reported hydraulic conductivity rather than 
Table 2-7. Reported Literature Values of Hydraulic Conductivity and Permeability for Compacted Bentonite

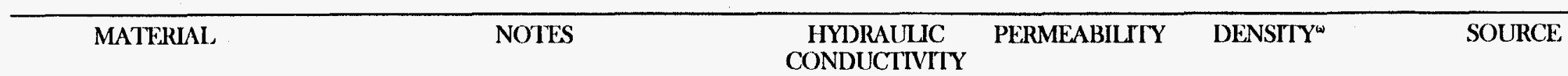

\section{GENERAL.}

Highly compacted bentonite

plugs

Water saturated, highly

compacted bentonite

Compacted bentonite

Highly compacted bentonite

Clays other than bentontite

Clay-bound aggregate mixtures

Bentonite

N

Compacted clay/sand

Compacted sand/bentonite

MX80 (Na - Wyoming)

Sodium bentonite

Calcium bentonite

Sodium bentonite

Bentonite

Proposed buffer material

Na bentonite (MX80)

$\mathrm{Na}$ bentonite (saturated)
Estimation based on plugs tested at Stripa

Reference to Pusch, SKB 80-16

Reference to Cheung (1997), also graph

Reported values

Similar values for ligher porosity

In situ compaction

For effective clay dry density of $0.5-2.25 \mathrm{~g} / \mathrm{cm} 3$

$\mathrm{K}$ as function of clay content and type,

for $10 \%$ to $100 \%$ Na bentonite

$\mathrm{K}$ as function of bentonite content,

for bentonite content greater than 25 to $30 \%$

Permeability vs. bulk density of saturated MX80

Experimental values plus model

Experimental values plus model

Confined element at pressures from $50-100 \mathrm{MPa}$

Rich in smectite, as a buffer material

Canada - 50/50 bentonite/sand

Fiuland - 100\% Na bentonite

France - 100\% Ca bentonite

Spain - 100\% Na bentonite

Sweden - 100\% Na bentonite

Switzerland - 100\% Ca bentonite

Bulk densitics

Bulk density
$1 \mathrm{e}-12$ to $1 \mathrm{e}-13 \mathrm{~m} / \mathrm{s}$

$$
<1 \mathrm{e}-11 \mathrm{~m} / \mathrm{s}
$$

< $1 \mathrm{e}-13 \mathrm{~m} / \mathrm{s}$

$1 \mathrm{e}-12$ to $1 \mathrm{e}-13 \mathrm{~m} / \mathrm{s}$

$1 \mathrm{e}-12$ to $1 \mathrm{e}-13 \mathrm{~m} / \mathrm{s}$

as low as $1 \mathrm{e}-9 \mathrm{~m} / \mathrm{s}$

as low as $1 \mathrm{e}-10 \mathrm{~m} / \mathrm{s}$

$1 \mathrm{e}-13$ to $5 \mathrm{e}-11 \mathrm{~m} / \mathrm{s}$

le-6 to $1 \mathrm{e}-12 \mathrm{~cm} / \mathrm{s}$

$1 \mathrm{e}-9 \mathrm{~cm} / \mathrm{s}$ or lower

le-11 to $1 \mathrm{e}-14 \mathrm{~m} / \mathrm{s}$

$1 \mathrm{e}-10$ to $1 \mathrm{e}-14 \mathrm{~m} / \mathrm{s}$

$1 \mathrm{e}-9$ to $1 \mathrm{e}-13 \mathrm{~m} / \mathrm{s}$

$<1 \mathrm{e}-12 \mathrm{~m} / \mathrm{s}$

$<1 \mathrm{e}-12 \mathrm{~m} / \mathrm{s}$

$1 \mathrm{e}-12$ to $1 \mathrm{e}-11 \mathrm{~m} / \mathrm{s}$

$2 \mathrm{e}-14$ to $2 \mathrm{e}-13 \mathrm{~m} / \mathrm{s}$

$2 \mathrm{c}-14$ to $2 \mathrm{e}-13 \mathrm{~m} / \mathrm{s}$

$2 \mathrm{e}-14$ to $2 \mathrm{e}-13 \mathrm{~m} / \mathrm{s}$

$2 \mathrm{e}-14$ to $2 \mathrm{e}-13 \mathrm{~m} / \mathrm{s}$

$1 \mathrm{e}-12$ to $1 \mathrm{e}-13 \mathrm{~m} / \mathrm{s}$

$1 \mathrm{e}-14 \mathrm{~m} / \mathrm{s}$
$5 \mathrm{e}-13 \mathrm{~m} / \mathrm{s}$
$1 \mathrm{e}-12 \mathrm{~m} / \mathrm{s}$
$2 \mathrm{e}-14 \mathrm{~m} / \mathrm{s}$

Gray, 1993

Gray, 1993

$2.20 \mathrm{t} / \mathrm{m} 3$

Gray, 1993

IAEA, 1990

IAEA, 1990

IAEA, 1990

IAEA, 1990

0.5 to $2.25 \mathrm{~g} / \mathrm{cm} 3$

ohnson et al., 1994

Kelsall et al., 1985

Meyer and Howard, 1983

Pusch, 1982

1.0 to $2.3 \mathrm{t} / \mathrm{m} 3$

1.2 to $2.2 \mathrm{~g} / \mathrm{cm}^{3}$

1.6 to $2.4 \mathrm{~g} / \mathrm{cm}^{3}$

1.4 to $1.8 \mathrm{t} / \mathrm{m} 3$

$>1.1 \mathrm{t} / \mathrm{m} 3$

$2.0 \mathrm{t} / \mathrm{m} 3$

$1.8 \mathrm{t} / \mathrm{m} 3$

$1.7 \mathrm{t} / \mathrm{m} 3$

$2.0 \mathrm{t} / \mathrm{m} 3$
Pusch and Borgesson, 1989

Pusch and Borgesson, 1989

Pusch and Borgesson, 1990

Pusch et al., 1989

Pusch et al., 1989

Pusch et al., 1989

Pusch et al., 1989

Pusch et al., 1989

Pusch et al., 1989

Pusch et al., 1989

Pusch et al., 1987a

Pusch et al., 1987a

Pusch et al., 1987a

Pusch et al., 1987b 
Table 2-7. Reported Literature Values of Hydraulic Conductivity and Permeability for Compacted Bentonite

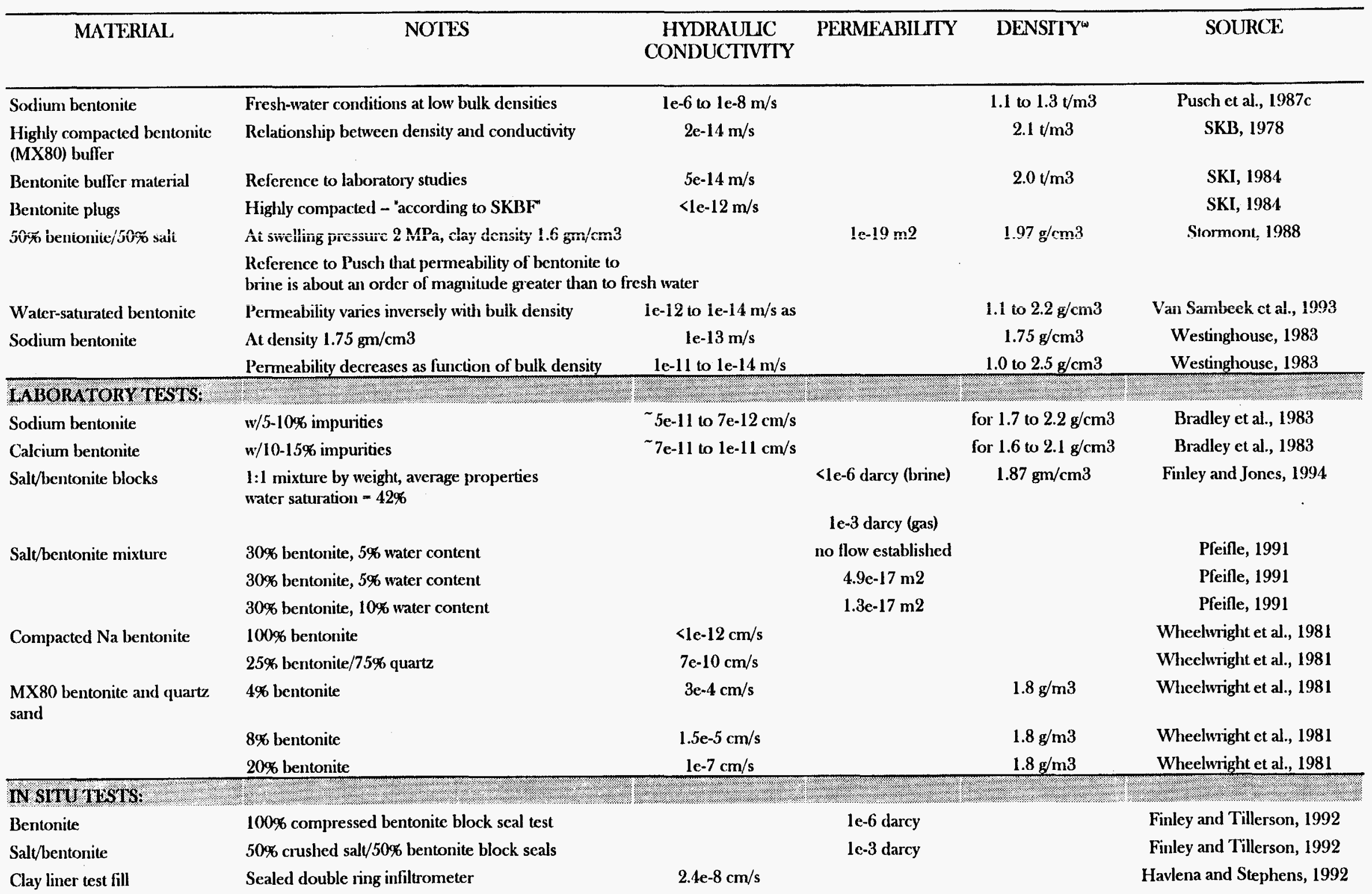


Table 2-7. Reported Literature Values of Hydraulic Conductivity and Permeability for Compacted Bentonite

\begin{tabular}{|c|c|c|c|c|c|}
\hline MATTERIAL & NOTES & $\begin{array}{c}\text { HYDRAUIIC } \\
\text { CONDUCITVTIY }\end{array}$ & PERMEABILITY & DENSITY' & SOURCE \\
\hline & BAT probe: Test 1 & $8.8 \mathrm{e}-9 \mathrm{~cm} / \mathrm{s}$ & & & Havlena and Stephens, 1992 \\
\hline & BAT probe: Test 2 & $7.4 \mathrm{e}-9 \mathrm{~cm} / \mathrm{s}$ & & & Havlena and Stephens, 1992 \\
\hline & Air entry permeameter & $2.6 \mathrm{e}-8 \mathrm{~cm} / \mathrm{s}$ & & & Havlena and Stephens, 1992 \\
\hline & Shelby tubes: Test 1 (laboratory analysis) & $7.3 e-9 \mathrm{~cm} / \mathrm{s}$ & & & Havlena and Stephens, 1992 \\
\hline & Shelby tubes: Test 2 (laboratory analysis) & $2.7 \mathrm{e}-9 \mathrm{~cm} / \mathrm{s}$ & & & Havlena and Stephens, 1992 \\
\hline \multirow[t]{5}{*}{ Highly compacted MX80 } & Bulk density (salurated state) vs. & $1 \mathrm{e}-14 \mathrm{~m} / \mathrm{s}$ & & $2.15 \mathrm{t} / \mathrm{m} 3$ & Pusch, 1985 \\
\hline & hydraulic conductivity (avg. for room temp & $3 \mathrm{e}-14 \mathrm{~m} / \mathrm{s}$ & & $2.10 \mathrm{t} / \mathrm{m} 3$ & Pusch, 1985 \\
\hline & and $70^{\circ} \mathrm{C}$ ) & $6 \mathrm{e}-14 \mathrm{~m} / \mathrm{s}$ & & $2.05 \mathrm{t} / \mathrm{m} 3$ & Pusch, 1985 \\
\hline & & $1 \mathrm{e}-13 \mathrm{~m} / \mathrm{s}$ & & $2.00 \mathrm{t} / \mathrm{m} 3$ & Pusch, 1985 \\
\hline & & $3 e-13 \mathrm{~m} / \mathrm{s}$ & & $1.95 \mathrm{t} / \mathrm{m} 3$ & Pusch, 1985 \\
\hline \multicolumn{6}{|c|}{ AACRFII, BUFFER: } \\
\hline Buffer material & 50:50 sand/bentonite mixture & $1 \mathrm{c}-12$ to $1 \mathrm{c}-10 \mathrm{~m} / \mathrm{s}$ & & $>1.67 \mathrm{~g} / \mathrm{cm} 3$ & Garisto and I $e$ Neveu, 1989 \\
\hline \multirow[t]{2}{*}{ Backfill material } & $75: 25$ sand/Lake Agassiz clay & $1 \mathrm{e}-10$ to $1 \mathrm{e}-9 \mathrm{~m} / \mathrm{s}$ & & $2.1 \mathrm{~g} / \mathrm{cm} 3$ & Garisto and LeNeveu, 1989 \\
\hline & (Lake Agassiz clay $=50 \%$ montmorillonite) & & & & \\
\hline \multirow[t]{6}{*}{ Black Hills bentonite } & mixed with $75 \%$ crushed granite & $1.2 \mathrm{e}-12 \mathrm{~m} / \mathrm{s}$ & & $1.89 \mathrm{~g} / \mathrm{m} 3$ & Radhakrishna et al., 1989 \\
\hline & mixed with $50 \%$ crushed granite & $3.7 \mathrm{e}-13 \mathrm{~m} / \mathrm{s}$ & & $1.8 \mathrm{~g} / \mathrm{m} 3$ & Radlıakrishna et al., 1989 \\
\hline & mixed with $50 \%$ crushed granite & $8.2 \mathrm{c}-13 \mathrm{~m} / \mathrm{s}$ & & $1.68 \mathrm{~g} / \mathrm{m} 3$ & Radhakrishna et al., 1989 \\
\hline & mixed with $50 \%$ crushed granite & $9.9 \mathrm{e}-13 \mathrm{~m} / \mathrm{s}$ & & $1.68 \mathrm{~g} / \mathrm{m} 3$ & Radhakrishna et al., 1989 \\
\hline & mixed with $50 \%$ crushed granite & $6.9 \mathrm{e}-13 \mathrm{~m} / \mathrm{s}$ & & $1.68 \mathrm{~g} / \mathrm{m} 3$ & Radlıakrishna et al., 1989 \\
\hline & mixed with $50 \%$ crushed granite & $1.4 c-12 \mathrm{~m} / \mathrm{s}$ & & $1.55 \mathrm{~g} / \mathrm{m} 3$ & Radhakrishna et al., 1989 \\
\hline \multirow[t]{4}{*}{ Pembina bentonite (Ca) } & mixed with $75 \%$ crushed granite & $2.1 \mathrm{e}-11 \mathrm{~m} / \mathrm{s}$ & & $1.88 \mathrm{~g} / \mathrm{m} 3$ & Radhakrishna et al., 1989 \\
\hline & mixed with $50 \%$ crushed granite & $3.7 \mathrm{e}-11 \mathrm{~m} / \mathrm{s}$ & & $1.88 \mathrm{~g} / \mathrm{m} 3$ & Radhakrishua et al., 1989 \\
\hline & mixed with $50 \%$ crushed granite & $4.2 \mathrm{e}-12 \mathrm{~m} / \mathrm{s}$ & & $1.56 \mathrm{~g} / \mathrm{m} 3$ & Radhakrishna et al., 1989 \\
\hline & mixed with $50 \%$ crushed granite & $9.1 \mathrm{e}-11 \mathrm{~m} / \mathrm{s}$ & & $1.59 \mathrm{~g} / \mathrm{m} 3$ & Radhakrishna et al., 1989 \\
\hline
\end{tabular}

(a) Units of $t / \mathrm{m}^{3}$ are metric tons per cubic meter. 
intrinsic permeability. Table 2-7 includes laboratory and in situ measurements of hydraulic conductivity and permeability for $100 \%$ sodium bentonite materials. Also included in Table 2-7 are hydraulic conductivity and permeability estimates for bentonite backfill/buffer materials for both sodium and calcium bentonites. Hydraulic conductivity can be related to intrinsic permeability using Equation 2-2. Table 2-8 presents permeabilities found in the literature or calculated from hydraulic conductivities found in the literature for compacted bentonite.

Figure 2-9 presents reported point values and reported ranges in permeability of bentonite as determined from the various literature sources included in Table 2-7. From Figure 2-9, it can be seen that the permeability of reported bentonites ranges from $1 \times 10^{-21}$ to $1 \times 10^{-15} \mathrm{~m}^{2}$.

Investigators have found that the permeability of bentonite is inversely correlated to the dry density of the clay. Figure 2-10 is a plot of bentonite permeability as a function of reported sample density for sodium bentonite samples. The permeability ranges from approximately $1 \times 10^{-21}$ to $1 \times 10^{-17} \mathrm{~m}^{2}$. Several investigators have published graphical relationships between clay permeability and dry density reported in the form of a line or polygon encompassing a range. These two types of data have been combined in Figure 2-11. In all cases, the data in Figure 2-11 are representative of low ionic strength permeant waters. Data provided in this figure were limited to sodium bentonite and bentonite/sand mixtures with clay content greater than or equal to 50\%. Cheung et al. (1987) reported that in bentonite/sand mixtures, the sand acts as an inert fraction which does not alter the permeability of the mixture from that of a $100 \%$ bentonite sample at the same equivalent dry density. Also included in Figure 2-11 are the three point estimates of permeability at dry densities of 1400,1800 , and $2100 \mathrm{~kg} / \mathrm{m}^{3}$ reported in Ran and Daemen (1995).

Several studies have found that the permeability of bentonite is affected by the permeant fluid salinity. Permeability increases as salinity increases. Researchers have found that the effects of salinity on permeability are greatly reduced, if not eliminated, at high dry densities. Cheung et al. (1987) reported that at dry densities greater than $1250 \mathrm{~kg} / \mathrm{m}^{3}$, salinity effects are reduced and ultimately eliminated at very high densities. Pusch et al. (1987a) reported that the pore water electrolyte concentration does not significantly affect swelling pressure or permeability of bentonite at densities greater than $2000 \mathrm{~kg} / \mathrm{m}^{3}$. However, they stated that it is extremely difficult to reach densities greater than $1900 \mathrm{~kg} / \mathrm{m}^{3}$ in boreholes. Therefore, salinity effects on clay properties were considered. Pusch et al. (1987a) estimated that increasing the bentonite pore water concentration to that of ocean salinity may reduce swelling pressure by $50 \%$ and increase hydraulic conductivity (and permeability) by as much as a factor of five (one-half order of magnitude). Bentonite permeability has also been observed to increase with increasing hydraulic gradient at dry densities less than $1250 \mathrm{~kg} / \mathrm{m}^{3}$ (Cheung et al., 1987). This phenomenon is expected to be minimal given the high emplacement density of the shaft clay seals.

Knowles and Howard (1996) summarized results of a series of in situ experiments designed to evaluate the feasibility of candidate seal materials for use at the WIPP. These tests are referred to as the Small Scale Seal Performance Tests (SSSPTs). Materials tested included salt-saturated concrete, compacted salt, and compacted bentonite. Small (less than $1 \mathrm{~m}$ in diameter) seals were constructed in vertical and horizontal boreholes drilled at the repository horizon. One test series evaluated the sealing capacity of $100 \%$ bentonite clay blocks emplaced 
Table 2-8. Calculated Permeability Values for Compacted Bentonite

\begin{tabular}{|c|c|c|c|c|c|c|}
\hline \multirow[t]{2}{*}{ MATERIAL } & \multirow[t]{2}{*}{ NOTES } & \multicolumn{2}{|c|}{ REPORTED VALUES: } & \multicolumn{2}{|c|}{$\begin{array}{l}\text { CALCULATED } \\
\text { PERMEABILITY } \\
\left(\mathrm{m}^{2}\right)\end{array}$} & \multirow[t]{2}{*}{ SOURCE } \\
\hline & & $\begin{array}{c}\text { Hydraulic } \\
\text { Conductivity } \\
\text {, }\end{array}$ & Permeability & & & \\
\hline \multicolumn{7}{|c|}{ CENBRAL } \\
\hline $\begin{array}{l}\text { Highly compacted bentonite } \\
\text { plugs }\end{array}$ & Estimation based on plugs tested at Stripa & le-12 to $1 \mathrm{e}-13 \mathrm{~m} / \mathrm{s}$ & & $1.02 \mathrm{e}-19$ & $1.02 \mathrm{e}-20$ & Gray, 1993 \\
\hline $\begin{array}{l}\text { Water saturated, highly } \\
\text { compacted bentonite }\end{array}$ & Reference to Pusch, SKB 80-16 & $<1 \mathrm{e}-11 \mathrm{~m} / \mathrm{s}$ & & $1.02 \mathrm{e}-18$ & & Gray, 1993 \\
\hline Compacted bentonite & Reference to Cheung (1997), also graph & $<1 \mathrm{e}-13 \mathrm{~m} / \mathrm{s}$ & & $1.02 \mathrm{e}-20$ & & Gray, 1993 \\
\hline \multirow[t]{2}{*}{ Highly compacted bentonite } & Reported values & $1 \mathrm{e}-12$ to $1 \mathrm{e}-13 \mathrm{~m} / \mathrm{s}$ & & $1.02 \mathrm{e}-19$ & $1.02 \mathrm{e}-20$ & IAEA, 1990 \\
\hline & Similar values for higher porosity & $1 \mathrm{c}-12$ to $1 \mathrm{e}-13 \mathrm{~m} / \mathrm{s}$ & & $1.02 \mathrm{e}-19$ & $1.02 \mathrm{e}-20$ & IAEA, 1990 \\
\hline Clays other than bentonite & In situ compaction & as low as $1 \mathrm{e}-9 \mathrm{~m} / \mathrm{s}$ & & $1.02 \mathrm{e}-16$ & & IAEA, 1990 \\
\hline Clay-bound aggregate mixtures & & as low as $1 \mathrm{e}-10 \mathrm{~m} / \mathrm{s}$ & & $1.02 \mathrm{c}-17$ & & IAEA, 1990 \\
\hline Bentonite & For effective clay dry density of $0.5-2.25 \mathrm{~g} / \mathrm{cm} 3$ & $1 \mathrm{c}-13$ to $5 \mathrm{c}-11 \mathrm{~m} / \mathrm{s}$ & & $1.02 \mathrm{c}-20$ & $5.10 \mathrm{e}-18$ & Johnson et al., 1994 \\
\hline Compacted clay/sand & $\begin{array}{l}\mathrm{K} \text { as function of clay content and type, } \\
\text { for } 10 \% \text { to } 100 \% \mathrm{Na} \text { bentonite }\end{array}$ & $1 \mathrm{e}-6$ to $1 \mathrm{e}-12 \mathrm{~cm} / \mathrm{s}$ & & $1.02 \mathrm{c}-15$ & $1.02 \mathrm{e}-21$ & Kelsall et al., 1985 \\
\hline Compacted sand/bentonite & $\begin{array}{l}\mathrm{K} \text { as function of bentonite content, } \\
\text { for bentonite content greater than } 25 \text { to } 30 \%\end{array}$ & $1 \mathrm{e}-9 \mathrm{~cm} / \mathrm{s}$ or lower & & $1.02 \mathrm{e}-18$ & & Meyer and Howard, 1983 \\
\hline MX80 (Na - Wyoming) & Permeability vs. bulk density of saturated MX80 & 1e-11 to $1 \mathrm{e}-14 \mathrm{~m} / \mathrm{s}$ & & $1.02 \mathrm{c}-18$ & $1.02 \mathrm{e}-21$ & Pusch, 1982 \\
\hline Sodium bentonite & Experimental values plus model & $1 \mathrm{e}-10$ to $1 \mathrm{e}-14 \mathrm{~m} / \mathrm{s}$ & & $1.02 \mathrm{c}-17$ & $1.02 \mathrm{e}-21$ & Pusch and Börgesson, 1989 \\
\hline Calcium bentonite & Experimental values plus model & $1 \mathrm{e}-9$ to $1 \mathrm{e}-13 \mathrm{~m} / \mathrm{s}$ & & $1.02 \mathrm{e}-16$ & $1.02 \mathrm{e}-20$ & Pusch and Börgesson, 1989 \\
\hline Sodium bentonite & Confined element at pressures from $50 \cdot 100 \mathrm{MPa}$ & $<1 \mathrm{e}-12 \mathrm{~m} / \mathrm{s}$ & & $1.02 \mathrm{e}-19$ & & Pusch and Börgesson, 1990 \\
\hline Bentonite & Rich in smectite, as a buffer material & $<\mathrm{le}-12 \mathrm{~m} / \mathrm{s}$ & & $1.02 \mathrm{e}-19$ & & Pusch et al., 1989 \\
\hline \multirow[t]{6}{*}{ Proposed buffer material } & Canada - 50/50 bentonite/sand & $1 \mathrm{e}-12$ to $1 \mathrm{e}-11 \mathrm{~m} / \mathrm{s}$ & & $1.02 \mathrm{e}-19$ & $1.02 \mathrm{e}-18$ & Pusch ct al., 1989 \\
\hline & Finland - $100 \% \mathrm{Na}$ bentonite & $2 \mathrm{e}-14$ to $2 \mathrm{e}-13 \mathrm{~m} / \mathrm{s}$ & & $2.04 \mathrm{e}-21$ & $2.04 \mathrm{e}-20$ & Pusch et al., 1989 \\
\hline & France $-100 \% \mathrm{Ca}$ bentonite & $2 \mathrm{e}-14$ to $2 \mathrm{e}-13 \mathrm{~m} / \mathrm{s}$ & & $2.04 \mathrm{e}-21$ & $2.04 \mathrm{e}-20$ & Pusch et al., 1989 \\
\hline & Spain - $100 \% \mathrm{Na}$ bentonite & $2 \mathrm{e}-14$ to $2 \mathrm{e}-13 \mathrm{~m} / \mathrm{s}$ & & $2.04 \mathrm{e}-21$ & $2.04 \mathrm{e}-20$ & Pusch et al., 1989 \\
\hline & Sweden - $100 \% \mathrm{Na}$ bentonite & $2 \mathrm{e}-14$ to $2 \mathrm{e}-13 \mathrm{~m} / \mathrm{s}$ & & $2.04 \mathrm{c}-21$ & $2.04 \mathrm{e}-20$ & Pusch et al., 1989 \\
\hline & Switzerland - $100 \%$ Ca bentonite & $1 \mathrm{e}-12$ to $1 \mathrm{c}-13 \mathrm{~m} / \mathrm{s}$ & & $1.02 \mathrm{e}-19$ & $1.02 \mathrm{e}-20$ & Pusch et al., 1989 \\
\hline \multirow[t]{3}{*}{ Na bentonite (MX80) } & Bulk densities & $1 \mathrm{c}-14 \mathrm{~m} / \mathrm{s}$ & & $1.02 \mathrm{e}-21$ & & Pusch et al., 1987a \\
\hline & & $5 \mathrm{e}-13 \mathrm{~m} / \mathrm{s}$ & & $5.10 \mathrm{e}-20$ & & Pusch et al., 1987a \\
\hline & & $1 \mathrm{e}-12 \mathrm{~m} / \mathrm{s}$ & & $1.02 \mathrm{e}-19$ & & Pusch et al., 1987a \\
\hline Na bentonite (saturated) & Bulk density & $2 \mathrm{e}-14 \mathrm{~m} / \mathrm{s}$ & & $2.04 \mathrm{e}-21$ & & Pusch et al., 1987b \\
\hline
\end{tabular}


Table 2-8. Calculated Permeability Values for Compacted Bentonite

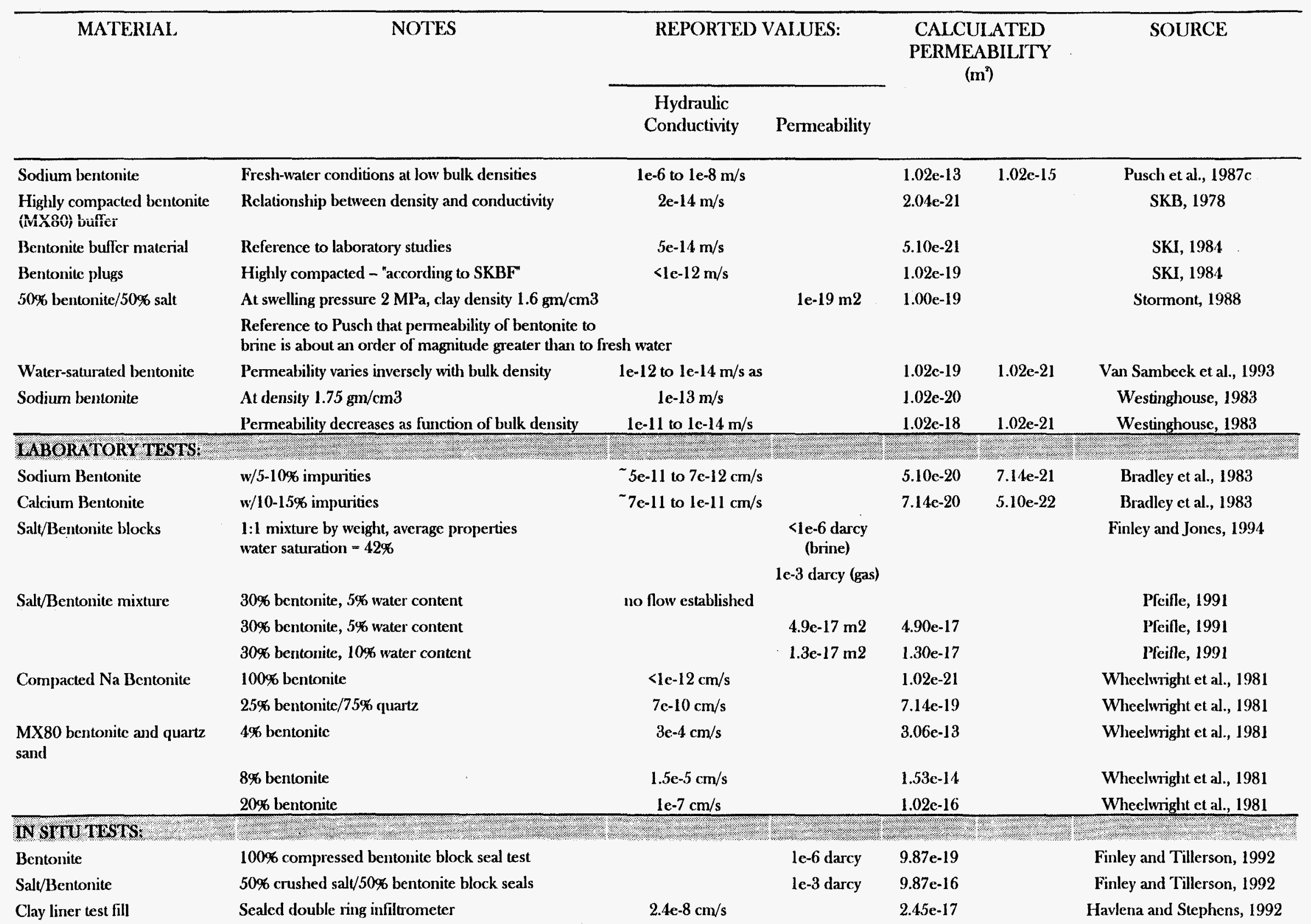


Table 2-8. Calculated Permeability Values for Compacted Bentonite

\begin{tabular}{|c|c|c|c|c|c|c|}
\hline \multirow[t]{2}{*}{ MATERIAL } & \multirow[t]{2}{*}{ NOTES } & \multicolumn{2}{|c|}{ REPORTED VALUES: } & \multicolumn{2}{|c|}{$\begin{array}{l}\text { CALCULATED } \\
\text { PERMEABILITY } \\
\left(\mathrm{m}^{*}\right)\end{array}$} & \multirow[t]{2}{*}{ SOURCE } \\
\hline & & $\begin{array}{l}\text { Hydraulic } \\
\text { Conductivity }\end{array}$ & Permeability & & & \\
\hline & BAT probe: Test I & $8.8 \mathrm{c}-9 \mathrm{~cm} / \mathrm{s}$ & & $8.97 e-18$ & & Havlena and Stephens, 1992 \\
\hline & BAT probe: Test 2 & $7.4 \mathrm{e}-9 \mathrm{~cm} / \mathrm{s}$ & & $7.54 \mathrm{e}-18$ & & Havlena and Stephens, 1992 \\
\hline & Air entry permeameter & $2.6 \mathrm{e}-8 \mathrm{~cm} / \mathrm{s}$ & & $2.65 \mathrm{e}-17$ & & Havlena and Stephens, 1992 \\
\hline & Shelby tubes: Test 1 (laboratory analysis) & $7.3 \mathrm{e}-9 \mathrm{~cm} / \mathrm{s}$ & & $7.44 \mathrm{e}-18$ & & Havlena and Stephens, 1992 \\
\hline & Shelby tubes: Test 2 (laboratory analysis) & $2.7 \mathrm{e}-9 \mathrm{~cm} / \mathrm{s}$ & & $2.75 \mathrm{c}-18$ & & Havlena and Stephens, 1992 \\
\hline \multirow[t]{5}{*}{ Highly compacted MX80 } & Bulk density (saturated state) vs. & $1 \mathrm{e}-14 \mathrm{~m} / \mathrm{s}$ & & $1.02 \mathrm{e}-21$ & & Pusch, 1985 \\
\hline & hydraulic conductivity lavg. for room temp & $3 \mathrm{e}-14 \mathrm{~m} / \mathrm{s}$ & & $3.06 \mathrm{e}-21$ & & Pusch, 1985 \\
\hline & and $70^{\circ} \mathrm{C}$ ) & $6 e-14 \mathrm{~m} / \mathrm{s}$ & & $6.12 \mathrm{e}-21$ & & Pusch, 1985 \\
\hline & & $1 \mathrm{e}-13 \mathrm{~m} / \mathrm{s}$ & & $1.02 \mathrm{e}-20$ & & Pusch, 1985 \\
\hline & & $3 \mathrm{e}-13 \mathrm{~m} / \mathrm{s}$ & & $3.06 \mathrm{e}-20$ & & Pusch, 1985 \\
\hline \multicolumn{7}{|l|}{ BACKFIU, BUHER: } \\
\hline Buffer material & $50: 50$ sand/bentonite mixture & $1 \mathrm{e}-12$ to $1 \mathrm{e}-10 \mathrm{~m} / \mathrm{s}$ & & $1.02 \mathrm{e}-19$ & $1.02 \mathrm{c}-17$ & Garisto and LeNeveu, 1989 \\
\hline \multirow[t]{2}{*}{ Backfill material } & 75:25 sand/Lake Agassiz clay & $1 \mathrm{e}-10$ to $1 \mathrm{e}-9 \mathrm{~m} / \mathrm{s}$ & & $1.02 \mathrm{e}-17$ & $1.02 \mathrm{e}-16$ & Garisto and LeNeveu, 1989 \\
\hline & (Lake Agassiz clay $-50 \%$ montmorillonite) & & & & & \\
\hline \multirow[t]{6}{*}{ Black Hills bentonite } & mixed with $75 \%$ crushed granite & $1.2 \mathrm{e}-12 \mathrm{~m} / \mathrm{s}$ & & $1.22 \mathrm{e}-19$ & & Radhakrishna et al., 1989 \\
\hline & mixed with $50 \%$ crushed granite & $3.7 \mathrm{e}-13 \mathrm{~m} / \mathrm{s}$ & & $3.77 \mathrm{e}-20$ & & Radhakrishna et al., 1989 \\
\hline & mixed with $50 \%$ crushed granite & $8.2 \mathrm{e}-13 \mathrm{~m} / \mathrm{s}$ & & $8.36 \mathrm{e}-20$ & & Radhakrishna et al., 1989 \\
\hline & mixed with $50 \%$ crushed granite & $9.9 \mathrm{e}-13 \mathrm{~m} / \mathrm{s}$ & & $1.01 \mathrm{e}-19$ & & Radhakrishna et al., 1989 \\
\hline & mixed with $50 \%$ crushed granite & $6.9 \mathrm{e}-13 \mathrm{~m} / \mathrm{s}$ & & $7.03 \mathrm{e}-20$ & & Radhakrishna et al., 1989 \\
\hline & mixed with $50 \%$ crushed granite & $1.4 \mathrm{e}-12 \mathrm{~m} / \mathrm{s}$ & & $1.43 \mathrm{e}-19$ & & Radhakrishna et al., 1989 \\
\hline \multirow[t]{4}{*}{ Pembina bentonite (Ca) } & mixed with $75 \%$ crushed granite & $2.1 \mathrm{e}-11 \mathrm{~m} / \mathrm{s}$ & & $2.14 \mathrm{e}-18$ & & Radhakrishna et al., 1989 \\
\hline & mixed with $50 \%$ crushed granite & $3.7 \mathrm{e}-11 \mathrm{~m} / \mathrm{s}$ & & $3.77 \mathrm{e}-18$ & & Radhakrishna et al., 1989 \\
\hline & mixed with $50 \%$ crushed granite & $4.2 \mathrm{e}-12 \mathrm{~m} / \mathrm{s}$ & & $4.28 \mathrm{e}-19$ & & Radhakrishna et al., 1989 \\
\hline & mixed with $50 \%$ crushed granite & $9.1 \mathrm{e}-11 \mathrm{~m} / \mathrm{s}$ & & $9.28 \mathrm{e}-18$ & & Radhakrishna et al., 1989 \\
\hline
\end{tabular}




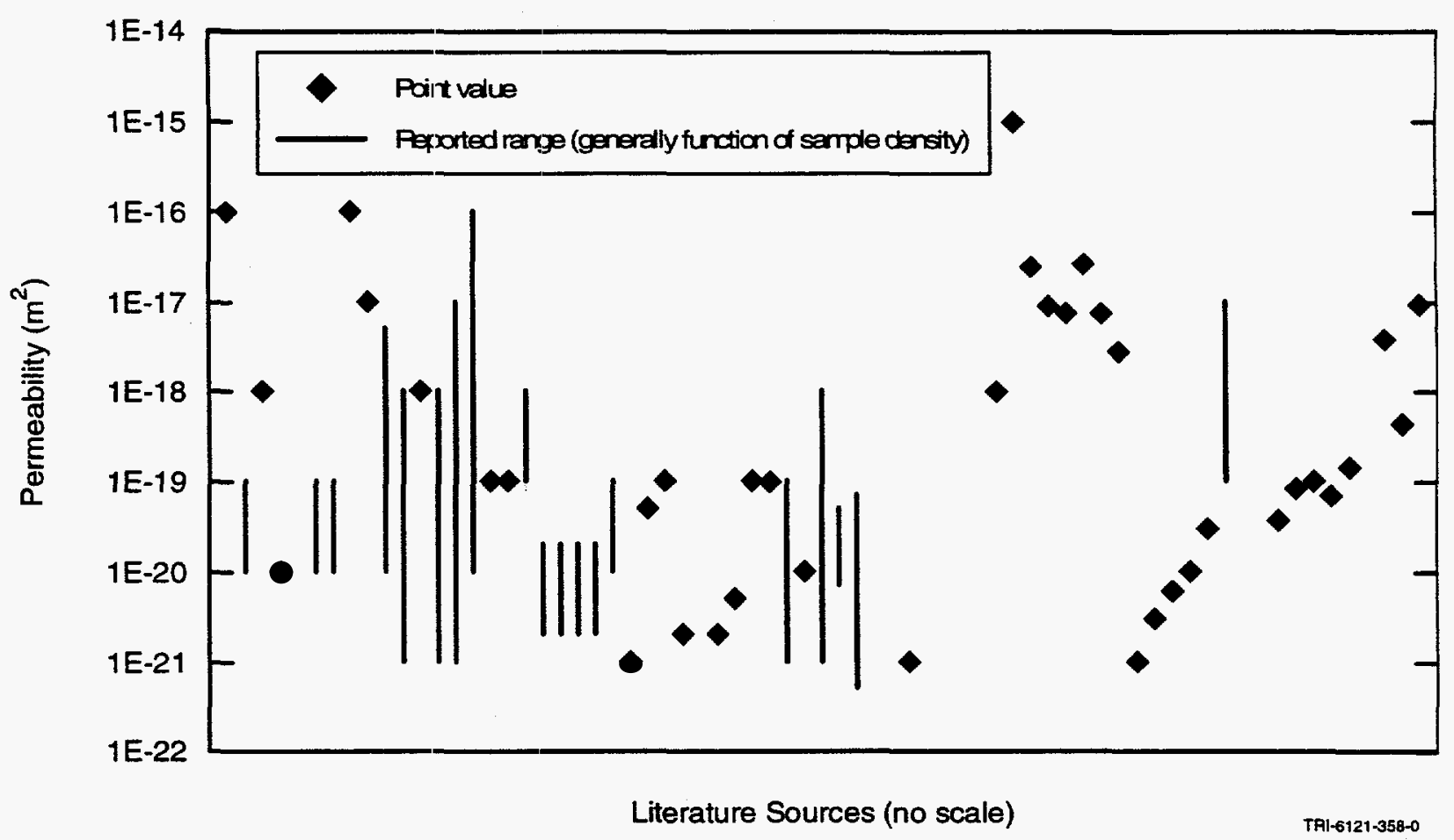

Figure 2-9. Compacted bentonite permeabilities for samples with $\geq 50 \%$ bentonite content.

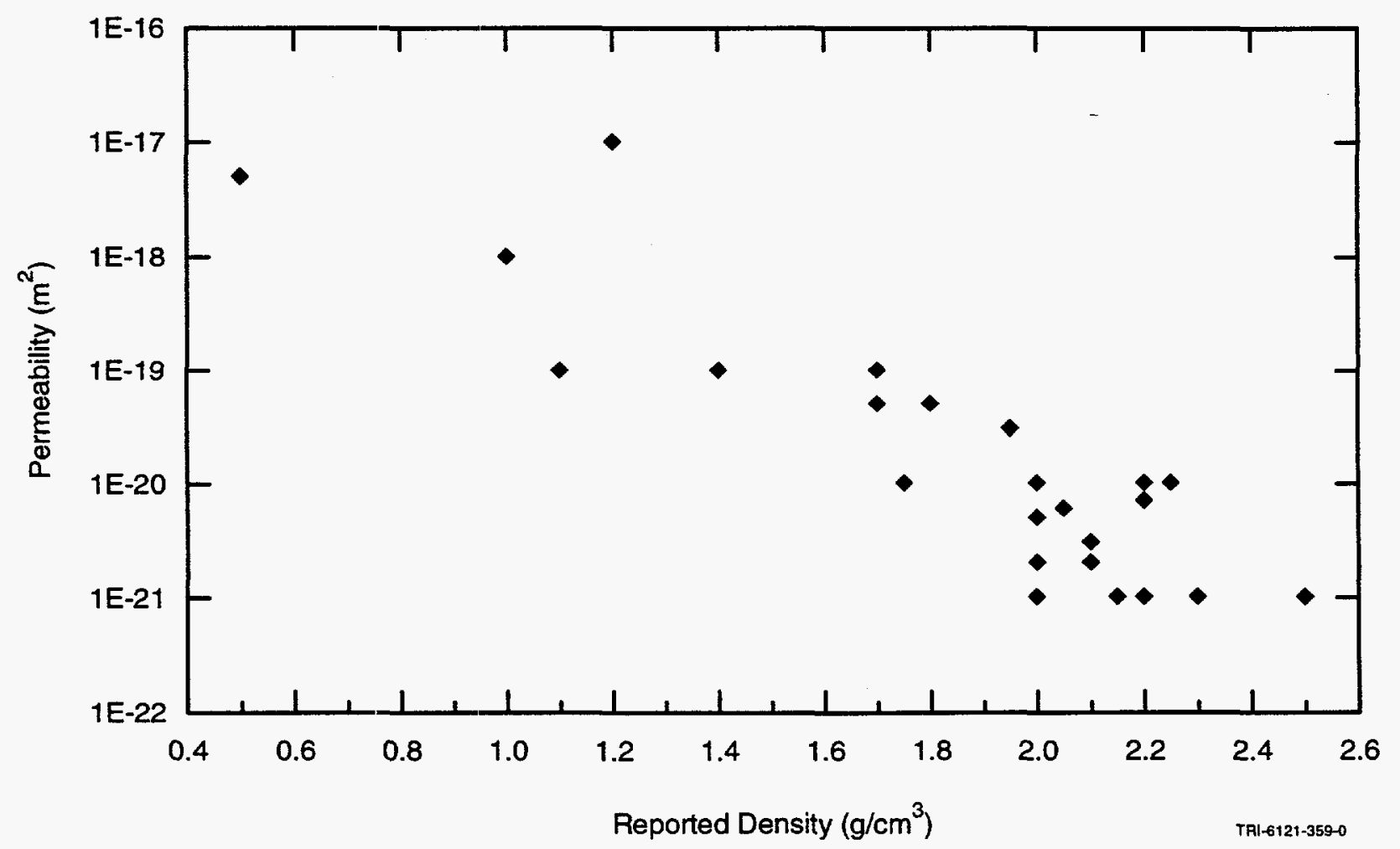

Figure 2-10. Relationship between compacted sodium bentonite intrinsic permeability and clay sample density. 


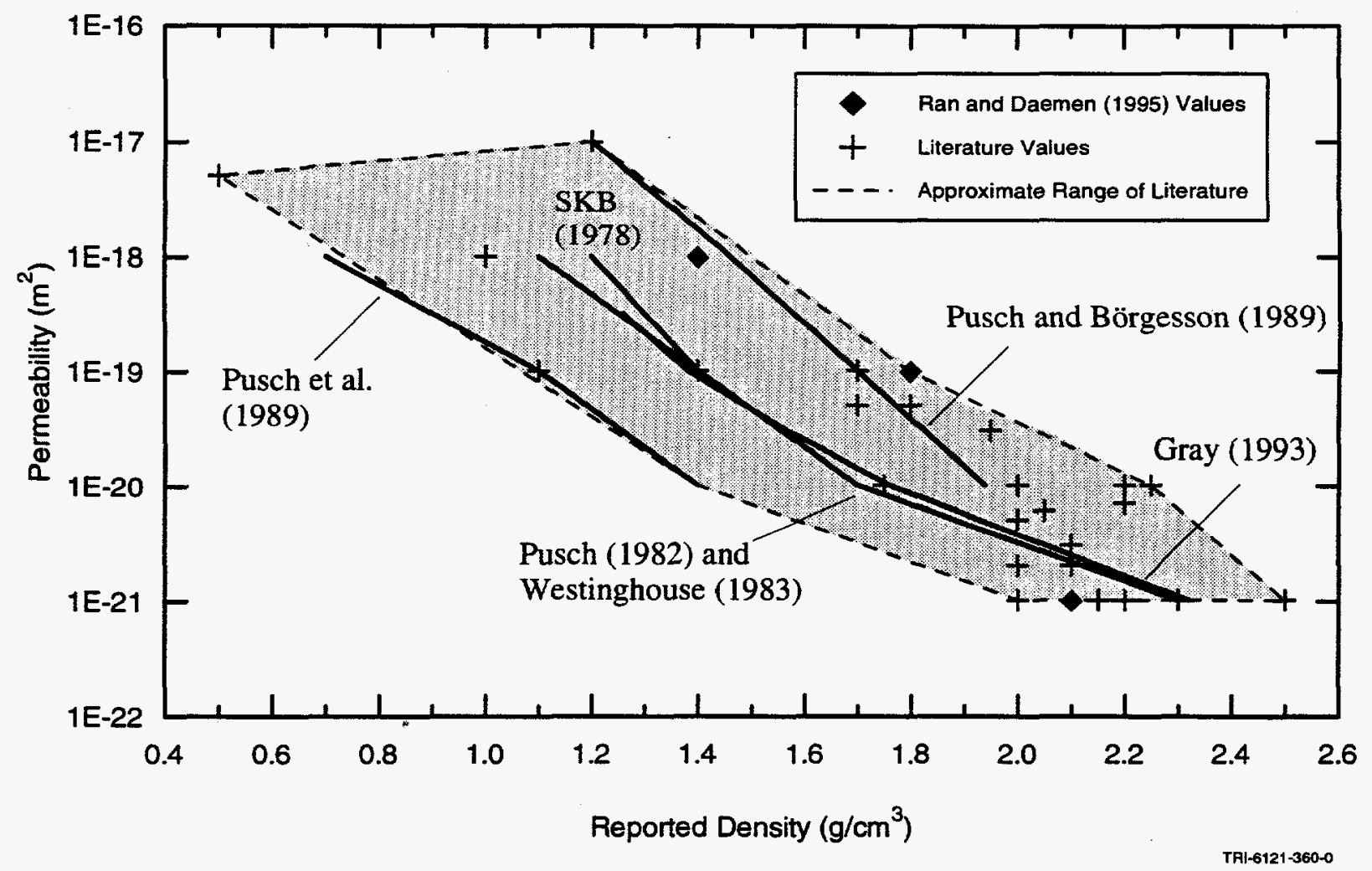

Figure 2-11. Sodium bentonite permeability versus density.

in two vertical boreholes. The bentonite blocks had initial dry densities of 1800 and $2000 \mathrm{~kg} / \mathrm{m}^{3}$. Brine flow testing was conducted on one seal for approximately five years, and on the other for just over one year. The seals were just over $0.9 \mathrm{~m}$ in length. Pressure differentials of 0.72 and $0.32 \mathrm{MPa}$ were maintained across the bentonite seals with a brine reservoir on the upstream (bottom) of the seals for several years. Over the course of these seals tests, no visible brine was observed at the downstream end of the seals. Because the saturation state of the bentonite seals was unknown, determination of the absolute permeability of the bentonite seals could not be estimated precisely. However, a bounding estimate of $1 \times 10^{-19} \mathrm{~m}^{2}$ was reported by Knowles and Howard (1996) for the bentonite seals.

\subsubsection{RATIONALE AND PARAMETER VALUE}

The material specification for the compacted bentonite specifies that the clay seals will be emplaced at a dry density of 1800 to $2000 \mathrm{~kg} / \mathrm{m}^{3}$. The recommended clay permeability distribution is presented in Figure 2-12. To arrive at this PDF, a practical minimum for the distribution was specified at the lowest reported value of $1 \times 10^{-21} \mathrm{~m}^{2}$. With the effective dry density of the bentonite emplaced in the seals only varying from 1800 to $2000 \mathrm{~kg} / \mathrm{m}^{3}$, a maximum expected permeability of $1 \times 10^{-19} \mathrm{~m}^{2}$ was extrapolated from Figure $2-11$. There is some uncertainty in the effective dry density of emplacement due to the difficulty of emplacing large columns of bentonite at high densities. To address this uncertainty, it was assumed that the 


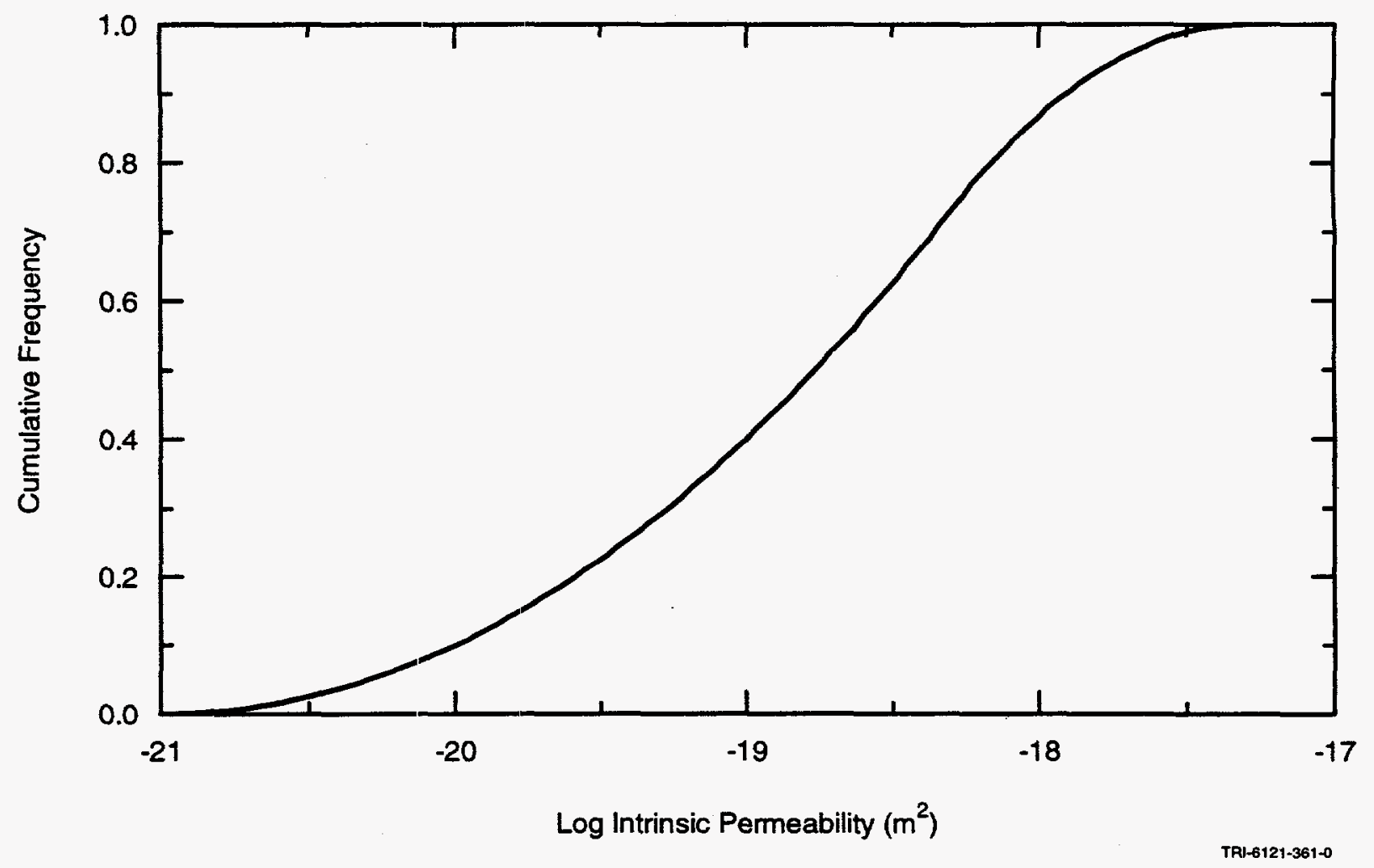

Figure 2-12. Cumulative frequency distribution function for compacted bentonite.

compacted clay may be emplaced at a dry density as low as $1600 \mathrm{~kg} / \mathrm{m}^{3}$, a situation not considered highly probable, but which could not be completely ruled out. At $1600 \mathrm{~kg} / \mathrm{m}^{3}$, the maximum permeability for the clay would be approximately $5 \times 10^{-19} \mathrm{~m}^{2}$. Therefore, assuming no salinity effects, the range of permeability becomes from $1 \times 10^{-21}$ to $5 \times 10^{-19} \mathrm{~m}^{2}$, with a best estimate of less than $1 \times 10^{-19} \mathrm{~m}^{2}$, assuming a best estimate emplacement density of $1800 \mathrm{~kg} / \mathrm{m}^{3}$.

As discussed earlier, the literature reports that salinity increases permeability. However, these effects are greatly reduced at the emplacement densities specified for the shaft seal. It is expected that, at the emplacement densities specified for the WIPP shafts, the effect of salinity on material permeability will be within an order of magnitude of the values reported in the literature for fresh pore water. Therefore, to account for salinity effects, the maximum permeability was increased by one order of magnitude from $5 \times 10^{-19}$ to $5 \times 10^{-18} \mathrm{~m}^{2}$, the best estimate permeability was increased by one-half order of magnitude from $1 \times 10^{-19}$ to $5 \times 10^{-19} \mathrm{~m}^{2}$, and the lower limit was held at $1 \times 10^{-21} \mathrm{~m}^{2}$. Thus, the PDF recommended for PA calculations was a maximum permeability of $5 \times 10^{-18} \mathrm{~m}^{2}$, a best estimate of $5 \times 10^{-19} \mathrm{~m}^{2}$, and a minimum of $1 \times 10^{-21} \mathrm{~m}^{2}$. This distribution function is shown in Figure 2-12.

The DRZ permeability adjacent to the compacted clay columns was explicitly calculated and then combined with the clay seal permeability in the conceptual model as described in Section 4.0. 


\subsubsection{Porosity}

\subsubsection{PARAMETER SOURCES}

The porosity of natural unconsolidated clays can vary from 0.4 to 0.8 (Freeze and Cherry, 1979). Consolidated clay formations such as shales have much smaller porosities ranging from 0.01 to 0.4 (Touloukian et al., 1981). Porosity values for compacted clay were not found in the literature. Therefore, the porosity of the clay seal material was calculated.

\subsubsection{RATIONALE AND PARAMETER VALUE}

The porosity of the compacted clay was calculated from Equation 2-9. The material matrix density was calculated from the specific gravity, $G$, as follows

$$
\rho_{g}=G \rho_{l}
$$

where $\rho_{l}$ is the pore liquid density, which is assumed to be water $\left(1000 \mathrm{~kg} / \mathrm{m}^{3}\right)$. The specific gravity of a commercial bentonite (Volclay GPG-30) is 2.5 (Ran and Daemen, 1995). For compacted clay dry densities ranging from 1800 to $2000 \mathrm{~kg} / \mathrm{m}^{3}$, the calculated porosity ranges from 0.2 to 0.28 . The average value of 0.24 was recommended as the compacted clay total porosity.

\subsubsection{Pore-Volume Compressibility}

The bulk modulus of the clay seal components in the Salado will be transient because of the creep of the host rock after closure. Furthermore, the magnitude and rate of change of the clay bulk modulus will be dependent on the emplacement depth within the Salado Formation. However, the pore-volume compressibility was treated as a constant in the PA simulations. Therefore, a bulk modulus value at 150 years was used to calculate the pore volume compressibility. The bulk modulus increases as a function of time and by 150 years is nearly constant. A value at 150 years was chosen because it is more representative of the 10,000 -year simulation period than the smaller values predicted for times less than 150 years. Assuming a compacted clay porosity of 0.24 , pore-volume compressibilities of $1.81 \times 10^{-9}$ and $1.59 \times 10^{-9} 1 / \mathrm{Pa}$ (calculated from Equation 2-13) were recommended for the upper and lower Salado compacted clay columns, respectively.

The bulk modulus of the Rustler clay column (component 4 in Figure 1-1) will not change as a function of time because the Rustler Formation will not creep in towards the shaft after closure. Therefore, the initial (emplaced) bulk modulus of $2.129 \times 10^{9} \mathrm{~Pa}$ (RISD, 1996) was used to calculate the Rustler clay column compressibility. Assuming a compacted clay porosity of 0.24 , the pore-volume compressibility recommended was $1.96 \times 10^{-9} 1 / \mathrm{Pa}$ for the Rustler compacted clay column. 


\subsubsection{Initial Wetting Phase Saturation}

The initial saturation of the compacted clay seal was estimated from the clay specific gravity, $G$, the seal porosity, and the emplaced water content. The liquid saturation was calculated from Equation 2-1.9. Assuming a porosity of 0.24 , a specific gravity of 2.5 , and a water content varying from 1.0 to $12 \%$, the brine saturation varies from 0.79 to 0.95 . For compliance calculation modeling purposes, an emplaced saturation of 0.79 was recommended for the compacted clay seal. The lower value was chosen because it is unlikely that the clay can be emplaced at liquid saturations approaching unity.

\subsection{Salado Mass Concrete}

The concrete mass components placed in the Salado Formation are constructed of a saltsaturated concrete called SMIC (Wakeley et al., 1994; 1995). Salt-saturated concrete is specified because freshwater concrete would dissolve part of the host rock. SMC is used as massive plugs, a monolith at the base of each shaft, and in tandem with asphalt waterstops. Concrete is a rigid material that will support overlying seal components while promoting natural healing processes within the salt DRZ.

Shaft station monoliths (component 13 in Figure 1-1) will be constructed at the base of each WIPP shaft. The purpose of the monoliths is to provide a structural component or platform on which the overlying shaft: seal materials can be emplaced. The monoliths are assumed to provide no hydrologic barrier to fluids entering or exiting the repository and, as such, are not considered part of the sealing system for performance assessment analyses.

\subsubsection{Material Specifications}

Dry materials for SMC include cementitious materials, fine and coarse aggregates, and sodium chloride. The fine aggregate shall consist of natural silica sand, while the coarse aggregate shall consist of gravel. The SMC will have a strength of about $40 \mathrm{MPa}$ at 28 days, and . will continue to gain strength after that time (Wakeley et al., 1995), as is typical of hydrating cementitious materials. Volume stability of the SMC will also be excellent, assuring a good bond with the salt.

\subsubsection{Intrinsic Permeability}

The intrinsic permeability of the concrete column was treated as a random (transient) variable for the time period 0 to 400 years after seal emplacement. It was assumed that the concrete seals will not deteriorate. Because the seal system design no longer relies on the concrete for sealing after 400 years, the intrinsic permeability for times greater than 400 years was treated as a constant with significantly higher permeability, even though it is not expected that the concrete will degrade in this period of time. In addition, no credit is taken in the seal system design for sealing capabilities of the concrete monolith. Therefore, the intrinsic 
permeability of the concrete monolith was treated as a constant for the period 0 to 10,000 years with a significantly higher permeability.

\subsubsection{PARAMETER SOURCES}

After 400 years all concrete seal elements in compliance calculations were recommended to have a permeability equivalent to that of earthen fill (Section 2.5.2), which is equivalent to a silty-sand in texture and flow characteristics. For the period 0 to 400 years after seal emplacement, the concrete components were assumed to be comprised of SMC. No permeability testing has been reported in the literature on this SMC. Therefore, the intrinsic permeability of the concrete column immediately after seal emplacement (i.e., 0 to 400 years) and its variability were derived from an experimental study performed for the shaft sealing system design (Pfeifle et al., 1996).

In this study, two permeability tests were performed on concrete samples prepared from cores recovered from the WIPP SSSPT (Section 2.2.2) field experiments and one test on a SMC specimen prepared from a sample batched by the U.S. Army Corps of Engineers, Waterways Experiment Station (WES). The concrete used for the SSSPT was an expansive salt-saturated concrete (ESC). Field and laboratory experiments that determine permeability of the ESC contribute to the overall database of properties for salt-saturated concrete. However, it should be stressed that the mixture proposed for use at the WIPP is SMC. The samples were tested as received with no attempts made to dry the samples or to determine their moisture content. Each test was performed using nitrogen gas as the permeant, flowmeters to measure steady-state gas flow, and fluid pressure differences of either $0.3,0.6$, or $0.75 \mathrm{MPa}$. The confining pressure in all tests was $1 \mathrm{MPa}$. Attempts were made to apply Klinkenberg corrections to measured values of permeability, but the range of pressure gradients used in the testing was not large enough to establish any particular trend when the permeability data were plotted as a function of reciprocal mean fluid pressure.

Eighteen permeability measurements were made by Pfeifle et al. (1996) on the three samples described above. The results are summarized in Table 2-9. The data illustrate that the permeabilities of SMC are different from the permeabilities of the SSSPT concrete. Permeability of the SMC sample ranged from $2.1 \times 10^{-21}$ to $7.51 \times 10^{-21} \mathrm{~m}^{2}$ with an average of $4.71 \times 10^{-21}$

$\mathrm{m}^{2}$. Permeability of the SSSPT samples ranged from $3.0 \times 10^{-20}$ to $5.04 \times 10^{-19} \mathrm{~m}^{2}$ with an average of $2.18 \times 10^{-19} \mathrm{~m}^{2}$. The data are plotted as a function of pressure gradient in Figure 2-13, which emphasizes the observed differences between the two types of concrete. Knowles and Howard (1996) presented results of field permeability tests performed on the SSSPT concrete seals during 1985-1987 and 1993-1995. Although individual seal system component material permeabilities for concrete, DRZ salt, and salt were not determined, overall seal system permeabilities were determined and ranged from $1.0 \times 10^{-20}$ to $1.0 \times 10^{-17} \mathrm{~m}^{2}$ and from $1.0 \times 10^{-23}$ to $1.0 \times 10^{-19} \mathrm{~m}^{2}$, respectively, for the 1985 to 1987 and the 1993 to 1995 tests. These ranges encompass the laboratory values of concrete permeabilities measured by Pfeifle et al. (1996). 
Table 2-9. Summary of Gas Permeability Measurements for SMC and SSSPT Concretes (after Pfeifle et al., 1995)

\begin{tabular}{ccc}
\hline Specimen Identification No. ${ }^{(a)}$ & $\begin{array}{c}\text { Fluid Pressure } \\
\text { Gradient }(\mathrm{MPa})\end{array}$ & $\begin{array}{c}\text { Intrinsic Permeability } \\
\left(1 \times 10^{-20} \mathrm{~m}^{2}\right)\end{array}$ \\
\hline MAC313-2/1 & 0.30 & 10.20 \\
& 0.30 & 3.00 \\
& 0.60 & 5.82 \\
& 0.60 & 34.50 \\
& 0.75 & 50.40 \\
& 0.75 & 4.29 \\
& 0.30 & 8.01 \\
& 0.60 & 37.90 \\
& 0.30 & 42.90 \\
\hline MAC314-1/1 & 0.30 & 22.70 \\
& 0.30 & 10.40 \\
& 0.60 & 22.00 \\
& 0.75 & 31.00 \\
\hline 40SM4-19/2-1/1 & 0.30 & 0.751 \\
& 0.30 & 0.413 \\
& 0.30 & 0.410 \\
& 0.60 & 0.210 \\
& 0.75 & 0.571 \\
\hline
\end{tabular}

(a) Specimens MAC313-2/1 and MAC314-1/1 were prepared from cores recovered from the SSSPT. Specimen 40SM4-19/2-1/1 was prepared from SMC cores batched by WES.

(b) Nitrogen gas permeability.

\subsubsection{RATIONALE AND PAFAMETER VALUE}

After 400 years, all concrete seal components were assumed to have the equivalent permeability of earthen fill (Section 2.5.2), as discussed above. Therefore, the effective permeability of the concrete seal at times greater than 400 years and the concrete monolith from 0 to 10,000 years were assumed to be in the range of $1 \times 10^{-17} \mathrm{~m}^{2}$ and $1 \times 10^{-12} \mathrm{~m}^{2}$. The median value of this range, $1 \times 10^{-14} \mathrm{~m}^{2}$, was recommended for use as a constant value in the PA calculations.

The intrinsic permeability of the concrete column prior to 400 years was derived from the experiments as described above. These data were derived from gas permeability measurements in which no Klinkenberg corrections were applied to the measured values. The Klinkenberg corrections were expected to be small because of the low mean pressure gradients used in the tests. However, the reported values of permeability contain bias because the Klinkenberg corrections could not be made. The true values are expected to be somewhat lower. The 


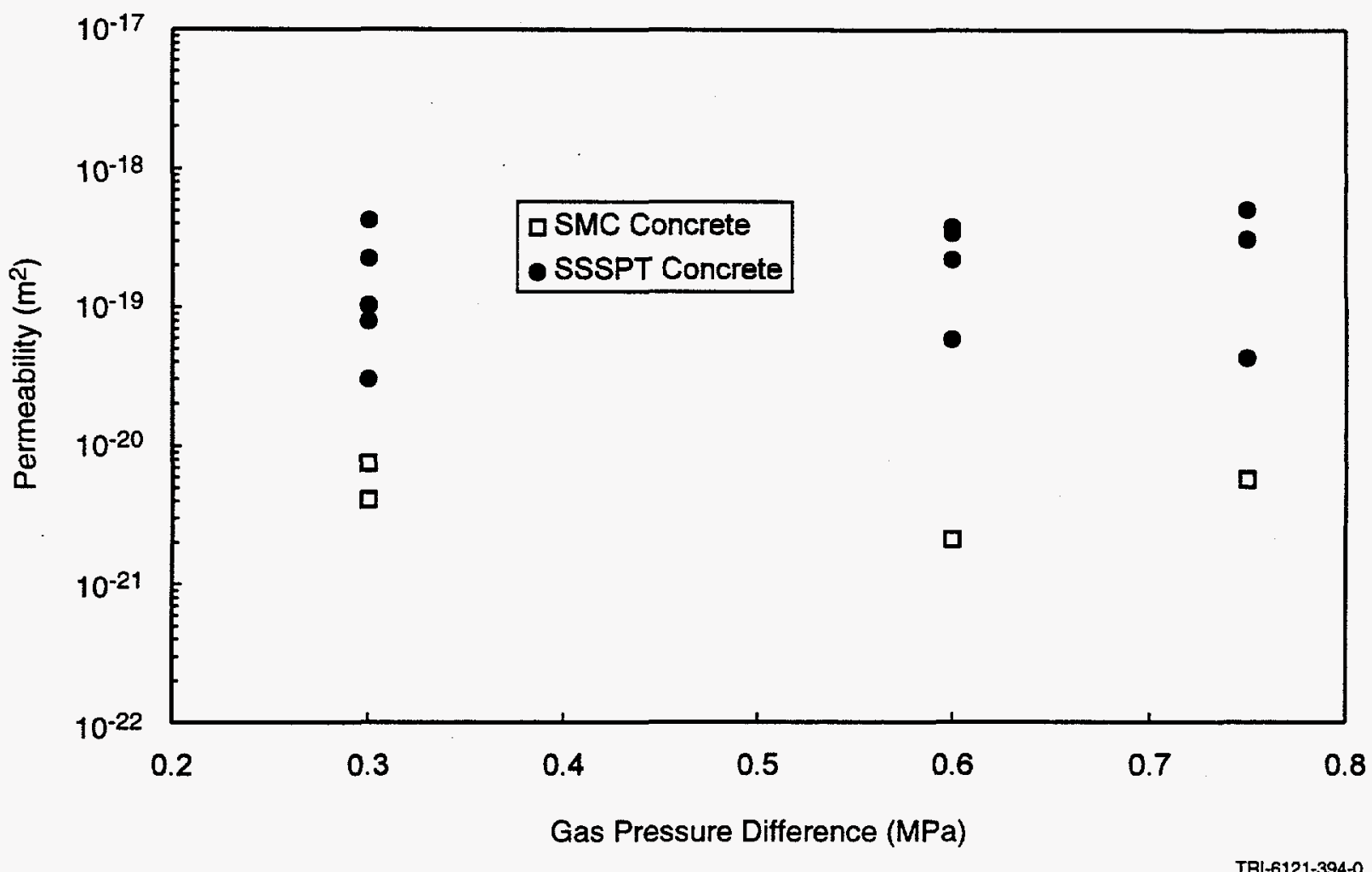

Figure 2-13. Permeability versus pressure difference determined from laboratory testing of SMC and SSSPT concretes.

reported values of permeability also contain a second bias. The SMC and SSSPT specimens contained some moisture and, therefore, were not fully saturated with gas during the gas permeability measurements. Thus the true gas permeability is expected to be somewhat higher than the measured (relative) permeabilities. Klinkenberg and relative permeability effects could result in variations of 10 to $20 \%$ for the experimental conditions.

Magnesium-rich brines are known to cause degradation of cementitious materials such as SMC (Wakeley et al., 1994). Degradation would increase the permeability of SMC components. In this analysis, it was assumed that the asphalt column extending from the Rustler/Salado contact into the Salado salt will protect all SMC seal components from effects of magnesium-rich brines during the specified performance period.

The permeability values presented in Table 2-9 were transformed using logarithms (base 10) and plotted in terms of a frequency histogram as shown in Figure 2-14. Based on the shape of the histogram, a triangular distribution function was fitted to the frequency data to obtain the PDF defined in terms of Equations 2-5 and 2-6. The CDF was obtained from the PDF through integration of Equations 2-5 and 2-6 over the limits from $a$ to $u$ and $u$ to $b$, respectively. The best estimator, $u$, was calculated from the transformed permeability data using Equation 2-7. The PDF determined from this procedure is superposed on the experimental frequency histogram in Figure 2-14. 


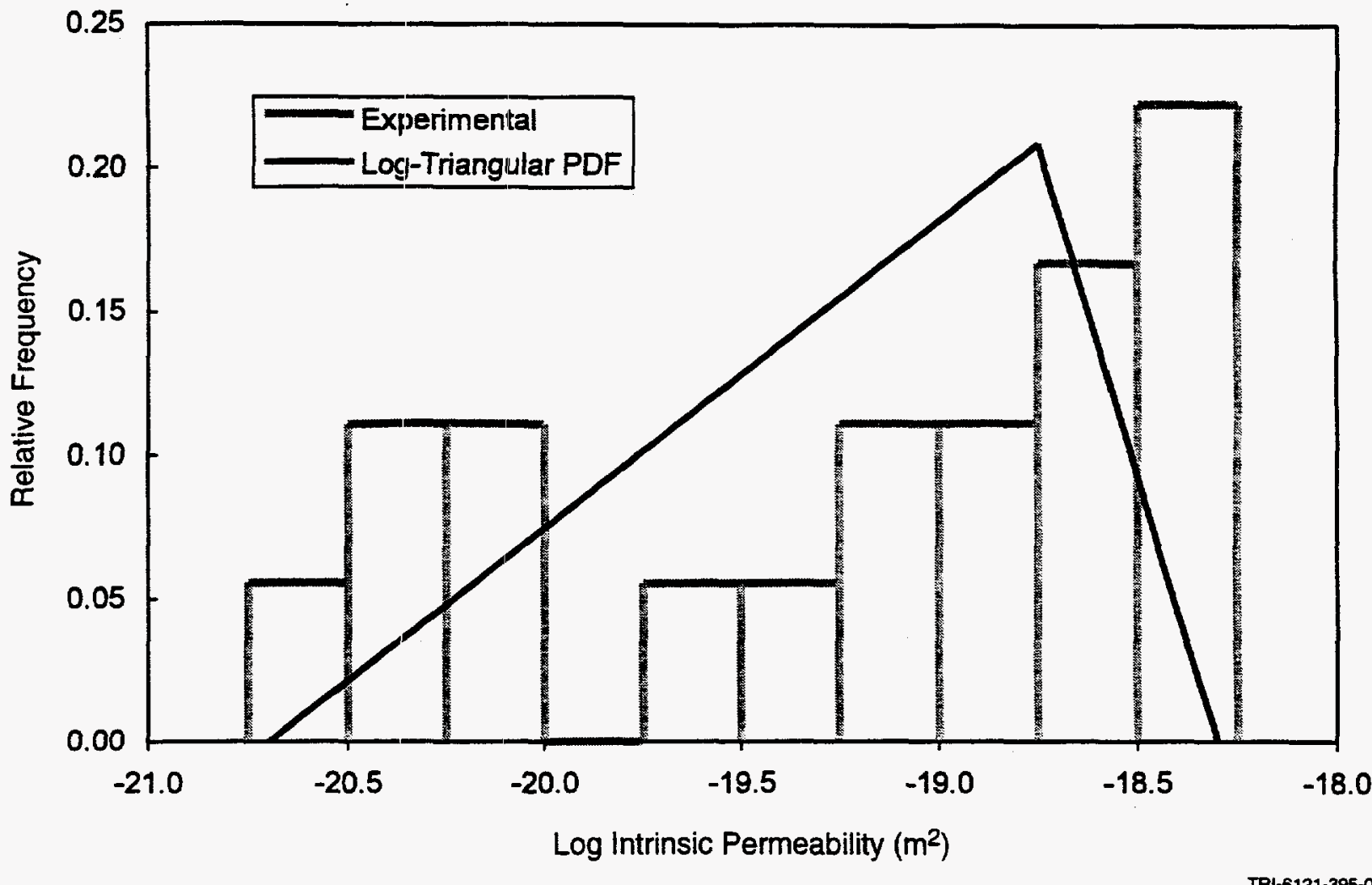

Figure 2-14. Experimental frequency histogram and log triangular PDF for permeability of SMC concrete - laboratory data only.

The interface between the Salado salt and the SMC components may provide a flow path around the SMC componerts. This flow path is possible if a small aperture develops as the concrete is curing or if the interface degrades because of corrosive brines. If such a flow path occurs, the effective permeability of the SMC will increase. Because of this uncertainty, the upper bound permeability determined from the procedure described above may be too low. To address this uncertainty, the upper bound permeability was increased to a transformed value of -17 , which corresponds to a permeability of $1.0 \times 10^{-17} \mathrm{~m}^{2}$. The value of $1.0 \times 10^{-17} \mathrm{~m}^{2}$ was selected after an effective permeability calculation was performed. In this calculation, the interface zone was assumed to have a permeability of $1.0 \times 10^{-14} \mathrm{~m}^{2}$ and concrete permeabilities were varied from $1.0 \times 10^{-23}$ to $1.0 \times 10^{-19} \mathrm{~m}^{2}$. Assuming the interface zone had a thickness of 0.001 times the shaft radius or smaller, the effective permeability of the concrete was about $1.0 \times 10^{-17} \mathrm{~m}^{2}$ regardless of the value selected for the permeability of the SMC seal. With the assumed increase in upper bound permeability, the permeability of the SMC seal components was also treated as a random variable defined by a log triangular distribution with a best estimator of $1.78 \times 10^{-19} \mathrm{~m}^{2}$ and lower and upper limits of $2.0 \times 10^{-21}$ and $1.0 \times 10^{-17} \mathrm{~m}^{2}$, respectively. The recommended distribution function parameters for SMC concrete are summarized in Table 2-10. Figures 2-15 and 2-16 show the PDF and CDF for this distribution, respectively, as well as the experimental data. 


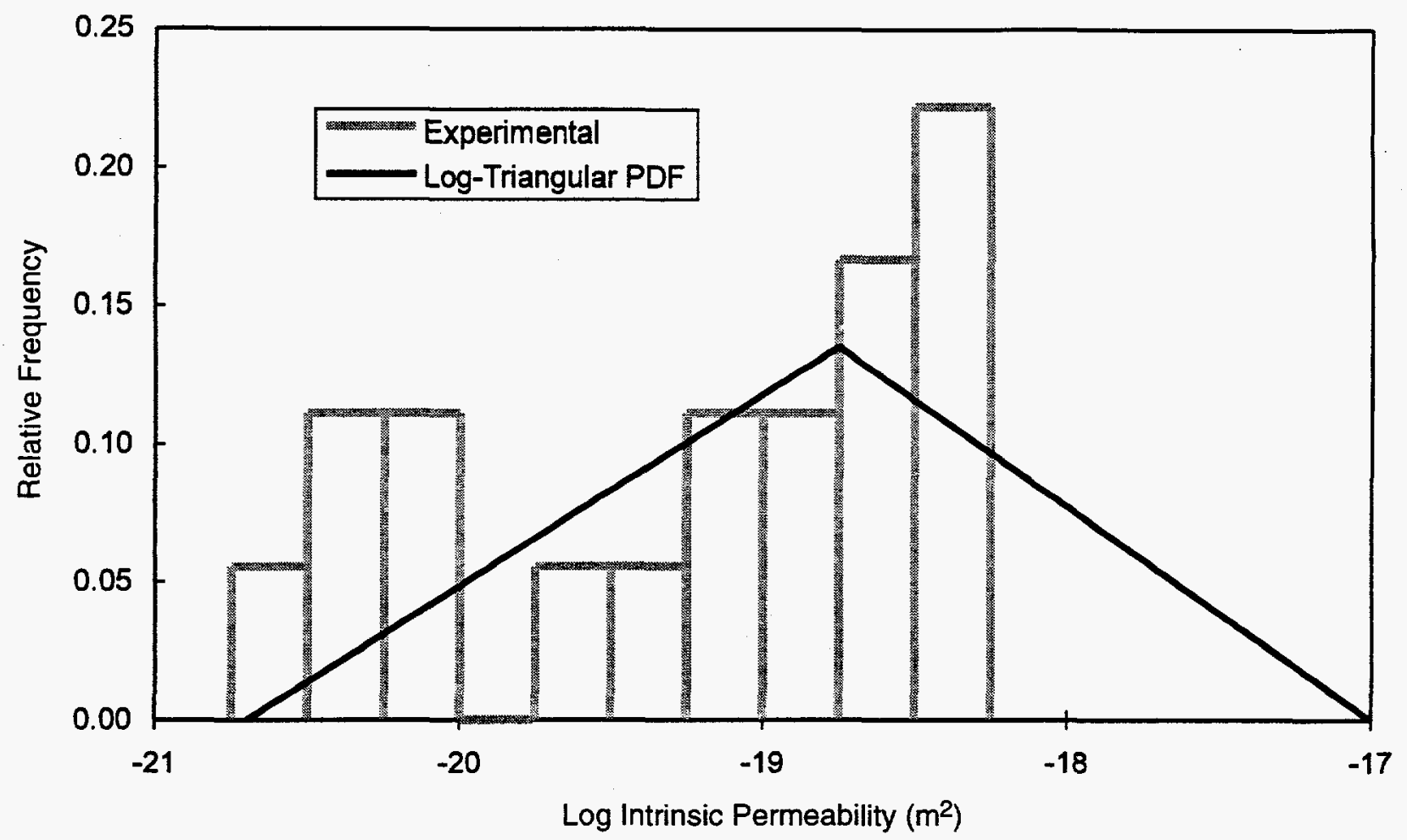

Figure 2-15. Experimental frequency histogram and log triangular PDF for permeability of SMC concrete, upper bound relaxed to account for uncertainty in concrete-salt interface.

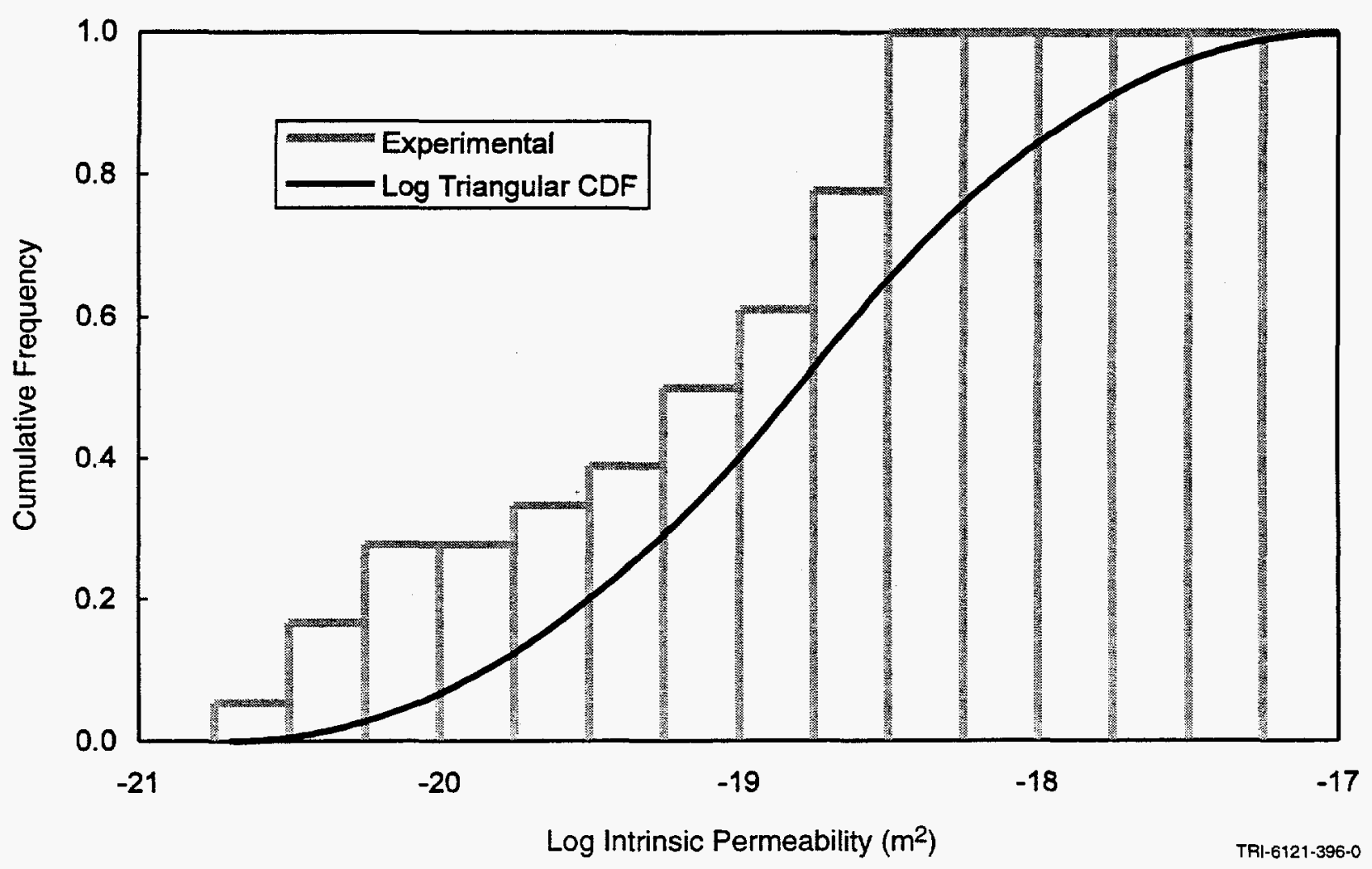

Figure 2-16. Experimental cumulative frequency and log triangular CDF for permeability of SMC concrete. 
Table 2-10. Log Triangular Distribution Function Parameters for SMC Permeability

\begin{tabular}{ccc}
\hline $\begin{array}{c}\text { Lower Bound } \\
\text { Permeability }\left(\mathrm{m}^{2}\right)\end{array}$ & Best Estimator $\left(\mathrm{m}^{2}\right)$ & $\begin{array}{c}\text { Upper Bound } \\
\text { Permeability }\left(\mathrm{m}^{2}\right)\end{array}$ \\
\hline $2.0 \times 10^{-21}$ & $1.78 \times 10^{-19}$ & $1.0 \times 10^{-17}$ \\
\hline
\end{tabular}

No DRZ was specified adjacent to the concrete because of the healing effects of the stiff concrete and the ability of the asphalt waterstops to intersect the DRZ.

\subsubsection{Porosity}

\subsubsection{PARAMETER SOURCES}

Data used in the development of the best estimator of porosity for SMC were derived from Wakeley et al. (1995), where air entrainment was measured in both "green" SMC and cured SMC concrete cores. Air entrainment measurements were assumed to be representative of porosity. Measurements of air entrainment were made for 19 batches of "green" SMC. For each batch, air entrainment was determined at two distinct times, once at the beginning of the mixing process and once near the end of the mixing process (approximately two hours). Table 2-11 summarizes the values of air entrainment reported by Wakeley et al. (1995). Air entrainment values of "green" SMC ranged from 1.1 to $3.4 \%$ with an average of $2.0 \%$.

Wakeley et al. (1995) also determined air entrainment from concrete cores recovered from two SMC cast monoliths identified as 161SM3 and 231SM3. These monoliths were prepared by discharging the portions of the SMC into oval galvanized metal tanks with approximate dimensions of $4 \times 8 \times 3 \mathrm{ft}$. The SMC was allowed to flow freely from one end of the tank to the opposite end of the tank. The placing and consolidating procedures for the two batches were different. For Batch 161SM3, the concrete was placed in one continuous lift $3 \mathrm{ft}$ deep and received minimal vibration. An internal vibrator having a 3 -in. diameter head was inserted four times after the tank was filled. Each insertion lasted approximately 3 seconds. For Batch 231SM3, concrete was placed in two lifts each $1.5 \mathrm{ft}$ deep and vibrated according to common practice. The same vibrator was inserted into both lifts 12 times. The duration of each insertion was 6 to 8 seconds.

After the monoliths had cured for six months, cores were recovered from six locations within the monoliths to obtain samples for determining air entrainment (and other characteristics). The locations included three horizontal sampling positions located at the discharge, near the middle, and at the far end and two vertical sampling depths located at the top and bottom. Air voids were determined by sectioning the samples and using petrographic techniques. Table 2-12 summarizes the values of entrainment measured for these 12 samples. Air entrainment values of the cast SMC ranged from 1.5 to $4.5 \%$ with an average of $3.2 \%$. 
Table 2-11. Summary of Air Entrainment for “Green” SMC (after Wakeley et al., 1995)

\begin{tabular}{ccc}
\hline & \multicolumn{2}{c}{ Air Entrainment (\%) } \\
\cline { 2 - 3 } Batch & Start of Mixing & End of Mixing $^{(\text {a) }}$ \\
\hline 097SM5 & 3.3 & 2.7 \\
106SM5 & 2.4 & 2.4 \\
113SM5 & 2.0 & 1.3 \\
133SM5 & 1.2 & 1.6 \\
153SM5 & 2.2 & 1.5 \\
106SM3 & 2.4 & 1.9 \\
113SM3 & 1.9 & 1.9 \\
133SM3 & 1.7 & 1.9 \\
153SM3 & 3.4 & 2.0 \\
174SM3 & 1.3 & 1.1 \\
190SM3 & NA & NA \\
024SM4 & 2.0 & 2.0 \\
025SM4 & 2.2 & 2.1 \\
032SM4(M) & 1.7 & 1.8 \\
032SM4(A) & 1.9 & 1.8 \\
040SM4 & 2.0 & 2.3 \\
159SM3 & 1.6 & 1.6 \\
161SM3 & 1.7 & 2.0 \\
231SM3 & 2.0 & 2.4 \\
& & Average $=2.0 \%$ \\
\hline
\end{tabular}

(a) Obtained approximately two hours after mixing.

Table 2-12. Summary of Air Entrainment for Cast SMC Monoliths (after Wakeley et al., 1995)

\begin{tabular}{ccccc}
\hline \multirow{2}{*}{ Batch } & \multicolumn{4}{c}{ Air Entrainment $^{(\mathrm{a})}(\%)$} \\
\cline { 2 - 5 } & $\begin{array}{c}\text { Vertical Position } \\
\text { within } \\
\text { Monolith }\end{array}$ & \multicolumn{3}{c}{ Horizontal Position within Monolith } \\
\cline { 3 - 5 } & Top & 3.7 & 3.3 & 4.4 \\
\cline { 3 - 5 } 161SM3 & At Discharge & At Middle & At Far End \\
& Bottom & 4.2 & 4.4 & 4.5 \\
\hline $231 \mathrm{SM} 3$ & Top & 2.4 & 1.5 & 2.1 \\
& Bottom & 3.2 & 2.5 & 1.7 \\
\hline & & \multicolumn{4}{c}{ Average $=3.2 \%$} \\
\hline
\end{tabular}

(a) Determined using petrographic techniques. 


\subsubsection{RATIONALE AND PAFAMETER VALUE}

The analysis presented for porosity of SMC assumed that air entrainment as measured either by standard procedures for concrete or by petrographic techniques accurately represents the porosity of the SMC. A review of the data presented above showed that the average porosity of SMC based on all measurements is $2.27 \%$. The average values of "green" and cast SMC samples are 2.0 and $3.2 \%$, respectively. The technique, by which the SMC will be emplaced in the field operation, includes the use of a slickline to transport the SMC from the surface to the emplacement depth, a tremie line to move the SMC from the slickline exit point to the emplacement location, and use of no vibration. The best analog to this emplacement technique currently available is the technique used to cast the 161SM3 monolith because this latter technique involves minimal vibration and small to moderate transport distances (at least for the concrete contained at the far end of the galvanized tank). The 161SM3 air entrainment data suggest that air entrainment in the field may range from 3.3 to $4.5 \%$ (with an average over $4 \%$ ) and may be slightly correlated with transport distance (concrete placed at the far end of the monolith had slightly higher air contents). Based on this rationale, the field-emplaced air entrainment of SMC may be greater than 4\%. The field-emplaced SMC will likely have air entrainment values of approximately $5 \%$ based on the work by Wakeley et al. (1995). Therefore, the best estimator for the porosity of SMC seal components was assigned to be 5\%. This porosity was recommended for the concrete column at all times and the concrete monolith.

It should be noted that the mass concrete placement uses neat concrete (i.e., no rebar) so the need to vibrate (as is normal for civil construction) is minimized. In addition, mass placement at the WES demonstrated that a porosity of $5 \%$ can be achieved without tremie line placement and with only minimal vibration. Because the construction method specified for the shaft uses tremie line placernent (a conventional construction method) air voids are minimized.

\subsubsection{Pore-Volume Cornpressibility}

\subsubsection{PARAMETER SOURCES}

Data used in the development of the best estimator of bulk modulus for SMC were derived from two sources: (1) literature reviews and (2) testing of both SMC cores and concrete cores recovered from the SSSPT.

RISD (1996) performed a literature review to develop material properties for use in rock mechanics analyses of SMC sealing materials. Their review revealed relatively few references, primarily because the SMC is a specially designed mix that has been developed only recently (Wakeley et al., 1994; Wakeley et al.,1995) and thus has been subjected to very little mechanical testing. Citing Wakeley et al. (1994) and Van Sambeek (1987), values were selected for Young's modulus and Poisson's ratio of $30.0 \mathrm{GPa}$ and 0.2 , respectively. Using Equation 2-15, the bulk modulus for SMC was calculated to be $16.7 \mathrm{GPa}$. Wakeley et al. (1995) have reported values for Young's modulus as determined from unconfined compression tests of SMC. However, no lateral strain measurements were made during the testing, so Poisson's ratio could not be 
determined. Furthermore, bulk modulus could not be calculated because only values of Young's modulus were determined from the testing.

In view of the limited data in the literature and from direct testing of SMC, additional testing was performed on WIPP concretes to obtain estimates of bulk modulus (Pfeifle et al., 1996). A total of three compression tests was performed to measure Young's modulus and Poisson's ratio. These values were then used to compute bulk modulus. One test was performed on SMC batched and cast at WES, while two tests were performed on concrete recovered from the SSSPT. The results of the testing are summarized in Table 2-13 and show that the value of bulk modulus determined for SMC and SSSPT concrete is 19.2 and $30.0 \mathrm{GPa}$, respectively, which is approximately $15 \%$ and $80 \%$ higher than that used in the rock mechanics analyses (RISD, 1996). The concrete components emplaced in the Salado Formation are expected to comprise materials nearly identical to the SMC tested in the laboratory by Pfeifle et al. (1996).

\subsubsection{RATIONALE AND PARAMETER VALUE}

The elastic moduli of SMC, such as bulk modulus, are age-dependent as reported by Wakeley et al. (1994). At early times, the bulk modulus is low. As the concrete cures, the bulk modulus increases until it reaches a constant value at approximately 100 to 200 days. The bulk modulus versus curing time relationship is nonlinear with a rapid increase in bulk modulus values at early times. For example, the bulk modulus reached nearly $85 \%$ of its peak value at a curing time of only 28 days. Because the bulk modulus of SMC achieves its peak value in short times relative to the times anticipated to construct the complete sealing system, it was assumed that the SMC achieves its peak value immediately after emplacement (i.e., age-dependent effects on bulk modulus are negligible). The best estimator for the bulk modulus of SMC components is 16.7 GPa. Assuming a concrete porosity of 0.05 (Section 2.3.3.2) and using Equation 2-13, the pore-volume compressibility for SMC was calculated to be $1.2 \times 10^{-9} 1 / \mathrm{Pa}$. However, the value of pore-volume compressibility that was recommended for PA calculations was $2.64 \times 10^{-9} 1 / \mathrm{Pa}$. This value was based on a porosity of 0.023 , which was the porosity originally recommended. Upon further investigation and technical review, the porosity was changed to 0.05 as is reflected in this report. The pore volume compressibility, which is dependent on porosity, was not similarly updated for the compliance calculations. It should be noted that performance calculations are not sensitive to this parameter. Consequently, the use of the incorrect value should not significantly impact the results of the PA calculations.

\subsubsection{Initial Wetting Phase Saturation}

Air entrained during construction of the concrete components will exist as occluded vesicles, and may be considered inaccessible to brine that permeates the cementitious matrix. The cementitious materials consist of hydrated calcium sulfates and aluminosilicates. It was therefore recommended that the initial brine saturation of the concrete components be 1.0 in the PA calculations. 
Table 2-13. Summary of Elastic Properties for Salado Mass Concrete Determined from Laboratory Tests (after Pfeifle et al., 1996)

\begin{tabular}{|c|c|c|c|c|}
\hline \multirow[t]{2}{*}{ Specimen I.D. } & \multirow{2}{*}{$\begin{array}{l}\text { Confining Pressure } \\
\text { (MPa) }\end{array}$} & \multicolumn{3}{|c|}{ Elastic Properties } \\
\hline & & $\begin{array}{l}\text { Young's Modulus } \\
\text { (GPa) }\end{array}$ & $\begin{array}{l}\text { Poisson's } \\
\text { Ratio }\end{array}$ & $\begin{array}{l}\text { Bulk Modulus } \\
\text { (GPa) }\end{array}$ \\
\hline $40 S M 4-19 / 2-1 / 1^{(b)}$ & 0 & 36.3 & 0.185 & 19.2 \\
\hline MAC313-2/1 ${ }^{(\mathrm{c})}$ & 0 & 40.8 & 0.278 & 30.6 \\
\hline $\operatorname{MAC} 314-1 / 1^{(\mathrm{c})}$ & 5 & 41.9 & 0.264 & 29.6 \\
\hline
\end{tabular}

(a) Calculated from Young's modulus and Poisson's ratio.

(b) Batched and cast at the Waterways Experiment Station.

(c) Recovered from the SSSPT field experiment.

\subsection{Asphalt}

Asphalt is a widely used construction material with properties considered desirable for sealing applications. Asphalt is a strong cement, is readily adhesive, highly waterproof, and durable. Furthermore, it is a plastic substance that provides controlled flexibility to mixtures of mineral aggregates with which it is usually combined. It is highly resistant to most acids, salts, and alkalis. A number of asphalts and asphalt mixes are available that cover a wide range of viscoelastic properties, which allows the properties of the mixture to be designed for a wide range of requirements for each application. These properties are well suited to the requirements of the WIPP shaft seal system.

\subsubsection{Material Specifications}

Asphalt mastic mix (AMM) is a mix of asphalt cement, sand, and other mineral fillers. The mix design specifies that the air void volume will be between 1 and $2 \%$ and that the mix consists of $20 \mathrm{wt} \%$ asphalt cement (AR-4000 graded asphalt), $70 \mathrm{wt} \%$ aggregate (silica sand), and $10 \mathrm{wt} \%$ hydrated lime. The AMM aggregation gradation completely passes a No. 8 Sieve (particle diameter $2.36 \mathrm{~mm}$ ). The high asphalt content along with the very fine-grained aggregate will result in a material with virtually no voids. The aggregate will resist settling and will provide a filter cake along the host rock contact to minimize possible loss of asphalt to the formation. Hydrated lime is included to increase the stability of the material, to decrease moisture susceptibility, and to act as an antimicrobial agent. 


\subsubsection{Intrinsic Permeability}

\subsubsection{PARAMETER SOURCES}

Several sources were reviewed to find relevant information on the permeability of asphalt and asphaltic-based construction materials. A large body of literature exists on applications of using asphalt as a barrier to water flow such as in the case of dams. Asphalt is routinely referred to in the literature as being impermeable, waterproof, etc. However, very little quantitative information exists regarding the permeability of asphalt. No permeability values were found for an AMM which shares the expected low-void volume and high-asphalt content that is expected in the shaft seal.

One of the most common uses of asphalt is in hot-mix asphalt concrete (HMAC) for the construction of pavement. The permeability of HMAC can be measured in situ by placing a container of water on the pavement surface, sealing the edge and measuring the rate at which the water permeates into the pavement. Lay (1986) reported that these permeabilities can be expected to range from $2.0 \times 10^{-15}$ to $2.0 \times 10^{-13} \mathrm{~m}^{2}$, with $2 \times 10^{-14} \mathrm{~m}^{2}$ being a typical value. These values are not representative of AMM. AMM is expected to have porosities on the order of $1 \%$, whereas HMAC may have porosities exceeding $10 \%$.

Several investigators have found that the permeability of asphaltic materials is related to the porosity, or percent of air voids, of the material. Brown (1990) investigated the density of asphalt concrete and the relationship between air voids and permeability. Brown (1990) reported that asphalt mixtures become permeable to water at approximately $8 \%$ air voids. In the ten projects studied, permeability was sufficiently low as long as the voids were below $8 \%$.

However, the permeability increased quickly as the void level increased above $8 \%$. Therefore, asphalt mixes were considered impermeable (to have low permeability) to water as long as the air void content was below approximately $8 \%$.

Terrel and Al-Swailmi (1993) also investigated the effect of air voids on the performance of asphalt pavements by studying the relationship between voids and permeability. They found that HMAC with minimal voids that were not interconnected were essentially impermeable. When air voids increased beyond some critical value, they became larger and interconnected and water flowed more easily through the HMAC. They found that at an air void volume of $4 \%$ or less, the HMAC was almost impermeable to water. In the laboratory, permeability, air void percentage, and degree of saturation were measured for six samples, two each with 30,8 , and $4 \%$ air voids. The specimens with high air voids $(30 \%)$ resulted in permeabilities of $6.82 \times 10^{-14}$ and $1.28 \times 10^{-13} \mathrm{~m}^{2}$. The specimens with lower air voids $(8 \%)$ resulted in permeabilities of $1.54 \times 10^{-15}$ and $1.25 \times 10^{-15} \mathrm{~m}^{2}$. The specimens with the lowest air voids (4\%) were simply reported as impermeable. When the air voids were reduced by a factor of approximately four, the permeability decreased by two orders of magnitude. Therefore, when the asphalt specification of $1 \%$ air voids is considered (a factor of 8 reduction from the middle air void percentage), the permeability could be expected to be 3 to 5 orders of magnitude less than $1 \times 10^{-15} \mathrm{~m}^{2}$. 
At Hanford, experiments are ongoing to develop a passive surface barrier designed to isolate wastes (in this case to prevent downward flux of water and upward flux of gases) for 1000 years with no maintenance (Freeman et al., 1994). The surface barrier uses asphalt as one of many horizontal components, since low-air-void, high-asphalt-content HMACs are noted for low permeability and improved mechanically stable compositions. The design objective of this asphalt concrete was to limit infiltration to $1.6 \times 10^{-9} \mathrm{~cm} / \mathrm{s}\left(1.6 \times 10^{-11} \mathrm{~m} / \mathrm{s}\right.$ or, for fresh water, an intrinsic permeability of $1.6 \times 10^{-18} \mathrm{~m}^{2}$ ). The asphalt component of the barrier was composed of a 15-cm layer of asphaltic concrete overlain with a 5-mm layer of fluid-applied asphalt (FAA). Myers and Duranceau (1994) reported that the asphalt concrete is a high-asphalt content product designed to minimize the void spaces. The reported hydraulic conductivity of the asphalt concrete was estimated to be $1 \times 10^{-9} \mathrm{~m} / \mathrm{s}$ (equivalent to an intrinsic permeability of approximately $1 \times 10^{-16} \mathrm{~m}^{2}$ assuming fresh water). Myers and Duranceau (1994) reported that the hydraulic conductivity of the FAA was estimated to be $1.0 \times 10^{-11}$ to $1.0 \times 10^{-10} \mathrm{~cm} / \mathrm{s}$ (equivalent to an intrinsic permeability of approximately $1.0 \times 10^{-20}$ to $1.0 \times 10^{-19} \mathrm{~m}^{2}$, assuming fresh water).

Recent measurements of both in situ and laboratory hydraulic conductivity on the HMAC portion of the Hanford prototype barrier show that the asphalt layers easily meet the Resource Conservation and Recovery Act (RCRA) standard of $1 \times 10^{-7} \mathrm{~cm} / \mathrm{s}$. In-place hydraulic conductivity measurements using a new field falling head technique showed an average of $2.39 \times 10^{-8}$ to $2.39 \times 10^{-7} \mathrm{~cm} / \mathrm{s}\left(2.44 \times 10^{-17}\right.$ to $\left.2.44 \times 10^{-16} \mathrm{~m}^{2}\right)$. This was considered to be a conservative estimate by the investigators. Falling head permeability measurements were made on a variety of samples in support of the prototype barrier, including HMAC cores from the north end of the 5-acre prototype barrier, FAA membrane samples taken during application on the prototype, and HMAC test specimens prepared in the laboratory. The core samples taken from the north end of the prototype barrier resulted in an average hydraulic conductivity of $4.69 \times 10^{-10} \mathrm{~cm} / \mathrm{s}\left(4.78 \times 10^{-19} \mathrm{~m}^{2}\right)$. Measurements made on the FAA membrane (polymermodified asphalt) showed an extremely low permeability of less than $1.0 \times 10^{-11} \mathrm{~cm} / \mathrm{s}$ $\left(1.0 \times 10^{-20} \mathrm{~m}^{2}\right)$, which was the minimum hydraulic conductivity that could be measured with the laboratory setup. Test specimens prepared using standard Marshall mix design procedures were tested in the laboratory using the falling head technique. A range of hydraulic conductivity from $2.09 \times 10^{-12}$ to $2.12 \times 10^{-10} \mathrm{~cm} / \mathrm{s}\left(2.13 \times 10^{-21}\right.$ to $\left.2.16 \times 10^{-19} \mathrm{~m}^{2}\right)$ was measured for an asphalt content range of 6.5 to $7.5 \mathrm{wt} \%$ (Freeman et al., 1994).

In related research, Freeman and Gee (1989) investigated the properties of rubberized asphalt, a solid material at ambient temperature that is sprayed as a hot liquid onto a geotextile fabric. When cool, the material exhibited dramatic elastic properties that allow it to stretch up to 13 times its original length without rupturing or exhibiting significant deformation. The material is used commercially to line: water storage ponds. Permeameter tests resulted in hydraulic conductivities of less than $1.6 \times 10^{-12}$ and $6.0 \times 10^{-11} \mathrm{~cm} / \mathrm{s}\left(<1.6 \times 10^{-21}\right.$ and $\left.6.1 \times 10^{-20} \mathrm{~m}^{2}\right)$.

Several asphalt material handbooks and properties books were reviewed for applicable permeability information of asphalt-rich materials. Abraham (1962) reported the permeability of asphalts to water at $25^{\circ} \mathrm{C}$ in terms of a permeability constant, with units of $[(\mathrm{g})(\mathrm{cm}) /(\mathrm{sq} \mathrm{cm})(\mathrm{mm}$ $\left.\mathrm{Hg})(\mathrm{hr}) \times 10^{9}\right]$. This unit of measurement can be converted to an intrinsic permeability by 
multiplying by viscosity and dividing by the density of water. The measured permeabilities and the converted permeabilities in units of $\mathrm{m}^{2}$ are reported in Table 2-14. The permeability of these asphaltic materials ranged from $5.8 \times 10^{-22}$ to $8.5 \times 10^{-21} \mathrm{~m}^{2}$. Other sources (Barth, 1962; Zakar, 1971) reported similar permeability constants for water vapor for various engineering materials (at temperatures between 21.1 and $25^{\circ} \mathrm{C}$ ) in terms of a coefficient of diffusion, defined as the grams of water vapor, at a pressure differential of $1 \mathrm{~mm} \mathrm{Hg}$, that diffuse through $1 \mathrm{~cm}$ of the substance whose surface area is $1 \mathrm{~cm}^{2}$ in the period of 1 hour. These values were not used because of uncertainty in their applicability.

Engelmann et al. (1989) reported on the modeling of a dam constructed to be a bulkhead in the Asse salt mine in Germany. Their initial estimate of the permeability of a liquid asphalt bitumen with a basalt filler at a density of $1650 \mathrm{~kg} / \mathrm{m}^{3}$ and a viscosity of $2 \times 10^{6} \mathrm{~Pa} \cdot \mathrm{s}$ was $1 \times 10^{-21} \mathrm{~m}^{2}$. This value is consistent with the literature reviewed and the low permeability proposed for the asphalt column.

Robert Romine, a research scientist in the Environmental Technology Division of Pacific Northwest National Laboratories (PNL), is one of the principal investigators working on the development of the Hanford Barrier. He is also a technical expert contracted to SNL for help with the development of the specifications for the shaft seal AMM. Based on Romine's experience designing and testing asphalt engineered barriers, he expects the permeability of the WIPP AMM seal to be less than $1 \times 10^{-20} \mathrm{~m}^{2}$.

\subsubsection{RATIONALE AND PARAMETER VALUE}

Table 2-14 summarizes the various sources of hydraulic conductivity for a range of asphaltic materials, from typical asphalt concrete pavement to bitumen. Calculated permeabilities for these materials range from $5 \times 10^{-22}$ to $2 \times 10^{-14} \mathrm{~m}^{2}$. The higher values of permeability are representative of asphalt concretes that have much higher void volumes than the AMM seal being designed for the WIPP shafts. Therefore, these permeabilities are not representative of the WIPP seal AMM. The permeability of the seal AMM is expected to be less than $1 \times 10^{-20} \mathrm{~m}^{2}$ because of the low design air void content of $1 \%$ for the AMM. The permeability of the AMM is expected to be of this magnitude based on (1) Romine's (PNL) experience with the Hanford Barrier and the very low field permeabilities measured on it and (2) the previously mentioned literature, in particular Myers and Duranceau (1994).

Considering a permeability of $1 \times 10^{-21} \mathrm{~m}^{2}$ to be a practical lower limit to permeability measurements, this value was assumed to define the lower limit of the asphalt seal permeability. The upper limit of the asphalt seal permeability was assumed to be $1 \times 10^{-18} \mathrm{~m}^{2}$. This value was based on consideration of the uncertainty associated with how well the asphalt column will seal the halite DRZ in the uppermost portion of the Salado Formation. The recommended intrinsic permeability of the asphalt column was defined as a log triangular distributed parameter, with a best estimate value of $1 \times 10^{-20} \mathrm{~m}^{2}$, a minimum value of $1 \times 10^{-21} \mathrm{~m}^{2}$, and a maximum value of $1 \times 10^{-18} \mathrm{~m}^{2}$, as shown in Figure 2-17. 
Table 2-14. Literature Hydraulic Conductivity Values for Asphalt

\begin{tabular}{|c|c|c|c|}
\hline Material & Reported Permeability & Calculated Permeability $\left(\mathrm{m}^{2}\right)$ & Source \\
\hline $\begin{array}{l}\text { Permeability of bitumens to water } \\
\left(25^{\circ} \mathrm{C}\right) \\
\text { Air-blown asphalt } \\
\text { Air-blown asphalt } \\
\text { Steam-refined asphalt } \\
\text { Steam-refined asphalt } \\
\text { Coal-tar pitch } \\
\text { Plasticized pitch (35\% } \\
\text { inorganic filler) }\end{array}$ & $\begin{array}{c}\text { (gm cm/ } / \mathrm{cm}^{2} \mathrm{mmHg} \mathrm{hr} \text { ) } \\
9.00 \times 10^{-9} \\
6.80 \times 10^{-9} \\
6.00 \times 10^{-9} \\
4.10 \times 10^{-9} \\
7.00 \times 10^{-9} \\
2.80 \times 10^{-9}\end{array}$ & $\begin{array}{l}1.88 \times 10^{-21} \\
1.42 \times 10^{-21} \\
1.25 \times 10^{-21} \\
8.54 \times 10^{-21} \\
1.46 \times 10^{-21} \\
5.83 \times 10^{-22}\end{array}$ & Abraham, 1962 \\
\hline $\begin{array}{l}\text { Rubberized asphalt tested in small- } \\
\text { tube lysimeters }\end{array}$ & $\begin{array}{l}6.0 \times 10^{-11} \mathrm{~cm} / \mathrm{s} \\
<1.6 \times 10^{-12} \mathrm{~cm} / \mathrm{s} \\
\end{array}$ & $\begin{array}{l}6.1 \times 10^{-20} \\
<1.6 \times 10^{-21} \\
\end{array}$ & Freeman and Gee, 1989 \\
\hline $\begin{array}{l}\text { In-place measurements on HMAC } \\
\text { Measurements on cores in laboratory } \\
\text { Fluid-applied asphalt membrane } \\
\text { Test specimens-Marshall mix design }\end{array}$ & $\begin{array}{c}2.39 \times 10^{-7} \text { to } 2.39 \times 10^{-8} \mathrm{~cm} / \mathrm{s} \\
4.69 \times 10^{-10} \mathrm{~cm} / \mathrm{s} \\
1.0 \times 10^{-11} \mathrm{~cm} / \mathrm{s} \\
2.12 \times 10^{-10} \text { to } 2.09 \times 10^{-12} \mathrm{~cm} / \mathrm{s}\end{array}$ & $\begin{array}{c}2.44 \times 10^{-16} \text { to } 2.44 \times 10^{-17} \\
4.78 \times 10^{-19} \\
1.0 \times 10^{-20} \\
2.16 \times 10^{-19} \text { to } 2.13 \times 10^{-21} \\
\end{array}$ & Freeman et al., 1994 \\
\hline $\begin{array}{l}\text { Field permeability of asphaltic } \\
\text { concrete: } \\
\text { Range of values } \\
\text { Typical value } \\
\end{array}$ & $\begin{array}{l}20 \text { to } 2000 \mathrm{~nm} / \mathrm{s} \\
200 \mathrm{~nm} / \mathrm{s} \\
\end{array}$ & $\begin{array}{l}2.0 \times 10^{-15} \text { to } 2.0 \times 10^{-13} \\
2.0 \times 10^{-14} \\
\end{array}$ & Lay, 1986 \\
\hline $\begin{array}{l}\text { Fluid-applied asphalt layer } \\
\text { (as surface coating) }\end{array}$ & $1.0 \times 10^{-10}$ to $1.0 \times 10^{-11} \mathrm{~cm} / \mathrm{s}$ & $1.0 \times 10^{-19}$ to $1.0 \times 10^{-20}$ & $\begin{array}{l}\text { Myers and Duranceau, } \\
1994\end{array}$ \\
\hline $\begin{array}{l}\text { Asphalt pavements: } \\
30 \% \text { air void volume } \\
08 \% \text { air void volume } \\
04 \% \text { air void volume }\end{array}$ & $\begin{array}{c}1.28 \times 10^{-13} \text { and } 6.82 \times 10^{-14} \mathrm{~m}^{2} \\
1.54 \times 10^{-15} \text { and } 1.25 \times 10^{-15} \mathrm{~m}^{2} \\
\text { "impermeable" }\end{array}$ & $\begin{array}{l}1.28 \times 10^{-13} \text { and } 6.82 \times 10^{-14} \\
1.54 \times 10^{-15} \text { and } 1.25 \times 10^{-15} \\
\text { "impermeable" }\end{array}$ & $\begin{array}{l}\text { Terrel and Al-Swailmi, } \\
1993\end{array}$ \\
\hline
\end{tabular}




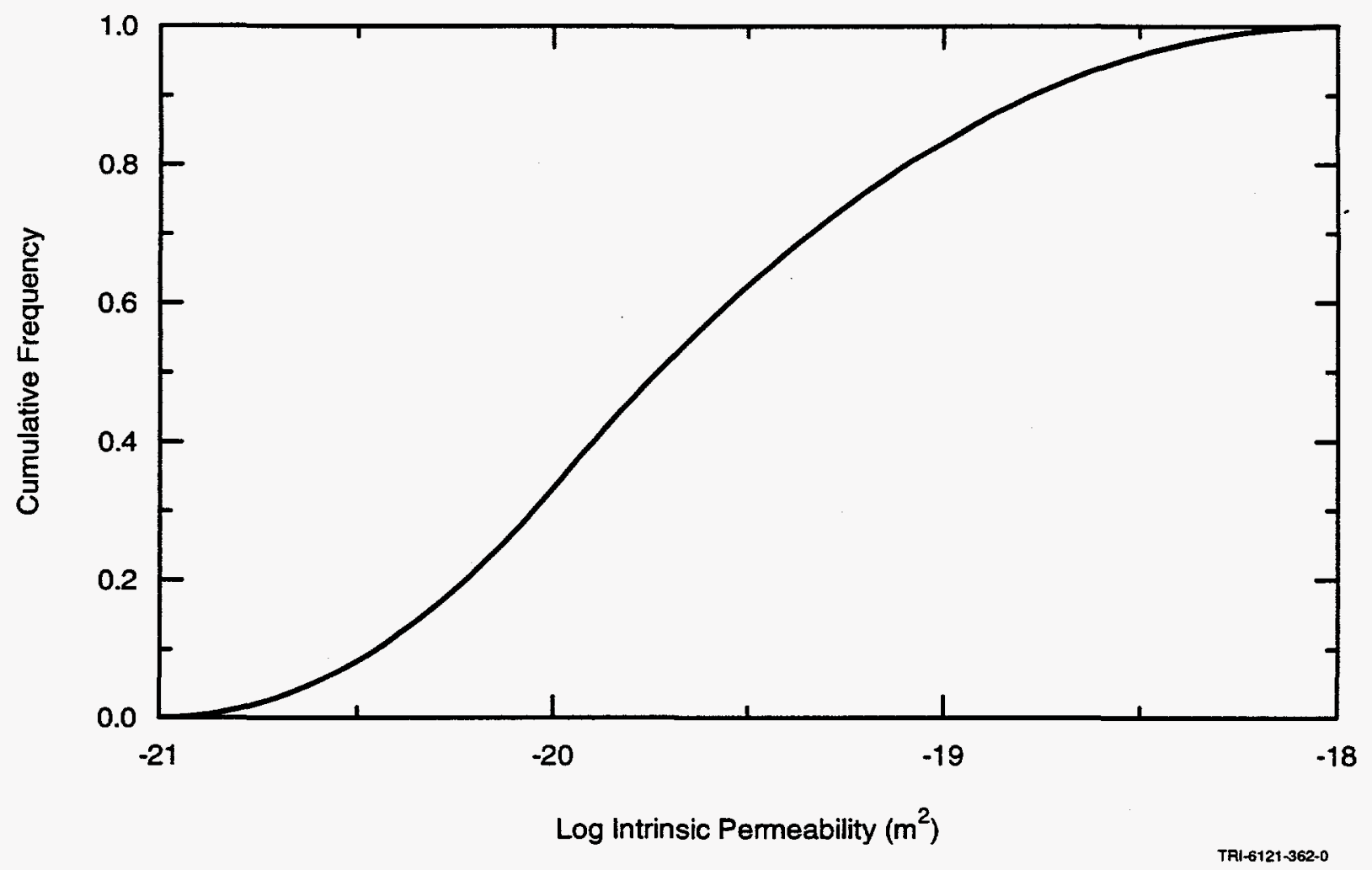

Figure 2-17. Asphalt column permeability cumulative frequency distribution function.

\subsubsection{Porosity}

The porosity of the AMM was specified in the material specifications for the shaft seal system. The asphalt column composed of an AMM will have an air void content (porosity), between 1 and $2 \%$. It was recommended that a porosity of $0.01(1 \%)$ be used for the asphalt column in the PA calculations. The lower limit of the expected asphalt porosities was chosen based on the professional judgment of Romine, who indicated that the porosity would be designed to be $0.01(1 \%)$ or less.

\subsubsection{Pore-Volume Compressibility}

The bulk modulus used for asphalt to perform creep closure calculations is $3.371 \times 10^{9} \mathrm{~Pa}$ (RISD, 1996). Assuming an asphalt porosity of 0.01 , the pore-volume compressibility for the asphalt column is $2.97 \times 10^{-8} 1 / \mathrm{Pa}$, which was recommended for use in PA calculations.

\subsubsection{Initial Wetting Phase Saturation}

No pore water is expected to be present in the asphalt column after emplacement. Water is not used in the mixing or emplacement of the asphalt column. The asphalt column will be placed at a temperature that will prevent water from being present as a liquid phase within the asphalt column. Trapped vapor or gases should vent while cooling. As a result, it was 
recommended that the water saturation of zero be used for the asphalt column in the compliance calculations. This water saturation was allowed to increase up to $10 \%$ as necessary for modeling purposes.

\subsection{Compacted Earthen Fill}

Compacted earthen fill will be emplaced from the surface to the top of the Rustler Formation in the shaft seal system. Earthen fill is not considered a primary seal material, and because of the expected minor importance of the earthen fill components, all parameters pertaining to earthen fill were not sampled in PA calculations, but were assigned best estimate values.

\subsubsection{Material Specifications}

Because a material specification for earthen fill was not given for the shaft seal system design, reference values were used to define the earthen fill physical properties. The earthen fill was classified in terms of textural properties. In terms of the Unified Soil Classification, the earthen fill will be SM (silty sand, sand-silt mixtures) or SC (clayey sand, clay-sand mixtures) (RISD, 1996). Geotechnical properties which are useful in the estimation of porosity and saturation of the earthen fill were found in the soils literature and are summarized in Table 2-15. The earthen fill will be compacted on emplacement.

\subsubsection{Intrinsic Permeability}

\subsubsection{PARAMETER SOURCES}

Several sources were reviewed to determine a representative range for the intrinsic permeability of silty and clayey sands (SM and SC soils according to the Unified Soil

Table 2-15. Reference Properties for Compacted SM and SC Soils

\begin{tabular}{lccc}
\hline \multicolumn{1}{c}{ Parameter } & Units & Range of Reported Values & Source \\
\hline Void Ratio & - & 0.48 & U.S. Bureau of Reclamation, 1977 \\
\hline Average Placement & - & 0.145 to 0.147 & U.S. Bureau of Reclamation, 1977 \\
Water Content & & 0.127 to 0.142 & U.S. Bureau of Reclamation, 1987 \\
\hline Unit Weight & $\mathrm{lb} / \mathrm{ft}^{3}$ & 114 to 115 & U.S. Bureau of Reclamation, 1977 \\
& & 112 to 115.6 & \\
& $\mathrm{~kg} / \mathrm{m}^{3}$ & 1826.10 to 1842.12 & U.S. Bureau of Reclamation, 1987 \\
& & 1794.07 to 1851.73 & \\
\hline
\end{tabular}


Classification). Table 2-16 summarizes the reported hydraulic conductivity values found for these types of sediments and converts those values into intrinsic permeabilities. Three of the references listed in Table 2-16 (Freeze and Cherry, 1979; Davis and DeWiest, 1966; Marsily, 1986) reported a range of hydraulic conductivity for silty and clayey sands. The two other references are dam design manuals published by the Department of Interior's Bureau of Reclamation which provide hydraulic conductivity estimates specific for SM and SC soils. Figure 2-18 presents the reported ranges in permeability for silty and clayey sands. All of the literature sources, with the exception of one, reported a maximum permeability for these types of soils of $1 \times 10^{-12} \mathrm{~m}^{2}$. Freeze and Cherry (1979) reported a maximum hydraulic conductivity for unconsolidated silty sand of $0.002 \mathrm{~m} / \mathrm{s}$, which converts to a permeability of $2.04 \times 10^{-10} \mathrm{~m}^{2}$. This value was not considered a maximum permeability value because the earthen fill in the shaft will be compacted.

\subsubsection{RATIONALE AND PARAMETER VALUE}

Because the earthen fill will be compacted and because the permeability of the earthen fill column will be controlled by low permeability lifts (layers), the maximum permeability assumed for earthen fill was $1 \times 10^{-12} \mathrm{~m}^{2}$. The best estimate permeability was assumed to be $1 \times 10^{-14} \mathrm{~m}^{2}$, and the minimum permeability was assumed to be $1 \times 10^{-17} \mathrm{~m}^{2}$. The minimum value was based on actual measurements of hydraulic conductivity of compacted SM and SC soils (U.S. Bureau of Reclamation, 1977; 1987). The recommended permeability distribution was log triangular with the maximum, best estimate, and minimum values as specified previously. Figure 2-19 presents the recommended distribution function for the earthen fill; as discussed previously, the best estimate value was used in compliance calculations as a constant.

Table 2-16. Reported Hydraulic Conductivity for Silty and Clayey Sands

\begin{tabular}{ccc}
\hline $\begin{array}{c}\text { Range of Reported } \\
\text { Hydraulic Conductivity }\end{array}$ & $\begin{array}{c}\text { Range of Calculated } \\
\text { Intrinsic Permeability }\left(\mathrm{m}^{2}\right)\end{array}$ & Source \\
\hline 0.1 to $12.3 \mathrm{ft} / \mathrm{year}$ & $9.8 \times 10^{-17}$ to $1.21 \times 10^{-14}$ & U.S. Bureau of Reclamation, 1977 \\
0.01 to $1000 \mathrm{ft} / \mathrm{year}$ & $9.8 \times 10^{-18}$ to $9.85 \times 10^{-13}$ & U.S. Bureau of Reclamation, 1987 \\
$1 \times 10^{-6}$ to $0.001 \mathrm{~cm} / \mathrm{s}$ & $1.0 \times 10^{-15}$ to $1.02 \times 10^{-12}$ & Davis and DeWiest, 1966: Table 6.1 \\
$1 \times 10^{-9}$ to $0.002 \mathrm{~m} / \mathrm{s}$ & $1.0 \times 10^{-16}$ to $2.04 \times 10^{-10}$ & Freeze and Cherry, 1979: Table 2.2 \\
$1 \times 10^{-9}$ to $1 \times 10^{-5} \mathrm{~m} / \mathrm{s}$ & $1.0 \times 10^{-16}$ to $1.02 \times 10^{-12}$ & Marsily, 1986: Page 78 \\
\hline $\begin{array}{l}\text { Assumed constants: } \\
\text { Water density }=1000 \mathrm{~kg} / \mathrm{m}^{3} \\
\text { Gravity }=9.806 \mathrm{~m} / \mathrm{s}^{2} \\
\text { Viscosity }=0.001 \mathrm{~Pa} \text { Pas }\end{array}$ & & \\
\end{tabular}




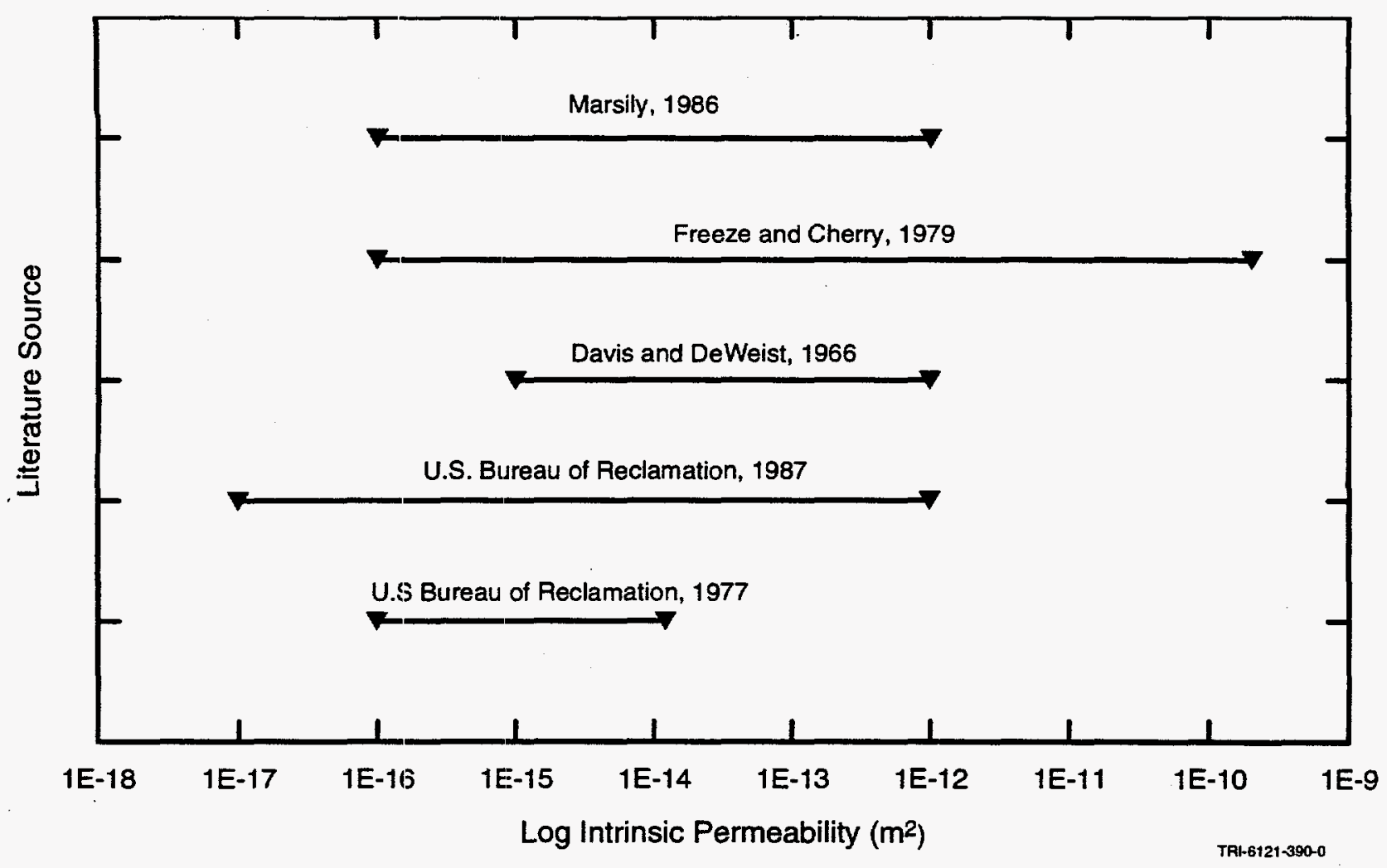

Figure 2-18. Representative range of intrinsic permeability for silty and clayey sands.

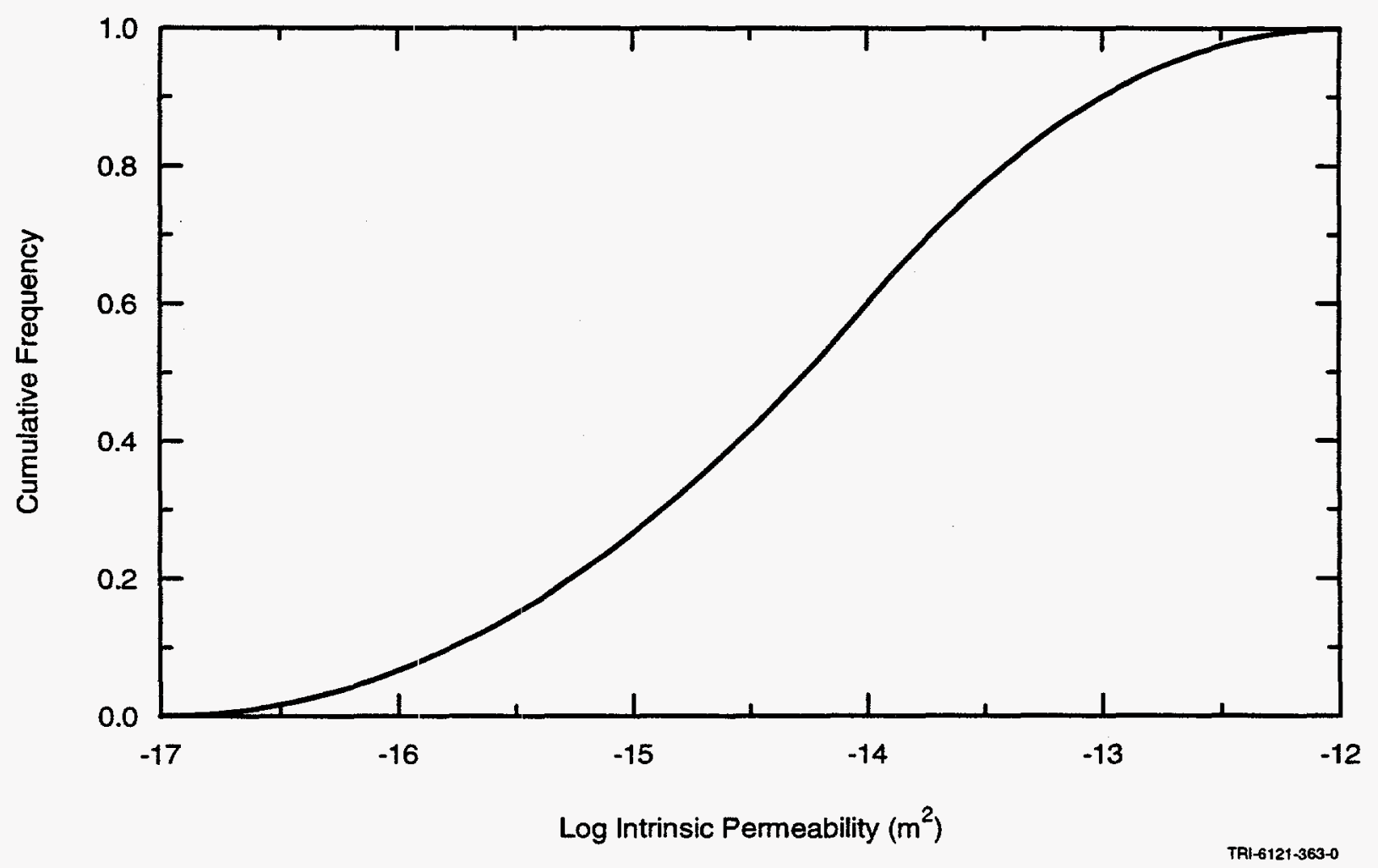

Figure 2-19. Cumulative frequency distribution function for earthen fill. 


\subsubsection{Porosity}

The porosity of the earthen fill was calculated from the void ratio $e$, where $e=\phi /(1-\phi)$ (Farmer, 1983). The void ratio for SM and SC soils was reported to be 0.48 (U.S. Bureau of Reclamation, 1977). The porosity of the earthen fill was calculated to be 0.32 (32\%), and this was the recommended value.

\subsubsection{Pore-Volume Compressibility}

The compressibilities reported by Freeze and Cherry (1979) for clays range from $1 \times 10^{-8}$ to $1 \times 10^{-6} 1 / \mathrm{Pa}$. The range of compressibility for sands reported by Freeze and Cherry (1979) is from $1 \times 10^{-9}$ to $1 \times 10^{-7} 1 / \mathrm{Pa}$. The earthen fill seal material will consist of a mixture of clay, silt, and sand. From the ranges reported in Freeze and Cherry (1979), a representative compressibility of $1 \times 10^{-8} 1 / \mathrm{Pa}$ was selected. Dividing this compressibility by a porosity of 0.32 yielded a recommended pore-volume compressibility of $3.1 \times 10^{-8} 1 / \mathrm{Pa}$.

\subsubsection{Initial Wetting Phase Saturation}

The initial wetting phase saturation was calculated from the water content, specific gravity, and porosity using Equation 2-19. Table 2-15 provides literature estimates of emplaced water contents and the void ratio of SM and SC soils. The porosity was calculated from the void ratio to be 0.32 . A representative water content after emplacement for compacted SM and SC soils is approximately 0.14 (see Table 2-15). The specific gravity of the earthen fill was calculated using:

$$
G=(e+1) \frac{\rho_{d}}{\rho_{w}}
$$

where (Farmer, 1983):

$e=$ void ratio $(0.48)$,

$\rho_{d}=$ dry density or unit weight (average of $1828 \mathrm{~kg} / \mathrm{m}^{3}$ ), and

$\rho_{w}=$ fluid density (assumed to be $1000 \mathrm{~kg} / \mathrm{m}^{3}$ ).

The average specific gravity was calculated to be 2.70 for the earthen fill. Assuming a water content of 0.14 and a porosity of 0.32 , the recommended fluid saturation of the earthen fill was estimated to be 0.8 using Equation 2-19. 


\subsection{TWO-PHASE FLOW PROPERTIES}

Modeling of a system containing two phases, such as brine and gas, requires knowledge of the capillary pressure and relative permeability curves for each phase. These characteristic curves have not been determined for the shaft seal materials. However, they can be estimated using functional relationships found in the literature (Corey, 1954; Brooks and Corey, 1964; Brooks, 1965; Brooks and Corey, 1966; Mualem, 1976; van Genuchten, 1980; van Genuchten and Nielsen, 1985; Parker et al., 1987; and Luckner et al., 1989).

Webb (1992) performed an in-depth literature review of the relationships for determining two-phase characteristic curves. In addition, he conducted detailed comparisons of various relationships to literature data. Based on those comparisons, he concluded that no single model best fits all the data, and he further recommended the use of two models for future performance assessment calculations. He referred to these two models as the mixed Brooks and Corey model and the van Genuchten/Parker model. Parameters for the van Genuchten/Parker model can be derived from the Brooks and Corey model; shaft seal parameters were derived from the Brooks and Corey model.

This section presents two-phase flow properties for the shaft seal materials, beginning with a review of the two capillary pressure and relative permeability models recommended by Webb (1992). The parameters used to describe these models are then defined. Available literature values for those parameters are presented for different geologic and shaft seal type materials. There are no literature or measured values for the two-phase flow properties of the materials specific for the WIPP shaft seals. Therefore, the two-phase properties were not specified for each seal material but were adopted universally for all seal material types except for the asphalt seal, as will be discussed in the following section.

\subsection{Model Review}

Brooks and Corey $(1964,1966)$ and Brooks (1965) observed that capillary pressure and effective saturation have a linear relationship on a log-log plot and defined that relationship by:

$$
S_{e}=\left(\frac{P_{t}}{P_{c}}\right)^{\lambda} \text { or } P_{c}=\frac{P_{t}}{S_{e}^{1 / \lambda}}
$$

where:

$$
S_{e}=\frac{S-S_{r}}{S_{c}-S_{r}}
$$

and

$$
\begin{aligned}
S_{e} & =\text { effective saturation, } \\
S & =\text { saturation, }
\end{aligned}
$$


$S_{r}=$ residual saturation,

$S_{c}=$ critical saturation,

$P_{t}=$ threshold displacement pressure,

$P_{c}=$ capillary pressure, and

$\lambda=$ pore-size distribution index.

Brooks and Corey (1964) assumed a value of unity for the critical saturation. Equation 3-1 applies only to the region where the effective saturation is less than the critical saturation and greater than the residual saturation.

Substituting Equation 3-1 into the Burdine (1953) approximations for the wetting phase relative permeability, $k_{r w}$, and the non-wetting phase relative permeability, $k_{r n w}$, Brooks and Corey (1964) obtained:

$$
k_{r w}=S_{e}^{(2+3 \lambda) \lambda}
$$

and

$$
k_{\text {rnw }}=\left(1-S_{e}\right)^{2}\left(1-S_{e}^{[2+\lambda] / \lambda}\right)
$$

Webb (1992) defined what he referred to as a mixed Brooks and Corey model, which assumes the critical saturation in Equation 3-2 is unity for development of the capillary pressure and wetting phase relative permeability curves using Equations 3-1 and 3-3, respectively, but not for development of the non-wetting phase relative permeability using Equation 3-4. The shaft seal properties recommended here assumed a unit critical saturation in all cases, thus eliminating a distinction between the mixed and original Brooks and Corey models.

Van Genuchten (1980) approximated the wetting phase relative permeability derived by Mualem (1976) by adopting the following relationship between effective saturation and capillary head:

$$
S_{e}=\left[1+(\alpha h)^{n}\right]^{m}
$$

where:

$$
\begin{aligned}
\alpha, n, \text { and } m & =\text { fitting, parameters, and } \\
h & =\text { capillary head. }
\end{aligned}
$$

Van Genuchten (1980) obtained a closed form solution to Mualem's approximation by restricting the values of $m$ and $n$ to:

$$
m=1-\frac{1}{n} \text { or } n=\frac{1}{1-m}
$$

With this restriction and a conversion from head to pressure, Equation 3-5 becomes:

$$
P_{c}=\frac{1}{\alpha}\left(S_{e}^{-1 / m}-1\right)^{1-m}
$$


Substituting Equation 3-7 into Mualem's approximation for wetting phase relative permeability, van Genuchten (1980) obtained:

$$
k_{n}=S_{e}^{1 / 2}\left[1-\left(1-S_{e}^{1 / m}\right)^{m}\right]^{2}
$$

Van Genuchten (1980) did not develop a relationship for the relative permeability of the non-wetting phase. However, Parker et al. (1987) extended Mualem's model and obtained the following relationship for the non-wetting phase relative permeability:

$$
k_{r m w}=\left(1-S_{e}\right)^{1 / 2}\left(1-S_{e}^{1 / m}\right)^{2 m}
$$

The combination of the van Genuchten (1980) expressions for capillary pressure (Equation 3-7) and wetting phase relative permeability (Equation 3-8), and the Parker et al. (1987) expression for the non-wetting phase relative permeability (Equation 3-9), is referred to by Webb (1992) as the van Genuchten/Parker model.

Assuming unit critical saturation for both phases, the Brooks and Corey model requires values for the threshold pressure, the wetting and non-wetting phase residual saturations, and the pore-size distribution index or $\lambda$. Similarly, the van Genuchten/Parker model requires values for the fitting parameters $m$ and $\alpha$, the residual wetting phase saturation, and the residual non-wetting phase saturation. To define one set of parameters which is consistent for both models, relationships between the parameters required by the two models were needed. The relative permeability expressions for the Brooks and Corey model and the van Genuchten/Parker model can be related through the parameters $\lambda$ and $m$ by (Webb, 1992):

$$
m \approx \frac{\lambda}{\lambda+1}
$$

WIPP PA (1992-1993) relates the threshold pressure parameters, $\alpha$ and $P_{t}$, for the two models by equating Equations 3-1 and 3-7 at an effective saturation of 0.5.

The following subsection discusses the parameters recommended for the Brooks and Corey model. In summary, these parameters are threshold pressure, residual wetting and nonwetting phase saturations, and pore-size distribution index or $\lambda$. For the shaft seals, the wetting phase is brine, and the non-wetting phase is gas. It was assumed that by employing suitable transformations like those proposed by WIPP PA, 1992-1993, the parameters required by the van Genuchten/Parker model could be determined using the recommended parameter values.

The Brooks and Corey model for capillary pressure (Equation 3-1) was not recommended for use for the asphalt seal material. Asphalt is a hydrophobic material. Using the threshold pressure, residual saturations, and $\lambda$ values described below, and the low initial brine saturation, the asphalt seal would maintain large suction pressures attracting water. Because this behavior was not considered consistent with a hydrophobic material, a linear capillary model was proposed for asphalt. Here, the capillary pressure varied from 0.0 to $0.1 \mathrm{MPa}$ over brine saturations ranging from zero to one with algebraic sign adjusted to represent a hydrophobic 
material. For PA calculations, which allow only hydrophilic materials, a zero capillary pressure was used. The treatment of the asphalt relative permeabilities was the same as for the other shaft seal materials.

\subsection{Parameter Estimates}

A literature search was conducted to develop estimates for the four parameters that describe the two-phase flow characteristic curves for the shaft seal materials. The following subsections describe the literature review, the recommended value, the range, and the type of distribution for threshold pressure, residual saturations, and pore-size distribution index.

\subsubsection{Threshold Pressure}

\subsubsection{PARAMETER SOURCES}

In his literature search, Davies (1991) found two approaches for estimating threshold pressure for geologic materials. The first approach employs a capillary tube model, which states:

$$
P_{t}=\sigma\left(\frac{T \phi}{k_{o} k}\right)^{1 / 2}
$$

where:

$$
\begin{aligned}
\sigma & =\text { surface tension, } \\
\phi & =\text { porosity } \\
k_{o} & =\text { pore shape factor, } \\
T & =\text { tortuosity, and } \\
k & =\text { intrinsic permeability. }
\end{aligned}
$$

The second approach uses correlations between threshold pressure and intrinsic permeability. These correlations have been reported for unconsolidated material in the soils literature and for consolidated rock in the petroleum literature. Development of these correlations was based on fitting observed data with a power curve having the form:

$$
y=a x^{b}
$$

For consolidated material, literature values for the coefficient range from $3 \times 10^{-7}$ to $9 \times 10^{-7}$, and literature values for the exponent range from -0.34 to -0.37 (Davies, 1991). The literature correlations separately considered carbonate, anhydrite, shale, and sandstone materials. Davies (1991) constructed a best-fit power curve to the combined data for all lithologies to obtain:

$$
P_{t}=5.6 \times 10^{-7} k^{-0.346}
$$


where $P_{t}$ is the threshold pressure in MPa and $k$ is the intrinsic permeability in $\mathrm{m}^{2}$. For intrinsic permeabilities less than $10^{-17} \mathrm{~m}^{2}$, Davies (1991) found the threshold pressures estimated using the capillary tube model to be less accurate than those estimated using the intrinsic permeability correlations.

Pihlajavaara (1991) conducted gas permeability tests on normal concretes under wet conditions. Based on the results of 23 tests, he developed the relationship between threshold pressure and permeability shown in Figure 3-1. His results covered a threshold pressure range of about 0.3 to $10 \mathrm{MPa}$ and a permeability range of about $10^{-21}$ to $10^{-18} \mathrm{~m}^{2}$. Figure $3-1$ shows threshold pressure increasing as concrete permeability decreases. The results of Pihlajavaara (1991) were compared to the threshold pressure-permeability correlation given in Equation 3-13. Using Equation 3-13, the calculated threshold pressures for permeabilities of $10^{-21}, 10^{-20}, 10^{-19}$, and $10^{-18} \mathrm{~m}^{2}$ are $10.3,4.7,2.1$, and $0.9 \mathrm{MPa}$, respectively. These calculated values fall within the experimental data from Pihlajavaara (1991) for permeabilities between $10^{-20}$ and $10^{-18} \mathrm{~m}^{2}$. For a permeability of $10^{-21}$, the calculated threshold pressure value falls above the shaded area in Figure 3-1. It appears, however, that the experimental threshold pressure data of Pihlajavaara (1991) are limited for this range of permeability and that the threshold pressure estimated using Equation 3-13 is consistent with the trend of the shaded area in Figure 3-1. This suggests that the correlation between threshold pressure and permeability given in Equation 3-13 is appropriate to use for the concrete seal materials as well as for seal components based on geologic materials.

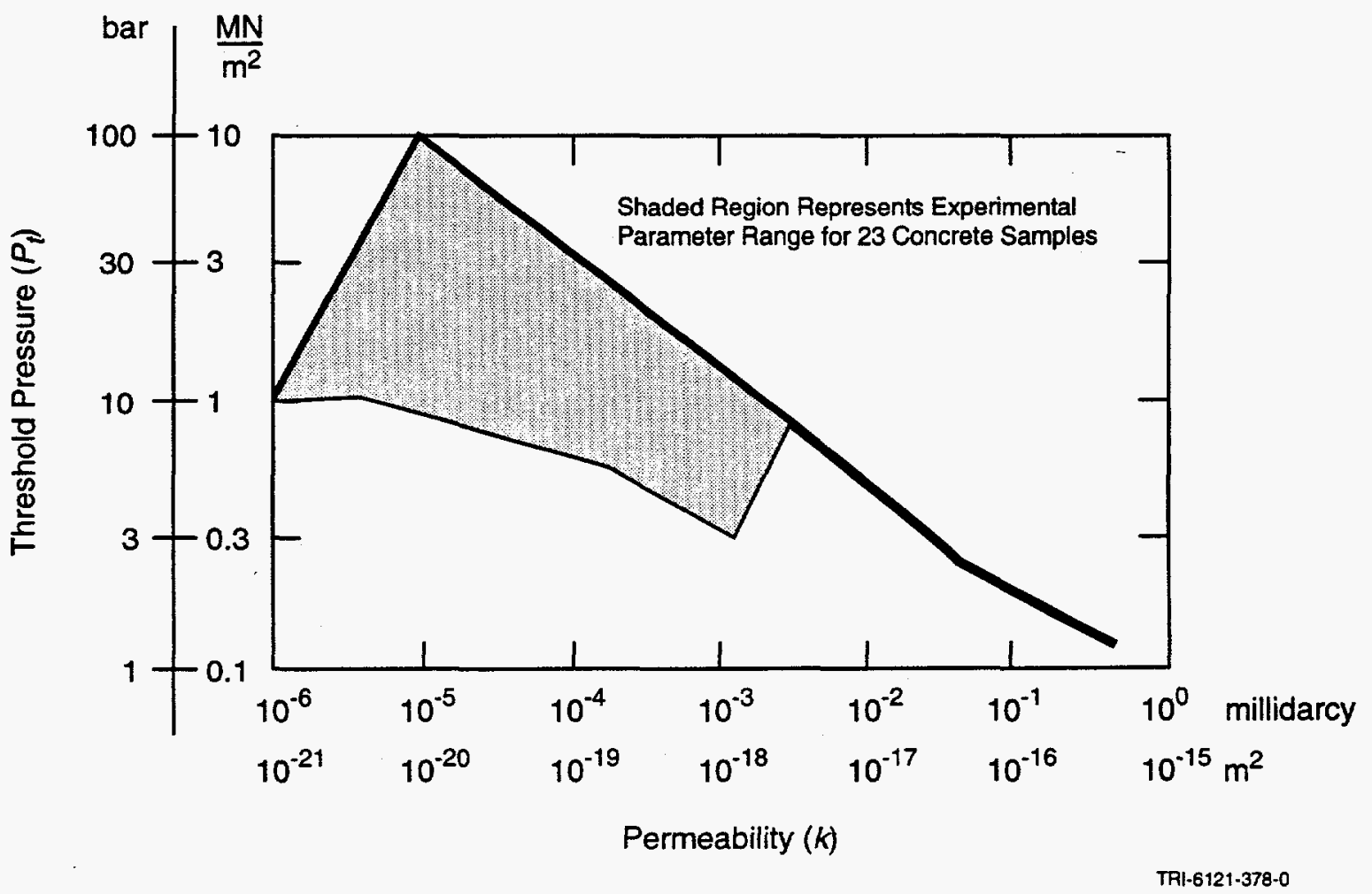

Figure 3-1. Threshold displacement pressure curve (after Pihlajavaara, 1991). 


\subsubsection{PARAMETER VALUE}

Based on Davies (1991), the correlation between the threshold pressure and the intrinsic permeability given in Equation 3-13 was recommended for determination of the threshold pressure for all shaft seal materials, with the exception of asphalt as discussed in Section 3.1, in performance assessment calculations. The distribution for the threshold pressure was therefore controlled by the distribution of the intrinsic permeability for each seal material.

\subsubsection{Residual Saturation}

\subsubsection{PARAMETER SOURCES}

A literature search was conducted to obtain residual saturation values for consolidated geologic materials, concrete, and asphalt. Residual liquid saturations for geologic materials were found in four references (Brooks and Corey, 1964; Lappala et al., 1987; Parker et al., 1987; and Rawls et al., 1982). Brooks and Corey (1964) determined residual saturations for five unconsolidated samples based on measured values of liquid saturation as a function of capillary pressure. Lappala et al. (1987) determined residual moisture content for 11 soils by obtaining best fits to measured moisture content versus pressure head data using three models. The residual moisture contents determined for each soil using the three models as reported by Lappala et al. (1987) were averaged and divided by the reported porosity to obtain a residual liquid saturation for each soil. Parker et al. (1987) fit their saturation-pressure relationship to observed data to obtain residual saturations for a sandy and clayey porous medium. Residual water contents reported by Rawls et al. (1982) for 11 soil texture classes were divided by the reported porosity to obtain residual saturations. The literature residual saturation values for geologic materials are summarized in Table 3-1 and graphed in Figure 3-2. Residual gas saturations for geologic materials were not found during the literature search.

Residual liquid and gas saturations for normal concrete were found in Mayer et al. (1992). They report a residual liquid saturation of 0.30 and a residual gas saturation of 0.18 . The residual liquid saturation was estimated by Mayer et al. (1992), and the residual gas saturation was determined based on gas permeability testing. Data regarding residual liquid and gas saturations in asphalt materials were not found in the literature.

\subsubsection{PARAMETER VALUE}

The literature values of residual liquid saturation for geologic materials and concrete fall within the range of 0.0 to 0.6 with all but two values falling within the range of 0.0 to 0.4 (see Table 3-1 and Figure 3-2). Figure 3-2 shows a relatively uniform distribution of values between 0.0 and 0.4 . For the purpose of compliance calculations, it was recommended that an expected value of 0.2 be used for the residual liquid saturation of all seal components. The recommended range was 0.0 to 0.6 with a uniform distribution. 
Table 3-1. Literature Values of Residual Liquid Saturations for Geologic Material and Concrete

\begin{tabular}{|c|c|c|}
\hline Material & Residual Liquid Saturation & Reference \\
\hline $\begin{array}{l}\text { Consolidated Rock } \\
\text { Berea Sandstone } \\
\text { Hygiene Sandstone }^{(\mathrm{b})} \\
\text { Hygiene Sandstone } \\
\end{array}$ & $\begin{array}{l}0.299 \\
0.577 \\
0.572 \\
\end{array}$ & $\begin{array}{l}\text { Brooks and Corey (1964) } \\
\text { Brooks and Corey (1964) } \\
\text { Lappala et al. (1987) }\end{array}$ \\
\hline $\begin{array}{l}\text { Sand } \\
\text { Sand } \\
\text { Sand (texture class) } \\
\text { Fine Sand G.E. 13 } \\
\text { Fine Sand G.E. } 13 \\
\text { Volcanic Sand } \\
\text { Del Monte Sand } \\
\text { Fresno Medium Sand } \\
\text { Sandy Porous Media } \\
\text { Unconsolidated Sand } \\
\text { Fragment Fox Hill SS } \\
\end{array}$ & $\begin{array}{l}0.110 \\
0.046 \\
0.186 \\
0.167 \\
0.157 \\
0.081 \\
0.085 \\
0.000 \\
0.146 \\
0.300\end{array}$ & $\begin{array}{l}\text { Lappala et al. (1987) } \\
\text { Rawls et al. (1982) } \\
\text { Lappala et al. (1987) } \\
\text { Brooks and Corey (1964) } \\
\text { Brooks and Corey (1964) } \\
\text { Lappala et al. (1987) } \\
\text { Lappala et al. (1987) } \\
\text { Parker et al. (1987) } \\
\text { Lappala et al. (1987) } \\
\text { Brooks and Corey (1964) }\end{array}$ \\
\hline $\begin{array}{l}\text { Loamy Sand } \\
\text { Loamy Sand (texture class) }\end{array}$ & 0.080 & Rawls et al. (1982) \\
\hline $\begin{array}{l}\text { Sandy Loam } \\
\text { Columbia Sandy Loam } \\
\text { Sandy Loam (texture class) }\end{array}$ & $\begin{array}{l}0.282 \\
0.091\end{array}$ & $\begin{array}{l}\text { Lappala et al. (1987) } \\
\text { Rawls et al. (1982) }\end{array}$ \\
\hline $\begin{array}{l}\text { Loam } \\
\text { Adelanto Loam } \\
\text { Loam (texture class) }\end{array}$ & $\begin{array}{l}0.374 \\
0.058\end{array}$ & $\begin{array}{l}\text { Lappala et al. (1987) } \\
\text { Rawls et al. (1982) }\end{array}$ \\
\hline $\begin{array}{l}\text { Silt } \\
\quad \text { Limon Silt }\end{array}$ & 0.009 & Lappala et al. (1987) \\
\hline $\begin{array}{l}\text { Silt Loam } \\
\text { Touchet Silt Loam } \\
\text { Touchet Silt Loam (GE 3) } \\
\text { Silt Loam (texture class) }\end{array}$ & $\begin{array}{l}0.337 \\
0.270 \\
0.030\end{array}$ & $\begin{array}{l}\text { Lappala et al (1987) } \\
\text { Brooks and Corey (1964) } \\
\text { Rawls et al. (1982) }\end{array}$ \\
\hline $\begin{array}{l}\text { Sandy Clay Loam } \\
\text { Sandy Clay Loam (texture class) }\end{array}$ & 0.171 & Rawls et al. (1982) \\
\hline $\begin{array}{l}\text { Clay Loam } \\
\text { Clay Loam (texture class) }\end{array}$ & 0.162 & Rawls et al. (1982) \\
\hline $\begin{array}{l}\text { Silty Clay Loam } \\
\text { Silty Clay Loam (texture class) }\end{array}$ & 0.085 & Rawls et al. (1982) \\
\hline $\begin{array}{l}\text { Sandy Clay } \\
\text { Sandy Clay (texture class) }\end{array}$ & 0.253 & Rawls et al. (1982) \\
\hline $\begin{array}{l}\text { Silty Clay } \\
\text { Silty Clay (texture class) }\end{array}$ & 0.117 & Rawls et al. (1982) \\
\hline
\end{tabular}


Table 3-1. Literature Values of Residual Liquid Saturations for Geologic Material and Concrete

Material Residual Liquid Saturation Reference

\begin{tabular}{lll}
\hline Clay & & \\
Yolo Light Clay & 0.299 & Lappala et al. (1987) \\
Clayey Porous Media & 0.360 & Parker et al. (1987) \\
Clay (texture class) & 0.189 & Rawls et al. (1982) \\
\hline $\begin{array}{l}\text { Fragmented Mixture } \\
\quad \text { Fragmented Mixture }\end{array}$ & 0.276 & \\
\hline Concrete & & Brooks and Corey (1964) \\
$\quad$ Normal Concrete & $0.300^{(\mathrm{c})}$ & Mayer et al. (1992) \\
\hline
\end{tabular}

(a) Core perpendicular to bedding planes.

(b) Core contained no visible bedding planes.

(c) Estimated.

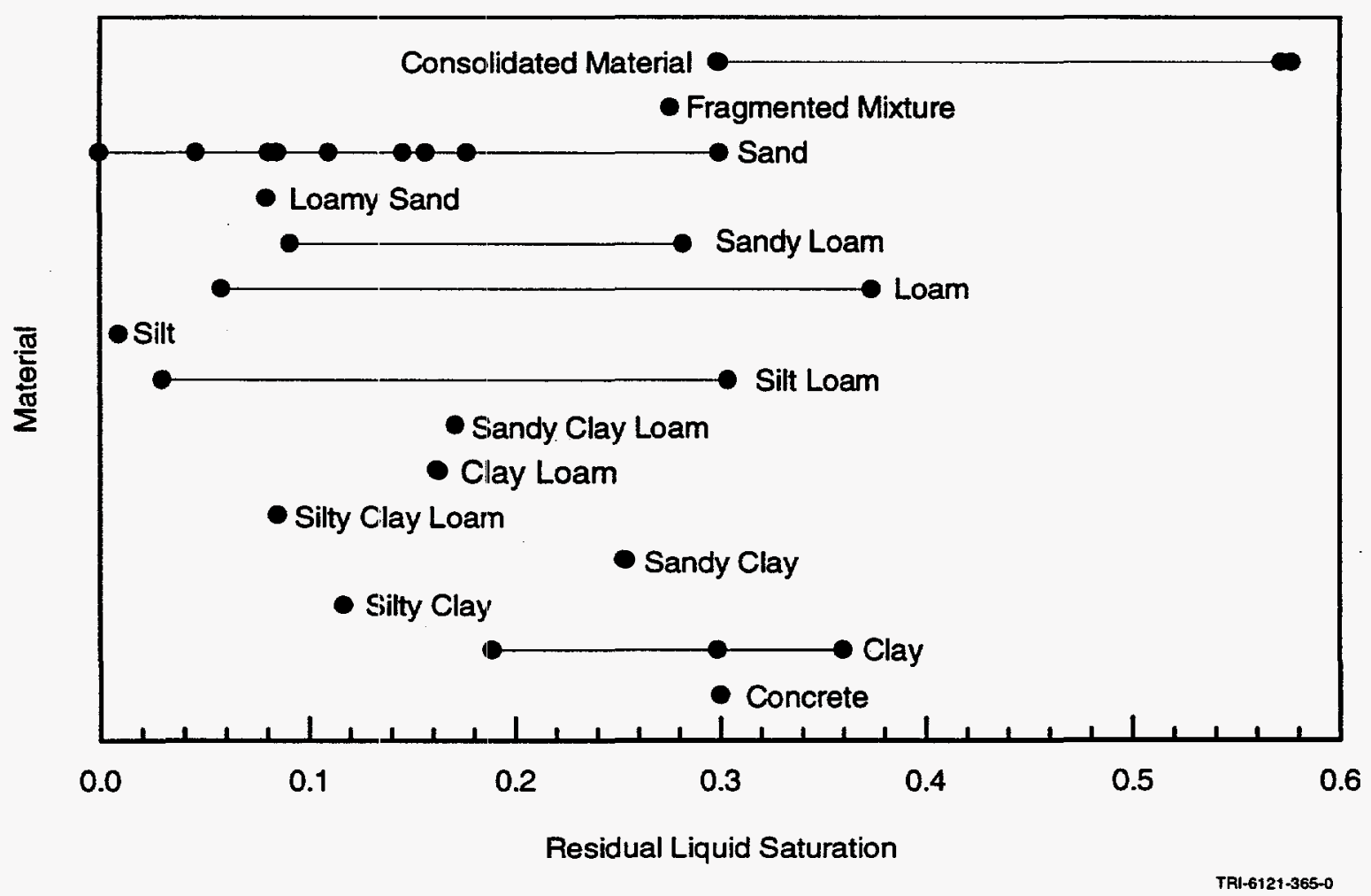

Figure 3-2. Residual liquid saturation distribution by geologic material. 
Literature values for residual gas saturation of geologic materials were not found. A single value of 0.18 was found for normal concrete. Because of the lack of data, value and range were assumed for the seal components. The recommended expected value was 0.2 , and the recommended range was 0.0 to 0.4 with a uniform distribution for all shaft seal materials.

\subsubsection{Pore-Size Distribution Index}

\subsubsection{PARAMETER SOURCES}

A literature search was conducted to find lambda (pore-size distribution, $\lambda$ ) values for geologic materials (Table 3-2) and concrete. For geologic materials, $81 \lambda$ values were found in five references (Brooks and Corey, 1964; Mualem, 1976; Rawls et al., 1982; Haverkamp and Parlange, 1986; and Lappala et al., 1987). In addition, $38 \lambda$ values were calculated from values of the van Genuchten parameter $n$ (see Equation 3-5) found in six references (van Genuchten, 1980; van Genuchten and Nielsen, 1985; Hopmans and Overmars, 1986; Parker et al., 1987; Stephens et al., 1988; and Wosten and van Genuchten, 1988). Values for $\lambda$ were calculated from $n$ values using the relationship (Webb, 1992):

$$
\lambda=m n
$$

Substituting the restricted form of $m$ as given in Equation 3-6 into Equation 3-14 yields:

$$
\lambda=n-1
$$

The total number of $\lambda$ values found in the literature or calculated from $n$ values found in the literature was 119. In a few cases, different literature sources reported different values of $\lambda$ and/or $n$ for the same materials. The different lambda values were arithmetically averaged to obtain a single value for the material. This procedure yielded $\lambda$ values for a total of 85 different geologic materials.

Brooks and Corey (1964) reported $\lambda$ values for five unconsolidated samples and two consolidated samples determined by fitting to observed capillary pressure curves. Values for 42 soils determined by fitting to observed drainage data are presented in Mualem (1976). Rawls et al. (1982) gave $\lambda$ values for the 11 USDA soil texture classes. They fit the measured water retention-matrix potential data reported in 26 sources and averaged within texture classes. Haverkamp and Parlange (1986) reported $\lambda$ values for ten sandy soils. They estimated the value using the cumulative particle-size distribution function. Values determined by fitting to experimental data for 11 soils were given in Lappala et al. (1987).

Van Genuchten (1980) reported $n$ values for five soils. These values were determined by fitting his model to measured conductivity curves. Values of $n$ for four soils determined by fitting to observed data were given in van Genuchten and Nielsen (1985). Hopmans and Overmars (1986) determined $n$ values for a Norfolk sandy loam at two soil temperatures by fitting to experimental data. Parker et al. (1987) reported $n$ values for a sandy porous medium 
Table 3-2. Literature Values of $\lambda$ for Geologic Materials

\begin{tabular}{|c|c|c|}
\hline Material & $\lambda$ & Reference \\
\hline \multicolumn{3}{|l|}{ Consolidated Rock } \\
\hline Berea Sandstone $e^{(a)}$ & 3.69 & Brooks and Corey (1964) \\
\hline Berea Sandstone & 2.13 & Mualem (1976) \\
\hline average & 2.91 & \\
\hline Hygiene Sandstone $\mathrm{b}^{(\mathrm{b})}$ & 4.17 & Brooks and Corey (1964) \\
\hline Hygiene Sandstone & 3.78 & Mualem (1976) \\
\hline Hygiene Sandstone & 9.4 & van Genuchten (1980) \\
\hline Hygiene Sandstone & 2.9 & Lappala et al. (1987) \\
\hline average & 6.75 & \\
\hline Tottori Sand & 2.157 & Haverkamp and Parlange (1986) \\
\hline Preston Sand & 1.653 & Haverkamp and Parlange (1986) \\
\hline Gormley Sand & 1.861 & Haverkamp and Parlange (1986) \\
\hline Botton Sand & 1.723 & Haverkamp and Parlange (1986) \\
\hline \multicolumn{3}{|l|}{ Netherlands Coarse- } \\
\hline \multicolumn{3}{|l|}{ Textured } \\
\hline topsoils $^{(\mathrm{c})}$ & 0.59 & Wosten and van Genuchten (1988) \\
\hline subsoils $^{(c)}$ & 1.01 & Wosten and van Genuchten (1988) \\
\hline \multirow{2}{*}{\multicolumn{3}{|c|}{$\begin{array}{l}\text { Netherlands Medium- } \\
\text { Textured }\end{array}$}} \\
\hline & & \\
\hline topsoils & 0.22 & Wosten and van Genuchten (1988) \\
\hline subsoils $^{(d)}$ & 0.27 & Wosten and van Genuchten (1988) \\
\hline \multicolumn{3}{|l|}{ Netherlands Fine-Textured } \\
\hline topsoils & 0.11 & Wosten and van Genuchten (1988) \\
\hline subsoils $^{(\mathrm{d})}$ & 0.12 & Wosten and van Genuchten (1988) \\
\hline \multicolumn{3}{|l|}{ Lacustrine Sediments } \\
\hline $\begin{array}{l}\text { thinly laminated clay to } \\
\text { silty clay }\end{array}$ & 0.65 & Stephens et al. (1988) \\
\hline massive clay to silty clay & 0.66 & Stephens et al. (1988) \\
\hline thin bedded silt & 0.8 & Stephens et al. (1988) \\
\hline thin bedded clay & 0.9 & Stephens et al. (1988) \\
\hline $\begin{array}{l}\text { thin bedded silts, clay and } \\
\text { clayey silt }\end{array}$ & 0.85 & Stephens et al. (1988) \\
\hline \multicolumn{3}{|l|}{ Sand } \\
\hline Sand & 1.83 & Mualem (1976) \\
\hline Sand & 2.87 & Mualem (1976) \\
\hline Sand & 0.84 & Lappala et al. (1987) \\
\hline average & 1.85 & \\
\hline Sand (texture class) & 0.694 & Rawls et al. (1982) \\
\hline Beit Dagan Sand & 0.37 & Mualem (1976) \\
\hline
\end{tabular}


Table 3-2. Literature Values of $\lambda$ for Geologic Materials

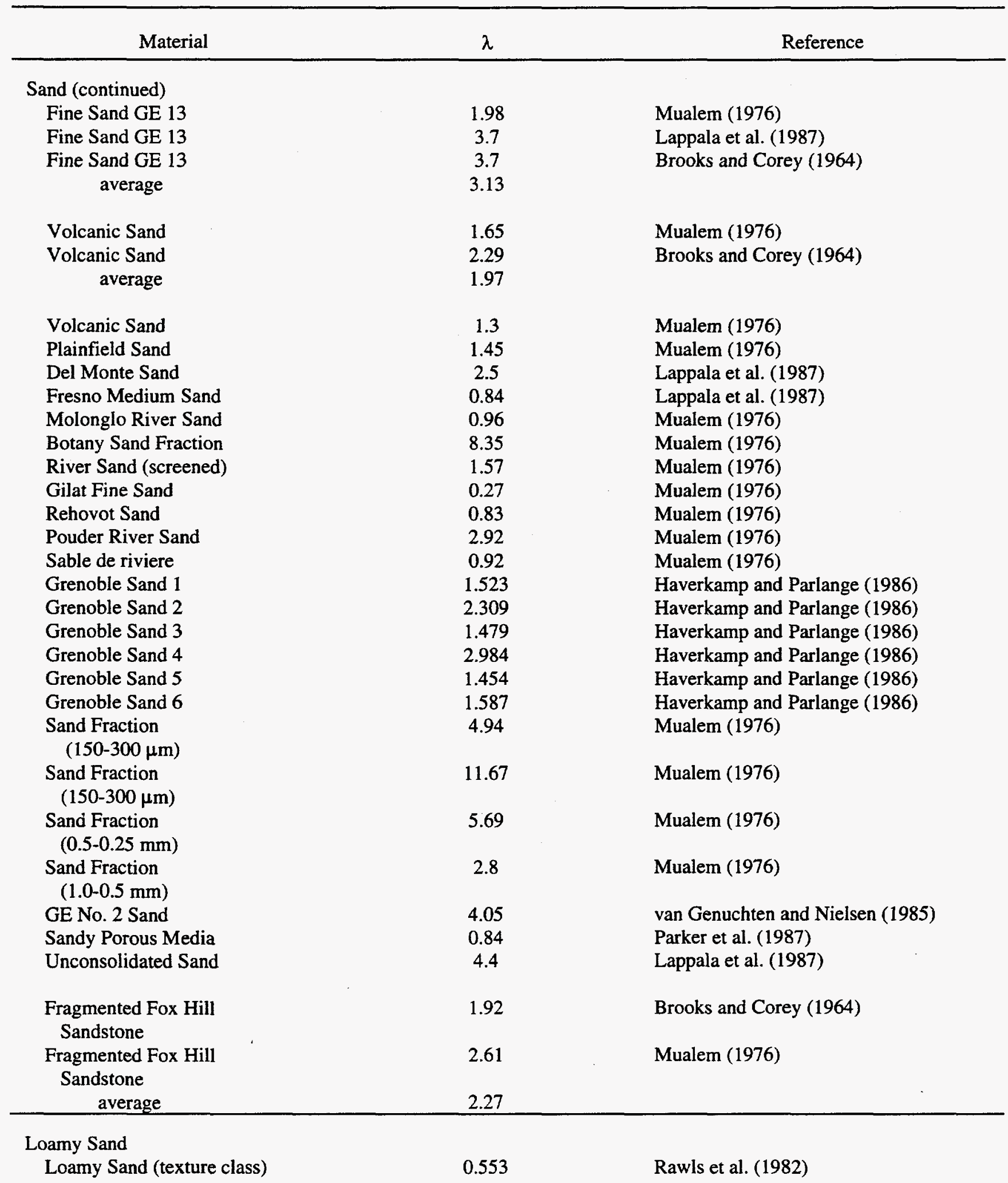


Table 3-2. Literature Values of $\lambda$ for Geologic Materials

\begin{tabular}{|c|c|c|}
\hline Material & $\lambda$ & Reference \\
\hline \multicolumn{3}{|l|}{ Sandy Loam } \\
\hline Columbia Sandy Loam & 1.6 & Lappala et al. (1987) \\
\hline Rubicon Sandy Loam & 2.08 & Mualem (1976) \\
\hline Gilat Sandy Loam & 0.44 & Mualem (1976) \\
\hline Norfolk Sandy Loam $20^{\circ} \mathrm{C}$ & 1.403 & Hopmans and Overmars (1986) \\
\hline Norfolk Sandy Loam $44.5^{\circ} \mathrm{C}$ & 1.339 & Hopmans and Overmars (1986) \\
\hline average & 1.371 & \\
\hline Sandy Loam (texture class) & 0.378 & Rawls et al. (1982) \\
\hline \multicolumn{3}{|l|}{ Loam } \\
\hline Guelph Loam & 0.41 & Mualem (1976) \\
\hline Guelph Loam & 1.03 & van Genuchten (1980) \\
\hline average & 0.72 & \\
\hline Sarpy Loam & 0.6 & van Genuchten and Nielsen (1985) \\
\hline Adelanto Loam & 0.5 & Mualem (1976) \\
\hline Adelanto Loam & 0.51 & Lappala et al. (1987) \\
\hline average & 0.51 & \\
\hline Pachappa Loam & 0.42 & Mualem (1976) \\
\hline Indio Loam & 0.81 & Mualem (1976) \\
\hline Loam (texture class) & 0.252 & Rawls et al. (1982) \\
\hline \multicolumn{3}{|l|}{ Silt } \\
\hline Silt Mont Cenis & 0.36 & Mualem (1976) \\
\hline Limon Silt & 0.22 & Lappala et al. (1987) \\
\hline \multicolumn{3}{|l|}{ Silt Loam } \\
\hline Touchet Silt Loam & 1.71 & Mualem (1976) \\
\hline Touchet Silt Loam & 2.59 & van Genuchten and Nielsen (1985) \\
\hline Touchet Silt Loam & 1.7 & Lappala et al. (1987) \\
\hline average & 2.00 & \\
\hline Touchet Silt Loam (GE 3) & 1.89 & Mualem (1976) \\
\hline Touchet Silt Loam (GE 3) & 1.82 & Brooks and Corey (1964) \\
\hline Touchet Silt Loam (GE 3) & 6.09 & van Genuchten (1980) \\
\hline average & 3.27 & \\
\hline Caribou Silt Loam & 0.91 & Mualem (1976) \\
\hline Grenville Silt Loam & 0.34 & Mualem (1976) \\
\hline Ida Silt Loam (>15 cm) & 0.38 & Mualem (1976) \\
\hline Ida Silt Loam (0-15 cm) & 0.27 & Mualem (1976) \\
\hline Silt Loam GE 3 & 1.06 & van Genuchten (1980) \\
\hline Silt Loam (texture class) & 0.234 & Rawls et al. (1982) \\
\hline
\end{tabular}


Table 3-2. Literature Values of $\lambda$ for Geologic Materials

\begin{tabular}{|c|c|c|}
\hline Material & $\lambda$ & Reference \\
\hline $\begin{array}{l}\text { Sandy Clay Loam } \\
\text { Sandy Clay Loam (texture } \\
\text { class) }\end{array}$ & 0.319 & Rawls et al. (1982) \\
\hline $\begin{array}{l}\text { Clay Loam } \\
\text { Rideau Clay Loam } \\
\text { Clay Loam (texture class) }\end{array}$ & $\begin{array}{c}1.62 \\
0.242 \\
\end{array}$ & $\begin{array}{l}\text { Mualem (1976) } \\
\text { Rawls et al. (1982) } \\
\end{array}$ \\
\hline $\begin{array}{l}\text { Silty Clay Loam } \\
\text { Weld Silty Clay Loam } \\
\text { Weld Silty Clay Loam } \\
\text { average }\end{array}$ & $\begin{array}{l}1.52 \\
4.45 \\
2.99\end{array}$ & $\begin{array}{l}\text { Mualem (1976) } \\
\text { van Genuchten and Nielsen (1985) }\end{array}$ \\
\hline $\begin{array}{l}\text { Amarillo Silty Clay Loam } \\
\text { Silty Clay Loam (texture } \\
\text { class) }\end{array}$ & $\begin{array}{l}2.35 \\
0.177\end{array}$ & $\begin{array}{l}\text { Mualem (1976) } \\
\text { Rawls et al. (1982) }\end{array}$ \\
\hline $\begin{array}{l}\text { Sandy Clay } \\
\text { Pachappa Fine Sandy Clay } \\
\text { Sandy Clay (texture class) }\end{array}$ & $\begin{array}{c}0.44 \\
0.223 \\
\end{array}$ & $\begin{array}{l}\text { Mualem (1976) } \\
\text { Rawls et al. (1982) } \\
\end{array}$ \\
\hline $\begin{array}{l}\text { Silty Clay } \\
\text { Shluhot Silty Clay } \\
\text { Silty Clay (texture class) } \\
\end{array}$ & $\begin{array}{c}0.2 \\
0.15 \\
\end{array}$ & $\begin{array}{l}\text { Mualem (1976) } \\
\text { Rawls et al. (1982) }\end{array}$ \\
\hline $\begin{array}{l}\text { Clay } \\
\text { Beit Netofa Clay } \\
\text { Beit Netofa Clay } \\
\text { average }\end{array}$ & $\begin{array}{l}0.19 \\
0.17 \\
0.18\end{array}$ & $\begin{array}{l}\text { Mualem (1976) } \\
\text { van Genuchten (1980) }\end{array}$ \\
\hline $\begin{array}{l}\text { Yolo Light Clay } \\
\text { Clayey Porous Media } \\
\text { Clay (texture class) } \\
\end{array}$ & $\begin{array}{c}0.25 \\
0.86 \\
0.165 \\
\end{array}$ & $\begin{array}{l}\text { Lappala et al. (1987) } \\
\text { Parker et al. (1987) } \\
\text { Rawls et al. (1982) } \\
\end{array}$ \\
\hline $\begin{array}{l}\text { Slate } \\
\text { Slate Dust } \\
\end{array}$ & 5.69 & Mualem (1976) \\
\hline $\begin{array}{c}\text { Fragmented Mixture } \\
\text { Fragmented Mixture } \\
\text { Fragmented Mixture } \\
\text { average }\end{array}$ & $\begin{array}{l}2.65 \\
2.89 \\
2.77\end{array}$ & $\begin{array}{l}\text { Mualem (1976) } \\
\text { Brooks and Corey (1964) }\end{array}$ \\
\hline
\end{tabular}

(a) Core perpendicular to bedding planes.

(b) Core contained no visible bedding planes.

(c) Average of four values reported in reference.

(d) Average of three values reported in reference. 
and a clayey porous mediurn which they determined by fitting to observed data. Stephens et al. (1988) determined five $n$ values for three stratigraphic units underlying the IT Corporation's Imperial Valley Facility located in southern California. The values were determined by fitting to the data obtained from in situ field testing. A single value was determined for two units, and three values were determined for a third stratified unit. The latter were for individual clay and silt layers and for the composite unit. Wosten and van Genuchten (1988) used observed hydraulic conductivity and water retention data from soils in the Netherlands to obtain $n$ values. They reported 20 average values for 105 coarse-textured samples, 43 medium-textured samples, and 49 fine-textured samples. Table 3-2 summarizes the literature values of $\lambda$ and their sources.

Figure 3-3 shows a histogram, and Figure 3-4 shows a cumulative distribution function for all values found in the literature. The distribution as a function of geologic material is shown in Figure 3-5.

For concrete, a literature search yielded only one reference (Mayer et al., 1992). This reference indicated that the Corey (1954) relationships were appropriate for describing the twophase characteristic curves for the normal concretes they tested. These relationships for the wetting and non-wetting phase relative permeabilities are:

$$
k_{n w}=S_{e}^{4}
$$

and

$$
k_{m w}=\left(1-S_{e}\right)^{2}\left(1-S_{e}^{2}\right)
$$

Mayer et al. (1992) replaced the effective saturation with a term they refer to as the normalized liquid saturation:

$$
S_{n l}=\frac{S-S_{r l}}{1-S_{r l}-S_{r g}}
$$

where:

$$
\begin{aligned}
S_{n l} & =\text { normalized liquid saturation, } \\
S & =\text { liquid saturation, } \\
S_{r l} & =\text { residual liquid saturation, and } \\
S_{r g} & =\text { residual gas saturation. }
\end{aligned}
$$

Comparison of Equations 3-16 and 3-17 to the Brooks and Corey model (Equations 3-3 and 3-4) shows that the use of a $\lambda$ value of two in the Brooks and Corey model reproduces the Corey equations. This indicates that the Brooks and Corey model with a $\lambda$ value of two fits the experimental concrete data in Mayer et al. (1992). Such a value falls within the range found for geologic materials. Data regarding $\lambda$ values for asphalt materials were not found in the literature. 


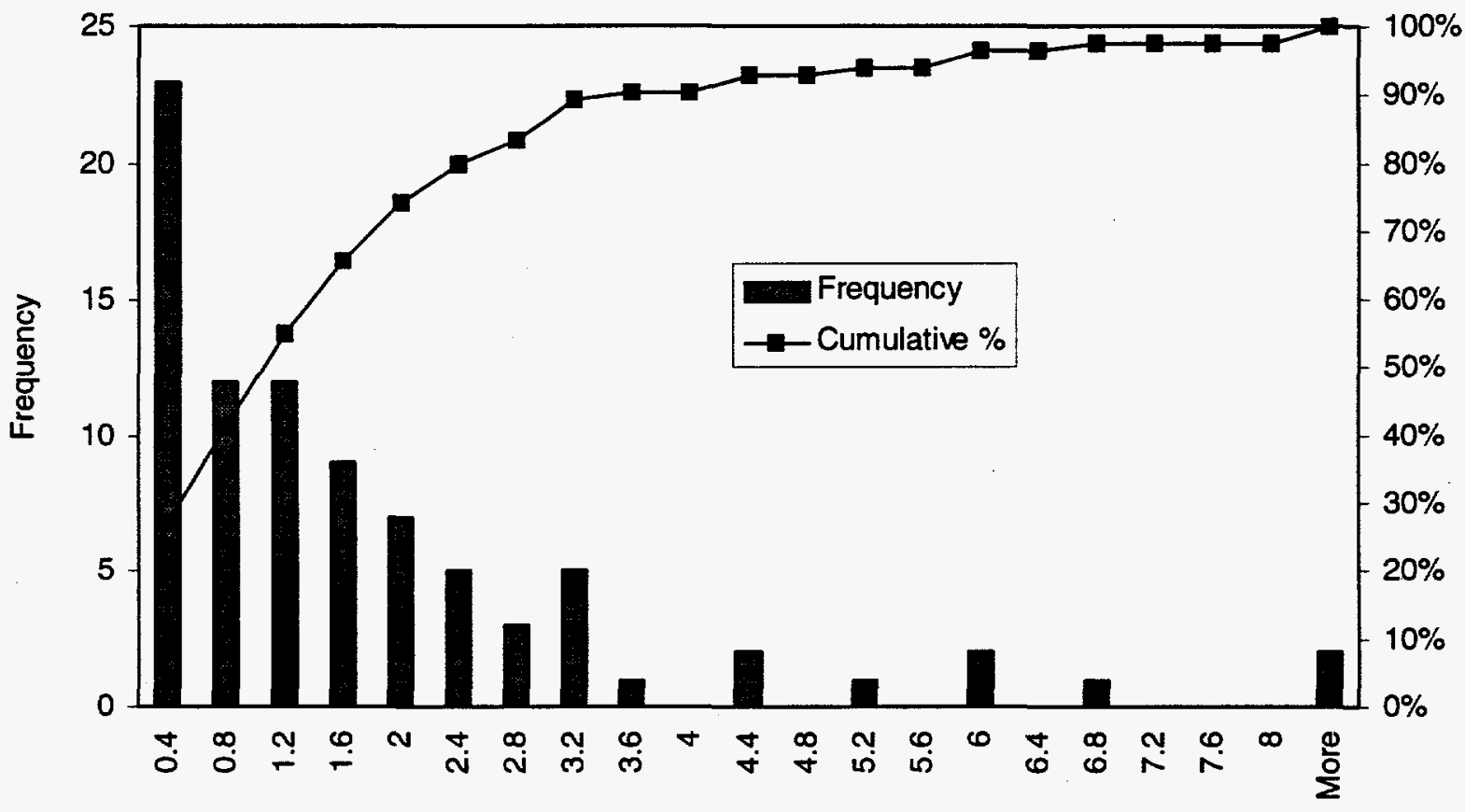

Bin

Figure 3-3. Frequency histogram and cumulative frequency histogram of $\lambda$ values found in the literature.

\subsubsection{PARAMETER VALUE}

The $\lambda$ values found in the literature range from 0.11 to 11.67 and have a median of 0.94 . Based on the shape of the histogram and cumulative distribution function, it appeared that the values are lognormally distributed. The Lilliefors test for normality (Iman and Conover, 1983) was applied to the data to verify that the logarithm of the values could be described by a normal distribution. Figure 3-6 shows the standardized $\log$ cumulative $\lambda$ data, the bounds yielded by the Lilliefors test, and the cumulative standard normal distribution. The standardized sample value as calculated by Iman and Conover (1983) is:

$$
Z=\frac{\ln X-\mu}{\sigma}
$$

where:

$$
\begin{aligned}
& Z=\text { standardized sample value } \\
& X=\text { raw sample value, } \\
& \mu=\text { sample mean, and } \\
& \sigma=\text { sample standard deviation. }
\end{aligned}
$$




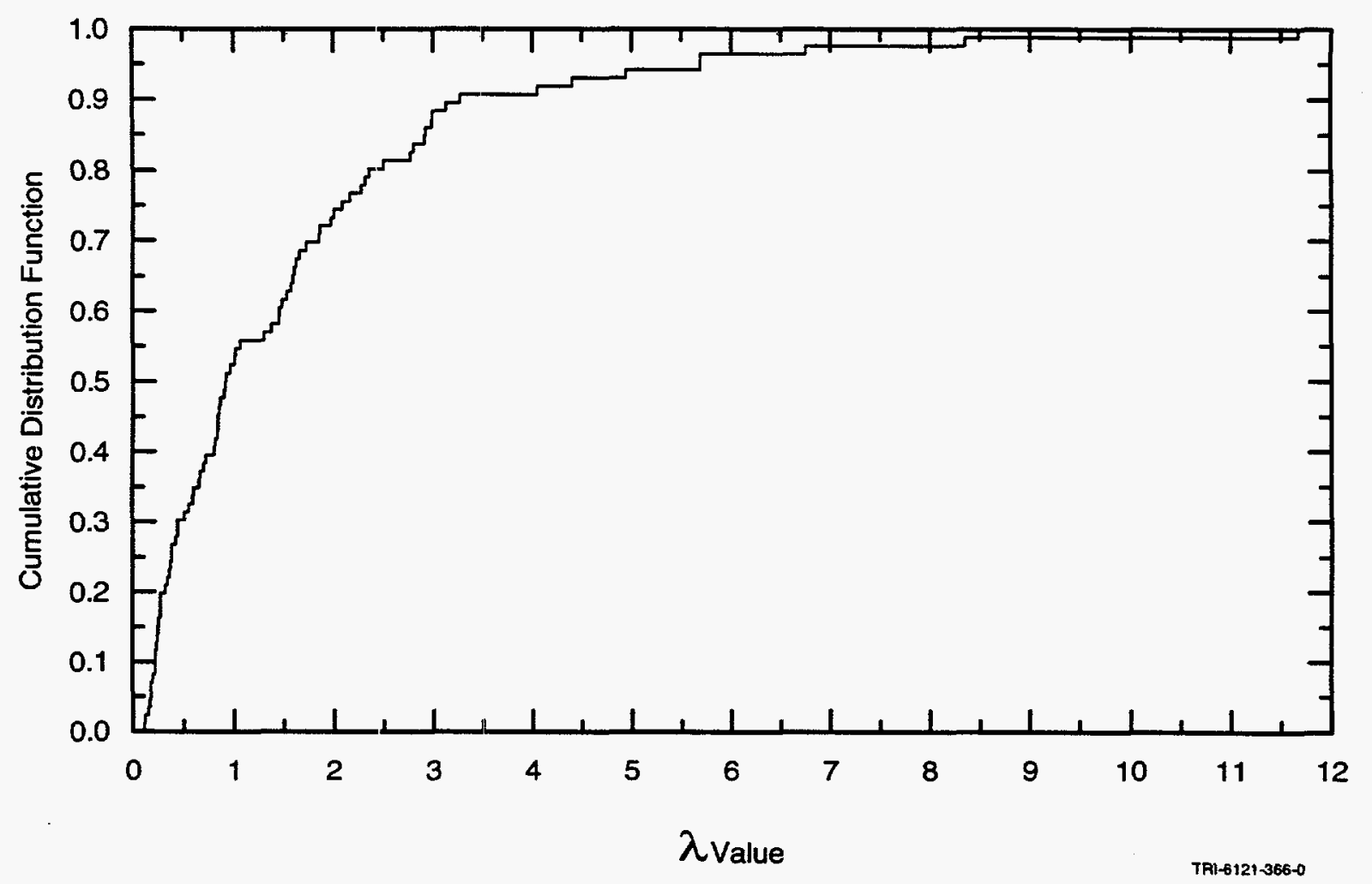

Figure 3-4. Cumulative distribution function for $\lambda$ values found in the literature.

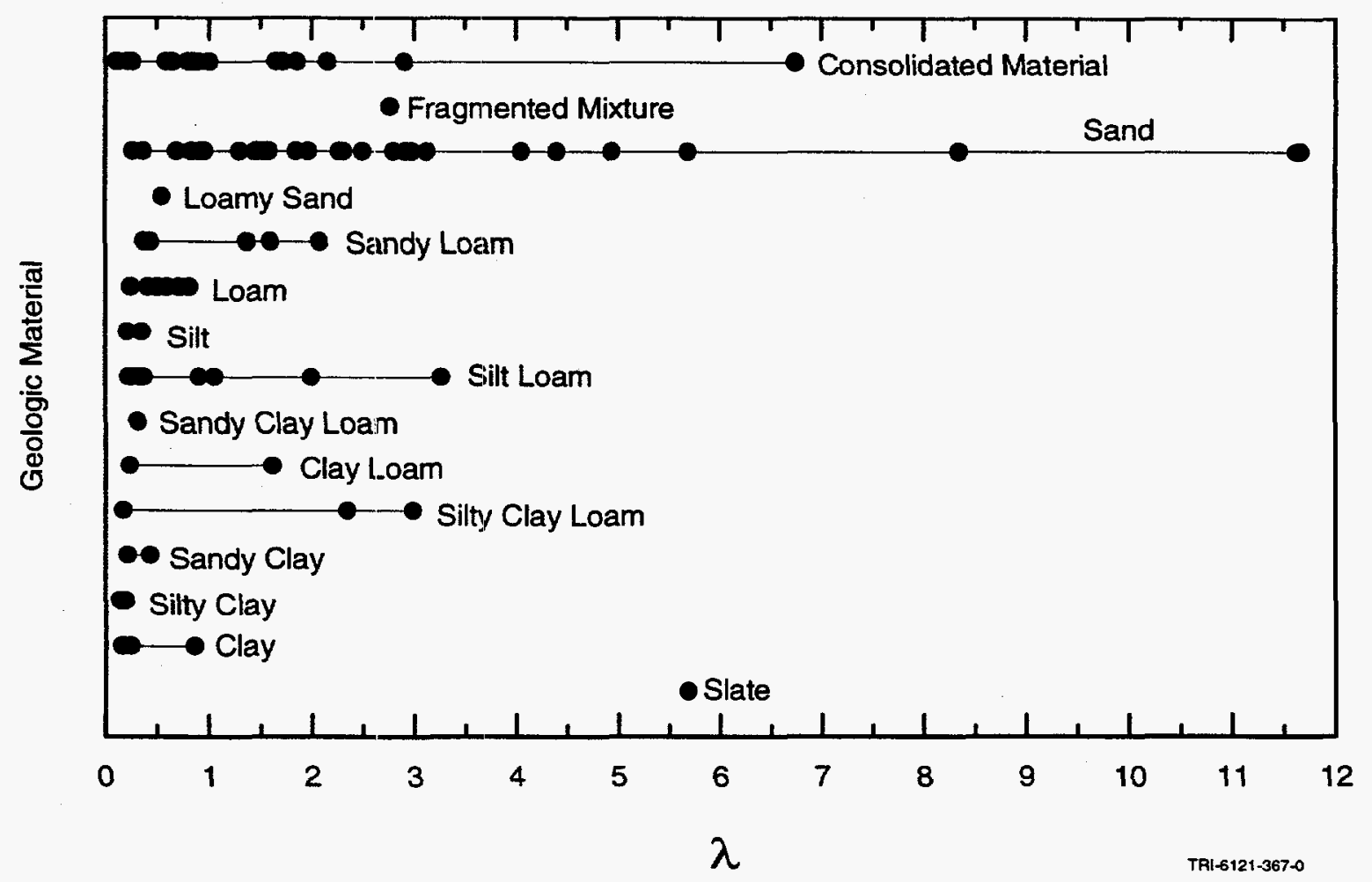

Figure 3-5. Lambda distribution by geologic material. 
The mean of the $\log \lambda$ values was found to be -0.064 with a standard deviation of 1.08 . The Lilliefors bounds represent the region within which $95 \%$ of normally distributed values will fall. Figure 3-6 shows that the $\log \lambda$ values found in the literature fall within the Lilliefors bounds and, therefore, can be treated as normally distributed.

For compliance calculations, it was recommended that a lognormal distribution be used to sample $\lambda$ values for the seal components constructed from granular earth materials (i.e., earthen fill, compacted clay, and reconsolidated crushed salt). The expected value recommended was 0.94 which is the median of the literature values for geologic materials (Table 3-2). The recommended range for the lognormal distribution was $\mathrm{e}^{(\mu-2 \sigma)}$ to $\mathrm{e}^{(\mu+2 \sigma)}$, or 0.11 to 8.1 . In the absence of literature data, the same distribution type, expected value, and range were also recommended for the concrete and asphalt seal components.

\subsection{Comparison of Recommended Two-Phase Flow Parameters to Previously Used Values}

Two-phase flow properties for the seal material have not previously been reported for performance calculations. However, it was considered useful to compare the values recommended in this document to those used for other WIPP performance analyses. The Salado Formation consists of low-permeability materials and was considered the closest analog to the low-permeability seal materials within the WIPP database. In addition, the two-phase parameters for the Salado halite and anhydrite layers have been evaluated more extensively than those for any other material simulated in the repository. Therefore, the recommended values for the seal materials are compared only to those used previously for the Salado units. Sensitivity studies conducted for the 1992 PA indicated that variation of two-phase parameters in the Salado halite did not significantly affect results of the calculations. Thus performance calculations for the CCA assigned constant values to the two-phase parameters in the Salado halite. Parameter values used in the 1992 Preliminary Performance Assessment (WIPP PA, 1992-1993) and for performance calculations conducted in support of the CCA (U.S. DOE, 1996) are compared to those recommended for the seal components in Table 3-3. The recommended values are consistent with those used in both of these publications. 


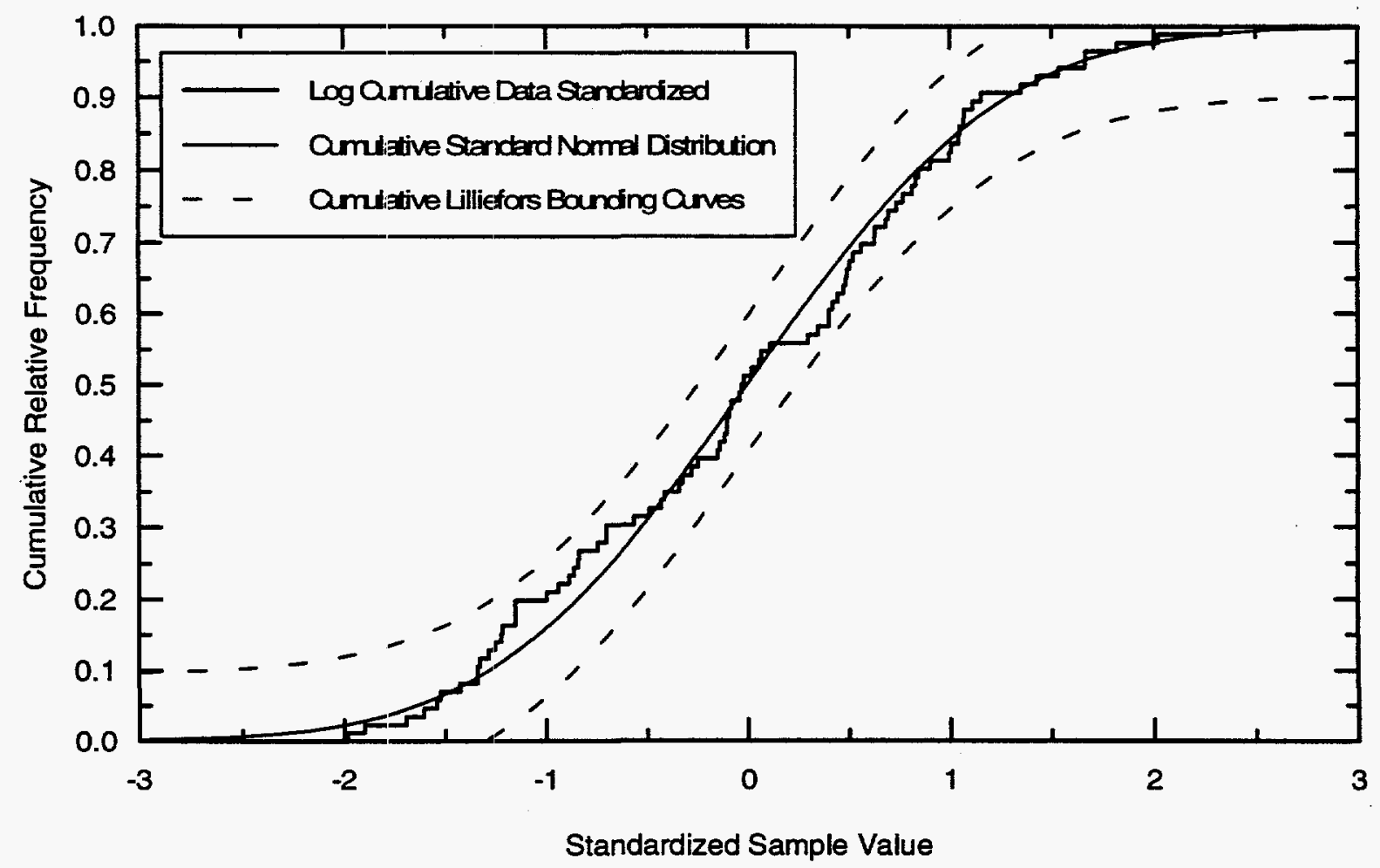

TRI-6121-368-0

Figure 3-6. Log cumulative $\lambda$ data standardized compared to the Lilliefors bounds and the cumulative standard normal distribution.

Table 3-3. Comparison of Parameter Values

\begin{tabular}{|c|c|c|c|}
\hline Parameter & $\begin{array}{l}1992 \text { Preliminary } \\
\text { Performance } \\
\text { Assessment }\end{array}$ & $\begin{array}{l}\text { Compliance } \\
\text { Certification } \\
\text { Application }\end{array}$ & $\begin{array}{l}\text { Recommended Values } \\
\text { for Seal Materials* }\end{array}$ \\
\hline $\begin{array}{l}\text { Threshold Pressure } \\
\text { (MPa) }\end{array}$ & $5.6 \times k^{-0.346}$ & $5.6 \times k^{-0.346}$ & $5.6 \times k^{-0.346}$ \\
\hline $\begin{array}{l}\text { Pore-size Distribution } \\
\text { Parameter }\end{array}$ & $0.2-10$ & 0.7 & $0.11-8.1$ \\
\hline Two-Phase Model & $\begin{array}{l}\text { 1/3 of calculations } \\
\text { used Brooks-Corey; } \\
2 / 3 \text { of calculations } \\
\text { used van Genuchten }\end{array}$ & Brooks-Corey & Brooks-Corey \\
\hline $\begin{array}{l}\text { Residual Brine } \\
\text { Saturation }\end{array}$ & $0.0-0.4$ & 0.3 & $0.0-0.6$ \\
\hline $\begin{array}{l}\text { Residual Gas } \\
\text { Saturation }\end{array}$ & $0.0-0.4$ & 0.2 & $0.0-0.4$ \\
\hline
\end{tabular}

* All seal materials except asphalt; a linear model was recommended for asphalt 


\subsection{DISTURBED ROCK ZONE}

The zone of disturbed salt around the excavation is termed the disturbed rock zone, or DRZ. The DRZ in the bedded halite of the Salado Formation forms immediately upon excavation and is thought to develop progressively as the salt formation creeps toward the opening (Stormont, 1990b). From a sealing perspective, the most important and controlling characteristic of the DRZ is its enhanced permeability which results from dilatant deformation and the resultant increased pore volume.

This section presents the methodology used to incorporate the Salado DRZ into the conceptual model for compliance calculations. The first subsection provides a description of the DRZ. The second subsection discusses the permeability and extent of the DRZ. The DRZ permeability characterization data, measured field and laboratory data, and model predictions are presented. These were used to provide insight into the magnitude and variation of the DRZ permeability as a function of radial distance from the shaft excavation. The third subsection describes the use of this information in development of a model for calculating an effective DRZ permeability. The model predicted an effective permeability that was applied over the radial extent of the DRZ. The method furnished for implementation of the effective DRZ permeability into the model is then described. The modeling of the WIPP shaft system did not explicitly incorporate the DRZ. Rather, the DRZ permeability was accounted for by combining it with the seal permeability. The calculations needed to combine seal and DRZ permeability and the methodology used to combine the four WIPP shafts into a single shaft for the PA model is explained.

\subsection{Description of the DRZ}

The Salado salt located immediately adjacent to the WIPP shafts is expected to be disturbed or damaged as a result of initial shaft excavation operations and time-dependent dilatant inelastic deformation that continues as long as the shaft remains open (Van Sambeek et al., 1993; Stormont, 1990a). Van Sambeek et al. (1993) referred to the disturbed zone which forms upon mining as the initial DRZ and the subsequent disturbed zone which forms as a result of creep deformation and stress redistribution as the secondary DRZ. Both the magnitude and extent of damage in the Salado DRZ are time-dependent because the micromechanical deformation mechanism governing the dilatant inelastic deformation of the salt is a timedependent micro-fracturing mechanism (Chan et al., 1992). This mechanism is operable only under a limited range of stress states, specifically high stress difference relative to low mean stress. At the shaft wall, the mean stress in the salt is low relative to the stress difference because the shaft serves as a stress concentrator, the magnitude of which depends on in situ stress conditions (e.g., stress produced by the overlying rock units or overburden). The stress difference in the salt relative to the mean stress significantly decreases with distance from the shaft as the stress-concentrating effect of the shaft is reduced. Therefore, damage in the salt is greatest at the shaft wall and decreases rapidly as distance from the shaft increases. Additionally, because the stress difference is a function of overburden pressure, the magnitude and extent of damage are also a function of depth. The Salado DRZ is expected to have the following 
characteristics: (1) increased volume resulting from micro- or macro-fracturing, (2) increased fluid (gas or liquid) permeability, (3) decreased brine saturation, (4) decreased load-bearing capacity, and (5) decreased pore pressure (Stormont, 1990a; Van Sambeek et al., 1993). Because of these properties, the DRZ could act as a vertical flow path for brine and gas around the shaft seal. Therefore, it is important to characterize the extent of the DRZ around the shaft excavations and its time-dependent properties (especially permeability).

When the shaft seals are emplaced, back pressures in the shaft sealing materials will develop with time as the surrounding salt creeps into the shaft. These back pressures both induce higher mean stress and reduce the magnitude of the stress difference in the DRZ which, ultimately, causes the micro-fracturing mechanism to become inactive. The higher mean stresses also induce healing of the DRZ as shown by Brodsky (1990). Healing is a time-dependent process; eventually, the permeability of the DRZ will return to that of intact salt. Because the creep rates of the salt surrounding the shaft depend on depth, back pressures in the shaft sealing materials develop more quickly at depth. Therefore, the rate of healing increases with depth.

\subsection{DRZ Permeability and Extent}

\subsubsection{Parameter Sources}

A significant number of laboratory and, to a lesser extent, field studies have been performed to characterize the DRZ and to determine the mechanics of DRZ development. DRZ development has been documented in almost all horizontal rectangular excavations of the WIPP underground facility by gas permeability testing (Stormont, 1990b; Knowles and Howard, 1996), visual observations (Borns and Stormont, 1988), and other methodologies (Holcomb, 1988; Pfeifer et al., 1989). Laboratory testing of salt cores has also provided significant insight into DRZ development. Hansen and Mellegard (1979) found that dilatancy is favored by conditions of low-confining stress and high deviatoric stress which characterize the region near an excavation. Laboratory testing has shown that a halite DRZ is self-healing given the proper stress conditions (Brodsky, 1990). Using laboratory samples with known amounts of induced volumetric strain, Brodsky (1990) showed that damaged cores could be healed with certain confining pressures and time.

\subsubsection{FIELD DATA}

A summary of field tests measuring permeability and extent of the DRZ is presented in Table 4-1. Measurements taken in the air intake shaft provide the only field information regarding the DRZ in a full-scale vertical shaft. 
Table 4-1. Summary of Field Test DRZ Data

\begin{tabular}{lccl}
\hline Test Borehole Configuration & $\begin{array}{c}\text { Permeability } \\
\left(\mathrm{m}^{2}\right)\end{array}$ & $\begin{array}{c}\text { Extent } \\
(\mathrm{r} / \overline{\mathrm{r}})\end{array}$ & \multicolumn{1}{c}{ Reference } \\
\hline $\begin{array}{l}\text { Drilled vertically into floor of } \\
\text { Room L }\end{array}$ & $10^{-13}-10^{-19}$ & $1.5-2^{(1)}$ & Stormont (1990b) \\
\hline $\begin{array}{l}\text { Drilled horizontally into the } \\
\text { wall of Room D }\end{array}$ & $10^{-12}-10^{-19}$ & $0.5-1.2^{(2)}$ & $\begin{array}{l}\text { Knowles and Howard } \\
(1996)\end{array}$ \\
\hline $\begin{array}{l}\text { Drilled vertically into floor of } \\
\text { Room M }\end{array}$ & $10^{-16}-10^{-21}$ & $0.6-1.2^{(1)}$ & Van Pelt (1995) \\
\hline $\begin{array}{l}\text { Drilled horizontally into AIS } \\
\text { wall }\end{array}$ & $10^{-13}-10^{-21}$ & $0.5-1^{(3)}$ & $\begin{array}{l}\text { Dale and Hurtado } \\
\text { (1996) }\end{array}$ \\
\hline
\end{tabular}

$\overline{\mathbf{r}}=$ extent of damaged zone normalized by excavation geometry, $R$

(1) $\mathrm{R}=$ room half-width or height

(2) $\mathrm{R}=$ borehole radius

(3) $\mathrm{R}=$ shaft radius

\subsubsection{LABORATORY DATA}

RE/SPEC (1996) summarized laboratory permeability data for damaged WIPP salt as cited in the literature and subsequently plotted the data as a function of damage or dilatant volumetric strain as shown in Figure 4-1. Based on the general trend of these data, the DRZ permeability as deduced from laboratory testing falls within the same range as predicted by field data.

\subsubsection{Rationale and Parameter Value}

The field and laboratory data discussed in Section 4.2.1 provided insight into the variation of permeability in the DRZ and the extent of the DRZ. The PDF for the permeability of the DRZ at the edge of the shafts is referred to as the skin permeability, $k_{i}$. It was assumed constant for all time and was constructed based on the results of these test programs. The skin permeability was treated as a random variable having a log-triangular distribution function with parameters given in Table 4-2. This distribution was developed with the knowledge that the same PDF for skin permeability would be used at all times, even though it is known that the DRZ permeability will reduce with time. The PDF and CDF for the DRZ permeability are given in Figures 4-2 and 4-3 respectively. 


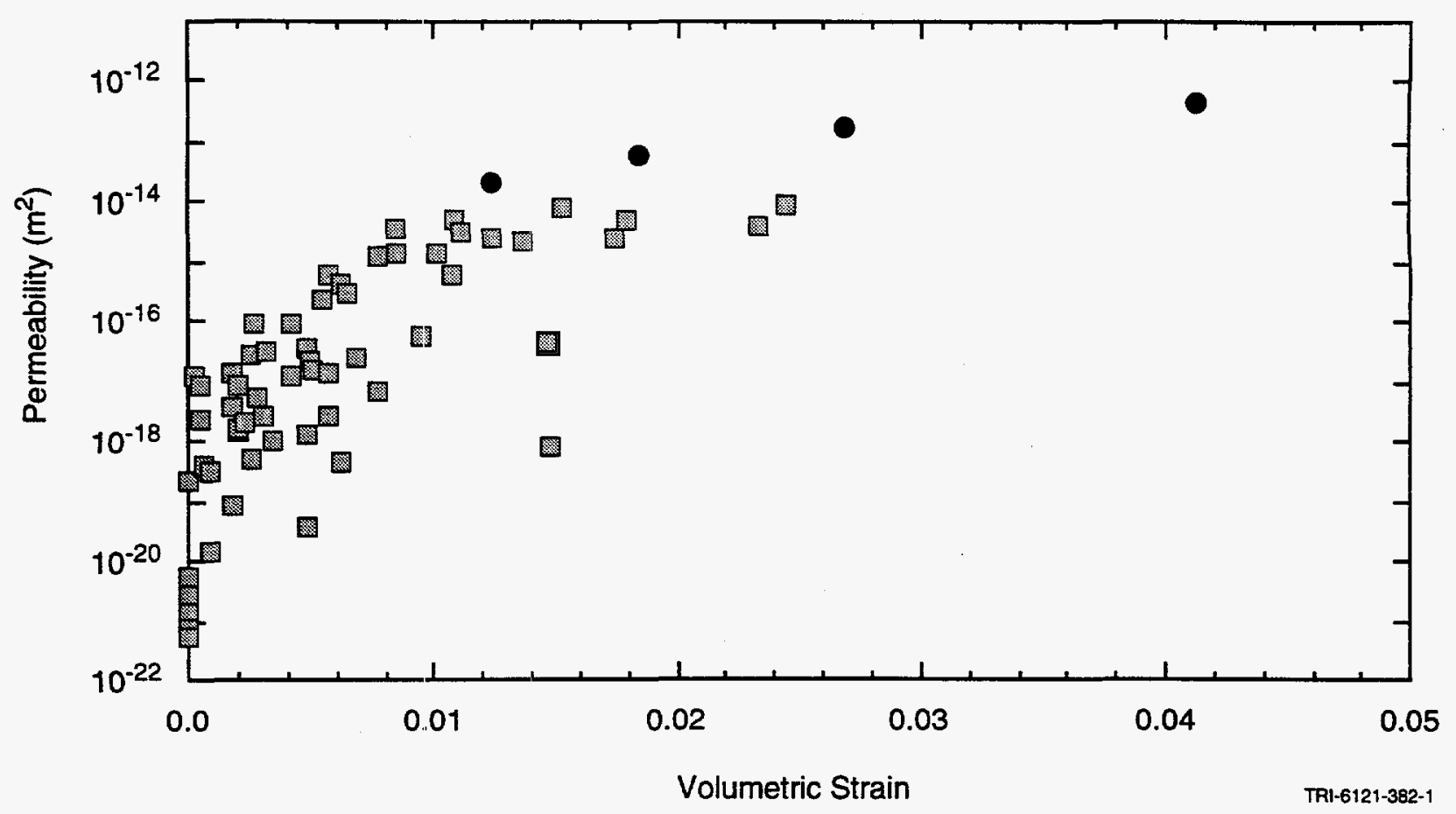

Figure 4-1. Permeability versus dilatant volumetric strain for WIPP salt (after RE/SPEC, 1996).

Table 4-2. Log Triangular Distribution Function Parameters for DRZ Skin Permeability $\left(k_{i}\right)$

\begin{tabular}{cccc}
\hline Seal Material & $\begin{array}{c}\text { Lower Bound } \\
\text { Permeability } \\
\left(\mathrm{m}^{2}\right)\end{array}$ & $\begin{array}{c}\text { Best Estimator } \\
\text { Permeability } \\
\left(\mathrm{m}^{2}\right)\end{array}$ & $\begin{array}{c}\text { Upper Bound } \\
\text { Permeability } \\
\left(\mathrm{m}^{2}\right)\end{array}$ \\
\hline $\begin{array}{c}\text { Upper and Lower Compacted Clay } \\
\mathrm{t}=0 \text { yrs }\end{array}$ & $1.0 \times 10^{-17}$ & $1.0 \times 10^{-15}$ & $1.0 \times 10^{-14}$ \\
$\begin{array}{c}\text { Compacted Crushed Salt } \\
\mathrm{t}=0 \text { yrs } \\
\text { Asphalt } \\
\mathrm{t}=0 \text { yrs }\end{array}$ & $1.0 \times 10^{-17}$ & $1.0 \times 10^{-15}$ & $1.0 \times 10^{-14}$ \\
\hline
\end{tabular}




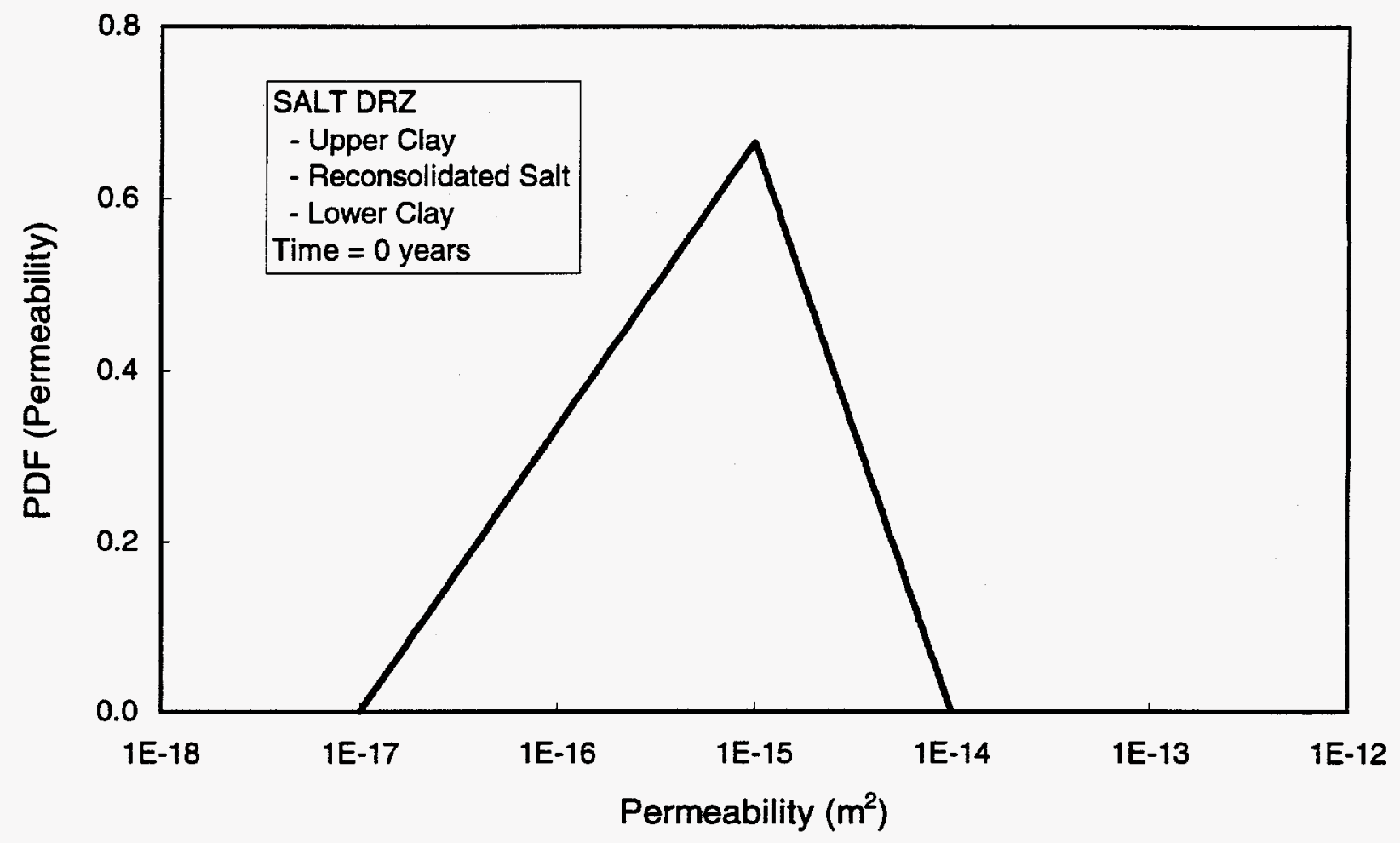

Figure 4-2. PDF for DRZ skin permeability $\left(k_{i}\right)$ immediately following seal emplacement.

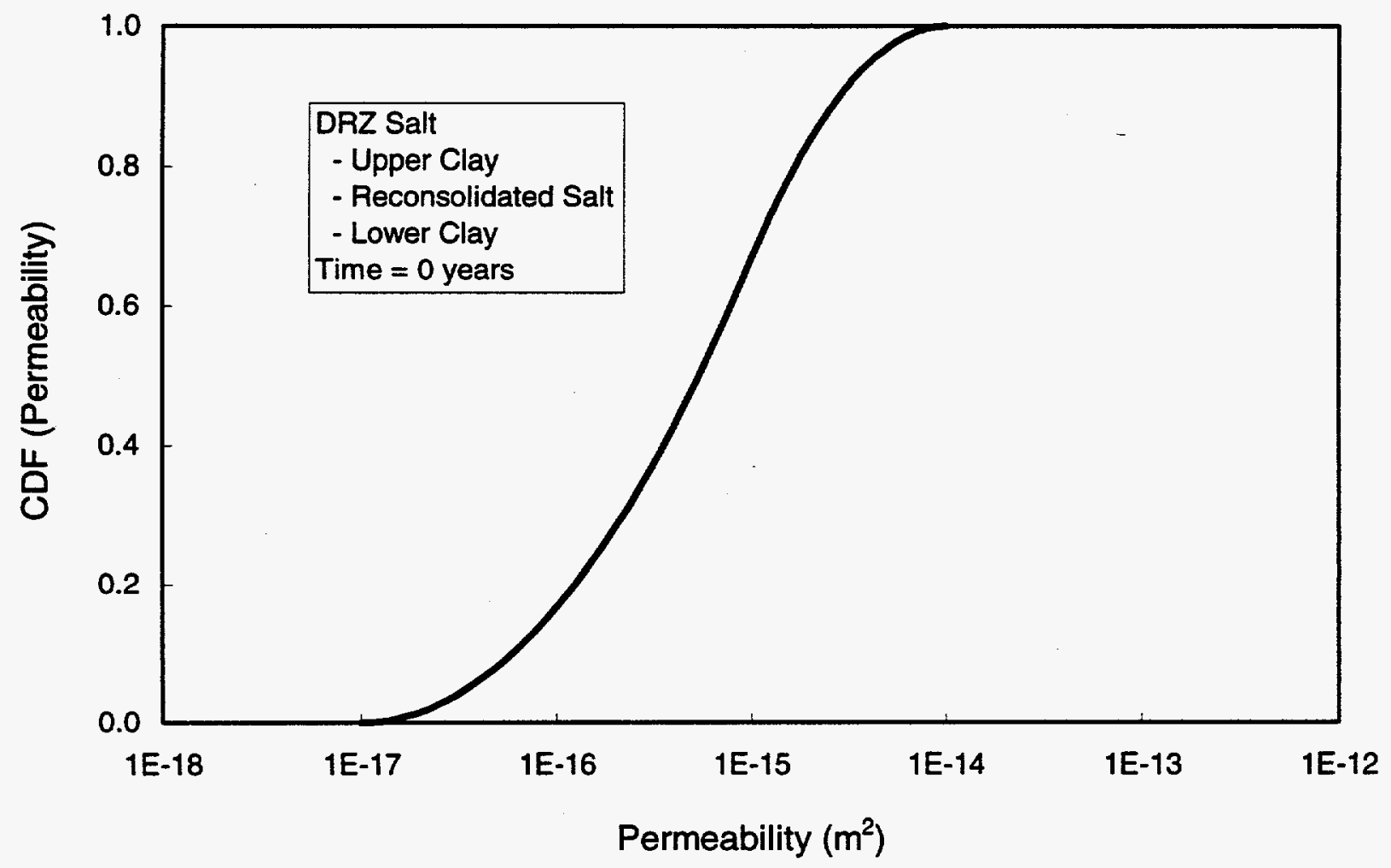

Figure 4-3. CDF for DRZ skin permeability $\left(k_{i}\right)$ immediately following seal emplacement. 
In addition, knowledge of the radial extent of the DRZ with time was necessary. The transient behavior of the radial extent of the DRZ was obtained by structural calculations. These calculations estimated the radial extent of the DRZ as a function of time and depth adjacent to the upper and lower compacted clay seals, the compacted crushed salt seal, and the asphalt seal (RISD, 1996). Figure 4-4 shows the normalized DRZ radius (i.e., ratio of DRZ extent and radius of shaft) as a function of time adjacent to the clay seals. The times considered were $0,10,25,50$, and 100 years after seal emplacement. Adjacent to the lower clay seal (depths ranging from 616 to $643 \mathrm{~m}$ ), the calculations indicate that the extent of the DRZ is approximately $85 \%$ of the shaft radius at a time of 0 years after seal emplacement and that the DRZ is fully healed after about 25 years. Adjacent to the upper clay seal (ranging from 308 to $413 \mathrm{~m}$ ), the calculations indicate that the extent of the DRZ is approximately $70 \%$ of the shaft radius immediately after seal emplacement and is reduced to zero after about 100 years. Figure $4-5$ provides a similar plot for the normalized DRZ radius adjacent to the compacted crushed salt seal (depths ranging from 429 to $600 \mathrm{~m}$ ). This figure shows that the DRZ extent is approximately $80 \%$ of the shaft radius immediately after seal emplacement and is reduced to zero at approximately $50 \mathrm{yrs}$ after seal emplacement. Figure 4-6 shows the normalized DRZ as a function of time adjacent to the asphalt seal. This figure indicates that the DRZ extent is approximately $65 \%$ adjacent to the asphalt seal (depths ranging from 256 to $293 \mathrm{~m}$ ) immediately after seal emplacement and reduces to $60 \%$ at 100 yrs after emplacement. Tables $4-3,4-4$, and $4-5$ give the normalized DRZ radius as a function of time adjacent to the clay seals, the crushed salt seal, and the asphalt seal, respectively, at five specified depths. Table 4-6 gives the normalized DRZ radius as a function of time at the mid-height of each material component. The open shaft model predicted the extent of the DRZ to have a normalized radius of 1.63 to 1.86 as compared to field results from the AIS testing, which indicated a normalized radius of 1.25 to 1.92 and are therefore more conservative.

\subsection{Implementation of DRZ Parameters into the Conceptual Model}

An effective DRZ permeability was estimated by defining a functional relationship describing the change in permeability as a function of radial distance in the DRZ. Figure 4-7 shows a schematic of a shaft with a DRZ of inner radius $r_{i}$ and outer radius $r_{o}$. The permeability $k_{i}$ at $r_{i}$ is the DRZ skin permeability; the intact undisturbed permeability, $k_{o}$, is defined at $r_{o}$. Figure 4-7 shows a log-linear variation of permeability as a function of radial distance within the DRZ. The results of the AIS field testing indicate a log-linear model is an appropriate assumption (Dale and Hurtado, 1996). Therefore, such a model was assumed to describe the DRZ permeability as a function of radial distance and was used to calculate an effective DRZ permeability. 


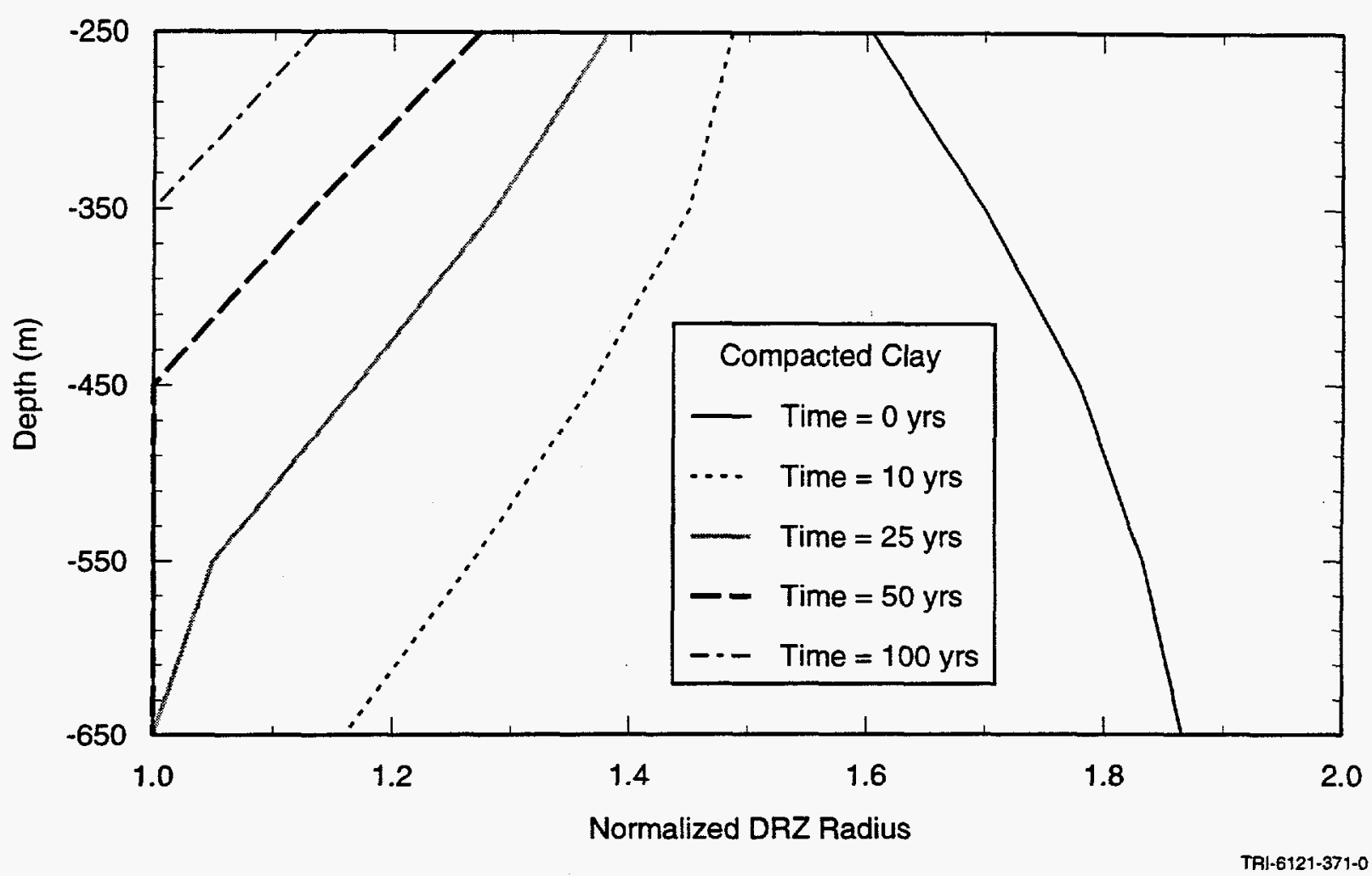

Figure 4-4. Normalized $D R Z$ radius versus depth and time for salt adjacent to compacted clay seals.

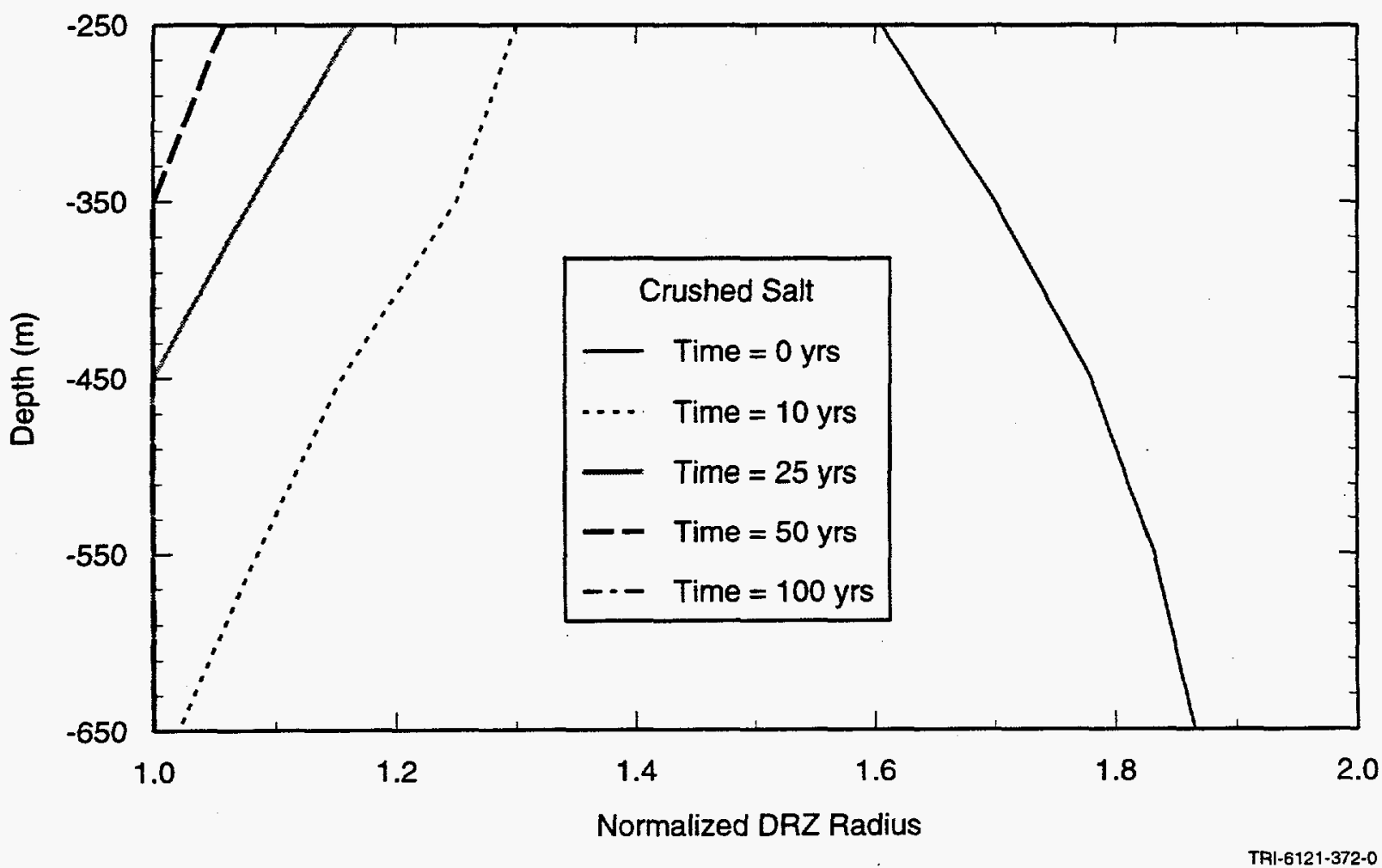

Figure 4-5. Normalized DRZ radius versus depth and time for salt adjacent to compacted crushed salt. 


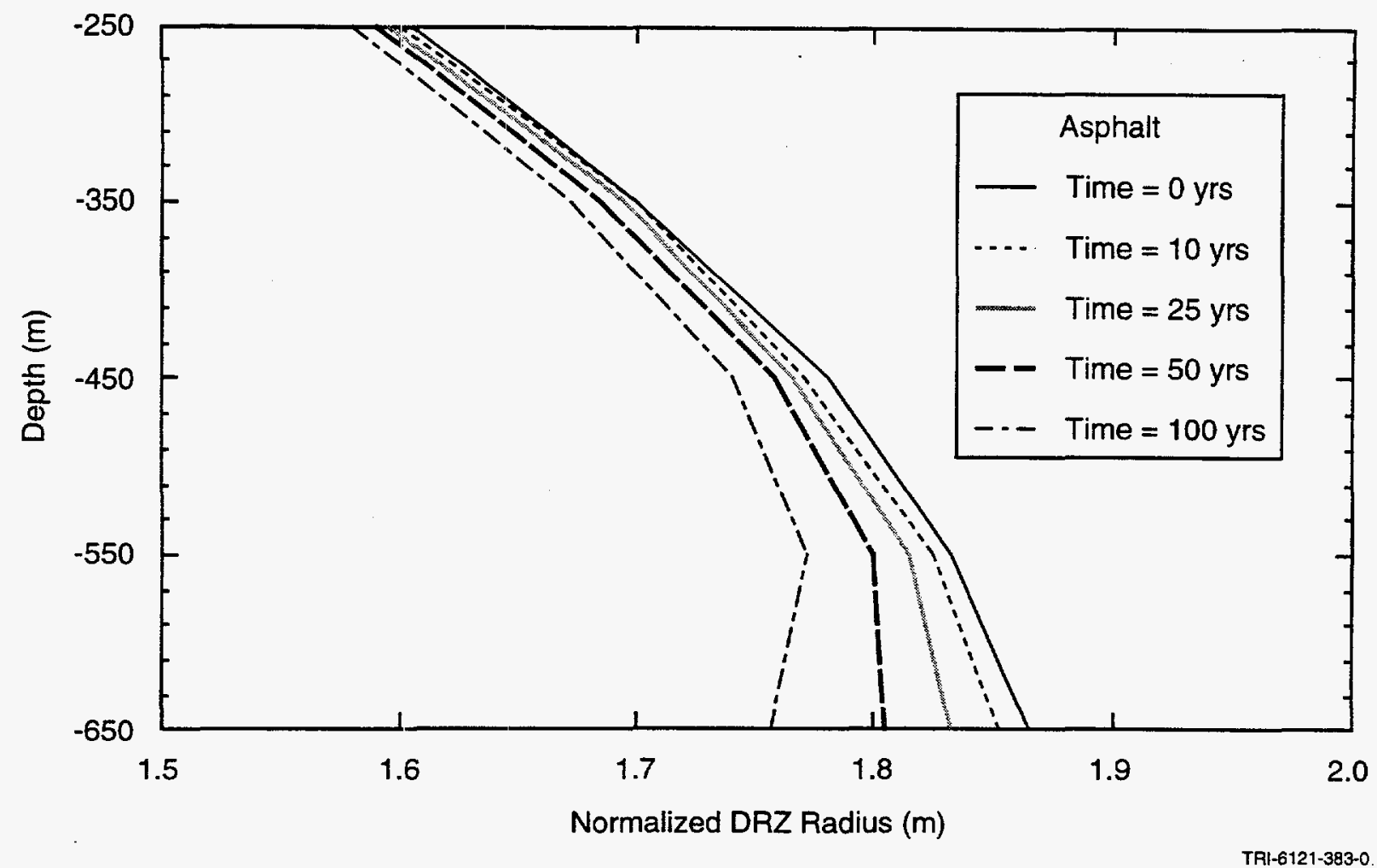

Figure 4-6. Normalized DRZ radius versus depth and time for salt adjacent to asphalt.

Table 4-3. Normalized DRZ Radius as a Function of Depth and Time for Upper and Lower Compacted Clay Seals

\begin{tabular}{cccccc}
\hline $\begin{array}{c}\text { Depth } \\
(\mathrm{m})\end{array}$ & \multicolumn{5}{c}{ Normalized DRZ Radius } \\
\cline { 2 - 5 } & $0 \mathrm{yrs}$ & $10 \mathrm{yrs}$ & $25 \mathrm{yrs}$ & $50 \mathrm{yrs}$ & $100 \mathrm{yrs}$ \\
\hline 250 & 1.605 & 1.486 & 1.381 & 1.273 & 1.135 \\
350 & 1.700 & 1.450 & 1.286 & 1.132 & 1.000 \\
450 & 1.780 & 1.368 & 1.170 & 1.000 & 1.000 \\
550 & 1.832 & 1.268 & 1.050 & 1.000 & 1.000 \\
650 & 1.865 & 1.160 & 1.000 & 1.000 & 1.000 \\
\hline
\end{tabular}


Table 4-4. Normalized DRZ Radius as a Function of Depth and Time for Compacted Crushed Salt Seal

\begin{tabular}{cccccc}
\hline $\begin{array}{c}\text { Depth } \\
(\mathrm{m})\end{array}$ & \multicolumn{5}{c}{ Normalized DRZ Radius } \\
\hline & $0 \mathrm{yrs}$ & $10 \mathrm{yrs}$ & $25 \mathrm{yrs}$ & $50 \mathrm{yrs}$ & $100 \mathrm{yrs}$ \\
\hline 250 & 1.605 & 1.300 & 1.165 & 1.058 & 1.000 \\
350 & 1.700 & 1.250 & 1.080 & 1.000 & 1.000 \\
450 & 1.780 & 1.155 & 1.000 & 1.000 & 1.000 \\
550 & 1.832 & 1.085 & 1.000 & 1.000 & 1.000 \\
650 & 1.865 & 1.020 & 1.000 & 1.000 & 1.000 \\
\hline
\end{tabular}

Table 4-5. Normalized DRZ Radius as a Function of Depth and Time for the Asphalt Seal

\begin{tabular}{cccccc}
\hline $\begin{array}{c}\text { Depth } \\
(\mathrm{m})\end{array}$ & \multicolumn{5}{c}{ Normalized DRZ Radius } \\
\hline & 0 yrs & $10 \mathrm{yrs}$ & $25 \mathrm{yrs}$ & $50 \mathrm{yrs}$ & $100 \mathrm{yrs}$ \\
\hline 250 & 1.605 & 1.600 & 1.595 & 1.590 & 1.580 \\
350 & 1.700 & 1.700 & 1.695 & 1.685 & 1.672 \\
450 & 1.780 & 1.770 & 1.765 & 1.758 & 1.740 \\
550 & 1.832 & 1.825 & 1.815 & 1.800 & 1.772 \\
650 & 1.865 & 1.852 & 1.832 & 1.805 & 1.757 \\
\hline
\end{tabular}


Table 4-6. Extent of the DRZ in Terms of Normalized Radius at Mid-Height of Component (after U.S. DOE, 1995)

\begin{tabular}{|c|c|c|c|c|c|}
\hline \multirow{3}{*}{$\begin{array}{c}\text { Seal Material and } \\
\text { Associated DRZ } \\
\text { Zone }\end{array}$} & \multicolumn{5}{|c|}{ DRZ Extent-Normalized Radius } \\
\hline & \multicolumn{5}{|c|}{ Time Reference to Instantaneous Emplacement of Seal Materials } \\
\hline & 0 yrs & 10 yrs & $25 \mathrm{yrs}$ & 50 yrs & 100 yrs \\
\hline Asphalt Column & 1.629 & 1.625 & 1.620 & 1.614 & 1.603 \\
\hline $\begin{array}{l}\text { Upper Salado } \\
\text { Compacted Clay }\end{array}$ & 1.709 & 1.469 & 1.283 & 1.107 & 1.000 \\
\hline $\begin{array}{c}\text { Reconsolidated } \\
\text { Salt }\end{array}$ & 1.814 & 1.110 & 1.000 & 1.000 & 1.000 \\
\hline $\begin{array}{l}\text { Lower Salado } \\
\text { Compacted Clay }\end{array}$ & 1.858 & 1.162 & 1.002 & 1.000 & 1.000 \\
\hline
\end{tabular}

The equation used to calculate the effective DRZ permeability, $k_{e}$, assuming the loglinear model is:

$$
k_{e}=\frac{2}{r_{o}+r_{i}}\left[\left(\frac{r_{o}\left[\ln \left(k_{o}\right)-\ln \left(k_{i}\right)\right]-\Delta r}{\left[\ln \left(k_{o}\right)-\ln \left(k_{i}\right)\right]^{2}}\right) k_{o}-\left(\frac{r_{i}\left[\ln \left(k_{o}\right)-\ln \left(k_{i}\right)\right]-\Delta r}{\left[\ln \left(k_{o}\right)-\ln \left(k_{i}\right)\right]^{2}}\right) k_{i}\right]
$$

where $\Delta \mathrm{r}$ is equal to the outer DRZ radius minus the inner DRZ radius $\left(r_{o}-r_{i}\right)$. This calculation accounts for both the decrease in DRZ permeability and the increase in flow area as a function of radius away from the excavation.

Using Equation 4-1, an effective permeability of the DRZ was calculated based on knowledge of the outer extent of the DRZ $\left(r_{o}\right)$, the DRZ skin permeability $\left(k_{i}\right)$, and the undisturbed Salado halite permeability. This approach assumed that the skin permeability (or the permeability of the salt immediately adjacent to the shaft) does not depend on depth or vary with time. The permeability of undisturbed halite was correlated to that of the sampled value of intact halite for the CCA calculations.

The DRZ permeability was incorporated into the model by combining it with the seal permeability. This methodology is illustrated in Figure 4-8. This was done by calculating a seal/DRZ composite permeability. The conceptual model combined all four shafts into a 


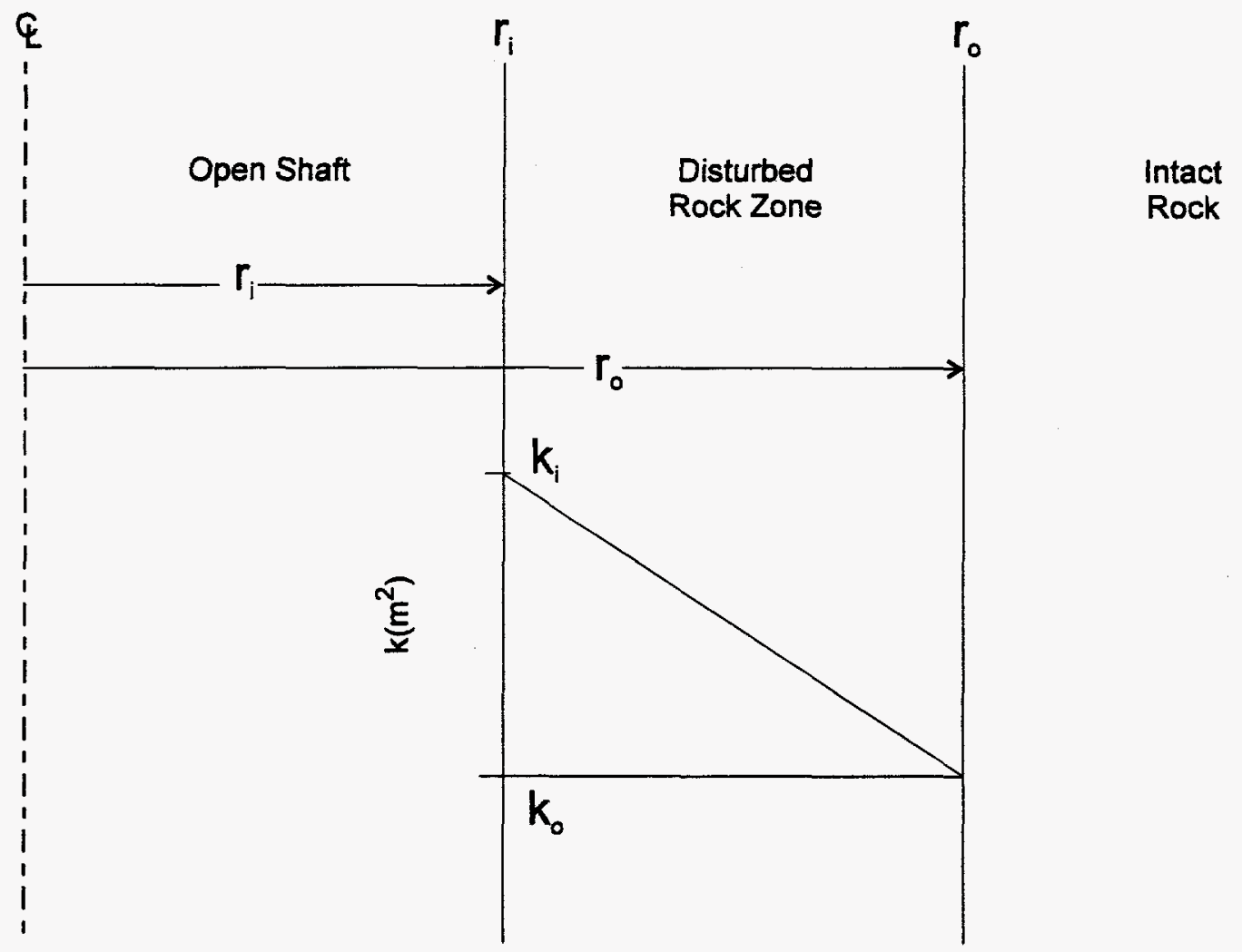

$k_{i}$ Represents Maximum Dilation

$k_{0}$ Represents Intact Conditions

$r_{i}$ Excavation Face, Inner Radius of DRZ

$r_{0}$ Outer Radius of DRZ

Figure 4-7. Log-linear model for the calculation of an effective permeability of the DRZ.

composite shaft. Therefore, special consideration was given to the calculation of the seal/DRZ composite permeability. The radii for the four WIPP shafts are:

Shaft

Air Intake

Salt Handling

Waste

Exhaust
Inner Radius $\left(r_{i}\right)$

(m)

3.1

1.8

3.5

2.3 
Sample Seal Permeability

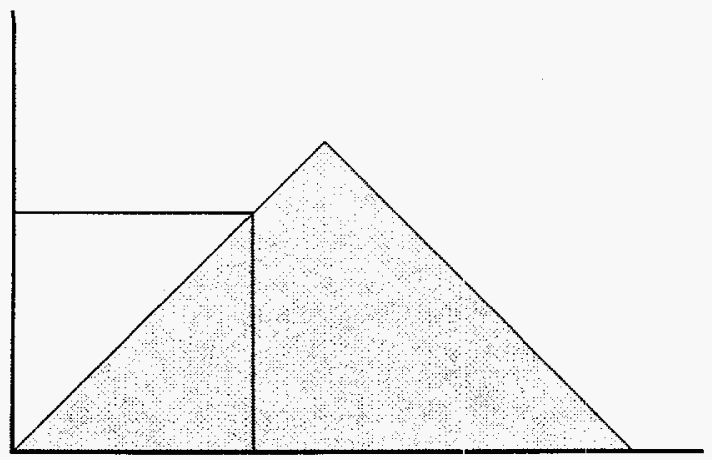

$k_{s}$

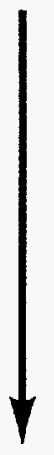

Calculate Total Seal Area

Permeability Product

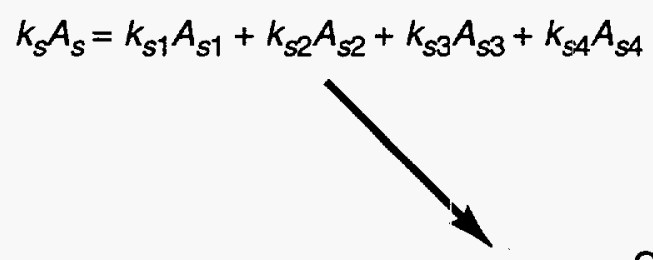

Sample Inner DRZ Permeability

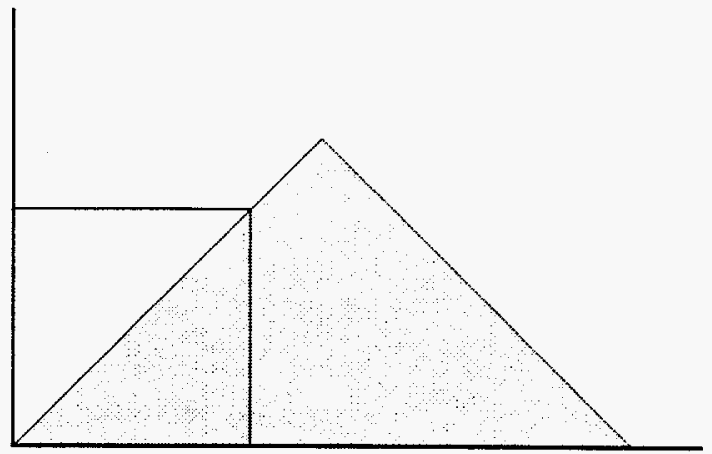

$k_{i}$

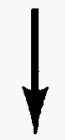

Calculate DRZ Effective Permeability for Each Shaft Using Eqn 4-1:

$$
k_{e}=\mathrm{F}\left(k_{i}, k_{o}, r_{i}, r_{o}\right)
$$

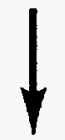

Calculate Total DRZ Area

Permeability Product

$$
k_{e} A_{e}=k_{e 1} A_{e 1}+k_{e 2} A_{e 2}+k_{e 3} A_{e 3}+k_{e 4} A_{e 4}
$$

\section{Calculate Composite \\ Seal Permeability}

$$
k_{\text {model }}=\frac{k_{e} A_{e}+k_{s} A_{s}}{A_{\text {model }}}
$$

Assumes $A_{\text {model }}=A_{s 1}+A_{s 2}+A_{s 3}+A_{s 4}=95 \mathrm{~m}^{2}$

TRI-6121-377-0

Figure 4-8. Composite seal/DRZ permeability calculation methodology. 
Because the DRZ is adjacent to each of the four shafts and the extent of the DRZ is a function of shaft radius, calculation of the effective DRZ permeability (Equation 4-1) was performed for all four shafts. If the inner and outer DRZ permeabilities are the same for each shaft, Equation 4-1 predicted the same effective DRZ permeability for all four shafts (i.e., regardless of shaft radius). However, the product of the DRZ permeability and shaft crosssectional area was different for each shaft because the shafts have different radii $\left(r_{i}\right)$. The DRZ effective permeability and area product were summed across the four shafts to calculate a term representative of all four shafts. The area of each shaft multiplied by the effective DRZ permeability yielded a different area-permeability product (hydraulic conductance assuming a unit length) for each shaft. The summation of the product of DRZ permeability and DRZ area across all four shafts is equal to:

$$
k_{e} A_{e}=k_{e 1} A_{e 1}+k_{e 2} A_{e 2}+k_{e 3} A_{e 3}+k_{e 4} A_{e 4}
$$

where:

$$
\begin{aligned}
k_{e} & =\text { effective } \mathrm{DRZ} \text { permeability } \\
A_{e} & =\mathrm{DRZ} \text { area, and } \\
e 1, e 2, e 3, e 4 & =\mathrm{DRZ} \text { for the four shafts. }
\end{aligned}
$$

An approximate effective permeability of the composite seal and DRZ for the PA model was calculated using:

$$
k_{\text {model }}=\frac{k_{s} A_{s}+k_{e} A_{e}}{A_{\text {model }}}
$$

where $A_{\text {model }}$ is equal to the modeled area for the composite shaft seal $\left(95 \mathrm{~m}^{2}\right)$ and $k_{s} A_{s}$ is the summation of the shaft seal area multiplied by the permeability for the four shafts and is equal to:

$$
k_{s} A_{s}=k_{s 1} A_{s 1}+k_{s 2} A_{s 2}+k_{s 3} A_{s 3}+k_{s 4} A_{s 4}
$$

This relationship is approximate and assumes that the modeled area $\left(A_{\text {model }}\right)$ is equal to the combined shaft seal area $\left(A_{s}\right)$. Note that when the DRZ normalized radius goes to one, the composite seal permeability becomes equal only to the sampled seal permeability with no magnitude adjustment required. Calculation of the composite permeability using Equations 4-2, 4-3, and 4-4 was conducted separately for the DRZ adjacent to the asphalt seal, the upper compacted clay seal, the crushed salt seal, and the lower compacted clay seal. 


\subsection{SUMMARY}

The conceptual model of the WIPP shaft sealing system was formulated to predict the system behavior over the regulatory period of 10,000 years. The simplified geometry of the conceptual model, presented in Section 1.0, reflects the configuration and functions of the individual components. The model will capture the fluid flow behaviors of the system, but is not expected to simulate the detailed flow patterns that will occur around individual components. The development of properties necessary for the model elements has been described in Sections 2 through 4. Uncertainty in material parameters is quantified through the PDFs of the parameters that are expected to significantly impact performance. Incorporation of effects resulting from the presence of a DRZ within the host rock surrounding the seal components was discussed and quantified in Section 4. The PDFs for seal material and DRZ properties were constructed for use within the LHS methodology utilized for the WIPP compliance calculations. This section summarizes the parameters necessary for implementation of the seal system conceptual model.

\subsection{Saturated Flow Parameters and Initial Conditions}

Certain material properties are insensitive to the relative saturation state of seal components. These properties include the intrinsic permeability, porosity, and compressibility of the materials. The initial pore pressure and water saturation state of the seal components must also be specified. Uncertainty in the seal material permeabilities was discussed in Section 2.0, and is reflected in the relevant PDFs. The proposed shaft sealing system design incorporates redundancy in materials and components to eliminate the probability of system failure. It was therefore possible to limit the uncertainty in material permeabilities to uncertainty in component behavior. This differs from previous approaches, whereby uncertainty in system performance necessitated inclusion of high material permeabilities associated with system failure. Table 5-1 outlines: (1) the sources of uncertainty for each seal material and (2) redundant components that provide assurance that the seal materials will perform their intended functions. Tables 5-2 through 5-6 present the saturated flow properties and initial conditions for the compacted crushed salt, compacted clay, asphalt, and earthen fill materials proposed for use as shaft sealing materials.

It was assumed that flow calculations are not sensitive to variation in seal porosity and compressibility. Estimated constant values for these properties were developed.

\subsection{Two-Phase Flow Parameters}

The necessary parameters for modeling two-phase flow were developed using literature values and professional judgment. The resultant parameters are consistent with those used in previous PA analyses, with the exception of those recommended for the asphalt column. Asphalt is a hydrophobic material. Using the recommended two-phase flow parameters and the low brine saturation, detailed models showed that the asphalt column could maintain a large suction pressure. This behavior was not considered physically realistic, and a linear capillary model was 
Table 5-1. Seal Materials, Uncertainty Sources, and Redundant Components

\begin{tabular}{|c|c|c|}
\hline Material & Source(s) of Uncertainty & Redundant Component(s) \\
\hline Compacted Crushed Salt & $\begin{array}{l}\text { - Constitutive Model } \\
\text { - Fractional Density versus } \\
\text { Permeability Relationship }\end{array}$ & $\begin{array}{l}\text { - Upper compacted clay } \\
\text { column } \\
\text { - Lower compacted clay } \\
\text { column }\end{array}$ \\
\hline Compacted Bentonite Clay & $\begin{array}{l}\text { - construction methods } \\
\text { - salinity effects }\end{array}$ & $\begin{array}{l}\text { - Concrete/asphalt waterstops } \\
\text { - Asphalt column } \\
\text { - Compacted salt column }\end{array}$ \\
\hline Salado Mass Concrete & $\begin{array}{l}\text { - construction methods } \\
\text { - degradation effects }\end{array}$ & $\begin{array}{l}\text { - Asphalt column } \\
\text { - Upper compacted clay } \\
\text { column } \\
\text { - Lower compacted clay } \\
\text { column }\end{array}$ \\
\hline Asphalt & $\begin{array}{l}\text { - construction methods } \\
\text { - lack of permeability data }\end{array}$ & $\begin{array}{l}\text { - Upper compacted clay } \\
\text { column } \\
\text { - Rustler clay column } \\
\text { - Concrete/asphalt waterstops }\end{array}$ \\
\hline Earthen Fill & - construction method & - Sealing function not required \\
\hline
\end{tabular}

Table 5-2. Reconsolidated Salt Parameters (Component 10)

\begin{tabular}{lcccc}
\hline Parameter & Best Estimate & $\begin{array}{c}\text { Minimum } \\
\text { Value }\end{array}$ & $\begin{array}{c}\text { Maximum } \\
\text { Value }\end{array}$ & $\begin{array}{c}\text { Distribution } \\
\text { Type }\end{array}$ \\
\hline $\begin{array}{l}\text { Intrinsic Permeability } \\
\left(\mathrm{m}^{2}\right)\end{array}$ & & & & $\begin{array}{c}\text { Log } \\
\text { Triangular }\end{array}$ \\
0 yrs & $1.65 \times 10^{-15}$ & $5.00 \times 10^{-18}$ & $5.43 \times 10^{-13}$ & \\
50 yrs & $6.83 \times 10^{-18}$ & $1.33 \times 10^{-23}$ & $1.12 \times 10^{-14}$ & \\
100 yrs & $5.27 \times 10^{-20}$ & $1.33 \times 10^{-23}$ & $3.75 \times 10^{-16}$ & \\
200 yrs & $5.35 \times 10^{-21}$ & $1.33 \times 10^{-23}$ & $2.15 \times 10^{-18}$ & \\
400 yrs & $5.35 \times 10^{-21}$ & $1.33 \times 10^{-23}$ & $2.15 \times 10^{-18}$ & \\
Porosity (fraction) & 0.05 & NA & NA & NA \\
Compressibility (1/Pa) & $1.69 \times 10^{-9}$ & NA & NA & NA \\
Initial Pressure (Pa) & 101356.5 & NA & NA & NA \\
Initial Liquid & 0.32 & NA & NA & NA \\
Saturation & & & & \\
\hline
\end{tabular}


Table 5-3. Bentonite Compacted Clay Parameters (Components 4, 8, and 12)

\begin{tabular}{lcccc}
\hline Parameter & Best Estimate & $\begin{array}{c}\text { Minimum } \\
\text { Value }\end{array}$ & $\begin{array}{c}\text { Maximum } \\
\text { Value }\end{array}$ & $\begin{array}{c}\text { Distribution } \\
\text { Type }\end{array}$ \\
\hline $\begin{array}{l}\text { Intrinsic Permeability } \\
\left(\mathrm{m}^{2}\right)\end{array}$ & $5 \times 10^{-19}$ & $1 \times 10^{-21}$ & $5 \times 10^{-18}$ & $\begin{array}{c}\text { Log } \\
\text { Triangular }\end{array}$ \\
$\begin{array}{l}\text { Porosity (fraction) } \\
\text { Compressibility (1/Pa) }\end{array}$ & 0.24 & $\mathrm{NA}$ & $\mathrm{NA}$ & $\mathrm{NA}$ \\
$\quad$ Upper Salado clay & $1.81 \times 10^{-9}$ & $\mathrm{NA}$ & $\mathrm{NA}$ & $\mathrm{NA}$ \\
$\quad$ Lower Salado clay & $1.59 \times 10^{-9}$ & $\mathrm{NA}$ & $\mathrm{NA}$ & $\mathrm{NA}$ \\
$\quad$ Rustler clay column & $1.96 \times 10^{-9}$ & $\mathrm{NA}$ & $\mathrm{NA}$ & $\mathrm{NA}$ \\
Initial Pressure (Pa) & 101356.5 & $\mathrm{NA}$ & $\mathrm{NA}$ & $\mathrm{NA}$ \\
Initial Liquid & 0.79 & $\mathrm{NA}$ & $\mathrm{NA}$ & $\mathrm{NA}$ \\
Saturation & & & & \\
\hline
\end{tabular}

Table 5-4. Salado Mass Concrete Parameters (Components 2, 5, 7, 9, and 11)

\begin{tabular}{lcccc}
\hline Parameter & Best Estimate & $\begin{array}{c}\text { Minimum } \\
\text { Value }\end{array}$ & $\begin{array}{c}\text { Maximum } \\
\text { Value }\end{array}$ & Distribution Type \\
\hline $\begin{array}{l}\text { Intrinsic Permeability } \\
\left(\mathrm{m}^{2}\right)\end{array}$ & $1.78 \times 10^{-19}$ & $2 \times 10^{-21}$ & $1 \times 10^{-17}$ & $\begin{array}{c}\text { Log } \\
\text { Triangular }\end{array}$ \\
Porosity (fraction) & 0.05 & $\mathrm{NA}$ & $\mathrm{NA}$ & $\mathrm{NA}$ \\
Compressibility (1/Pa) & $1.2 \times 10^{-9}$ & $\mathrm{NA}$ & $\mathrm{NA}$ & $\mathrm{NA}$ \\
Initial Pressure (Pa) & 101356.5 & $\mathrm{NA}$ & $\mathrm{NA}$ & $\mathrm{NA}$ \\
Initial Liquid & 1.0 & $\mathrm{NA}$ & $\mathrm{NA}$ & $\mathrm{NA}$ \\
Saturation & & & & \\
\hline
\end{tabular}


Table 5-5. Asphalt Parameters (Component 6)

\begin{tabular}{lcccc}
\hline Parameter & Best Estimate & $\begin{array}{c}\text { Minimum } \\
\text { Value }\end{array}$ & $\begin{array}{c}\text { Maximum } \\
\text { Value }\end{array}$ & $\begin{array}{c}\text { Distribution } \\
\text { Type }\end{array}$ \\
\hline $\begin{array}{l}\text { Intrinsic Permeability } \\
\left(\mathrm{m}^{2}\right)\end{array}$ & $1 \times 10^{-20}$ & $1 \times 10^{-21}$ & $1 \times 10^{-18}$ & $\begin{array}{c}\text { Log } \\
\text { Triangular }\end{array}$ \\
Porosity (fraction) & 0.01 & $\mathrm{NA}$ & $\mathrm{NA}$ & $\mathrm{NA}$ \\
Compressibility $(1 / \mathrm{Pa})$ & $2.97 \times 10^{-8}$ & $\mathrm{NA}$ & $\mathrm{NA}$ & $\mathrm{NA}$ \\
Initial Pressure (Pa) & 101356.5 & $\mathrm{NA}$ & $\mathrm{NA}$ & $\mathrm{NA}$ \\
Initial Liquid & 0.0 & $\mathrm{NA}$ & $\mathrm{NA}$ & $\mathrm{NA}$ \\
Saturation & & & & \\
\hline
\end{tabular}

Table 5-6. Earthen Fill Parameters (Components 1 and 3)

\begin{tabular}{lcccc}
\hline Parameter & Best Estimate & $\begin{array}{c}\text { Minimum } \\
\text { Value }\end{array}$ & $\begin{array}{c}\text { Maximum } \\
\text { Value }\end{array}$ & $\begin{array}{c}\text { Distribution } \\
\text { Type }\end{array}$ \\
\hline $\begin{array}{l}\text { Intrinsic Permeability } \\
\left(\mathrm{m}^{2}\right)\end{array}$ & $1 \times 10^{-14}$ & $1 \times 10^{-17}$ & $1 \times 10^{-12}$ & $\begin{array}{c}\text { Log } \\
\text { Triangular }\end{array}$ \\
Porosity (fraction) & 0.32 & $\mathrm{NA}$ & $\mathrm{NA}$ & $\mathrm{NA}$ \\
Compressibility (1/Pa) & $3.1 \times 10^{-8}$ & $\mathrm{NA}$ & $\mathrm{NA}$ & $\mathrm{NA}$ \\
Initial Pressure (Pa) & 101356.5 & $\mathrm{NA}$ & $\mathrm{NA}$ & $\mathrm{NA}$ \\
Initial Liquid Saturation & 0.8 & $\mathrm{NA}$ & $\mathrm{NA}$ & $\mathrm{NA}$ \\
\hline
\end{tabular}

proposed for the asphalt. Table 5-7 summarizes the two-phase flow parameters developed for the shaft seal materials.

\subsection{Disturbed Rock Zone}

Two effects must be considered when developing parameters related to a DRZ in salt: damage and healing. Quantification of DRZ damage requires knowledge of both the radial extent and increased permeability resulting from the damage process. The healing process depends on the mechanical properties of the emplaced seal material, and on the stress difference (i.e., depth of emplacement) surrounding the material. In order to simplify the parameterization process, an approximation of the radial extent of the time-dependent DRZ was utilized as discussed in Section 4.0. The radial extent of the DRZ is deterministic, and results for each seal component were presented in Tables 4-3 through 4-6. It was assumed that the maximum 
Table 5-7. Capillary Pressure and Relative Permeability Model BRAGFLO Parameters for Compacted Clay, Concrete, Reconsolidated Salt, Asphalt, and Earthen Fill

\begin{tabular}{lcccc}
\hline \multicolumn{1}{c}{ Parameter } & $\begin{array}{c}\text { Best } \\
\text { Estimate }\end{array}$ & $\begin{array}{c}\text { Minimum } \\
\text { Value }\end{array}$ & $\begin{array}{c}\text { Maximum } \\
\text { Value }\end{array}$ & Distribution Type \\
\hline Threshold Pressure $^{(\mathrm{a})}(\mathrm{MPa})$ & & $P_{t}=5.6 \times 10^{-7} k^{-0.346(\mathrm{~b})}$ & \\
$\lambda$ & 0.94 & 0.11 & 8.1 & Lognormal \\
Residual Liquid Saturation & 0.2 & 0.0 & 0.6 & Uniform \\
Residual Gas Saturation & 0.2 & 0.0 & 0.4 & Uniform \\
\hline
\end{tabular}

(a) Not applicable for asphalt, which was assigned a zero capillary pressure.

(b) $k=$ intrinsic permeability $\left(\mathrm{m}^{2}\right)$.

permeability of the damaged zone remains constant until complete healing is achieved. A logtriangular distribution was developed for the maximum DRZ permeability. Table 5-8 summarizes the PDF for the maximum DRZ permeability, which is applied at the shaft wall. Because the seal conceptual model does not include an explicit representation for the DRZ, a process for calculation of the effective $\mathrm{DRZ}$ and seal permeability was developed. It was recommended that the DRZ permeability be sampled separately from seal material permeability and that the effective permeability should then be calculated from the sampled values.

\subsection{Conclusions}

The compliance application conceptual model for the WIPP shaft sealing system incorporates the design strategy of utilizing multiple components and materials to assure that system performance objectives are met. The model and all necessary parameters are presented and discussed in this document. Uncertainty in material properties is captured within the discussion, and those properties that can significantly impact repository performance reflect relevant uncertainty. This approach incorporates good engineering judgment, yet reflects conservatism where significant uncertainty exists.

Table 5-8. Salt DRZ BRAGFLO Parameters (Zones 1 through 4)

\begin{tabular}{lcccc}
\hline Parameter & Best Estimate & $\begin{array}{c}\text { Minimum } \\
\text { Value }\end{array}$ & $\begin{array}{c}\text { Maximum } \\
\text { Value }\end{array}$ & $\begin{array}{c}\text { Distribution } \\
\text { Type }\end{array}$ \\
\hline $\begin{array}{l}\text { Skin Permeability }\left(\mathrm{m}^{2}\right) \\
0 \text { yrs to } t_{h}{ }^{(a)}\end{array}$ & $1.0 \times 10^{-15}$ & $1 \times 10^{-17}$ & $1 \times 10^{-14}$ & Log Triangular \\
$t_{h}$ to 10,000 yrs & (b) & NA & NA & NA \\
\hline
\end{tabular}

(a) $t_{h}=$ DRZ healing time.

(b) Equivalent to value for intact salt. 


\subsection{QUALITY ASSURANCE}

All parameters for the shaft seal conceptual model were developed by two contractors, INTERA, Inc. and RE/SPEC, Inc., with Sandia technical supervision. Both contractors were working under approved Quality Assurance (QA) programs, which have been regularly audited and which were surveilled on this particular task. In addition, the records from this task have been either audited or reviewed.

The data used for the development of the parameters was taken either from standard references or data packages or developed as part of the material specification for the sealing system design. The data packages used were either developed under approved QA programs, qualified by the Qualification of Existing Data (QED) process, qualified by confirmatory testing, and/or peer reviewed. Professional judgment was used in the development of all parameters, and in specifying the ranges of probability density functions (PDFs) derived from the data. In all cases, rationale for judgments made are included in this document and the shaft seals parameter package (Hurtado, 1996). All parameters and PDFs, including judgments made in their development, have undergone at least one form of technical review, including review by technical experts and/or a Technical Peer Review Panel. Finally, this document has been reviewed by technical personnel, management, and QA personnel.

Table 6.1 provides pertinent information on contractors used for parameter development, expert judgment, and/or technical review.

Table 6.1. Contractors for Conceptual Model Development

\begin{tabular}{lc}
\hline Name & SNL Contract \# \\
\hline $\begin{array}{l}\text { Jaak Daemen } \\
\quad \text { (clay expert) }\end{array}$ & AG-4915 \\
$\begin{array}{l}\text { Bob Romine } \\
\text { (asphalt expert) }\end{array}$ & AO-1555 \\
$\begin{array}{l}\text { INTERA, Inc. } \\
\quad \text { (parameter development-compacted clay, asphalt, } \\
\text { compacted earthen fill, two-phase flow properties) }\end{array}$ & AG-4910 \\
$\begin{array}{l}\text { RE/SPEC, Inc. } \\
\quad \text { (parameter development-Salado mass concrete, } \\
\text { compacted crushed salt, disturbed rock zone) }\end{array}$ & AG-4911 \\
\hline
\end{tabular}




\subsection{REFERENCES}

Abraham, H. 1962. Asphalts and Allied Substances: Their Occurrence, Modes of Production, Uses in the Arts, and Methods of Testing. Volume Four: Methods of Testing: Industrial Raw Bituminous Materials. 6th ed. Princeton, NJ: D. Van Nostrand Company, Inc. Vol. 4.

Ahrens, E.H., and F.D. Hansen. 1995. Large-Scale Dynamic Compaction Demonstration Using WIPP Salt: Fielding and Preliminary Results. SAND95-1941. Albuquerque, NM: Sandia National Laboratories. $44 \mathrm{pp}$.

Ang, A.H.-S., and W.H. Tang. 1975. Probability Concepts in Engineering Planning and Design. Volume 1. Basic Principles. New York, NY: John Wiley \& Sons. 391 pp.

Barth, E.J. 1962. Asphalt: Science and Technology. New York, NY: Gordon and Breach Science Publishers. 700 pp.

Bear, J. 1972. Dynamics of Fluids in Porous Media. New York, NY: Elsevier Science Publishing Co., Inc. p. 52.

Bear, J. 1979. Hydraulics of Groundwater. New York, NY: McGraw-Hill. p. 191.

Borns, D.J., and J.C. Stormont. 1988. An Interim Report on Excavation Effects Studies at the Waste Isolation Pilot Plant: The Delineation of the Disturbed Rock Zone. SAND871375. Albuquerque, NM: Sandia National Laboratories. $30 \mathrm{pp}$.

Bradley, D.J., D.G. Coles, F.N. Hodges, G.L. McVay, and R.E. Westerman. 1983. Nuclear Waste Package Materials Testing Report: Basaltic and Tuffaceous Environments. PNL-4452. Richland, WA: Pacific Northwest Laboratory. 139 pp. (Available from the National Technical Information Service, Springfield, VA as DE83010270.)

Brodsky, N.S. 1990. Crack Closure and Healing Studies in WIPP Salt Using Compressional Wave Velocity and Attenuation Measurements: Test Methods and Results. SAND907076. Albuquerque, NM: Sandia National Laboratories. 51 pp.

Brodsky, N.S. 1994. Hydrostatic and Shear Consolidation Tests With Permeability Measurements on Waste Isolation Pilot Plant Crushed Salt. SAND93-7058. Albuquerque, NM: Sandia National Laboratories. 227 pp.

Brodsky, N.S., F.D. Hansen, and T. Pfeifle. 1996. "Properties of Dynamically Compacted WIPP Salt," Proceedings of the 4th International Conference on the Mechanical Behavior of Salt, Montreal, Quebec, Canada, June 17-18, 1996. SAND96-0838C. Albuquerque, NM: Sandia National Laboratories. 14 pp. 
Brooks, R.H. 1965. "Hydraulic Properties of Porous Media." Ph.D. dissertation. Fort Collins, CO: Colorado State University. 102 pp. (Copy on file in the Sandia WIPP Central Files, Sandia National Laboratories, Albuquerque, NM as WPO\#44992.)

Brooks, R.H., and A.T. Corey. 1964. Hydraulic Properties of Porous Media. Hydrology Paper No. 3. Fort Collins, CO: Colorado State University. $27 \mathrm{pp}$. (Copy on file in the Sandia WIPP Central Files, Sandia National Laboratories, Albuquerque, NM as WPO\#41117.)

Brooks, R.H., and A.T. Corey. 1966. "Properties of Porous Media Affecting Fluid Flow," Journal of the Irrigation and Drainage Division, Proceedings of the American Society of Civil Engineers ( $A S C E$ ). Vol. 92, no. IR2, 61-88. (Copy on file in the Sandia WIPP Central Files, Sandia National Laboratories, Albuquerque, NM as WPO\#42326.)

Brown, E.R. 1990. Density of Asphalt Concrete -- How Much is Needed? Transportation Research Record 1282. Washington, DC: Transportation Research Board. 27-32. (Copy on file in the Sandia WIPP Central Files, Sandia National Laboratories, Albuquerque, NM as WPO\#43384.)

Burdine, N.T. 1953. "Relative Permeability Calculations from Pore Size Distribution Data," Petroleum Transactions, American Institute of Mining and Metallurgical Engineers. Vol. 198, 71-78. (Copy on file in the Sandia WIPP Central Files, Sandia National Laboratories, Albuquerque, NM as WPO\#45630.)

Chan, K.S., S.R. Bodner, A.F. Fossum, and D.E. Munson. 1992. "A Constitutive Model for Inelastic Flow and Damage Evolution in Solids Under Triaxial Compression," Mechanics of Materials. SAND92-0546J. Vol. 14, no. 1, 1-14.

Cheung, S.C.H., M.N. Gray, and D.A. Dixon. 1987. "Hydraulic and Ionic Diffusion Properties of Bentonite-Sand Buffer Materials," Coupled Processes Associated with Nuclear Waste Repositories, International Symposium on Coupled Processes Affecting the Performance of a Nuclear Waste Repository, Berkeley, CA, September 18-20, 1985. Ed. C-F. Tsang. Orlando, FL: Acadenic Press, Inc. 383-407. (Copy on file in the Sandia WIPP Central Files, Sandia National Laboratories, Albuquerque, NM as WPO\#42327.)

Corey, A.T. 1954. "The Interrelation Between Gas and Oil Relative Permeabilities," Producer's Monthly. Vol. XIX, no. 1,38-41. (Copy on file in the Sandia WIPP Central Files, Sandia National Laboratories, Albuquerque, NM as WPO\#42427.)

Dale, T.F., and L.D. Hurtado. 1996. "WIPP Air-Intake Shaft Disturbed-Rock Zone Study," Proceedings of the 4ih International Conference on the Mechanical Behavior of Salt, Montreal, Quebec, Canada, June 17-18, 1996. SAND96-1327C. Albuquerque, NM: Sandia National Laboratories. 12 pp. (Copy on file in the Sandia WIPP Central Files, Sandia National Laboratories, Albuquerque, NM as WPO\#42134.)

Davies, P.B. 1991. Evaluation of the Role of Threshold Pressure in Controlling Flow of WasteGenerated Gas into Bedded Salt at the Waste Isolation.Pilot Plant. SAND90-3246. Albuquerque, NM: Sandia National Laboratories. 53 pp. 
Davis, S.N., and R.J.M. DeWiest. 1966. Hydrogeology. New York, NY: John Wiley \& Sons. $475 \mathrm{pp}$.

Engelmann, H.-J., P.W. Broochs, W. Hänsel, and L. Peters. 1989. "Dams as Sealing Systems in Rock Salt Formations-Test Dam Construction and Determination of Permeability," Sealing of Radioactive Waste Repositories, Proceedings of an NEA/CEC Workshop, Braunschweig, Federal Republic of Germany, May 22-25, 1989. EUR 12298. Paris: Organisation for Economic Co-Operation and Development. 151-162. (Copy on file in the Sandia WIPP Central Files, Sandia National Laboratories, Albuquerque, NM as WPO\#45632.)

Farmer, I.W. 1983. Engineering Behaviour of Rocks. 2nd ed. London; New York: Chapman and Hall. p. 18.

Finley, R.E., and R.L. Jones. 1994. Results of Brine Flow Testing and Disassembly of a Crushed Salt/Bentonite Block Seal at the Waste Isolation Pilot Plant. SAND93-0808. Albuquerque, NM: Sandia National Laboratories. $52 \mathrm{pp}$.

Finley, R.E., and J.R. Tillerson. 1992. WIPP Small Scale Seal Performance Tests-Status and Impacts. SAND91-2247. Albuquerque, NM: Sandia National Laboratories. 20 pp.

Fossum, A.F., T.W. Pfeifle, K.D. Mellegard, and D.E. Munson. 1994. "Probability Distributions for Parameters of the Munson-Dawson Salt Creep Model," Rock Mechanics: Models \& Measurements: Challenges from Industry: Proceedings of the 1st North American Rock Mechanics Symposium, Austin, TX, June 1-3, 1994. Eds. P.P. Nelson and S.E. Laubach. SAND93-2090C. Brookfield, VT: A.A. Balkema. 715-722.

Freeman, H.D., and G.W. Gee. 1989. Hanford Protective Barriers Program: Asphalt Barrier Studies-FY 1988. PNL-6874. Richland, WA: Pacific Northwest Laboratory. 47 pp. (Available from the National Technical Information Service, Springfield, VA as DE89014622/XAB.)

Freeman, H.D., R.A. Romine, and A.H. Zacher. 1994. Hanford Permanent Isolation Barrier Program: Asphalt Technology Data and Status Report-FY 1994. PNL-10194. Richland, WA: Pacific Northwest Laboratory. 40 pp. (Available from the National Technical Information Service, Springfield, VA as DE95005752/XAB.)

Freeze, R.A., and J.A. Cherry. 1979. Groundwater. Englewood Cliffs, NJ: Prentice-Hall, Inc. $619 \mathrm{pp}$.

Fung, Y.C. 1977. A First Course in Continuum Mechanics. 2nd ed. Englewood Cliffs, NJ: Prentice-Hall, Inc. $340 \mathrm{pp}$. 
Garisto, N.C., and D.M. LeNeveu. 1989. The Vault Model for the Disposal of Used CANDU® Fuel: Documentation and Analysis of Scoping Calculations. AECL-9578. Pinawa, Manitoba, Canada: Whiteshell Nuclear Research Establishment, Atomic Energy of Canada Limited. 222 pp. (Available from the National Technical Information Service, Springfield, VA as DE91639589/XAB.)

Gray, M.N. 1993. OECD/NEA International Stripa Project Overview. Volume III: Engineered Barriers. Stockholm, Sweden: SKB (Swedish Nuclear Fuel and Waste Management Company). 233 pp.

Hansen, F.D., and E.H. Ahrens. 1996. "Large-Scale Dynamic Compaction of Natural Salt," Proceedings of the 4th International Conference on the Mechanical Behavior of Salt, Montreal, Quebec, Canada, June 17-18, 1996. SAND96-O792C. Albuquerque, NM: Sandia National Laboratories. 13 pp. (Available from the National Technical Information Service, Springfield, VA as DE96010849/XAB.)

Hansen, F.D., and K.D. Mellegard. 1979. Creep Behavior of Bedded Salt from Southeastern New Mexico at Elevated Temperature. Technical Memorandum Report RSI-0062; SAND79-7030. Rapid City, SD: RE/SPEC Inc.; Albuquerque, NM: Sandia National Laboratories. $126 \mathrm{pp}$.

Hansen, F.D., E.H. Ahrens, V.C. Tidwell, J.R. Tillerson, and N.S. Brodsky. 1995. "Dynamic Compaction of Salt: Initial Demonstration and Performance Testing," Rock Mechanics, Proceedings of the 35th U.S. Symposium, University of Nevada, Reno, NV, June 5-7, 1995. Eds. J.J.K. Da.emen and R.A. Schultz. SAND94-2313C. Brookfield, VT: A.A. Balkema. 755-760.

Haverkamp, R., and J.Y. Parlange. 1986. "Predicting the Water-Retention Curve From ParticleSize Distribution: 1. Sandy Soils Without Organic Matter," Soil Science. Vol. 142, no. $6,325-339$.

Havlena, J.A., and D.B. Stephens. 1992. "Vadose Zone Characterization Using Field Permeameters and Instrumentation," Current Practices in Ground Water and Vadose Zone Investigations. Eds. D.M. Nielsen and M.N. Sara. ASTM STP 1118. Philadelphia, PA: American Society for Testing and Materials. 93-110.

Holcomb, D.J. 1988. "Cross-Hole Measurements of Velocity and Attenuation to Detect a Disturbed Zone in Salt at the Waste Isolation Pilot Plant," Key Questions in Rock Mechanics, Proceedings of the 29th U.S. Symposium, University of Minnesota, Minneapolis, MN, June 13-15, 1988. Eds. P.A. Cundall, R.L. Sterling, and A.M. Starfield. SAND87-3016C. Brookfield, VT: A.A. Balkema. 633-640.

Holcomb, D.J., and D.W. Hannum. 1982. Consolidation of Crushed Salt Backfill Under Conditions Appropriate to the WIPP Facility. SAND82-0630. Albuquerque, NM: Sandia National Laboratories. $108 \mathrm{pp}$. 
Holcomb, D.J., and M.E. Shields. 1987. Hydrostatic Creep Consolidation of Crushed Salt with Added Water. SAND87-1990. Albuquerque, NM: Sandia National Laboratories. 125 pp.

Hopmans, J.W., and B. Overmars. 1986. "Presentation and Application of an Analytical Model to Describe Soil Hydraulic Properties," Journal of Hydrology. Vol. 87, no. 1-2, 135-143.

Hubbert, M.K. 1956. "Darcy's Law and the Field Equations of the Flow of Underground Fluids," Journal of Petroleum Technology. Vol. 8, 222-239. (Copy on file in the Sandia WIPP Central Files, Sandia National Laboratories, Albuquerque, NM as WPO\#44971.)

Hurtado, L.D. 1996. "Shaft Seals Parameters." Records package. Albuquerque, NM: Sandia National Laboratories. (Copy on file in the Sandia WIPP Central Files, Sandia National Laboratories, Albuquerque, NM as WPO \#30640.)

Iman, R.L., and W.J. Conover. 1983. Modern Business Statistics. New York, NY: John Wiley \& Sons, Inc. $777 \mathrm{pp}$.

International Atomic Energy Agency (IAEA). 1990. Sealing of Underground Repositories for Radioactive Wastes. Prepared by M. Gray and F. Gera, with the assistance of J.R. Wiley. Revised by Z. Dlouhy and D. Squires for the IAEA's Technical Review Committee on Underground Disposal. STIDOC/10/319, Technical Reports Series No. 319. Vienna: International Atomic Energy Agency; Lanham, MD: Unipub. 125 pp. (Copy on file in the Sandia WIPP Central Files, Sandia National Laboratories, Albuquerque, NM as WPO\#41649.)

Jaeger, J.C., and N.G.W. Cook. 1976. Fundamentals of Rock Mechanics. 2nd ed. New York, NY: John Wiley \& Sons, Inc. p. 111.

Johnson, L.H., J.C. Tait, D.W. Shoesmith, J.L. Crosthwaite, and M.N. Gray. 1994. The Disposal of Canada's Nuclear Fuel Waste: Engineered Barriers Alternatives. AECL10718. Pinawa, Manitoba, Canada: Whiteshell Laboratories. 381 pp.

Kelsall, P.C., J.B. Case, D. Meyer, J.G. Franzone, and W.E. Coons. 1985. Schematic Design for Penetration Seals for a Repository in Richton Dome. BMI/ONWI-562. Columbus, OH: Office of Nuclear Waste Isolation, Battelle Memorial Institute. 182 pp. (Available from the National Technical Information Service, Springfield, VA as DE86007014/XAB.)

Knowles, M.K., and C.L. Howard. 1996. "Field and Laboratory Testing of Seal Materials Proposed for the Waste Isolation Pilot Plant," Waste Management '96, Session 7-Poster -HLW, Tucson, AZ, February 25-29, 1996. SAND95-2082C; WM '96 Paper 7-1. Tucson, AZ: Laser Optics, Inc. 9 pp. (WM '96 proceedings available only in CD-ROM. Copy of Paper 7-1 on file in the Sandia WIPP Central Files, Sandia National Laboratories, Albuquerque, NM as WPO\#44995.) 
Lappala, E.G., R.W. Healy, and E.P. Weeks. 1987. Documentation of Computer Program VS2D to Solve the Equations of Fluid Flow in Variably Saturated Porous Media. WaterResources Investigations Report 83-4099. Denver, CO: U.S. Geological Survey. 184 pp.

Lay, M.G. 1986. Handbook of Road Technology. Volume 1-Planning and Pavements. New York, NY: Gordon and Breach Science Publishers. Vol. 1.

Luckner, L., M.Th. van Genuchten, and D.R. Nielsen. 1989. "A Consistent Set of Parametric Models for the Two-Phase Flow of Immiscible Fluids in the Subsurface," Water Resources Research. Vol. 25, no. 10, 2187-2193.

Marsily, G. de. 1986. Quantitative Hydrogeology: Groundwater Hydrology for Engineers. Orlando, FL: Acadernic Press, Inc. 459 pp.

Mayer, G., F. Jacobs, and F.H. Wittmann. 1992. "Experimental Determination and Numerical Simulation of the Permeability of Cementitious Materials," Nuclear Engineering and Design. Vol. 138, no. 2, 171-177.

Meyer, D., and J.J. Howard, eds. 1983. Evaluation of Clays and Clay Minerals for Application to Repository Sealing. ONWI-486. Columbus, OH: Office of Nuclear Waste Isolation, Battelle Memorial Institute. $189 \mathrm{pp}$. (Available from the National Technical Information Service, Springfield, VA as DE83017788.)

Montgomery, D.C., and E.A. Peck. 1982. Introduction to Linear Regression Analysis. New York, NY: John Wiley \& Sons, Inc. 504 pp.

Mualem, Y. 1976. "A New Model for Predicting the Hydraulic Conductivity of Unsaturated Porous Media," Water Resources Research. Vol. 12, no. 3, 513-522. (Copy on file in the Sandia WIPP Central Files, Sandia National Laboratories, Albuquerque, NM as WPO\#41123.)

Myers, D.R., and D.A. Duranceau. 1994. Prototype Hanford Surface Barrier: Design Basis Document. BHI-00007, Rev. 00. Richland, WA: Bechtel Hanford, Inc. for the U.S. Department of Energy, Office of Environmental Restoration and Waste Management. $237 \mathrm{pp}$. (Available from the National Technical Information Service, Springfield, VA as DE95005256/XAB.)

Nowak, E.J., J.R. Tillerson, and T.M. Torres. 1990. Initial Reference Seal System Design: Waste Isolation Pilot Plant. SAND90-0355. Albuquerque, NM: Sandia National Laboratories. $58 \mathrm{pp}$.

Parker, J.C., R.J. Lenhard, and T. Kuppusamy. 1987. "A Parametric Model for Constitutive Properties Governing Multiphase Flow in Porous Media," Water Resources Research. Vol. 23, no. 4, 618-624. 
Pfeifer, M.C., D.J. Borns, C.K. Skokan, H.T. Andersen, and J.M. Starrett. 1989. “Geophysical Methods to Monitor Development of the Disturbed Rock Zone Around Underground Excavations in Bedded Salt," Proceedings of the Symposium on the Application of Geophysics to Engineering and Environmental Problems, Golden, CO, March 13-16, 1989. SAND89-7055A. Vol. 2, 400-411. (Copy on file in the Sandia WIPP Central Files, Sandia National Laboratories, Albuquerque, NM as WPO\#44690.)

Pfeifle, T.W. 1991. Consolidation, Permeability, and Strength of Crushed Salt/Bentonite Mixtures With Application to the WIPP. SAND90-7009. Albuquerque, NM: Sandia National Laboratories. $105 \mathrm{pp}$.

Pfeifle, T.W., F.D. Hansen, and M.K. Knowles. 1996. "Salt-Saturated Concrete Strength and Permeability," 4th Materials Engineering Conference, ASCE Materials Engineering Division, Washington, DC, November 10-14, 1996. SAND96-1789C. Albuquerque, NM: Sandia National Laboratories. 11 pp.

Pihlajavaara, S.E. 1991. "Long-Term Gas Permeability Properties of Concrete in Wet Repository Conditions," Nuclear Engineering and Design. Vol. 129, no. 1, 41-48.

Prindle, N.H., F.T. Mendenhall, W. Beyeler, K. Trauth, S. Hora, D. Rudeen, and D.M. Boak. 1996. The Second Iteration of the Systems Prioritization Method: A Systems Prioritization and Decision-Aiding Tool for the Waste Isolation Pilot Plant-Volume II: Summary of Technical Input and Model Implementation. SAND95-2017/2. Albuquerque, NM: Sandia National Laboratories. 192 pp.

Pusch, R. 1980. Permeability of Highly Compacted Bentonite. SKBF/KBS 80-16. Stockholm: Svensk Kärnbränsleförsörjning $\mathrm{AB}$ / Projekt Kärnbränslesäkerhet. 42 pp. (Copy on file in the Sandia WIPP Central Files, Sandia National Laboratories, Albuquerque, NM as WPO\#46068.)

Pusch, R. 1982. "Mineral-Water Interactions and Their Influence on the Physical Behavior of Highly Compacted Na Bentonite," Canadian Geotechnical Journal. Vol. 19, no. 3, 381-387.

Pusch, R. 1985. "The Buffer Mass Test," Proceedings of the Symposium on In Situ Experiments in Granite Associated With the Disposal of Radioactive Waste, International Stripa Project, Stockholm, Sweden, June 4-6, 1985. Paris: Organisation for Economic CoOperation and Development. 120-131. (Copy on file in the Sandia WIPP Central Files, Sandia National Laboratories, Albuquerque, NM as WPO\#44972.)

Pusch, R., and L. Börgesson. 1989. "Bentonite Sealing of Rock Excavations," Sealing of Radioactive Waste Repositories, Proceedings of an NEA/CEC Workshop, Braunschweig, Federal Republic of Germany, May 22-25, 1989. EUR 12298. Paris: Organisation for Economic Co-Operation and Development. 297-308. (Copy on file in the Sandia WIPP Central Files, Sandia National Laboratories, Albuquerque, NM as WPO\#42423.) 
Pusch, R., and L. Börgesson. 1990. "Borehole, Shaft, and Tunnel Sealing of Rock Repositories," Proceedings of the 3rd NEA/SKB Symposium on In Situ Experiments Associated With the Disposal of Radioactive Waste, International Stripa Project, Stockholm, Sweden, October 3-4, 1989. Paris: Organisation for Economic Co-Operation and Development. 263-272. (Copy on file in the Sandia WIPP Central Files, Sandia National Laboratories, Albuquerque, NM as WPO\#43256.)

Pusch, R., L. Börgesson, and G. Ramqvist. 1987a. Final Report of the Borehole, Shaft, and Tunnel Sealing Test--Volume I: Borehole Plugging. SKB-SP-TR-87-01. Stockholm, Sweden: SKB (Swedish Nuclear Fuel and Waste Management Company). 79 pp. (Available from the National Technical Information Service, Springfield, VA as DE88753021/XAB.)

Pusch, R., L. Börgesson, and G. Ramqvist. 1987b. Final Report of the Borehole, Shaft, and Tunnel Sealing Test--Volume II: Shaft Plugging. SKB-SP-TR-87-02. Stockholm, Sweden: SKB (Swedish Nuclear Fuel and Waste Management Company). 64 pp. (Available from the National Technical Information Service, Springfield, VA as DE88753022/XAB.)

Pusch, R., L. Börgesson, and G. Ramqvist. 1987c. Final Report of the Borehole, Shaft, and Tunnel Sealing Test--Volume III: Tunnel Plugging. SKB-SP-TR-87-03. Stockholm, Sweden: SKB (Swedish Nuclear Fuel and Waste Management Company). 110 pp. (Available from the National Technical Information Service, Springfield, VA as DE88753310/XAB.)

Pusch, R., M. Gray, F. Huertas, M. Jorda, A. Barbreau, and R. Andre-Jehan. 1989. "Sealing of Radioactive Waste Repositories in Crystalline Rock," Sealing of Radioactive Waste Repositories, Proceedings of an NEA/CEC Workshop, Braunschweig, Federal Republic of Germany, May 22-25, 1989. EUR 12298. Paris: Organisation for Economic CoOperation and Development. 214-228. (Copy on file in the Sandia WIPP Central Files, Sandia National Laboratories, Albuquerque, NM as WPO\#42438.)

Radhakrishna, H.S., H.T. Chan, A.M. Crawford, and K.C. Lau. 1989. "Thermal and Physical Properties of Candidate Buffer-Backfill Materials for a Nuclear Fuel Waste Disposal Vault," Canadian Geotechnical Journal. Vol. 26, no. 4, 629-639. (Copy on file in the Sandia WIPP Central Files, Sandia National Laboratories, Albuquerque, NM as WPO\#44975.)

Ran, C., and J. Daemen. 1995. "Bentonite Properties." University of Nevada-Reno, Department of Mining Engineering memorandum to F. Hansen, December 4, 1995. Reprinted in Appendix A.

Rawls, W.J., D.L. Brakensiek, and K.E. Saxton. 1982. "Estimation of Soil Water Properties," Transactions of the A.SAE (American Society of Agricultural Engineers). 1316-1320. (Copy on file in the Sandia WIPP Central Files, Sandia National Laboratories, Albuquerque, NM as WPO\#42417.) 
RE/SPEC. 1996. "Fitting of RE/SPEC, Inc. and Stormont Permeability Versus Volumetric Strain Data." Calculation File 325/09/03. Prepared for Sandia National Laboratories, Albuquerque, NM. Rapid City, SD: RE/SPEC, Inc. (Copy on file in the Sandia WIPP Central Files, Sandia National Laboratories, Albuquerque, NM as WPO\#36435.)

RISD (Repository Isolation Systems Department). 1996. Waste Isolation Pilot Plant Shaft Sealing System Compliance Submittal Design Report. SAND96-1326/1/2. Albuquerque, NM: Sandia National Laboratories. Vols. 1-2. 443 pp.

Sjaardema, G.D., and R.D. Krieg. 1987. A Constitutive Model for the Consolidation of WIPP Crushed Salt and Its Use in Analyses of Backfilled Shaft and Drift Configurations. SAND87-1977. Albuquerque, NM: Sandia National Laboratories. 68 pp.

SKB (Swedish Nuclear Fuel and Waste Management Company). 1978. Handling and Final Storage of Unreprocessed Spent Nuclear Fuel-Volume II: Technical. Stockholm, Sweden: SKB (Swedish Nuclear Fuel and Waste Management Company). (Copy on file in the Sandia WIPP Central Files, Sandia National Laboratories, Albuquerque, NM as WPO\#43363.)

SKI (Swedish Nuclear Power Inspectorate). 1984. Review of Final Storage of Spent Nuclear Fuel-KBS-3. A. Larsson, J-E. Andersson, K. Andersson, F. Kautsky, S. Norrby, A. Rantanen, M. Trolle, and S. Wingefors. SKI TR 84:5. Stockholm: SKI (Swedish Nuclear Power Inspectorate). 250 pp. (Copy on file in the Sandia WIPP Central Files, Sandia National Laboratories, Albuquerque, NM as WPO\#45629.)

Stephens, D.B., M. Unruh, J. Havlena, R.G. Knowlton, Jr., E. Mattson, and W. Cox. 1988.

"Vadose Zone Characterization of Low-Permeability Sediments Using Field Permeameters," Ground Water Monitoring Review. Vol. 8, no. 2, 59-66.

Stormont, J.C. 1988. Preliminary Seal Design Evaluation for the Waste Isolation Pilot Plant. SAND87-3083. Albuquerque, NM: Sandia National Laboratories.

Stormont, J.C. 1990a. "Discontinuous Behavior Near Excavations in a Bedded Salt Formation," International Journal of Mining and Geologic Engineering. SAND89-2403J. Vol. 8, no. $1,35-56$.

Stormont, J.C. 1990b. Summary of 1988 WIPP Facility Horizon Gas Flow Measurements. SAND89-2497. Albuquerque, NM: Sandia National Laboratories. 260 pp.

Stormont, J.C., and C.L. Howard. 1987. Development, Implementation and Early Results: Test Series $C$ of the Small-Scale Seal Performance Tests. SAND87-2203. Albuquerque, NM: Sandia National Laboratories. 78 pp. 
Struhrenberg, D., and C.L. Zhang. 1995. "Results of Experiments on the Compaction and Permeability Behavior of Crushed Salt," Proceedings of the 5th International Conference on Radioactive Waste Management and Environmental Remediation (ICEM '95). Volume 1: Cross-Cutting Issues and Management of High-Level Waste and Environmental Remediation, Berlin, Germany, September 3-7, 1995. Eds. S. Slate and F. Fiezollahi. New York, NY: American Society of Mechanical Engineers. Vol. 1, 797-801. (Copy on file in the Sandia WIPP Central Files, Sandia National Laboratories, Albuquerque, NM as WPO\#41580.)

Terrel, R.L., and S. Al-Swailmi. 1993. Role of Pessimum Voids Concept in Understanding Moisture Damage to Asphalt Concrete Mixtures. Transportation Research Record No. 1386. Washington, DC: Transportation Research Board. 31-37. (Copy on file in the Sandia WIPP Central Files, Sandia National Laboratories, Albuquerque, NM as WPO\#44965.)

Touloukian, Y.S., W.R. Judd, and R.F. Roy, eds. 1981. Physical Properties of Rocks and Minerals. McGraw-Hill/CINDAS Data Series on Material Properties Volume II-2. Eds. Y.S. Touloukian and C.Y. Ho. New York, NY: McGraw-Hill Book Company. 548 pp.

U.S. Bureau of Reclamation. 1977. Design of Small Dams. 2nd ed., rev. reprint. A Water Resources Technical Publication. GPO Stock Number: 024-003-00119-8. Washington, DC: Department of the Interior, Bureau of Reclamation; For Sale by the Superintendent of Documents, U.S. Government Printing Office. 816 pp.

U.S. Bureau of Reclamation. 1987. Design of Small Dams. 3rd ed. A Water Resources Technical Publication. W. Duncan, C. Huntley, J. Hokenstrom, A. Cudworth, and T. McDaniel. GPO Stock Number: 024-003-0164-3. Washington, DC: Department of the Interior, Bureau of Reclamation; For Sale by the Superintendent of Documents, U.S. Government Printing Office. 860 pp. (Available from the National Technical Information Service, Springfield, VA as PB95-176368/XAB.)

U.S. Department of Energy (DOE). 1995. Waste Isolation Pilot Plant Sealing System Design Report. DOE/WIPP-95-3117. Carlsbad, NM: Waste Isolation Pilot Plant. (Copy on file in the Sandia WIPP Central Files, Sandia National Laboratories, Albuquerque, NM as WPO\#29062.)

U.S. Department of Energy (DOE). 1996. Title 40 CFR Part 191 Compliance Certification Application for the Waste Isolation Pilot Plant. DOE/CAO-1996-2184. Carlsbad, NM: United States Department of Energy, Waste Isolation Pilot Plant, Carlsbad Area Office.

van Genuchten, M.Th. 1980. "A Closed-Form Equation for Predicting the Hydraulic Conductivity of Unsaturated Soils," Soil Science Society of America Journal. Vol. 44, no. 5, 892-898. 
van Genuchten, M.Th., and D.R. Nielsen. 1985. "On Describing and Predicting the Hydraulic Properties of Unsaturated Soils," Annales Geophysicae. Vol. 3, no. 5, 615-628. (Copy on file in the Sandia WIPP Central Files, Sandia National Laboratories, Albuquerque, NM as WPO\#41129.)

Van Pelt, R.S. 1995. "Permeability Estimates from Boreholes MGF08 and MGF09." Intera Inc memorandum to M.K. Knowles, November 20, 1995. Reprinted in Appendix A.

Van Sambeek, L.L. 1987. Thermal and Thermomechanical Analyses of WIPP Shaft Seals. Topical Report RSI-0324; SAND87-7039. Rapid City, SD: RE/SPEC Inc.; Albuquerque, NM: Sandia National Laboratories. 91 pp.

Van Sambeek, L.L., D.D. Luo, M.S. Lin, W. Ostrowski, and D. Oyenuga. 1993. Seal Design Alternatives Study. SAND92-7340. Albuquerque, NM: Sandia National Laboratories. $202 \mathrm{pp}$.

Wakeley, L.D., T.S. Poole, and J.P. Burkes. 1994. Durability of Concrete Materials in HighMagnesium Brine. SAND93-7073. Albuquerque, NM: Sandia National Laboratories. $86 \mathrm{pp}$.

Wakeley, L.D., P.T. Harrington, and F.D. Hansen. 1995. Variability in Properties of Salado Mass Concrete. SAND94-1495. Albuquerque, NM: Sandia National Laboratories. 78 pp.

Webb, S.W. 1992. "Uncertainty Estimates for Two-Phase Characteristic Curves for 199240 CFR 191 Calculations," Preliminary Performance Assessment for the Waste Isolation Pilot Plant, December 1992. Volume 3: Model Parameters. Sandia WIPP Project. SAND92-0700/3. Albuquerque, NM: Sandia National Laboratories. A-147 through A155.

Westinghouse Electric Corporation (WEC). 1983. Conceptual Waste Package Designs for Disposal of Nuclear Waste in Tuff. ONWI-439. Pittsburgh, PA: Westinghouse Electric Corporation, Advanced Energy Systems Division; Columbus, OH: Office for Nuclear Waste Isolation, Battelle Memorial Institute. $466 \mathrm{pp}$. (Available from the National Technical Information Service, Springfield, VA as DE83013112.)

Wheelwright, E.J., F.N. Hodges, L.A. Bray, J.H. Westsik, Jr., D.H. Lester, T.L. Nakai, M.E. Spaeth, and R.T. Stula. 1981. Development of Backfill Material as an Engineered Barrier in the Waste Package System-Interim Topical Report. PNL-3873. Richland, WA: Pacific Northwest Laboratory. 105 pp. (Available from the National Technical Information Service, Springfield, VA as DE82000937.)

WIPP PA (Performance Assessment). 1991-1992. Preliminary Comparison with 40 CFR Part 191, Subpart B for the Waste Isolation Pilot Plant, December 1991. SAND91-0893. Albuquerque, NM: Sandia National Laboratories. Vols. 1-4. 
WIPP PA (Performance Assessment). 1992-1993. Preliminary Performance Assessment for the Waste Isolation Pilot Plant, December 1992. SAND92-0700. Albuquerque, NM: Sandia National Laboratories. Vols. 1-5.

Wosten, J.H.M., and M.Th. van Genuchten. 1988. "Using Texture and Other Soil Properties to Predict the Unsaturated Soil Hydraulic Functions," Soil Science Society of America Journal. Vol. 52, no. 6, 1762-1770.

Zakar, P. 1971. Asphalt. Translation of Bitumen. New York, NY: Chemical Publishing Company, Inc. 205 pp.

Zeuch, D.H., D.J. Zimmerer, and M.E. Shields. 1991. Interim Report on the Effects of BrineSaturation and Shear Stress on Consolidation of Crushed, Natural Rock Salt from the Waste Isolation Pilot Plant (WIPP). SAND91-0105. Albuquerque, NM: Sandia National Laboratories. 76 pp. 


\section{APPENDIX A}

\section{Memoranda Regarding Reference Data}




\section{Errata}

Review of the two memos in this appendix revealed the following inaccuracies.

\begin{tabular}{|l|l|}
\hline \multicolumn{1}{|c|}{ Page } & \multicolumn{1}{c|}{ Change } \\
\hline A-5 & $\begin{array}{l}\text { The word "Arlington" is misspelled in the first reference. This } \\
\text { reference is also available as: } \\
\text { American Colloid Company. 1995. "Technical Data Sheet, Volclay } \\
\text { GPG 30." Arlington Heights, IL: American Colloid } \\
\text { Company, Industrial Chemical Division. (Copy on file in the } \\
\text { Sandia WIPP Central Files, Sandia National Laboratories, } \\
\text { Albuquerque, NM as WPO\#39636.) }\end{array}$ \\
\hline A-5 & $\begin{array}{l}\text { In the third reference, the name of the final author should be spelled } \\
\text { "Kiefer." }\end{array}$ \\
\hline
\end{tabular}


to: Frank Hansen, SNL<smiles>c1ccccc1</smiles>

from: Chongwei Ran and Jaak Daemen

c.: Van Kelley, INIERA; Tom Pfeifle, RE/SPEC; Dianc Hurado, SNL 6121

subject: Bentonite Properties

\section{Permeability of bentonite}

\begin{tabular}{|l|l|l|l|}
\hline Dry Density $\left(\mathrm{g} / \mathrm{cm}^{3}\right)$ & 1.4 & 1.8 & 2.1 \\
\hline Permeability $\left(\mathrm{m}^{2}\right)$ & $1.0 \times 10^{-18}$ & $1.0 \times 10^{-19}$ & $1.0 \times 10^{-21}$ \\
\hline
\end{tabular}

2. Effects of permeant salinity on permesbility

\begin{tabular}{|l|l|}
\hline $\mathrm{NaCl}$ concentration $(\mathrm{M})$ & Increase in permeability orders of magnitude \\
\hline$<1.0$ & $\begin{array}{l}2 \text { for all densities (Kenney et al. 1992) } \\
\text { (Pusch. 1994. 0-2 }\end{array}$ \\
\hline$>2.0$ & about 322). \\
\hline
\end{tabular}

* from Kenney et al. (1992) for $20: 80$ bentonite to sand, permeant with $0.7 \mathrm{M} \mathrm{NaCl}$ with dry density' from 1.5 to $1.8 \mathrm{~g} / \mathrm{cm}^{3}$.

** our test result for bentonite with 1.2 to $1.4 \mathrm{~g} / \mathrm{cm}^{3}$ permeated with $100 \%$ WIPP brine.

\section{Young's modulus}

Figure 1 shows the relationship between Young's Modulus and minor principal stress $\sigma_{3}$ (after Janbu, 1963). The Young's modulus (E) of clay is given by (Janbu, 1963):

$$
\mathrm{E}=K_{0}\left(\frac{\sigma_{3}}{p_{a}}\right)^{n}
$$

where $K$ is a dimensionless modulus number that varies from about 300 to 2000 (Mitchell, 1993, p. 339), for saturated bentosite, the range probably is much narrow about 100 to 300 , or less,

$\mathrm{D}$ is an exponent usually in the range of 0.3 to 0.6 (Mitchell, 1993, p. 339),

$p_{\mathbf{a}}$ is a unit constant equal to atmospheric pressure, and $\sigma_{3}$ is minor principal stress.

Yin at al. (1990) concluded that the Young's modulus of a 50:50 bentonite sand mixture is:

$$
E=k p
$$

where $k$ is a constant $k=80$ for $50: 50$ bentonite sand mixture, and $p^{\prime}$ is the effective mean stress $p^{\prime}=1 / 3$

$$
\left(\sigma_{1}{ }^{\circ}+2 \sigma_{3}{ }^{*}\right) \text {. }
$$

The Young's modulus of bentonite should be lower than that of a bentonite sand mixture. Highly compacted bentonite $\left(2.0 \mathrm{~g} / \mathrm{cm}^{3}\right.$ with $10 \%$ water content) has a Young's modulus up to $300 \mathrm{MPa}$ and decreases with the uptaking water (Meyer and Howard, 1983) 


\section{Bulk modulus}

Yin at al. (1990) conciuded that the bulk modulus of a 50:50 bentonite sand mixture is: 13.7 p'. Again, for bentonite by itself, the modulus almost certainly is lowier.

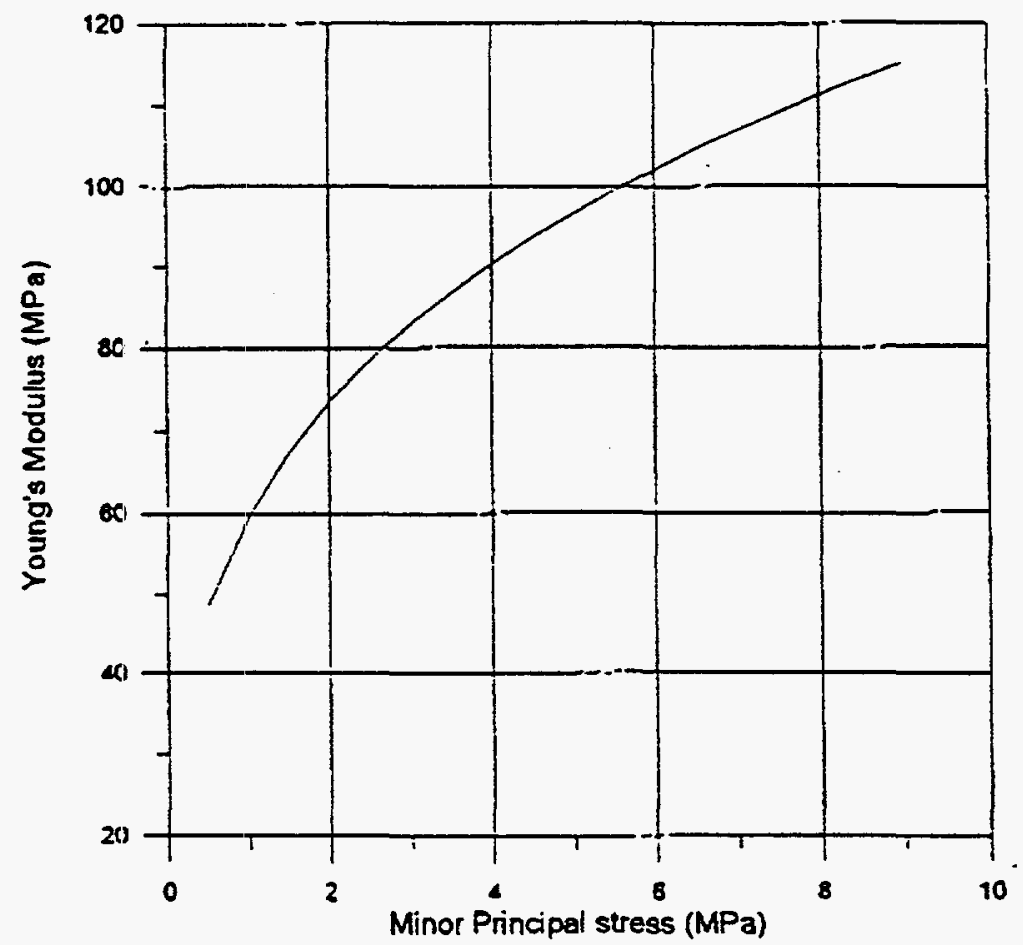

Figure 1. Young's Modulus of clay as a function of minor principal stress with $K=300, P_{2}=14.4$ psi, and $\mathrm{n}=0.3$ in Eq. (1), after Janbu, 1963).

Poisson's ratio

Mejer and Howard (198:) reported that for highly compacted bentonite $\left(2.0 \mathrm{~g} / \mathrm{cm}^{3}\right.$ with $10 \%$ water content), the poisson's ratio is about 0.15 .

For soft clay, the Poisson's satio should be about 0.375 according to Dunn et al. (1980, p. 113-114). We know saturated bentonite is extremely plastic. Therefore we would expect Poisson's ratio to be larger, i.e. at least 0.4 and probably 0.45 òr larger.

\section{Porosity of bentonite}<smiles>C1CCCC1</smiles>

The porosity of bentonite should be calculated from void ratio with some deduction (maybe $20-50 \%$ ) due to unremovable water molecules on the surface of the bentonite particles.

$$
n=-\frac{e}{1+e}
$$

where $e$ is the void ratio, and can be calculated from specific gravity $\left(G_{2}\right)$ of bentonite, the dry density ( $p_{d}$ ) of the bentonite seal, and the density of water $\left(\rho_{w}\right)$.

$$
e=G_{s} \frac{\rho_{w}}{\rho_{d}}-1
$$


The specific gravity of bentonite is about 2.4 to 2.8. For Volclay GPG-30, the specific gravity is 2.5 (American Colloid Company, 1995). The effective porosity should vary with moisture content and salt concentration in bentonite seals. Diamond (1970) measured the effective porosity of montmorillonite is $35 \%$ less than the calculated porosity. Figure two shows dry density varies as a function of porosity .

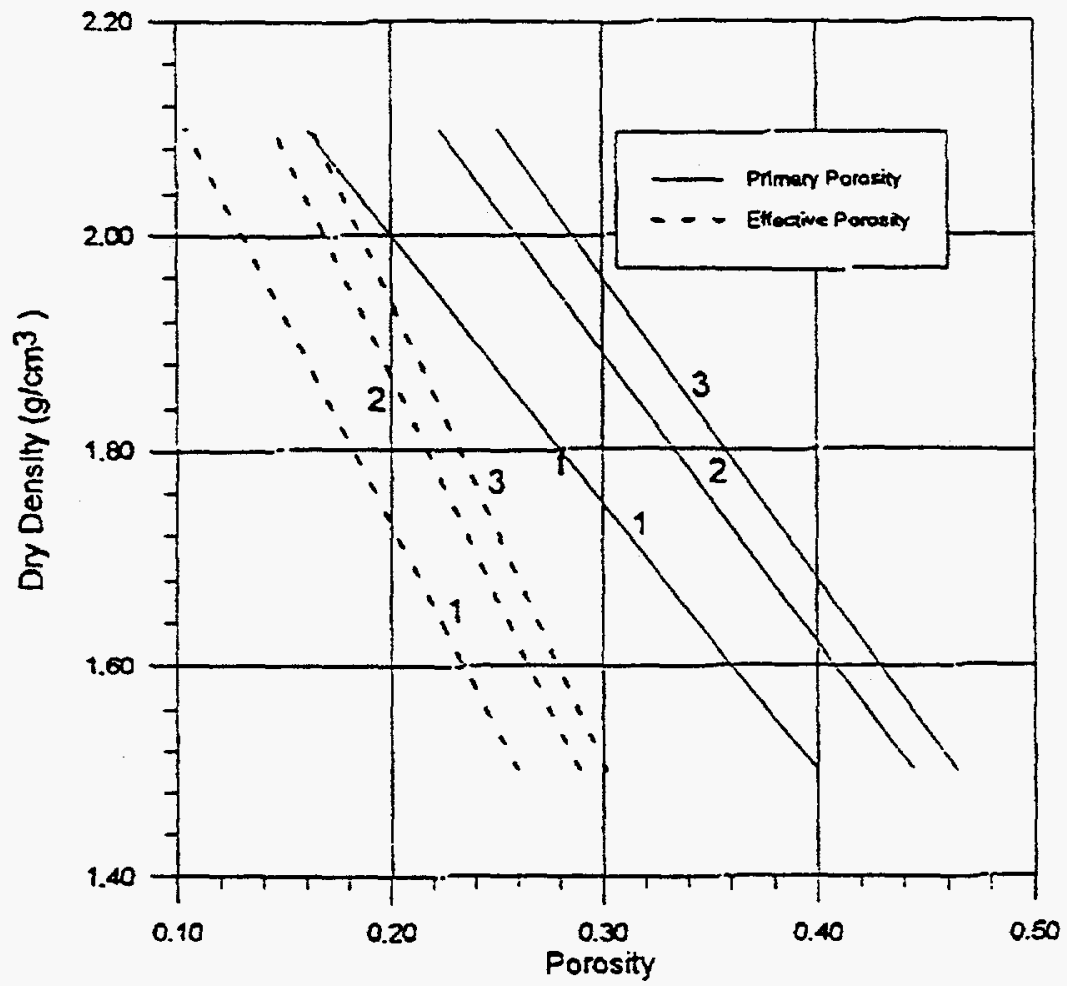

Figure 2. Dry density of bentonite as a function of porosity, where $1-G_{6}=2.5,2-G_{t}=2.7$ and $3-G_{c}=2.8$. The effective porosity is $65 \%$ of the primary porosity (calculated from eqs 3 and 4 ).

References:

American Colloid Company, 1995, Material Safety Data Sheet, Volclay GPG-30. Industry Chemical Division, American Colloid Company, Arington Heights, Illinois. 3 p.

Diamond, S., 1970. Pore Size Distributions in Clays. Clays \& Clay Minerals, Vol. 18. pp. 7-23.

Dunn, I.S., L.R. Anderson, and F.W. Kieter, 1980. Fundamentals of Geotechnical Analysis, John Wiley \& Sons, New York.

Janbu, N., 1963. Soil compressibility as determined by oedometer and triaxial tests. European conference on soil mechanism and foundation engineering, Wiesbaden, Germany, Vol. 1, pp. 19-25.

Kenney, I.C., W.A. van Veen, M.A. Swallow and M.A. Sungaila, 1992. Hydraulic conductivity of compacted bentonite-sand mixtures., Can. Geotech. J. Vol. 29, p. 364-374.

Meyer, D. and J.J. Howrard, Editors, 1983. Evaluation of Clays and Clay Minerals for Application to Repository Sealing, Technical Report ONWI-486, Office of Nuclear Waste Isolacion, Columbus, OH.

Mitchell, J. K., 1993. Fundamentals of Soil Behavior, 2nd Ed, John Wiley \& Sons, New York.

Pusch R., 1994. Waste Disposal in Rock. Elsevier, Amsterdam. 490 p. 
Yin, J.II., F. Saadat, and J. Graham, 1990. Constitutive modeling of a compacted sand-bentonite mixture using three-modulus hyposlasticity, Can. Geotech. J. Vol. 27. p. 365-372. 


\section{LIJ J I J}

INTERA INC. - 6850 Austin Center Boulevard - Suite 300 - Austin. Texas 78731. USA - Telephone: 512-346-2000 - Facsimile:512-346-9436 MEMORANDUM

To: M.K. Knowles, SNL 6121 MS\#1322

From: $\quad$ R.S. Van Pelt, INTERA, WIPP site MS\#13955iy

Date: November 20, 1995

Re: $\quad$ Permeability Estimates from Boreholes MGF08 and MGF09

As per your request of last Friday, I am submitting this memo as a short summary of results for two of the nine boreholes tested as part of the SSSPT-A Postmortem Activities. Both boreholes were tested with the 3.5" four-packer test tool and DGFT 001. The tests were conducted according to the low pressure nitrogen gas injection section of WIPP/SNL Procedure 447. Data was collected on a HP 3497 a based DAS according to WIPP/SNL Procedure 430 and data was processed according to WIPP/SNL Procedure 528. Permeability estimates were simulated and matched with the test observations of constant pressure flow rates and pressure decay curves with GTFM ver. 5.20. Assumptions used in the simulations included a formation porosity of 0.01 , a spherical flow geometry, a formation pressure of $0 \mathrm{psig}$, and no zero flow boundary closer than $100 \mathrm{~m}$ from the test interval. The permeability estimates are presented in the following tables.

\begin{tabular}{|c|c|}
\hline \multicolumn{2}{|c|}{ Gas-Permeability } \\
\hline \hline Test Zone Depth (in) & Estimated for MGF08 \\
\hline $54-69$ & $2.0 \times 10^{-16}\left(\mathrm{~m}^{2}\right)$ \\
\hline $83-98$ & $2.1 \times 10^{-21}$ \\
\hline
\end{tabular}

\begin{tabular}{|c|c|}
\hline \multicolumn{2}{|c|}{ Gas-Permeability Estimates for MGF09 } \\
\hline \hline Test Zone Depth (in) & Estimated $\mathrm{k}_{\text {gas }}\left(\mathrm{m}^{2}\right)$ \\
\hline $54-69$ & $2.7 \times 10^{-20}$ \\
\hline $83-98$ & $7.0 \times 10^{-21}$ \\
\hline $119-134$ & $9.0 \times 10^{-22}$ \\
\hline $153-163$ & $5.0 \times 10^{-21}$ \\
\hline
\end{tabular}

Albuquerque - Austin - Carlsbad - Los Angeles - Switzerlano 
Over-coring activities performed in october 1994 caused the partial filling of MGF08. The muck was subsequently wetted with brine that seeped into the borehole from the surrounding formation. Through consultation with the WID Experimental operations drill crew, we determined that we would have to re-drill the borehole in order to test the bottom two intervals. Due to lack of available time and funds, this salvage operation was not performed.

Borehole MGFO9 was located 4 radii (6') from the longitudinal centerline of MAE32 in relatively undisturbed halite. The lack of mechanical disturbance is evident in the relatively uniform profile of permeability with depth.

Borehole MGF08 was located 1.25 radii (22.5") from the longitudinal centerline of MAE:32 on a line from the centerline of MGFO9 to the centerline of MAE'32. The radius of MAE32 (18") and of MGFO8 (2") only left 2.5" of halite between the adjacent walls of the two boreholes.

The $54-69^{\prime \prime}$ deep testzone was apparently, as evidenced by the high gas permeability estimate, influenced by the mechanical damage due to the mining and presence of MAE32. The 83 - 98 " deep testzone was adjacent to the rigid inclusion offered by the concrete seal cast in MAE32. These results are consistent with those found in the DRZ characterization study performed around the horizontal seals in Room $D$.

cC: Tim Dale, INTERA, Austin

J.F. Pickens, INTERA, Austin 


\section{UC721 - DISTRIBUTION LIST \\ SAND97-1287}

\section{Federal Agencies}

US Department of Energy (4)

Office of Civilian Radioactive Waste Mgmt.

Attn: Deputy Director, RW-2

Acting Director, RW-10

Office of Human Resources \& Admin.

Director, RW-30

Office of Program Mgmt. \& Integ.

Director, RW-40

Office of Waste Accept., Stor., \& Tran.

Forrestal Building

Washington, DC 20585

Attn: Project Director

Yucca Mountain Site Characterization Office

Director, RW-3

Office of Quality Assurance

P.O. Box 30307

Las Vegas, NV 89036-0307

US Department of Energy

Albuquerque Operations Office

Attn: National Atomic Museum Library

P.O. Box 5400

Albuquerque, NM 87185-5400

US Department of Energy

Research \& Waste Management Division

Attn: Director

P.O. Box E

Oak Ridge, TN 37831

US Department of Energy (5)

Carlsbad Area Office

Attn: G. Dials

D. Galbraith

M. McFadden

R. Lark

J. A. Mewhinney

P.O. Box 3090

Carlsbad, NM 88221-3090

US Department of Energy

Office of Environmental Restoration and

Waste Management

Attn: M Frei, EM-30

Forrestal Building

Washington, DC 20585-0002
US Department of Energy (3)

Office of Environmental Restoration and Waste Management

Attn: J. Juri, EM-34, Trevion II

Washington, DC 20585-0002

US Department of Energy

Office of Environmental Restoration and

Waste Management

Attn: S. Schneider, EM-342, Trevion II

Washington, DC 20585-0002

US Department of Energy (2)

Office of Environment, Safety \& Health

Attn: C. Borgstrom, EH-25

R. Pelletier, EH-231

Washington, DC 20585

US Department of Energy (2)

Idaho Operations Office

Fuel Processing \& Waste Mgmt. Division

785 DOE Place

Idaho Falls, ID 83402

US Environmental Protection Agency (2)

Radiation Protection Programs

Attn: M. Oge

ANR-460

Washington, DC 20460

\section{Boards}

Defense Nuclear Facilities Safety Board

Attn: D. Winters

625 Indiana Ave. NW, Suite 700

Washington, DC 20004

Nuclear Waste Technical Review Board (2)

Attn: Chairman

$$
\text { J. L. Cohon }
$$

1100 Wilson Blvd., Suite 910

Arlington, VA 22209-2297 


\section{State Agencies}

Attomey General of New Mexico

P.O. Drawer 1508

Santa Fe, NM 87504-1508

Environmental Evaluation Group (3)

Attn: Library

7007 Wyoming NE

Suite F-2

Albuquerque, NM 87109

NM Environment Department (3)

Secretary of the Environment

Attn: Mark Weidler

1190 St. Francis Drive

Santa Fe, NM 87503-0968

NM Bureau of Mines \& Mineral Resources Socorro, NM 87801

\section{Laboratories/Corporations}

Battelle Pacific Northwest Laboratories Battelle Blvd.

Richland, WA 99352

Los Alamos National Laboratory

Attn: B. Erdal, INC-12

P.O. Box 1663

Los Alamos, NM 87544

Tech Reps, Inc. (3)

Attn: J. Chapman (1) Loretta Robledo (2)

5000 Marble NE, Suite 222

Albuquerque, NM 87110

Westinghouse Electric Corporation (5)

Attn: Library

J. Epstein

J. Lee

B. A. Howard

R. Kehrman

P.O. Box 2078

Carlsbad, NM 88221

S. Cohen \& Associates

Attn: Bill Thurber

1355 Beverly Road

McLean, VA 22101
National Academy of Sciences, WIPP Panel

Howard Adler

Oxyrase, Incorporated

7327 Oak Ridge Highway

Knoxville, TN 37931

Tom Kiess

Board of Radioactive Waste Management

GF456

2101 Constitution Ave.

Washington, DC 20418

Rodney C. Ewing

Department of Geology

University of New Mexico

Albuquerque, NM 87131

Charles Fairhurst

Department of Civil and Mineral Engineering

University of Minnesota

500 Pillsbury Dr. SE

Minneapolis, MN 55455-0220

B. John Garrick

PLG Incorporated

4590 MacArthur Blvd., Suite 400

Newport Beach, CA 92660-2027

Leonard F. Konikow

US Geological Survey

431 National Center

Reston, VA 22092

Carl A. Anderson, Director

Board of Radioactive Waste Management

National Research Council

HA 456

2101 Constitution Ave. NW

Washington, DC 20418

Christopher G. Whipple

ICF Kaiser Engineers

1800 Harrison St., 7th Floor

Oakland, CA 94612-3430

John O. Blomeke

720 Clubhouse Way

Knoxville, TN 37909 
Sue B. Clark

University of Georgia

Savannah River Ecology Lab

P.O. Drawer E

Aiken, SC 29802

Konrad B. Krauskopf

Department of Geology

Stanford University

Stanford, CA 94305-2115

Della Roy

Pennsylvania State University

217 Materials Research Lab

Hastings Road

University Park, PA 16802

David A. Waite

$\mathrm{CH}_{2} \mathrm{M}$ Hill

P.O. Box 91500

Bellevue, WA 98009-2050

Thomas A. Zordon

Zordan Associates, Inc. 3807 Edinburg Drive

Murrysville, PA 15668

\section{Universities}

University of New Mexico

Geology Department

Attn: Library

141 Northrop Hall

Albuquerque, NM 87131

University of Washington

College of Ocean \& Fishery Sciences

Attn: G. R. Heath

583 Henderson Hall, HN-15

Seattle, WA 98195

\section{Libraries}

Thomas Brannigan Library

Attn: D. Dresp

106 W. Hadley St.

Las Cruces, NM 88001

Government Publications Department

Zimmerman Library

University of New Mexico

Albuquerque, NM 87131
New Mexico Junior College

Pannell Library

Attn: R. Hill

Lovington Highway

Hobbs, NM 88240

New Mexico State Library

Attn: N. McCallan

325 Don Gaspar

Santa Fe, NM 87503

New Mexico Tech

Martin Speere Memorial Library

Campus Street

Socorro, NM 87810

WIPP Public Reading Room

Carlsbad Public Library

$101 \mathrm{~S}$. Halagueno St.

Carlsbad, NM 88220

Foreign Addresses

Atomic Energy of Canada, Ltd.

Whiteshell Laboratories

Attn: B. Goodwin

Pinawa, Manitoba, CANADA R0E ILO

Francois Chenevier (2)

ANDRA

Route de Panorama Robert Schumann

B. P. 38

92266 Fontenay-aux-Roses, Cedex

FRANCE

Claude Sombret

Centre d'Etudes Nucleaires de la Vallee Rhone

CEN/VALRHO

S.D.H.A. B.P. 171

30205 Bagnols-Sur-Ceze

FRANCE

Commissariat a L'Energie Atomique

Attn: D. Alexandre

Centre d'Etudes de Cadarache

13108 Saint Paul Lez Durance Cedex

FRANCE 
Bundesanstalt fur Geowissenschaften und

Rohstoffe

Attn: M. Langer

Postfach 510153

D-30631 Hannover

GERMANY

Bundesministerium fur Forschung und

Technologie

Postfach 200706

5300 Bonn 2

GERMANY

Institut fur Tieflagerung

Attn: K. Kuhn

Theodor-Heuss-Strasse 4

D-3300 Braunschweig

GERMANY

Gesellschaft fur Anlagen und Reaktorsicherheit (GRS)

Attn: B. Baltes

Schwertnergasse 1

D-50667 Cologne

GERMANY

Shingo Tashiro

Japan Atomic Energy Research Institute

Tokai-Mura, Ibaraki-Ken, 319-11

JAPAN

Netherlands Energy Research Foundation ECN

Attn: J. Prij

3 Westerduinweg

P.O. Box 1

1755 ZG Petten

THE NETHERLANDS

Svensk Karnbransleforsorjning AB

Attn: F. Karlsson

Project KBS (Kambranslesakerhet)

Box 5864

S-102 48 Stockholm

SWEDEN

Nationale Genossenschaft fur die Lagenung

Radioaktiver Abfalle (2)

Attn: S. Vomvoris

P. Zuidema

Hardstrasse 73

CH-5430 Wettingen

SWITZERLAND
AEA Technology

Attn: J. H. Rees

D5W/29 Culham Laboratory

Abington, Oxfordshire OX14 3DB

UNITED KINGDOM

AEA Technology

Attn: W. R. Rodwell

044/A31 Winfrith Technical Centre

Dorchester, Dorset DT2 8DH

UNITED KINGDOM

AEA Technology

Attn: J. E. Tinson

B4244 Harwell Laboratory

Didcot, Oxfordshire OX11 ORA

UNITED KINGDOM

Other

V. A. Kelley

INTERA Inc.

6850 Austin Center Blvd

Austin, TX 78731

T. W. Pfeifle

RE/SPEC, Inc

P. O. Box 725

Rapid City, SD 57709.

\section{Internal}

$\begin{array}{lll}\frac{\text { MS }}{1324} & \frac{\text { Org. }}{6115} & \text { P. B. Davies } \\ 1320 & 6831 & \text { E. J. Nowak } \\ 1322 & 6121 & \text { J. R. Tillerson } \\ 1328 & 6849 & \text { D. R. Anderson } \\ 1328 & 6848 & \text { H. N. Jow } \\ 1335 & 6801 & \text { M. Chu } \\ 1341 & 6832 & \text { J. T. Holmes } \\ 1395 & 6800 & \text { L. Shephard } \\ 1395 & 6821 & \text { M. Marietta } \\ 1395 & 6801 & \text { F. D. Hansen } \\ 1395 & 6821 & \text { Knowles, K. } \\ 1322 & 6121 & \text { Hurtado, L. D. } \\ 1330 & 6811 & \text { K. Hart (2) } \\ 1330 & 4415 & \text { NWM Library (20) } \\ 9018 & 8940-2 & \text { Central Technical Files } \\ 0899 & 4916 & \text { Technical Library (5) } \\ 0619 & 12690 & \text { Review and Approval Desk (2), } \\ & & \text { For DOE/OSTI }\end{array}$

